RONALDO CÂMARA COZZA

\title{
ESTUDO DO COMPORTAMENTO DO COEFICIENTE DE DESGASTE E DOS MODOS DE DESGASTE ABRASIVO EM ENSAIOS DE DESGASTE MICRO-ABRASIVO
}

Dissertação apresentada à Escola Politécnica da Universidade de São Paulo, como parte dos requisitos para a obtenção do título de Mestre em Engenharia 


\section{UNIVERSIDADE DE SÃO PAULO}

\section{Relatório de Defesa}

Relatório de defesa pública de Dissertação do(a) Senhor(a) Ronaldo Câmara Cozza no Programa: Engenharia Mecânica, do(a) Escola Politécnica da Universidade de São Paulo.

Aos 24 dias do mês de fevereiro de 2006, realizou-se a Defesa da Dissertação do(a) Senhor(a) Ronaldo Câmara Cozza, apresentada para a obtenção do título de Mestre em Engenharia - Área: Engenharia Mecânica de Projeto de Fabricação, intitulada:

"Estudo do comportamento do coeficiente de desgaste e dos modos de desgaste abrasivo em ensaios de desgaste micro-abrasivo"

Após declarada aberta a sessão, o(a) $\operatorname{Sr}(a)$ Presidente passa a palavra aos examinadores para as devidas argüições que se desenvolvem nos termos regimentais. Em seguida, a Comissão Julgadora proclama o resultado:

\begin{tabular}{l|cc|c|}
\hline Nome dos Participantes da Banca & Vinculo do Docente & Sigla da Unidade & Resultado \\
\hline Roberto Martins de Souza & Presidente & EP - USP APROVADO \\
Deniol Katsuki Tanaka & Titular & EP - USP Ap roubd O \\
Jose Daniel Biasoli de Mello & Titular & UFU - Externo Afmoreado \\
\hline Resultado Final: $x$ & \\
\hline \hline \multicolumn{3}{|c|}{} \\
\hline
\end{tabular}

Eu, Elisabete Aparecida F da Silva Ramos , Técnico Acadêmico, lavrei a presente ata, que assino juntamente com os(as) Senhores(as). São Paulo, aos 24 dias do mês de fevereiro de 2006.
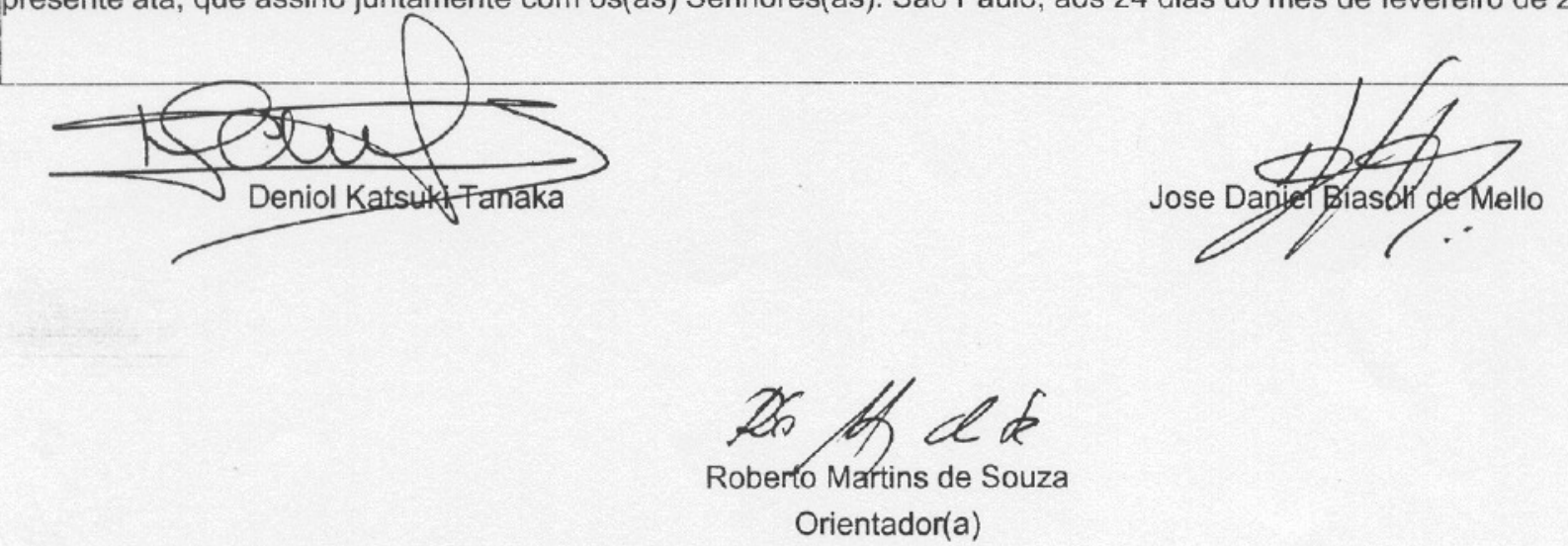

* Obs: Se o candidato for reprovado por algum dos membros, o preenchimento do parecer é obrigatório. Nos termos do artigo 110, do RG-USP, encaminhe-se o presente relatório à CPG, para homologação. 
RONALDO CÂMARA COZZA

\section{ESTUDO DO COMPORTAMENTO DO COEFICIENTE DE DESGASTE E DOS MODOS DE DESGASTE ABRASIVO EM ENSAIOS DE DESGASTE MICRO-ABRASIVO}

Dissertação apresentada à Escola Politécnica
da Universidade de São Paulo, como parte
dos requisitos para a obtenção do título de
Mestre em Engenharia
Orientador: Prof. Dr. Roberto Martins de Souza

São Paulo

2006 


\section{FICHA CATALOGRÁFICA}

\section{Cozza, Ronaldo Câmara}

Estudo do comportamento do coeficiente de desgaste e dos modos de desgaste abrasivo em ensaios de desgaste micro-abrasivo. São Paulo, 2006. 192 p.

Dissertação (Mestrado) - Escola Politécnica da Universidade de São Paulo. Departamento de Engenharia Mecânica.

1) Desgaste; 2) Desgaste abrasivo por riscamento; 3) Desgaste abrasivo por rolamento; 4) Desgaste abrasivo misto; 5) Ensaio de desgaste por microabrasão; 6) Regime permanente de desgaste I. Universidade de São Paulo. Escola Politécnica. Departamento de Engenharia Mecânica II. t. 
Dizem que, "por trás de um grande homem, existe sempre uma grande mulher". Talvez eu não seja um grande homem, mas a mulher que está atrás de mim, sim. Dedico este trabalho à minha mãe, Geni França, responsável por eu ter chegado até aqui. 


\section{AGRADECIMENTOS}

Aos Professores da "Escola Estadual Prof Pedra de Carvalho", pela formação do $1^{\circ}$. e $2^{\circ}$. grau e incentivo na continuação dos estudos.

Aos Professores das escolas SENAI Almirante Tamandaré e SENAI Mario Amato, pela amizade, formação profissional, incentivo na continuação dos estudos e rigor na disciplina.

Aos Professores da Faculdade de Engenharia Industrial, pela formação e incentivo ao início da Pós-Graduação.

Ao Professor Roberto Martins de Souza, pessoa de fundamental importância ao longo deste caminho, pela amizade (principalmente, por ser corinthiano, também), conhecimentos transmitidos, por toda ajuda, pela constante preocupação com o andamento do trabalho e orientação.

Aos Professores Deniol Katsuki Tanaka e Amilton Sinatora, pela amizade, pelos conhecimentos transmitidos, por toda ajuda e atenção.

Ao Professor José Daniel Biasoli de Mello, da Universidade Federal de Uberlândia, pela atenção.

Ao Professor José Carlos Bressiani, do Instituto de Pesquisas Energéticas e Nucleares, pela atenção.

A todos os Professores da Escola Politécnica, pela receptividade.

Aos amigos da Volkswagen do Brasil: Sérgio Scuotto, Raymundo Duarte, Wagner Duarte e Daniel Duarte, pelo apoio profissional.

Aos amigos Norberto, "Karluz", Marina, Karen, Walter, Denis, Bernardete, Rogério, Bárbara, Mateus, Daniela, Érique e Marcel, pessoas que nos ensinam a tentar sempre "sermos melhores a cada dia".

Ao amigo Humberto's, pelos conselhos.

À Marjorie e Alessandra, pela amizade.

Ao Sydnei, Cilene e Ricardo, pela amizade e ajuda nas questões burocráticas.

Aos técnicos Raquel, Jovânio, Leandro e Francisco, pela amizade e ajuda.

Ao pessoal do Laboratório de Fenômenos de Superfície, pela amizade.

À Marília, Marcelo e Carlos, da GlobalMag, por toda ajuda.

À minha Família que sempre me apoiou nesta trajetória.

A Deus por conceder-me o privilégio de estudar na $\boldsymbol{F E I}$ e na USP. 


\section{SUMÁRIO}

2.1. DESGASTE ABRASIVO: DEFINIÇÃO - CLASSIFICAÇÃO - TERMINOLOGIA_ 7

2.2. EQUAÇÃO DE ARCHARD PARA O DESGASTE ABRASIVO __ 11

2.3. ENSAIO DE DESGASTE POR MICRO-ABRASÃO__ 12

2.4. PARÂMETROS DO ENSAIO DE DESGASTE MICRO-ABRASIVO__ 16

2.4.1. Força normal 17

2.4.2. Rotação da esfera de ensaio _ـ 20

2.4.3. Distância de deslizamento entre a esfera e o corpo-de-prova___ 21

2.4.4. Concentração da pasta abrasiva ___ 23

2.4.5. Transição dos modos de desgaste abrasivo __ 26

2.4.6. Dureza, forma e tamanho das partículas abrasivas ___ 31

2.5. REGIME PERMANENTE DE DESGASTE___ 35

CAPÍTULO 3 - OBJETIVOS DO TRABALHO__ 41

CAPITULO 4 - MÁQUINA DE ENSAIO DE DESGASTE MICRO-ABRASIVO POR ESFERA ROTATIVA FIXA MODELO LFS 2005

4.1. DESCRIÇÃO GERAL DO EQUIPAMENTO__ 44

4.2. FUNCIONAMENTO DO EQUIPAMENTO _ 45

4.2.1. Sistema de controle de rotação da esfera de ensaio ___ 45

4.2.2. Sistema de avanço e posição do corpo-de-prova __ 51

CAPÍTULO 5 - MATERIAIS E MÉTODOS

5.1. MATERIAIS UTILIZADOS _ 55

5.2. PROCEDIMENTO EXPERIMENTAL__ 59

5.3. ENSAIOS PRELIMINARES __ 60

5.3.1. Verificação da reprodutibilidade do equipamento___60

5.3.2. Estudo da transição entre os modos de desgaste abrasivo___ 62

5.4. ENSAIOS DEFINITIVOS___63

5.4.1. Estudo da relação do quociente $A_{R O L} / A_{R I S}$ com a distância de deslizamento___ 63

5.4.2. Estudo da obtenção do regime permanente de desgaste ___ 66

CAPÍTULO 6 - ENSAIOS PRELIMINARES - RESULTADOS E DISCUSSÃO___ 68

6.1. VERIFICAÇÃO DA REPRODUTIBILIDADE DO EQUIPAMENTO_ 68

6.2. ESTUDO DA TRANSIÇÃO ENTRE OS MODOS DE DESGASTE ABRASIVO__ 74

CAPÍTULO 7 - ENSAIOS DEFINITIVOS - RESULTADOS E DISCUSSÃO 79

7.1. ESTUDO DA RELAÇÃO DO QUOCIENTE AROL/ARIS COM A DISTÂNCIA DE DESLIZAMENTO _ 79

7.1.1. Corpos-de-prova de HSS M2 - Resultados obtidos pelo Método 1 _ 79

7.1.2. Corpos-de-prova de HSS M2 - Resultados obtidos pelo Método $2 \_84$

7.1.3. Corpos-de-prova de WC-Co P20 - Resultados obtidos pelo Método $1 \_93$

7.1.4. Corpos-de-prova de WC-Co P20 - Resultados obtidos pelo Método 2 _ 100

7.1.5. Contornos das crateras de desgaste __ 113

7.1.6. Relação entre o desgaste da esfera e o desvio-padrão de dmédio___ 120

7.1.7. Atuação dos modos de desgaste abrasivo___ 122

7.1.8. Alterações dos contornos das crateras de desgaste ___ 128 
7.2. ESTUDO DA OBTENÇÃO DO REGIME PERMANENTE DE DESGASTE

7.2.1. Resultados dos ensaios realizados com os corpos-de-prova de HSS M2

7.2.2. Resultados dos ensaios realizados com os corpos-de-prova de WC-Co P20

7.2.3. Regime permanente de desgaste

7.3. COMENTÁRIOS

CAPÍTULO 8 - CONCLUSÕES 138

SUGESTÕES PARA TRABALHOS FUTUROS 140

ANEXO I - DEDUÇÃO DA EQUAÇÃO DE ARCHARD PARA O DESGASTE ABRASIVO 143

ANEXO II - ENSAIO DE MICRO-ABRASÃO: EQUAÇÕES UTILIZADAS 145

ANEXO III - EQUAÇÃO ALTERNATIVA PARA O CÁLCULO DO COEFICIENTE DE DESGASTE 153 ANEXO IV - CONTATOS \& DESENHOS TÉCNICOS 155 REFERÊNCIAS BIBLIOGRÁFICAS 190 


\section{LISTA DE SÍMBOLOS}

$\boldsymbol{A}_{\boldsymbol{R} I S} \quad$ Área projetada de atuação do desgaste abrasivo por riscamento $A_{R O L} \quad$ Área projetada de atuação do desgaste abrasivo por rolamento

$\boldsymbol{A}_{t} \quad$ Área projetada total da cratera de desgaste

$\boldsymbol{d} \quad$ Diâmetro da calota esférica

$\boldsymbol{d}_{\text {médio } \quad \text { Diâmetro médio das calotas esféricas }}$

$D_{C}$ Tamanho crítico das partículas abrasivas

$D_{P} \quad$ Tamanho médio das partículas abrasivas

$E_{E} \quad$ Módulo de elasticidade da esfera de ensaio

$E_{C P} \quad$ Módulo de elasticidade do corpo-de-prova

$f \quad$ Freqüência da rede

$f_{i n v} \quad$ Freqüência definida no inversor de freqüência

$\boldsymbol{F}_{N} \quad$ Força normal

$\boldsymbol{F}_{\boldsymbol{T}} \quad$ Força tangencial

$\boldsymbol{h} \quad$ Profundidade de penetração da esfera de ensaio

$\boldsymbol{H}_{\boldsymbol{A}} \quad$ Dureza do abrasivo

$\boldsymbol{H}_{C P} \quad$ Dureza do corpo-de-prova

$H_{E} \quad$ Dureza da esfera de ensaio

$\boldsymbol{H}_{\boldsymbol{S}} \quad$ Dureza da superfície

$i_{p o l} \quad$ Relação de transmissão das polias

$i_{\text {red }} \quad$ Relação de transmissão do redutor

$\boldsymbol{k} \quad$ Coeficiente de desgaste

$K \quad$ Severidade do desgaste

$\mathrm{KOH} \quad$ Hidróxido de potássio

$K_{3} \mathrm{Fe}(\mathrm{CN})_{6} \quad$ Ferrocianeto de potássio

n Rotação do rotor

$n_{E S F} \quad$ Rotação da esfera de ensaio

$n_{R} \quad$ Rotação do rotor devido ao escorregamento (a plena carga)

$n_{S} \quad$ Rotação síncrona do rotor

$\boldsymbol{p} \quad$ Número de pólos do motor

$\boldsymbol{Q} \quad$ Taxa de desgaste 


$\begin{array}{ll}\boldsymbol{R} & \text { Raio da esfera de ensaio } \\ \boldsymbol{r p m} & \text { Rotação por minuto } \\ \boldsymbol{s} & \text { Escorregamento do rotor } \\ \boldsymbol{s} & \text { Distância de deslizamento } \\ \boldsymbol{S} \boldsymbol{c} & \text { Severidade de Contato } \\ \boldsymbol{S i C} & \text { Carbeto de silício } \\ \boldsymbol{t} & \text { Tempo de ensaio } \\ \boldsymbol{V} & \text { Volume de desgaste } \\ \boldsymbol{v}_{\boldsymbol{t}} & \text { Velocidade tangencial periférica da esfera de ensaio }\end{array}$




\title{
LISTA DE SÍMBOLOS GREGOS
}

\author{
$\vartheta \quad$ Porcentagem em volume, de material abrasivo na pasta abrasiva \\ $\mu_{c} \quad$ Coeficiente de atrito cinético \\ $V_{E} \quad$ Coeficiente de Poisson da esfera de ensaio \\ $v_{C P} \quad$ Coeficiente de Poisson do corpo-de-prova \\ $\Xi \quad$ Nível de desgaste da esfera de ensaio \\ $\sigma_{P} \quad$ Desvio-padrão
}




\section{LISTA DE SIGLAS}

AISI American Iron and Steel Institute

ASTM American Society for Testing and Materials

CAD Computer Aided Design

CATIA V4 Computer Graphic Aided Tridimensional Interactive Aplication - V4

CVD Chemical Vapor Deposition

HSM High Speed Machine

LFS Laboratório de Fenômenos de Superfície

LTM Laboratório de Tribologia e Materiais

PA Poliamida

PBT Poli(tereftalato de butileno)

POM Poli(óxido de metileno)

PP Polipropileno

PMMA Poli(metacrilato de metila)

SENAI Serviço Nacional de Aprendizagem Industrial

UFU Universidade Federal de Uberlândia 


\section{LISTA DE FIGURAS}

\section{CAPÍTULO 2}

Figura 2.1: Visão tri-dimensional de uma cratera de desgaste formada em um corpo-de-prova de ferro sinterizado oxidado a vapor, em um ensaio de desgaste por micro-abrasão por esfera rotativa (Silva Jr., 2003). 6

Figura 2.2: Cratera de desgaste gerada em um filme fino de TiN, com espessura de aproximadamente $3 \mu \mathrm{m}$. 7

Figura 2.3: a) Desgaste abrasivo por riscamento; b) desgaste abrasivo por rolamento (Hutchings, 1992).__ 9

Figura 2.4: Superfície de um corpo-de-prova de aço ferramenta que sofreu desgaste abrasivo por riscamento por uma esfera de aço para rolamento e partículas abrasivas de diamante (Trezona et al., 1999).

Figura 2.5: Superfície de um corpo-de-prova de aço ferramenta que sofreu desgaste abrasivo por rolamento por uma esfera de aço para rolamento e partículas abrasivas de SiC (Trezona et al., 1999). 10

Figura 2.6: Partícula idealizada deslizando sobre a superfície de um material dútil (Hutchings, 1992). __ 11

Figura 2.7: Dimple grinder (Hogmark et al., 2000). ___ 13

Figura 2.8: Princípio de funcionamento do equipamento de ensaio de desgaste micro-abrasivo por esfera fixa. 14

Figura 2.9: (a) Máquina de ensaio de desgaste micro-abrasivo por esfera rotativa livre (Silva Jr., 2003); (b) visão frontal do equipamento (Foto: Cortesia Prof. Dr. J. D. B. Mello - UFU - Faculdade de Engenharia Mecânica - LTM - Laboratório de Tribologia e Materiais).

Figura 2.10: a) Vista frontal de uma cratera de desgaste, mostrando o diâmetro "d" da mesma (Kelly e Hutchings, 2001); b) profundidade de penetração " $h$ " da esfera de ensaio.

Figura 2.11: Variação da taxa de desgaste em função da força normal, para um revestimento de carbeto de boro, esfera de aço AISI 52100 e partículas abrasivas de SiC (Bose e Wood, 2005). 17

Figura 2.12: Variação do coeficiente de desgaste em função da carga normal, para um revestimento de carbeto de boro, esfera de aço AISI 52100 e partículas abrasivas de SiC (Bose e Wood, 2005).

Figura 2.13: Variação do coeficiente de desgaste em função da carga normal, para revestimentos de $P A-11$, esferas de aço carbono e partículas abrasivas de SiC (Bello e Wood, 2005).

Figura 2.14: Variação da taxa de desgaste em função da carga norma, para revestimentos de PA-11, esferas de aço carbono e partículas abrasivas de SiC (Bello e Wood, 2005).

Figura 2.15: Variação do coeficiente de desgaste em função da carga normal, para um revestimento de carbeto de boro, esfera de aço AISI 52100 e partículas abrasivas de SiC (Bose e Wood, 2005). __ 20

Figura 2.16: Cratera de desgaste com borda difusa (Trezona e Hutchings, 1999). _ 21

Figura 2.17: Diferentes estágios de formação de uma cratera de desgaste, com as respectivas distâncias de deslizamento (Trezona e Hutchings, 1999).

Figura 2.18: Volume de desgaste em função da distância de deslizamento e da força normal (Trezona e Hutchings, 1999).

Figura 2.19: Variação do coeficiente de desgaste em função da concentração da pasta abrasiva para o POM (Mergler e Huis in 't Veld, 2003).

Figura 2.20: Variação do coeficiente de desgaste em função da concentração da pasta abrasiva para o PBT (Mergler e Huis in 't Veld, 2003).

Figura 2.21: Variação do coeficiente de desgaste em função da concentração da pasta abrasiva para o $P A-6,6$ (Mergler e Huis in 't Veld, 2003).

Figura 2.22: Volume de desgaste em função da porcentagem, em volume, de SiC na pasta abrasiva, para esferas de aço para rolamento e corpos-de-prova de aço ferramenta (Trezona et al., 1999).

Figura 2.23: Transição dos modos de desgaste em função da força normal e da concentração da pasta abrasiva. Esfera de aço para rolamento, corpo-de-prova de aço ferramenta e partículas abrasivas de SiC (Trezona et al., 1999).

Figura 2.24: Transição dos modos de desgaste em função da força normal e da concentração da pasta abrasiva. Esfera de aço para rolamento, corpo-de-prova de aço ferramenta e partículas abrasivas de alumina (Trezona et al., 1999).

Figura 2.25: Transição dos modos de desgaste em função da força normal e da concentração da pasta abrasiva. Esfera de aço para rolamento, corpo-de-prova de aço ferramenta e partículas abrasivas de diamante (Trezona et al., 1999).

Figura 2.26: Corpo-de-prova de PMMA que sofreu desgaste abrasivo por riscamento na região central e desgaste abrasivo por rolamento nas extremidades. A força normal foi de 0,2 $\mathrm{N}$ e as partículas abrasivas foram de SiC, com uma fração volumétrica de $10 \%$ na pasta abrasiva (Adachi e Hutchings, 2003).

Figura 2.27: Superfícies características dos modos de desgaste, em função da carga normal e da concentração da pasta abrasiva.

Figura 2.28: Transição dos modos de desgaste em função da severidade de contato $S_{C}$ e da razão $H_{C P} / H_{E}$ (Adachi e Hutchings, 2005).

Figura 2.29: Relação esquemática entre a taxa de desgaste e a razão $H_{A} / H_{s}$. Os pontos $p_{1}$ e $p_{2}$ limitam a região de transição entre os regimes de desgaste (Kruschov, 1957 apud Pintaúde, 2002).

Figura 2.30: Alguns dos formatos de partículas abrasivas utilizadas por Kelly e Hutchings (2001). 33 
Figura 2.31: Volume de desgaste em função do produto da distância de deslizamento pela força normal, para os materiais (a) e (b) da Figura 2.30 (Kelly e Hutchings, 2001).

Figura 2.32: Variação da taxa de desgaste em função do tamanho das partículas abrasivas, para superfícies de cobre e grãos abrasivos de SiC (Sasada et al., 1984).

Figura 2.33: Gráfico exibindo o alcance do regime permanente de desgaste, que ocorreu a partir de 25 minutos de ensaio (Figura: Cortesia Prof. Dr. J. D. B. Mello - UFU - Faculdade de Engenharia Mecânica - LTM Laboratório de Tribologia e Materiais).

Figura 2.34: Gráfico exibindo o alcance do regime permanente de desgaste, que ocorreu a partir de 40 minutos de ensaio (Figura: Cortesia Prof. Dr. J. D. B. Mello - UFU - Faculdade de Engenharia Mecânica - LTM Laboratório de Tribologia e Materiais).

Figura 2.35: Variação linear do volume de desgaste com a distância de deslizamento (Trezona et al., 1999). _ 38

\section{CAPÍTULO 4}

Figura 4.1: Visão geral do equipamento de ensaio de desgaste por micro-abrasão construído. 44

Figura 4.2: (A) Motor de corrente alternada.

Figura 4.3: (A) Redutor de eixos reversos; (B) polia escalonada fixada no eixo de saída do redutor. 45 Figura 4.4: (A) Polia escalonada fixada na extremidade do eixo de ensaio. 46 Figura 4.5: Combinações utilizadas, para a variação de rotação da esfera de ensaio.

Figura 4.6: Inversor de freqüência, utilizado em conjunto com as polias escalonadas.__ 47

Figura 4.7: Esfera de ensaio (A) fixada no eixo de ensaio (B). _ 48

Figura 4.8: Entre o berço movimentado $(A)$ e o berço de movimentação $(B)$ está a célula de carga $(C)$, que mede a força normal aplicada sobre o corpo-de-prova. A carga normal é aplicada através de um fuso (D). _ 51

Figura 4.9: Sistema de posição horizontal e sistema de posição vertical. ___ 52

Figura 4.10: Pastilha intercambiável de metal duro fixada no porta-amostra.

Figura 4.11: Célula de carga para medição da força tangencial desenvolvida durante o ensaio.__ 53

Figura 4.12: Circuito eletrônico $(A)$ montado para trabalhar em conjunto com o multímetro $(B)$. ___ 53

\section{CAPÍTULO 5}

Figura 5.1: Microestrutura do aço ferramenta M2. Imagem obtida por microscopia óptica (Microscópio óptico OLYMPUS BX60M, pertencente ao Laboratório de Fenômenos de Superfície - LFS).

Figura 5.2: Microestrutura do WC-Co P20. Imagem obtida por microscopia óptica (Microscópio óptico OLYMPUS $B X 60 M$, pertencente ao LFS).

Figura 5.3: Microestrutura do aço AISI 52100 temperado e revenido. Imagem obtida por microscopia óptica

(Microscópio óptico OLYMPUS BX60M, pertencente ao LFS).

Figura 5.4: Micrografia eletrônica de varredura do pó abrasivo SiC 1000 (Izhevskyi et al., 2004).___ 58

Figura 5.5: Distribuição granulométrica do SiC 1000 (Izhevskyi et al., 2004). __ 58

Figura 5.6: Organização dos ensaios realizados nesta Dissertação.__ 60

\section{CAPÍTULO 6}

Figura 6.1: (a) Atuação de desgaste abrasivo misto. (b) Região de atuação de desgaste abrasivo por riscamento. Corpo-de-prova de WC-Co P20.

Figura 6.2: Forma padrão de cratera de desgaste obtida na condição de ensaio 2. Corpos-de-prova de aço ferramenta M2.

Figura 6.3: Forma da primeira cratera de desgaste obtida com a esfera E-1010C-1. Essa cratera de desgaste não foi considerada na análise dos resultados.

Figura 6.4: Guias da mesa de translação que devem ser lubrificadas antes do início dos ensaios. __ 72

Figura 6.5: Momento que tende girar o corpo-de-prova quando a força normal é aplicada no mesmo.__ 72

Figura 6.6: Componente de fixação do corpo-de-prova unido à célula de carga. ___ 73

Figura 6.7: Ação de desgaste abrasivo por riscamento (centro) e desgaste abrasivo por rolamento (extremidades), para uma força normal de 1,25 N e uma concentração de pasta abrasiva de 1,045 $\mathrm{g} / \mathrm{cm}^{3}$ (25\% SiC / 75\% água destilada).

Figura 6.8: Cratera de desgaste no corpo-de-prova de aço ferramenta M2, para uma força normal de $5 \mathrm{~N}$ e uma concentração de pasta abrasiva de $1,045 \mathrm{~g} / \mathrm{cm}^{3}$ (25\% SiC / 75\% água destilada). Esta cratera de desgaste foi gerada durante o quarto ensaio. 
Figura 6.9: Transição dos modos de desgaste em função da severidade de contato $S_{C}$ e da razão $H_{C P} / H_{E}(A d a c h i$ e Hutchings, 2005).

\section{CAPÍTULO 7}

Figura 7.1: Dependência de $A_{R O L} / A_{R I S}$ com a distância de deslizamento, para os corpos-de-prova de aço ferramenta M2. Resultados obtidos pelo Método 1.

Figura 7.2: Corpo-de-prova de aço ferramenta M2. (a) Cratera de desgaste gerada com uma distância de deslizamento de 8 metros. (b) Ampliação de (a), exibindo a atuação de desgaste abrasivo por rolamento.

80

Figura 7.3: Corpo-de-prova de aço ferramenta M2. (a) Cratera de desgaste gerada com uma distância de deslizamento de 8 metros. (b) Ampliação de (a), exibindo a atuação de desgaste abrasivo por rolamento.

81

Figura 7.4: Corpo-de-prova de aço ferramenta M2. Cratera de desgaste gerada com uma distância de deslizamento de 15 metros. Atuação de desgaste abrasivo misto.

Figura 7.5: Corpo-de-prova de aço ferramenta M2. (a) Cratera de desgaste gerada com uma distância de deslizamento de 20 metros. (b) Ampliação de (a), exibindo a atuação de desgaste abrasivo misto. 81

Figura 7.6: Corpo-de-prova de aço ferramenta M2. Cratera de desgaste gerada com uma distância de deslizamento de 25 metros. Atuação de desgaste abrasivo misto.

82

Figura 7.7: Corpo-de-prova de aço ferramenta M2. (a) Cratera de desgaste gerada com uma distância de deslizamento de 35 metros. (b) Ampliação de (a), exibindo a atuação de desgaste abrasivo por rolamento.

Figura 7.8: Corpo-de-prova de aço ferramenta M2. (a) Cratera de desgaste gerada com uma distância de deslizamento de 35 metros. (b) Ampliação de (a), exibindo a atuação de desgaste abrasivo por rolamento.

Figura 7.9: Corpo-de-prova de aço ferramenta M2. (a) Cratera de desgaste gerada com uma distância de deslizamento de 40 metros. (b) Ampliação de (a), exibindo a atuação de desgaste abrasivo por rolamento.

Figura 7.10: Corpo-de-prova de aço ferramenta M2. (a) Cratera de desgaste gerada com uma distância de deslizamento de 40 metros. (b) Ampliação de (a), exibindo a atuação de desgaste abrasivo por rolamento.

Figura 7.11: Corpo-de-prova de aço ferramenta M2. (a) Cratera de desgaste gerada com uma distância de deslizamento de 40 metros. (b) Ampliação de (a), exibindo a atuação de desgaste abrasivo por rolamento.

Figura 7.12: Dependência de $A_{R O L} / A_{R I S}$ com a distância de deslizamento, para os corpos-de-prova de aço ferramenta M2. Resultados obtidos pelo Método 2.

Figura 7.13: Corpo-de-prova de aço ferramenta M2. Distância de deslizamento de 8 metros. $A$ área $A_{t}$ foi medida pelo Método 2. Atuação de desgaste abrasivo por rolamento $\left(A_{t}=A_{R O L}\right)$.

Figura 7.14: Corpo-de-prova de aço ferramenta M2. Distância de deslizamento de 15 metros. As áreas At, $A_{R I S} e$ $A_{R O L}$ foram medidas pelo Método 2. Atuação de desgaste abrasivo misto.

Figura 7.15: Corpo-de-prova de aço ferramenta M2. Distância de deslizamento de 20 metros. As áreas $A_{t}, A_{R I S} e$ $A_{R O L}$ foram medidas pelo Método 2. Atuação de desgaste abrasivo misto.

Figura 7.16: Corpo-de-prova de aço ferramenta M2. Distância de deslizamento de 25 metros. As áreas $A_{t}, A_{R I S} e$ $A_{R O L}$ foram medidas pelo Método 2. Atuação de desgaste abrasivo misto.

Figura 7.17: Corpo-de-prova de aço ferramenta M2. Distância de deslizamento de 35 metros. $A$ área $A_{t}$ foi medida pelo Método 2. Atuação de desgaste abrasivo por rolamento ( $\left.A_{t}=A_{R O L}\right)$.

Figura 7.18: Corpo-de-prova de aço ferramenta M2. Distância de deslizamento de 35 metros. $A$ área $A_{t}$ foi medida pelo Método 2. Atuação de desgaste abrasivo por rolamento $\left(A_{t}=A_{R O L}\right)$. 90

Figura 7.19: Corpo-de-prova de aço ferramenta M2. Distância de deslizamento de 40 metros. $A$ área $A_{t}$ foi medida pelo Método 2. Atuação de desgaste abrasivo por rolamento ( $A_{t}=A_{R O L}$ ).

Figura 7.20: Corpo-de-prova de aço ferramenta M2. Distância de deslizamento de 40 metros. $A$ área $A_{t}$ foi medida pelo Método 2. Atuação de desgaste abrasivo por rolamento $\left(A_{t}=A_{R O L}\right)$.

Figura 7.21: Corpo-de-prova de aço ferramenta M2. Distância de deslizamento de 40 metros. $A$ área $A_{t}$ foi medida pelo Método 2. Atuação de desgaste abrasivo por rolamento $\left(A_{t}=A_{R O L}\right)$.

Figura 7.22: Dependência de $A_{R O L} / A_{R I S}$ com a distância de deslizamento, para os corpos-de-prova de WC-Co P20. Resultados obtidos pelo Método 1.

Figura 7.23: Corpo-de-prova de WC-Co P20. (a) Cratera de desgaste gerada com uma distância de deslizamento de 8 metros. (b) Ampliação de (a), exibindo a atuação de desgaste abrasivo por rolamento.

Figura 7.24: Corpo-de-prova de WC-Co P20. (a) Cratera de desgaste gerada com uma distância de deslizamento de 8 metros. (b) Ampliação de (a), exibindo a atuação de desgaste abrasivo misto.

Figura 7.25: Corpo-de-prova de WC-Co P20. (a) Cratera de desgaste gerada com uma distância de deslizamento de 8 metros. (b) Ampliação de (a), exibindo a atuação de desgaste abrasivo misto. 
Figura 7.26: Corpo-de-prova de WC-Co P20. (a) Cratera de desgaste gerada com uma distância de deslizamento de 15 metros. (b) Ampliação de (a), exibindo a atuação de desgaste abrasivo misto.

Figura 7.27: Corpo-de-prova de WC-Co P20. (a) Cratera de desgaste gerada com uma distância de deslizamento de 15 metros. (b) Ampliação de (a), exibindo a atuação de desgaste abrasivo misto. 96

Figura 7.28: Corpo-de-prova de WC-Co P20. (a) Cratera de desgaste gerada com uma distância de deslizamento de 15 metros. (b) Ampliação de (a), exibindo a atuação de desgaste abrasivo misto. 96

Figura 7.29: Corpo-de-prova de WC-Co P20. (a) Cratera de desgaste gerada com uma distância de deslizamento de 15 metros. (b) Ampliação de (a), exibindo a atuação de desgaste abrasivo misto. 96

Figura 7.30: Corpo-de-prova de WC-Co P20. (a) Cratera de desgaste gerada com uma distância de deslizamento de 20 metros. (b) Ampliação de (a), exibindo a atuação de desgaste abrasivo misto. __ 97

Figura 7.31: Corpo-de-prova de WC-Co P20. (a) Cratera de desgaste gerada com uma distância de deslizamento de 20 metros. (b) Ampliação de (a), exibindo a atuação de desgaste abrasivo misto.

Figura 7.32: Corpo-de-prova de WC-Co P20. (a) Cratera de desgaste gerada com uma distância de deslizamento de 20 metros. (b) Ampliação de (a), exibindo a atuação de desgaste abrasivo misto.

Figura 7.33: Corpo-de-prova de WC-Co P20. (a) Cratera de desgaste gerada com uma distância de deslizamento de 20 metros. (b) Ampliação de (a), exibindo a atuação de desgaste abrasivo por rolamento. __ 98

Figura 7.34: Corpo-de-prova de WC-Co P20. (a) cratera de desgaste obtida com uma distância de deslizamento de 25 metros. (b) Ampliação de (a), exibindo a atuação de desgaste abrasivo por rolamento.

Figura 7.35: Corpo-de-prova de WC-Co P20. (a) Cratera de desgaste gerada com uma distância de deslizamento de 35 metros. (b) Ampliação de (a), exibindo a atuação de desgaste abrasivo por rolamento. 98

Figura 7.36: Corpo-de-prova de WC-Co P20. (a) Cratera de desgaste gerada com uma distância de deslizamento de 40 metros. (b) Ampliação de (a), exibindo a atuação de desgaste abrasivo por rolamento. _ 99

Figura 7.37: Dependência de $A_{R O L} / A_{R I S}$ com a distância de deslizamento, para os corpos-de-prova de WC-Co P20. Resultados obtidos pelo Método 2.

Figura 7.38: Corpo-de-prova de WC-Co P20. Distância de deslizamento de 8 metros. $A$ área $A_{t}$ foi medida pelo Método 2. Atuação de desgaste abrasivo por rolamento $\left(A_{t}=A_{R O L}\right)$. 101

Figura 7.39: Corpo-de-prova de WC-Co P20. Distância de deslizamento de 8 metros. As áreas $A_{t}, A_{R I S} e A_{R O L}$ foram medidas pelo Método 2. Atuação de desgaste abrasivo misto. 102

Figura 7.40: Corpo-de-prova de WC-Co P20. Distância de deslizamento de 8 metros. As áreas $A_{t}, A_{R I S} e A_{R O L}$ foram medidas pelo Método 2. Atuação de desgaste abrasivo misto. 103

Figura 7.41: Corpo-de-prova de WC-Co P20. Distância de deslizamento de 15 metros. As áreas $A_{t}, A_{R I S} e A_{R O L}$ foram medidas pelo Método 2. Atuação de desgaste abrasivo misto. 104

Figura 7.42: Corpo-de-prova de WC-Co P20. Distância de deslizamento de 15 metros. As áreas $A_{t}, A_{R I S} e ~ A_{R O L}$ foram medidas pelo Método 2. Atuação de desgaste abrasivo misto. 105

Figura 7.43: Corpo-de-prova de WC-Co P20. Distância de deslizamento de 15 metros. As áreas $A_{t}, A_{R I S} e A_{R O L}$ foram medidas pelo Método 2. Atuação de desgaste abrasivo misto. 106

Figura 7.44: Corpo-de-prova de WC-Co P20. Distância de deslizamento de 15 metros. As áreas $A_{t}, A_{R I S} e A_{R O L}$ foram medidas pelo Método 2. Atuação de desgaste abrasivo misto. 107

Figura 7.45: Corpo-de-prova de WC-Co P20. Distância de deslizamento de 20 metros. As áreas $A_{t}, A_{R I S} e A_{R O L}$ foram medidas pelo Método 2. Atuação de desgaste abrasivo misto. 108

Figura 7.46: Corpo-de-prova de WC-Co P20. Distância de deslizamento de 20 metros. As áreas $A_{t}, A_{R I S} e A_{R O L}$ foram medidas pelo Método 2. Atuação de desgaste abrasivo misto. 109

Figura 7.47: Corpo-de-prova de WC-Co P20. Distância de deslizamento de 20 metros. A área $A_{t}$ foi medida pelo Método 2. Atuação de desgaste abrasivo por rolamento $\left(A_{t}=A_{R O L}\right)$.

Figura 7.48: Corpo-de-prova de WC-Co P20. Distância de deslizamento de 20 metros. $A$ área $A_{t}$ foi medida pelo Método 2. Atuação de desgaste abrasivo por rolamento $\left(A_{t}=A_{R O L}\right)$.

Figura 7.49: Corpo-de-prova de WC-Co P20. Distância de deslizamento de 25 metros. $A$ área $A_{t}$ foi medida pelo Método 2. Atuação de desgaste abrasivo por rolamento $\left(A_{t}=A_{R O L}\right)$.

Figura 7.50: Corpo-de-prova de WC-Co P20. Distância de deslizamento de 35 metros. $A$ área $A_{t}$ foi medida pelo Método 2. Atuação de desgaste abrasivo por rolamento $\left(A_{t}=A_{R O L}\right)$.

Figura 7.51: Corpo-de-prova de WC-Co P20. Distância de deslizamento de 40 metros. $A$ área $A_{t}$ foi medida pelo Método 2. Atuação de desgaste abrasivo por rolamento $\left(A_{t}=A_{R O L}\right)$. 112

Figura 7.52: Corpos-de-prova de aço ferramenta M2. Gráfico de $A_{t}$ em função da distância de deslizamento. 114

Figura 7.53: Corpos-de-prova de WC-Co P20. Gráfico de $A_{t}$ em função da distância de deslizamento. __ 115

Figura 7.54: Quando $R_{A B}=R$ ou $R_{A B} \cong R$, o contorno da cratera de desgaste tenderá a uma circunferência. _ 116

Figura 7.55: Quando $R_{A B}$ '> R, o contorno da cratera de desgaste tende a uma elipse. 117

Figura 7.56: CRATERA $(A)$ : ensaio realizado em um corpo-de-prova de aço ferramenta M2. Contorno da cratera de desgaste tendendo a uma circunferência. CRATERA (B): ensaio realizado em um corpo-de-prova de WC-Co P20. Contorno da cratera de desgaste tendendo a uma elipse.

Figura 7.57: Caso em que $R_{A B}$ ' >> $R$. "Contorno oblongo" da cratera de desgaste. 119

Figura 7.58: "Contorno oblongo" apresentado pela cratera de desgaste gerada em um corpo-de-prova de WC-Co P2O.

Figura 7.59: Corpos-de-prova de HSS M2 e WC-Co P20. Gráfico de $\sigma_{P}$ em função de $\Xi$. 121 
Figura 7.60: Corpos-de-prova de aço ferramenta M2. Sobreposição dos valores de $A_{R O L} / A_{R I S}$ obtidos pelos Métodos 1 e 2.

Figura 7.61: Corpos-de-prova de WC-Co P20. Sobreposição dos valores de $A_{R O L} / A_{R I S}$ obtidos pelos Métodos 1 e 2.

Figura 7.62: HIPÓTESE 1. (a) Variação ascendente e (b), tendência de $A_{R O L} / A_{R I S}$ permanecer constante com a distância de deslizamento.

Figura 7.63: HIPÓTESE 1. (a) Variação descendente e (b), tendência de $A_{R O L} / A_{R I S}$ permanecer constante com a distância de deslizamento.

Figura 7.64: Corpo-de-prova de WC-Co P20. Distância de deslizamento de 15 metros. Atuação de desgaste abrasivo misto.

Figura 7.65: Corpo-de-prova de WC-Co P20. Distância de deslizamento de 15 metros. Atuação de desgaste abrasivo misto.

Figura 7.66: Corpo-de-prova de WC-Co P20. Distância de deslizamento de 35 metros. Atuação de desgaste abrasivo misto.

Figura 7.67: Corpo-de-prova de WC-Co P20. Distância de deslizamento de 15 metros. Atuação de desgaste abrasivo misto.

Figura 7.68: Corpo-de-prova de WC-Co P20. Distância de deslizamento de 35 metros. Atuação de desgaste abrasivo misto.

Figura 7.69: Corpo-de-prova de WC-Co P20. Distância de deslizamento de 15 metros. Atuação de desgaste abrasivo misto.

Figura 7.70: Corpo-de-prova de WC-Co P20. Distância de deslizamento de 35 metros. Atuação de desgaste abrasivo misto.

Figura 7.71: Corpo-de-prova de WC-Co P20. Distância de deslizamento de 35 metros. Atuação de desgaste abrasivo misto.

Figura 7.72: Atuação dos modos de desgaste abrasivo em função de $\Xi$.

Figura 7.73: Ordem de alterações dos contornos das crateras de desgaste.

Figura 7.74: Classificação dos níveis de desgaste $\Xi$ da esfera, em função do contorno da cratera de desgaste.

Figura 7.75: Gráfico de $k=f(S)$, para os corpos-de-prova de aço ferramenta M2. __ 130

Figura 7.76: Gráfico de $k=f(S)$, para os corpos-de-prova de WC-Co P20. ___ 131

Figura 7.77: Corpo-de-prova de WC-Co P20. (a) Cratera de desgaste gerada com uma distância de deslizamento de 25 metros; (b) Total atuação do desgaste abrasivo por rolamento.

Figura 7.78: Corpo-de-prova de WC-Co P20. (a) Cratera de desgaste gerada com uma distância de deslizamento de 25 metros; (b) Total atuação do desgaste abrasivo por rolamento.

Figura 7.79: Corpo-de-prova de WC-Co P20. (a) Cratera de desgaste gerada com uma distância de deslizamento de 35 metros; (b) Total atuação do desgaste abrasivo por rolamento.

Figura 7.80: Corpo-de-prova de WC-Co P20. (a) Cratera de desgaste gerada com uma distância de deslizamento de 35 metros; (b) Total atuação do desgaste abrasivo por rolamento.

Figura 7.81: Corpo-de-prova de WC-Co P20. (a) Cratera de desgaste gerada com uma distância de deslizamento de 40 metros; (b) Total atuação do desgaste abrasivo por rolamento.

Figura 7.82: Corpo-de-prova de WC-Co P20. (a) Cratera de desgaste gerada com uma distância de deslizamento de 40 metros; (b) Total atuação do desgaste abrasivo por rolamento. 


\section{LISTA DE TABELAS}

\section{CAPÍTULO 4}

Tabela 4.1: Combinações entre as polias e as respectivas faixas de rotações. 48

\section{CAPÍTULO 5}

Tabela 5.1: Denominações dadas às esferas de ensaio. 57

Tabela 5.2: Dureza dos materiais utilizados nos ensaios

Tabela 5.3: Parâmetros definidos para a verificação da reprodutibilidade do equipamento. ___ 61

Tabela 5.4: Concentração da pasta abrasiva. 61

Tabela 5.5: Parâmetros definidos para o estudo da transição entre os modos de desgaste abrasivo. 62

Tabela 5.6: Valores dos parâmetros estabelecidos para os ensaios realizados nos corpos-de-prova de HSS M2.

Tabela 5.7: Valores dos parâmetros estabelecidos para os ensaios realizados nos corpos-de-prova de WC-Co P2O.

Tabela 5.8: Valores dos parâmetros estabelecidos para os ensaios realizados nos corpos-de-prova de WC-Co P20, com a esfera E-52100-2.

\section{CAPÍTULO 6}

Tabela 6.1: Dimensões das crateras de desgaste para a condição de ensaio 1. 69

Tabela 6.2: Dimensões das crateras de desgaste para a condição de ensaio 2.

Tabela 6.3: Dimensões das crateras de desgaste para a condição de ensaio 3.

Tabela 6.4: Dimensões das crateras de desgaste geradas no corpo-de-prova de aço ferramenta M2, para a força normal de $5 \mathrm{~N}$.

Tabela 6.5: Dimensões das crateras de desgaste geradas no corpo-de-prova de WC-Co P20, para a força normal de 1,25 N.

\section{CAPÍTULO 7}

Tabela 7.1: Resultados obtidos com os corpos-de-prova de HSS M2, pelo Método 1. 79

Tabela 7.2: Resultados obtidos para os corpos-de-prova de HSS M2, pelo Método 2.

Tabela 7.3: Resultados obtidos para os corpos-de-prova de WC-Co P20, pelo Método 1.

Tabela 7.4: Resultados obtidos para os corpos-de-prova de WC-Co P20, pelo Método 2. 100

Tabela 7.5: Corpos-de-prova de aço ferramenta M2. Valores de $A_{t}$ obtidos pelos Métodos 1 e 2. Tabela 7.6: Corpos-de-prova de WC-Co P20. Valores de $A_{t}$ obtidos pelos Métodos 1 e 2 .__ 114 Tabela 7.7: Corpos-de-prova de HSS M2 e WC-Co P20. Valores de $d_{\text {médio }}$ e $\sigma_{P .}$. 120

Tabela 7.8: Valores de $A_{t}$ e k. Resultados obtidos com os corpos-de-prova de HSS M2. 130 Tabela 7.9: Valores de $A_{t}$ e k. Ensaios realizados nos corpos-de-prova de WC-Co P20, com a esfera E-52100-2. 


\section{LISTA DE EQUAÇÕES}

\section{CAPÍTULO 2}

$Q=K \frac{F_{N}}{H}$

Equação 2.1 11

$Q=k \cdot F_{N}$

Equação 2.2 11

$h=12,70-\sqrt{161,29-0,25 d^{2}}$

Equação 2.3 15

$V=\pi\left(12,70 h^{2}-\frac{h^{3}}{3}\right)$

Equação 2.4 15

$k=\frac{d^{4}}{128 \cdot t \cdot n_{E S F} \cdot F_{N} \cdot R^{2}}$

Equação 2.5 19

$$
k=\frac{A_{t}^{2}}{4 \cdot \pi \cdot F_{N} \cdot S \cdot R}
$$

Equação 2.6 19

$V=k \cdot S \cdot F_{N}$

Equação 2.7 23

$$
S_{C}=\frac{F_{N}\left(\frac{1}{H_{E}}+\frac{1}{H_{C P}}\right)}{\pi\left[\sqrt[3]{\left[0,75 \cdot F_{N} \cdot R \cdot\left(\frac{1-v_{E}^{2}}{E_{E}}+\frac{1-v_{C P}^{2}}{E_{C P}}\right)\right]^{2}}+2 \cdot R \cdot D_{P}\right] \cdot \vartheta}
$$

Equação 2.8 30 


\section{CAPÍTULO 4}

$n=\frac{120 f}{p}(1-s)$

Equação 4.1 49

$n_{E S F}=\frac{120 f_{\text {inv }}}{p} i_{\text {red }} . i_{p o l}$

Equação 4.2 50

$n_{E S F}=i_{p o l} 1,50 f_{i n v}$

Equação 4.3 50

CAPÍTULO 5

$t=\frac{S}{v_{t}}$

Equação 5.1 61

$t=\frac{S}{2 \cdot \pi \cdot n_{E S F} R}$

Equação 5.2 62 


\section{RESUMO}

Esta Dissertação tem por objetivo estudar o comportamento de diferentes materiais sob a ação de desgaste micro-abrasivo. Como parte do trabalho, foi projetada e construída uma máquina de ensaio desgaste por micro-abrasão por esfera rotativa fixa, com configuração mecânica com diferenças em relação às observadas na literatura (Gee et al., 2005).

Como corpos-de-prova, foram utilizadas pastilhas intercambiáveis de metal duro (classe P20) e aço ferramenta M2. As esferas foram de aço AISI 1010 cementado e aço AISI 52100 temperado e revenido. Durante os ensaios, foi inserida entre a esfera e o corpo-de-prova uma pasta abrasiva preparada com carbeto de silício preto, com tamanho médio de partícula de $5 \mu \mathrm{m}$.

Inicialmente, foram realizados ensaios preliminares, com a finalidade de analisar não só o comportamento do equipamento, mas também estudar a transição entre os modos de desgaste que podem ocorrer durante o desgaste micro-abrasivo. A transição entre os modos de desgaste foi estudada em função da carga normal e dos materiais utilizados durante o ensaio. Os resultados obtidos indicaram boa reprodutibilidade do equipamento e coerência com resultados da literatura.

Em seguida, em ensaios denominados definitivos, foram pesquisadas as atuações dos modos de desgaste abrasivo e a obtenção do regime permanente de desgaste. Os resultados mostraram que, com a variação da distância de deslizamento, houve alterações nas ocorrências dos modos de desgaste abrasivo. Por outro lado, em alguns ensaios, o coeficiente de desgaste tendeu a permanecer constante, o que caracteriza a obtenção do regime permanente de desgaste. Entretanto, em outros, o coeficiente de desgaste teve uma evolução aleatória com a distância de deslizamento, fornecendo indicativos de que o desgaste não entrou em regime.

Palavras-chave: Desgaste, desgaste abrasivo por riscamento, desgaste abrasivo por rolamento, desgaste abrasivo misto, ensaio de desgaste por micro-abrasão, regime permanente de desgaste. 


\section{ABSTRACT}

This work presents a study on the behavior of different materials under the action of micro-abrasive wear. A micro-abrasive wear testing machine with fixed sphere was designed and constructed, presenting a mechanical configuration with differences with respect to those found in the literature (Gee et al., 2005).

M2 tool steel and WC-Co P2O were used as testing specimen materials. Ball materials were cemented AISI 1010 steel and quenched and tempered AISI 52100 steel. During the tests, an abrasive slurry, prepared with black silicon carbide ( $\mathrm{SiC}$ ) particles (average particle size of $5 \mu \mathrm{m}$ ), was supplied to the contact between the specimen and the ball.

Initially, preliminary tests were conducted to study the wear mode transitions that can occur during the micro-abrasive wear and to analyze the operational conditions of the equipment. The wear mode transitions were evaluated as a function of the applied normal load and of the materials used. The results indicated good reproducibility and qualitative agreement with those found in the litarature.

Later, a new set of tests was conducted, which analyzed the evolution of the abrasive wear modes and the achievement of steady state wear as a function of sliding distance. The results indicated a continuous variation in the abrasive wear modes with sliding distance. Additionally, in some tests, the wear coefficient tended to stabilize in constant value, which characterizes the achievement of steady state regime. However, in other tests, the wear coefficient presented a non constant evolution of wear coefficient with the sliding distance, which denotes that the constant regime of wear was not obtained.

Keywords: Wear, grooving abrasion, rolling abrasion, mixed-mode abrasion, microabrasive wear testing, constant regime of wear. 
Muitas vezes, as pessoas são egocêntricas, ilógicas e insensatas.

Perdoe-as assim mesmo.

Se você é gentil, as pessoas podem acusá-lo de egoísta, interesseiro.

Seja gentil assim mesmo.

Se você é um vencedor, terá alguns falsos amigos e alguns inimigos verdadeiros.

Vença assim mesmo.

Se você é honesto e franco, as pessoas podem enganá-lo.

Seja honesto assim mesmo.

O que levou anos para construir, alguém pode destruir de uma hora para outra.

Construa assim mesmo.

Se você tem paz, é feliz, as pessoas podem sentir inveja.

Seja feliz assim mesmo.

Dê ao mundo o melhor de você, mas isso pode nunca ser o bastante.

Dê o melhor assim mesmo.

Veja você que, no final das contas, É ENTRE VOCÊ E DEUS.

Nunca entre você e as outras pessoas. 


\section{CAPÍTULO 1 - INTRODUÇÃO}

Em setores industriais onde o desgaste causa a parada ou a diminuição da produção, ou envolve elevados custos de manutenção, não é suficiente adquirir conhecimentos apenas em materiais e processos metalúrgicos e/ou mecânicos de fabricação. Tão importante quanto isso, é pesquisar, estudar e entender os processos de desgaste que atuam em condições específicas.

Em geral, o desgaste está presente em situações em que há contato e movimento. Em alguns casos, o mesmo é considerado benéfico, em outras, maléfico. $O$ desgaste sofrido por uma ferramenta de corte é um caso maléfico. Por outro lado, o desgaste que a mesma gera no material a ser usinado é um exemplo benéfico. Entretanto, de um modo geral, o desgaste é visto como o "vilão da história".

Dentre os vários tipos de desgaste classificados pela norma ASTM G40 - 96, está o desgaste abrasivo.

Recentemente, o desgaste abrasivo vem sendo estudado por uma nova configuração de equipamento, comumente denominada de "máquina de desgaste micro-abrasivo". Na língua inglesa, a mesma é denominada "micro-abrasive wear testing machine". Para a realização desta Dissertação, foi projetado e construído um equipamento desse tipo, denominado "Máquina de Ensaio de Desgaste Micro-Abrasivo por Esfera Rotativa Fixa - Modelo LFS 2005'. Através do contato entre uma esfera (que está em movimento de rotação) e um corpo-de-prova, são geradas calotas esféricas, ou, também chamadas, crateras de desgaste. Através das análises dessas crateras, pode ser possível prever, ou, pelo menos estimar, o comportamento ao desgaste abrasivo de um material em condições reais de trabalho.

Uma possível aplicação do equipamento acima mencionado, está ligada à pesquisas envolvendo o estudo do desgaste micro-abrasivo atuante em ferramentas de corte, durante operações de usinagem. Atualmente, talvez essa seja uma das tarefas importantes que são conferidas a um pesquisador envolvido na área de tribologia.

Esse tipo de estudo deve ser mais difundido entre os pesquisadores brasileiros, pois o Brasil encontra-se em posição de destaque no setor de usinagem. 
Essa posição privilegiada começa no próprio aprendizado. A Alemanha, um dos países mais avançados na área de mecânica, tem como referência o ensino realizado no Brasil pelas escolas SENAI. Um exemplo da qualidade dos profissionais brasileiros envolvidos em usinagem está no fato de que, atualmente, estão sendo fabricadas em território nacional (pela própria rede SENAI), vários componentes para a Estação Espacial Internacional, projeto do qual o Brasil faz parte.

Todo o panorama ao redor da usinagem realizada no Brasil mostra que não é importante investir somente no desenvolvimento de novos equipamentos, como as máquinas HSM (High Speed Machine). Tão importante quanto isso, é desenvolver pesquisas com a finalidade de melhorar o desempenho das ferramentas de corte utilizadas por esses novos equipamentos. Isso porque, atualmente, em operações de usinagem que utilizem tecnologias de ponta (tanto as tecnologias relacionadas aos equipamentos, quanto aos avanços atingidos na parte de materiais), a limitação em geral é a ferramenta de corte, e não a máquina.

O melhor desempenho das ferramentas de corte almejada pelos profissionais envolvidos na área (tanto pesquisadores, quanto profissionais da própria área de usinagem) pode ser obtida através de pesquisas envolvendo materiais e/ou pesquisas envolvendo o estudo dos tipos de desgaste que as ferramentas de corte estão submetidas (entre eles, o desgaste abrasivo).

Apenas para se ter uma idéia da importância do setor de usinagem, tomando-se como referência os Estados Unidos, em 1989, foram investidos US $\$ 100$ bilhões nesse setor, o que mostra a importância não só deste processo na economia de um país (Marcondes, 1990), como também na pesquisa científica envolvida.

Esse texto inicia-se por uma revisão bibliográfica (Capítulo 2) referente ao desgaste abrasivo, seguida (Capítulo 3) pela apresentação dos objetivos e das hipóteses levantadas com base na literatura e em alguns ensaios preliminares. Em seguida, o Capítulo 4 apresenta o projeto da "Máquina de Ensaio de Desgaste Micro-Abrasivo por Esfera Rotativa Fixa - Modelo LFS 2005" (projetada e construída no âmbito deste trabalho).

No Capítulo 5 está a metodologia de pesquisa adotada nesta Dissertação. Os resultados obtidos, assim como as discussões, encontram-se nos Capítulos 6 e 7. Finalmente, o Capítulo 8 expõe as conclusões do trabalho. 
Completando este texto, o Anexo / apresenta a dedução da equação de Archard para o desgaste abrasivo, explicada de forma mais detalhada do que a apresentada no trabalho de Hutchings (1992). No Anexo // estão as equações utilizadas para o estudo do desgaste abrasivo, deduzidas de maneira diferente à que se encontra na literatura (Rutherford e Hutchings, 1997) e, no Anexo III, uma equação alternativa para o cálculo do coeficiente de desgaste. Por fim, no Anexo IV estão, além dos contatos realizados, os desenhos do equipamento projetado e construído. 
“...Divino Espírito Santo, a Vós que estais comigo em todos os instantes eu quero, humildemente, agradecer por tudo que eu sou, por tudo que eu tenho..."

Trecho da ORAÇÃO AO DIVINO ESPÍRITO SANTO 


\section{CAPÍTULO 2 - DESGASTE ABRASIVO}

Desgaste pode ser definido como sendo "o dano em uma superfície sólida, envolvendo perda progressiva de massa, devido ao movimento relativo entre a superfície e o contato com outro material ou materiais" (ASTM G77 - 91).

Entretanto, para cada tipo de desgaste, tem-se uma definição específica. $O$ desgaste abrasivo, que é o tipo de desgaste focado nesta Dissertação, é definido como sendo "o desgaste devido a partículas duras ou protunberâncias duras forçadas contra e movendo-se ao longo de uma superfície sólida" (ASTM G40 - 96).

Dentro do conceito de desgaste abrasivo, está o desgaste micro-abrasivo (discutido do Item 2.1), que pode ser estudado através de ensaios de desgaste por micro-abrasão. O "ensaio de desgaste micro-abrasivo por esfera rotativa" ("ball-cratering abrasion test" ou "micro-scale abrasive wear test" (Adachi e Hutchings, 2003), em inglês) é um teste bastante difundido no meio acadêmico, embora tenha surgido no setor produtivo. O mesmo consiste no desgaste gerado em um corpo-de-prova, por uma esfera e por partículas abrasivas. A Figura 2.1 mostra uma visão tri-dimensional de uma cratera de desgaste formada em um corpo-deprova de ferro sinterizado oxidado a vapor, em um ensaio de desgaste por microabrasão por esfera rotativa (Silva Jr., 2003). Maiores detalhes sobre esse tipo de ensaio estão apresentados no Item 2.3.

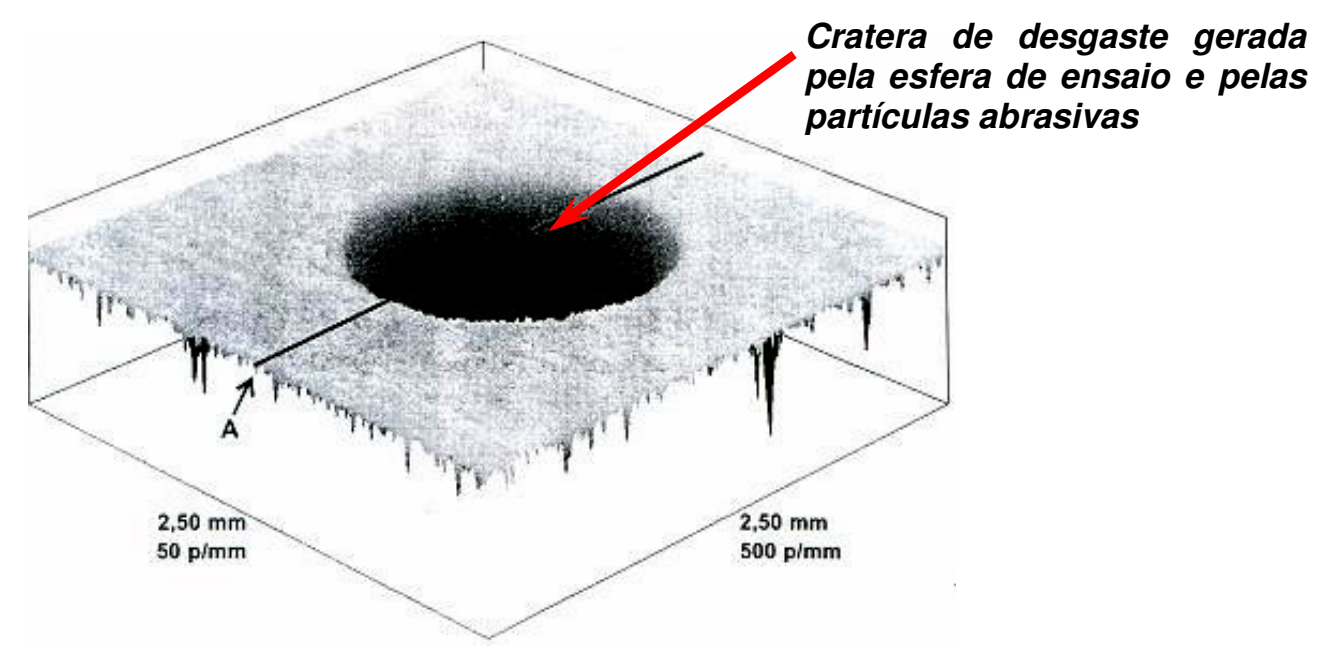

Figura 2.1: Visão tri-dimensional de uma cratera de desgaste formada em um corpode-prova de ferro sinterizado oxidado a vapor, em um ensaio de desgaste por microabrasão por esfera rotativa (Silva Jr., 2003). 
A Figura 2.2 exibe duas crateras de desgaste geradas em um filme fino de nitreto de titânio ( $T i M)$, com espessura de aproximadamente $3 \mu \mathrm{m}$. Através de medições realizadas em um microscópio óptico, observou-se que a calota esférica da direita, possuía diâmetro de $0,2 \mathrm{~mm}$, e que o desgaste não atingiu o substrato.

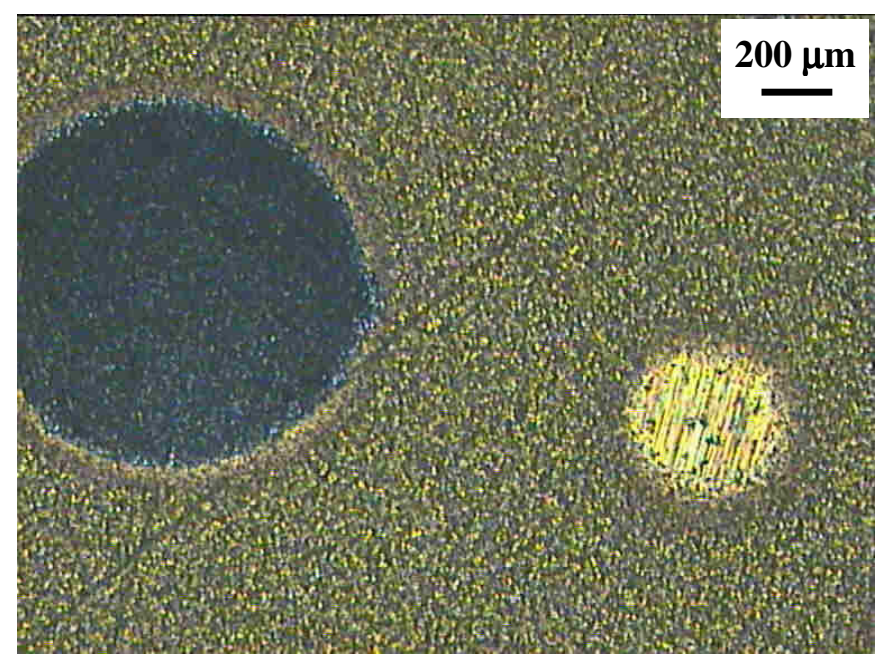

Figura 2.2: Cratera de desgaste gerada em um filme fino de TiN, com espessura de aproximadamente $3 \mu \mathrm{m}$.

\subsection{DESGASTE ABRASIVO: DEFINIÇÃO - CLASSIFICAÇÃO - TERMINOLOGIA}

"Desgaste abrasivo" e "desgaste micro-abrasivo" são termos encontrados em diversos artigos técnicos e científicos. Entretanto, a literatura (ASM Handbook, 1998; ASTM G40 - 96; Coutinho, 1992; Ohring, 1995) não define separadamente cada um desses termos. Isso porque o "desgaste micro-abrasivo" enquadra-se no conceito de "desgaste abrasivo".

Alguns parâmetros que podem ser utilizados para diferenciar o "desgaste abrasivo" do "desgaste micro-abrasivo" são a taxa de desgaste $(Q)$ e o coeficiente de desgaste $(\boldsymbol{k})$. Enquanto que no "desgaste micro-abrasivo" $\boldsymbol{k}$ varia entre $1.10^{-6} \mathrm{e}$ $2,5.10^{-4} \frac{\mathrm{mm}^{3}}{\mathrm{~N} \cdot \mathrm{m}}$ (Kattamis et al., 1994; Shipway e Howell, 2005; Trezona et al., 1999), no "desgaste abrasivo" observam-se valores de $\boldsymbol{k}$ até 100 mil vezes maiores, variando entre $1.10^{-2}$ e $1,2.10^{-1} \frac{\mathrm{mm}^{3}}{\mathrm{~N} \cdot \mathrm{m}}$ (Hutchings, 1992).

Porém, além do coeficiente de desgaste, há outras maneiras possíveis de diferenciar "desgaste abrasivo" de "desgaste micro-abrasivo". 
Através do tamanho médio das partículas abrasivas, também pode ser realizada a distinção entre "desgaste abrasivo" e "desgaste micro-abrasivo". O "desgaste micro-abrasivo" ocorre com participação de partículas abrasivas com tamanho médio na ordem de micrometro. Por exemplo, partículas abrasivas com tamanho médio entre 3 e $6 \mu \mathrm{m}$, aproximadamente, são comuns de serem utilizadas em ensaios de desgaste micro-abrasivo por esfera rotativa (Adachi e Hutchings, 2003; 2005; Baptista et al., 2000; Cozza et al., 2005; Trezona et al., 1999). Já o "desgaste abrasivo" é gerado por partículas abrasivas relativamente maiores, entre 50 e $250 \mu m$, por exemplo (Hutchings, 1992).

Nesta Dissertação serão encontradas frases envolvendo os termos "desgaste abrasivo" e "ensaio de desgaste micro-abrasivo". Isso pode fazer com que surja a seguinte dúvida: "...se o material foi submetido a um ensaio de desgaste micro-abrasivo, significa que o mesmo sofreu desgaste micro-abrasivo, e não desgaste abrasivo?". Isso significa que o tipo de desgaste sofrido pelo material foi abrasivo, mas que o mesmo foi submetido a um ensaio que forneceu escalas relativamente pequenas de taxas de desgaste ou coeficientes de desgaste.

Para que o material sofra desgaste micro-abrasivo, não é preciso que o mesmo seja necessariamente submetido a um ensaio de desgaste micro-abrasivo por esfera rotativa. Por intermédio de um equipamento com configuração completamente diferente ao de esfera rotativa, Sasada et al. (1984) relataram valores de $\boldsymbol{k}$ similares aos mencionados acima, ou seja, eles produziram desgaste micro-abrasivo nos corpos-de-prova.

Tradicionalmente, o contato entre as partículas abrasivas e a superfície que sofre desgaste tem sido classificado em dois modos: i) desgaste abrasivo a dois-corpos e ii) desgaste abrasivo a três-corpos (Hutchings, 1992).

$\mathrm{Na}$ língua inglesa, os termos "desgaste abrasivo a dois-corpos" e "desgaste abrasivo a três-corpos" são encontrados, cada um, sob duas denominações: "grooving abrasion" ou "two-body abrasive wear", e "rolling abrasion" ou "three-body abrasive wear", respectivamente (Trezona et al., 1999). "Grooving abrasion" devido às ranhuras ("grooves") que as superfícies apresentam e "rolling abrasion", devido ao movimento de rolamento que as partículas abrasivas realizam no desgaste.

$\mathrm{Na}$ língua portuguesa, os termos "desgaste abrasivo a dois-corpos" e "desgaste abrasivo a três-corpos" podem ser substituídos por "desgaste abrasivo por riscamento" ("grooving abrasion") e "desgaste abrasivo por rolamento" ("rolling 
abrasion"), respectivamente. Essa classificação se baseia nas marcas de desgaste geradas pelas partículas abrasivas no corpo-de-prova, como será exibido a seguir, nas Figuras 2.4 e 2.5. Nesta Dissertação, foram adotados os termos "desgaste abrasivo por riscamento" e "desgaste abrasivo por rolamento", para diferenciar os modos de desgaste abrasivo.

Na literatura (Coutinho, 1992; Gates, 1998; Misra e Finnie, 1980; Spero et al., 1991), pode-se encontrar, ainda, outras classificações para o desgaste abrasivo, mas as mesmas não serão apresentadas neste texto.

Considerando duas superfícies em movimento relativo, no desgaste abrasivo por riscamento as partículas abrasivas estão incrustadas em uma das superfícies (Figura 2.3a). Sendo assim, elas só podem deslizar sobre o contra-corpo. No desgaste abrasivo por rolamento, as partículas estão livres entre as duas superfícies, podendo rolar entre as mesmas (Figura 2.3b) (Hutchings, 1992).

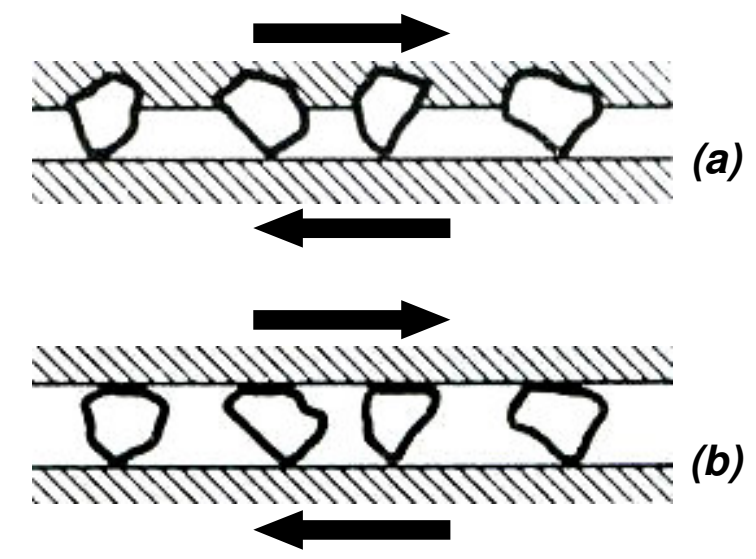

Figura 2.3: a) Desgaste abrasivo por riscamento; b) desgaste abrasivo por rolamento (Hutchings, 1992).

A Figura 2.4 mostra uma imagem típica de uma superfície que sofreu desgaste abrasivo por riscamento durante ensaio de micro-abrasão, com carga relativamente alta e baixa concentração de pasta abrasiva. Nesse ensaio utilizou-se uma força normal de 0,25 $N$ e concentração de pasta abrasiva (de diamante) de $3 \frac{\mathrm{mg}}{\mathrm{cm}^{3}}$. O corpo-de-prova foi de aço-ferramenta (1\% C, 1,2\% Mn, 0,2\% Si, 0,5\% Cr, $0,15 \% V, 0,5 \% W$, em massa) e a esfera de ensaio, de aço para rolamento (Trezona et al., 1999). Observa-se que as ranhuras formadas durante o desgaste são paralelas entre si. Isso mostra que as partículas, durante os ensaios, incrustaram na esfera, produzindo desgaste abrasivo por riscamento. 


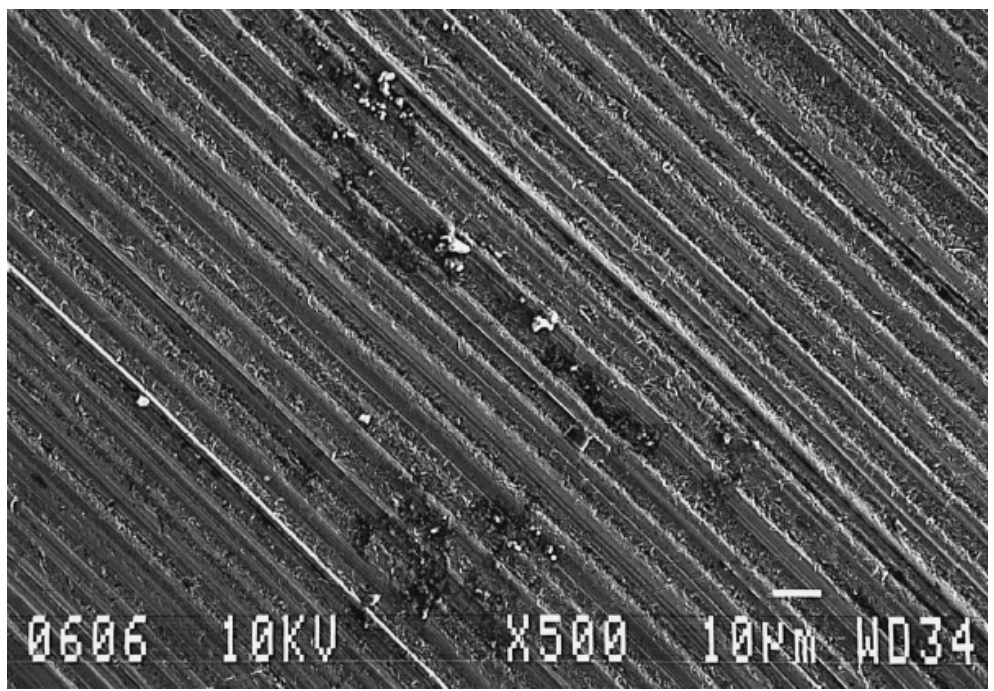

Figura 2.4: Superfície de um corpo-de-prova de aço ferramenta que sofreu desgaste abrasivo por riscamento por uma esfera de aço para rolamento e partículas abrasivas de diamante (Trezona et al., 1999).

A Figura 2.5 mostra a imagem de uma superfície que sofreu desgaste abrasivo por rolamento durante ensaio de micro-abrasão com uma elevada concentração de pasta abrasiva, $0,237 \frac{\mathrm{g}}{\mathrm{cm}^{3}}$, e baixa força normal, 0,25 N. O corpode-prova foi confeccionado em aço-ferramenta (1\% C, 1,2\% Mn, 0,2\% Si, 0,5\% Cr, $0,15 \% V, 0,5 \% W$, em massa) e a esfera de ensaio, em aço para rolamento (Trezona et al., 1999). Observa-se que, diferentemente da Figura 2.4, não foi formado um padrão para as marcas de desgaste. As mesmas formaram-se aleatoriamente. Isso mostra que as partículas permaneceram livres durante os ensaios.

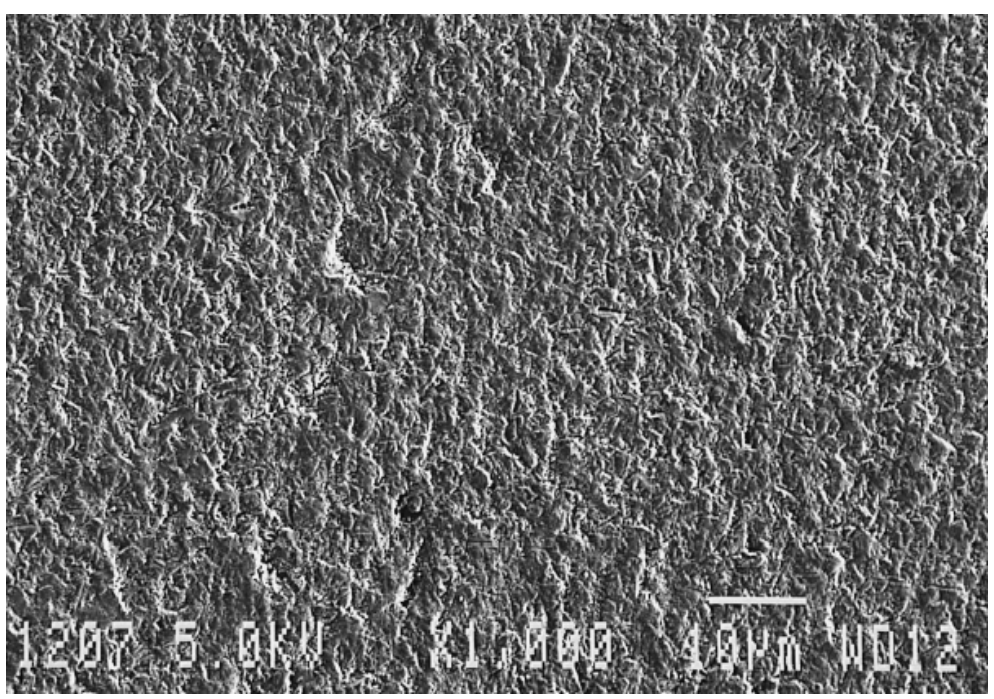

Figura 2.5: Superfície de um corpo-de-prova de aço ferramenta que sofreu desgaste abrasivo por rolamento por uma esfera de aço para rolamento e partículas abrasivas de SiC (Trezona et al., 1999). 


\subsection{EQUAÇÃO DE ARCHARD PARA O DESGASTE ABRASIVO}

Na Figura 2.6 tem-se uma partícula cônica deslizando sobre uma superfície plana de um material dútil e sob a ação de uma carga normal $\Delta \boldsymbol{F}_{\boldsymbol{N}}$.

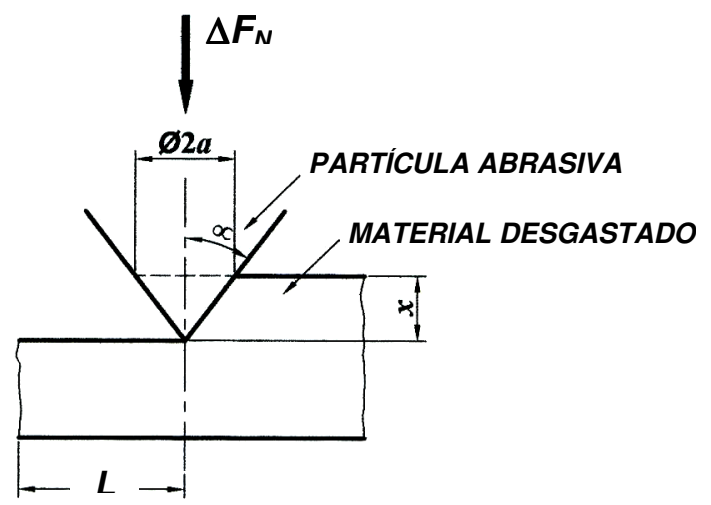

Figura 2.6: Partícula idealizada deslizando sobre a superfície de um material dútil (Hutchings, 1992).

A taxa de desgaste gerada pelas " $\boldsymbol{n}_{\boldsymbol{P}}$ " partículas abrasivas atuantes no sistema pode ser definida pela equação de Archard para o desgaste abrasivo (Equação 2.1) (Hutchings, 1992). A dedução dessa equação está no ANEXO I.

$$
Q=K \frac{F_{N}}{H}
$$

Na Equação 2.1, $Q$ é a taxa de desgaste, que é interpretada, nesse caso, como o volume de material removido por unidade de distância de deslizamento $\left(\frac{m m^{3}}{m}\right) . K$ mede a severidade do desgaste (quanto maior for $\boldsymbol{K}$, maior será a taxa de desgaste). É um valor adimensional e sempre menor que 1. Para o desgaste abrasivo por riscamento, $K$ está entre $\cong 5.10^{-3} \mathrm{e} \cong 50.10^{-3} \mathrm{e}$, para o desgaste abrasivo por rolamento, entre $\cong 0,50 \cdot 10^{-3} \mathrm{e} \cong 5 \cdot 10^{-3}$ (Hutchings, 1992). $\boldsymbol{F}_{\boldsymbol{N}}$ é a força normal total aplicada sobre o sistema e $\boldsymbol{H}$ é a dureza do material desgastado.

Fazendo $k=\frac{K}{H}$ e substituindo na Equação 2.1, a Equação de Archard para o desgaste abrasivo torna-se:

$$
Q=k \cdot F_{N}
$$


Neste caso, o coeficiente de desgaste $(\boldsymbol{k})$ pode ser interpretado como o volume de material desgastado por unidade de força e por unidade de distância de

deslizamento $\left(\frac{m m^{3}}{N \cdot m}\right)$. Pode-se dizer, também, que $\boldsymbol{k}$ é a taxa de desgaste, considerando, além da distância de deslizamento, a força normal.

A Equação 2.2 apresenta algumas limitações: $i$ ) a equação não considera se o desgaste é por riscamento ou por rolamento; ii) não são considerados a dureza e o tamanho médio das partículas abrasivas; iii) todas as partículas são consideradas como cones ideais (na prática, as partículas terão formatos variados, desgastando a superfície de maneiras diferentes).

\subsection{ENSAIO DE DESGASTE POR MICRO-ABRASÃO}

Atualmente, existem ensaios para os mais diversos estudos de materiais: dureza, tenacidade à fratura, tensão residual, taxa de desgaste etc (Allsopp e Hutchings, 2001; Kennedy e Hashmi, 1998; Trezona e Hutchings, 1999). Com o objetivo de estudar a abrasão de metais, minerais e vidros, Mikhail Lomonosov, membro da Academia Científica de Moscou, realizou um dos primeiros ensaios de abrasão, entre 1745 e 1765. Basicamente, seu equipamento era formado por um rebolo de diâmetro $460 \mathrm{~mm}$ fixo a uma manivela. A aplicação da força normal sobre os corpos-de-prova era realizada através de um sistema de peso-morto (Rutherford e Hutchings, 1997). O contato entre o rebolo e o corpo-de-prova gerava uma marca de desgaste.

O ensaio sofreu algumas modificações em 1921, por Brinell. Além da substituição do rebolo por um disco de aço de $100 \mathrm{~mm}$ de diâmetro, partículas de quartzo foram inseridas entre a amostra e o disco (Rutherford e Hutchings, 1997). $\mathrm{Na}$ realidade, Mikhail Lomonosov estava realizando desgaste abrasivo por riscamento, e Brinell, por rolamento. Entretanto, o princípio do ensaio proposto por Brinell permaneceu o mesmo que o realizado por Mikhail Lomonosov.

Em 1949, Haworth realizou o primeiro ensaio de abrasão utilizando um volante de borracha. Nesse mesmo ano, Grodzinski realizou, pela primeira vez, um ensaio de micro-abrasão (por rolamento). Neste caso, foi utilizado um disco de ferro fundido com $25 \mathrm{~mm}$ de diâmetro e as forças normais que atuavam sobre a amostra 
variavam de 0,2 $\mathrm{N}$ a $5 \mathrm{~N}$. Entre o disco e a amostra foram inseridas partículas de diamante (Rutherford e Hutchings, 1997).

O ensaio de desgaste abrasivo, aplicado em filmes finos, teve um progresso significativo em 1991, quando Kassman utilizou um "dimple grinder" (Figura 2.7, Hogmark et al., 2000), determinando, pela primeira vez, os coeficientes de desgaste do revestimento e do substrato de forma independente (Rutherford e Hutchings, 1997).

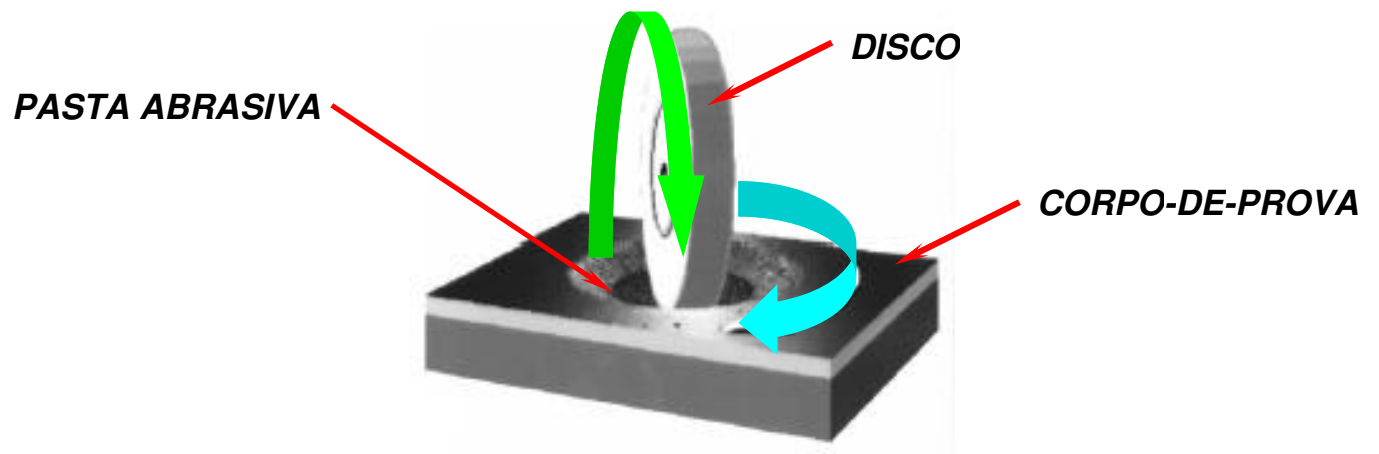

Figura 2.7: Dimple grinder (Hogmark et al., 2000).

Em 1996, Rutherford \& Hutchings desenvolveram o ensaio de micro-abrasão por esfera rotativa. A finalidade dessa nova configuração era apenas medir a espessura de revestimentos. Entretanto, atualmente, pelo potencial do ensaio, o mesmo é aplicado em pesquisas, envolvendo desgaste abrasivo de materiais (Kusano e Hutchings, 2005; Silva Jr., 2003) metálicos e não-metálicos, sob várias condições de ensaio. Atualmente, não há nenhuma norma que rege esse tipo de ensaio. Porém, alguns laboratórios europeus estão tentando normalizar o mesmo (Gee et al., 2005).

Existem duas configurações de equipamentos para o ensaio de desgaste micro-abrasivo por esfera rotativa: i) máquina de ensaio de desgaste micro-abrasivo por esfera rotativa fixa e ii) máquina de ensaio de desgaste micro-abrasivo por esfera rotativa livre.

A Figura 2.8 ilustra o princípio de funcionamento do equipamento de ensaio de desgaste micro-abrasivo por esfera rotativa fixa. Sobre a esfera de ensaio, é aplicada a força normal $\left(\boldsymbol{F}_{N}\right)$, definida pelo usuário. Ao lado da esfera de ensaio, e em contato com a mesma, está o corpo-de-prova. O contato e o movimento relativo entre esses dois elementos produz uma força tangencial (força de atrito), $\boldsymbol{F}_{\boldsymbol{T}}$. Com 
essa configuração, é possível controlar, também, a rotação da esfera de ensaio $\left(\boldsymbol{n}_{E S F}\right)$, a distância de deslizamento entre a esfera e o corpo-de-prova (S), a concentração da pasta abrasiva, que é introduzida no contato corpo-de-prova/esfera, e a vazão da mesma.

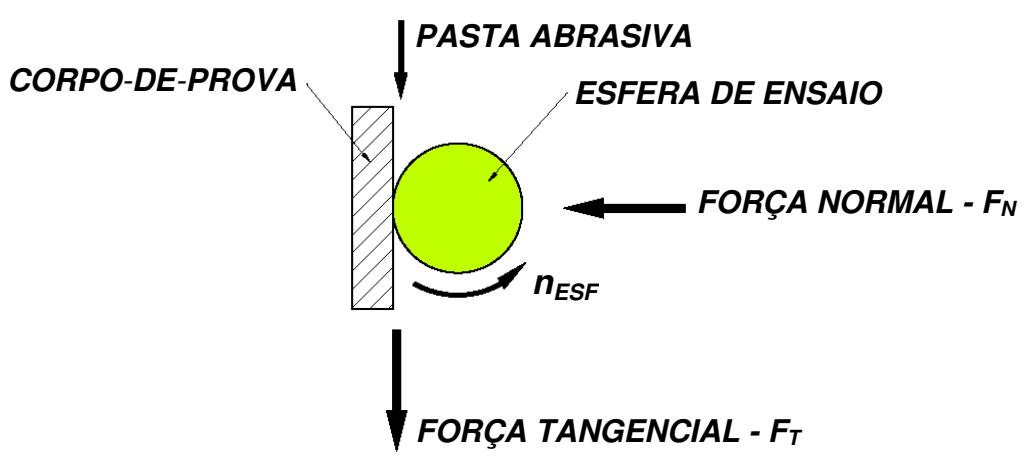

Figura 2.8: Princípio de funcionamento do equipamento de ensaio de desgaste microabrasivo por esfera fixa.

No equipamento de ensaio de desgaste micro-abrasivo por esfera rotativa livre (Figura 2.9), a força normal é definida pelo próprio peso da esfera, além da inclinação do corpo-de-prova e sua posição em relação ao eixo motor (Silva Jr., 2003).

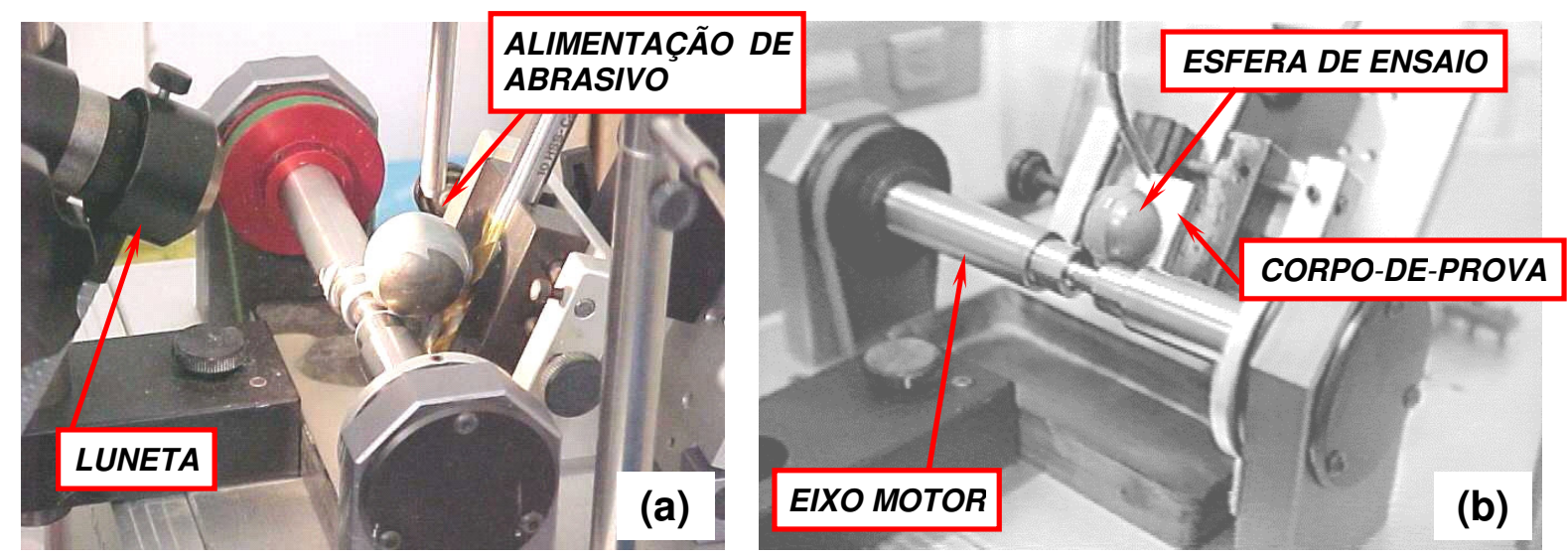

Figura 2.9: (a) Máquina de ensaio de desgaste micro-abrasivo por esfera rotativa livre (Silva Jr., 2003); (b) visão frontal do equipamento (Foto: Cortesia Prof. Dr. J. D. B. Mello - UFU - Faculdade de Engenharia Mecânica - LTM - Laboratório de Tribologia e Materiais).

A Figura 2.10 mostra uma cratera de desgaste gerada em um ensaio de micro-abrasão. 


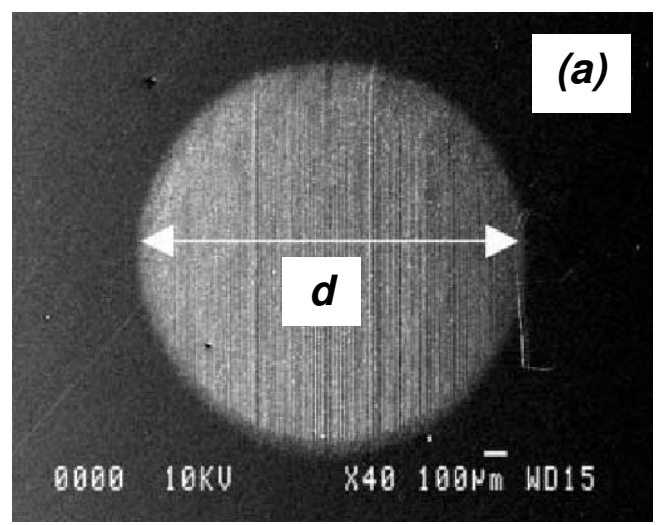

(b)

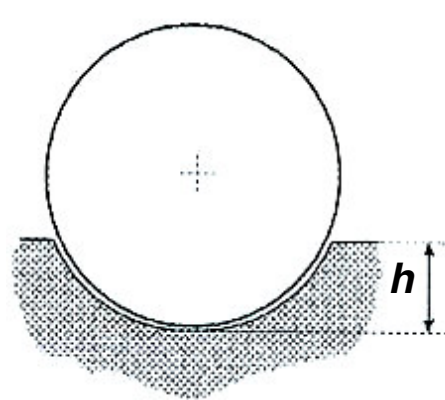

Figura 2.10: a) Vista frontal de uma cratera de desgaste, mostrando o diâmetro "d" da mesma (Kelly e Hutchings, 2001); b) profundidade de penetração " $h$ " da esfera de ensaio.

A profundidade de penetração $(\boldsymbol{h})$ da esfera de ensaio e o volume da cratera de desgaste $(\boldsymbol{V})$ são calculados através das Equações 2.3 e 2.4:

- Profundidade de penetração da esfera de ensaio (h):

$$
h=12,70-\sqrt{161,29-0,25 d^{2}}
$$

Unidades: $h \Rightarrow[\mathrm{mm}]$ e $d \Rightarrow[\mathrm{mm}]$

- Volume da cratera de desgaste (V):

$$
V=\pi\left(12,70 h^{2}-\frac{h^{3}}{3}\right)
$$

Unidades: $V \Rightarrow\left[\mathrm{mm}^{3}\right]$ e $h \Rightarrow[\mathrm{mm}]$

As Equações 2.2 e 2.3 foram deduzidas para uma esfera de ensaio de diâmetro 25,4 mm. A dedução de cada equação está no ANEXO II. Essas e outras equações estão apresentadas de forma diferente ao que se encontra nos trabalhos publicados por Baptista et al., 2000; Hutchings, 1998; Rutherford e Hutchings, 1996; Rutherford e Hutchings, 1997. 
Nas equações utilizadas por Baptista et al. (2000), Hutchings (1998), Rutherford e Hutchings (1996) e Rutherford e Hutchings (1997) para o cálculo de $\boldsymbol{h}$ e $\boldsymbol{V}$, deve ser considerada a seguinte condição: $\boldsymbol{d}<<\boldsymbol{R}$, onde $\boldsymbol{R}$ é o raio da esfera de ensaio. Embora desprezíveis, essa condição insere erros nos cálculos. Nas equações utilizadas nesta Dissertação, não se tem essa limitação, o que aumenta a precisão dos resultados.

\subsection{PARÂMETROS DO ENSAIO DE DESGASTE MICRO-ABRASIVO}

Propriedades como dureza e tenacidade à fratura, e parâmetros microestruturais, como porosidade e tamanho de grão, influenciam na resistência ao desgaste micro-abrasivo de um material (Dogan e Hawk, 2001; Erickson et al., 2001). Entretanto, a resistência ao desgaste abrasivo não é uma propriedade do material. Ela depende, também, dos parâmetros de ensaio (Dogan e Hawk, 2001; Kato, 2000).

Conforme mencionado no Item 2.3, em um ensaio de desgaste micro-abrasivo por esfera rotativa fixa, os parâmetros que podem ser controlados são: i) força normal atuante sobre o corpo-de-prova, ii) rotação da esfera de ensaio, iii) distância de deslizamento entre a esfera e o corpo-de-prova iv) concentração da pasta abrasiva e a v) vazão de pasta abrasiva sobre o corpo-de-prova/esfera. O tempo de ensaio pode ser considerado um parâmetro dependente, ou seja, é determinado em função da distância de deslizamento e da rotação da esfera. A dureza, o tamanho e o formato das partículas abrasivas, além da concentração da pasta abrasiva, também podem ser escolhidos. A combinação dessas variáveis pode fazer com que, durante ensaios de desgaste por micro-abrasão, ocorra a transição entre os modos de desgaste abrasivo (de riscamento para rolamento, ou de rolamento para riscamento).

A variação desses fatores pode alterar a intensidade do desgaste gerado no corpo-de-prova. Essa alteração de intensidade do desgaste pode ser verificada pelo aumento ou diminuição: da taxa de desgaste, do coeficiente de desgaste, ou pelo volume de desgaste da cratera formada, conforme será exposto a seguir. 


\subsubsection{Força normal}

A Figura 2.11 (Bose e Wood, 2005) mostra a variação da taxa de desgaste em função da carga normal aplicada sobre o corpo-de-prova, em um ensaio de micro-abrasão por esfera rotativa fixa. O revestimento foi de carbeto de boro, obtido por CVD (Chemical Vapor Deposition - Deposição Química de Vapor) com espessura de $18 \mu \mathrm{m}$. Como material abrasivo, utilizou-se SiC (carbeto de silício) com tamanho médio de 4,3 $\mu \mathrm{m}$. A concentração da pasta abrasiva ficou definida em $0,5 \frac{\mathrm{g}}{\mathrm{cm}^{3}}$ (em água destilada). A esfera de ensaio, de aço AISI 52100, possuía diâmetro de 25,4 mm. A rotação de $75 \mathrm{rpm}$ foi mantida constante durante todo o ensaio. A força normal variou de 0,3 a $2 N$. Pela equação de Archard para o desgaste abrasivo (Equação 2.2), mantendo-se $\boldsymbol{k}$ constante, a taxa de desgaste deve ser proporcional à força normal aplicada. Nota-se que o desgaste, pelos pontos marcados, foi praticamente proporcional à força normal, conforme prediz a teoria.

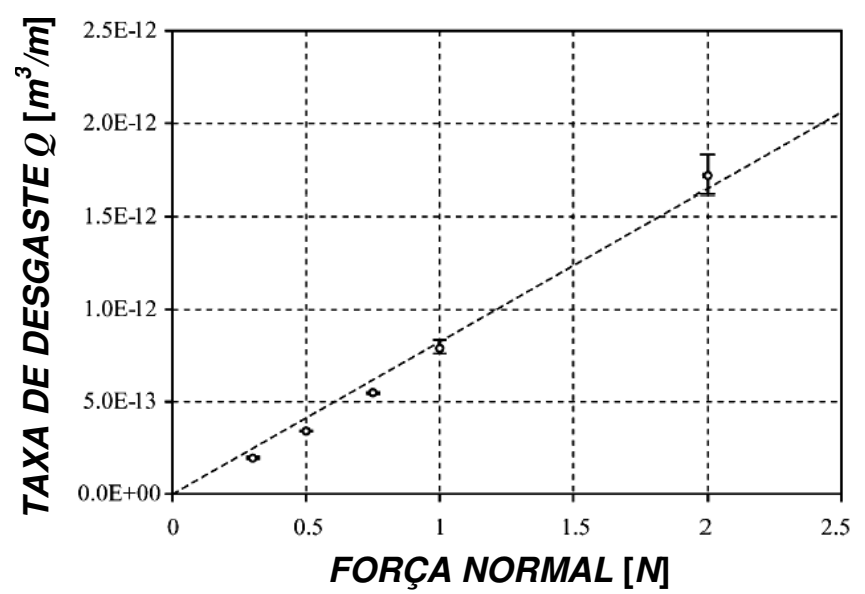

Figura 2.11: Variação da taxa de desgaste em função da força normal, para um revestimento de carbeto de boro, esfera de aço AISI 52100 e partículas abrasivas de SiC (Bose e Wood, 2005).

Entretanto, a Figura 2.12 (Bose e Wood, 2005) mostra que $\boldsymbol{k}$ variou com a força normal. Nesse caso, $\boldsymbol{k}$ aumentou com o aumento da força normal. 


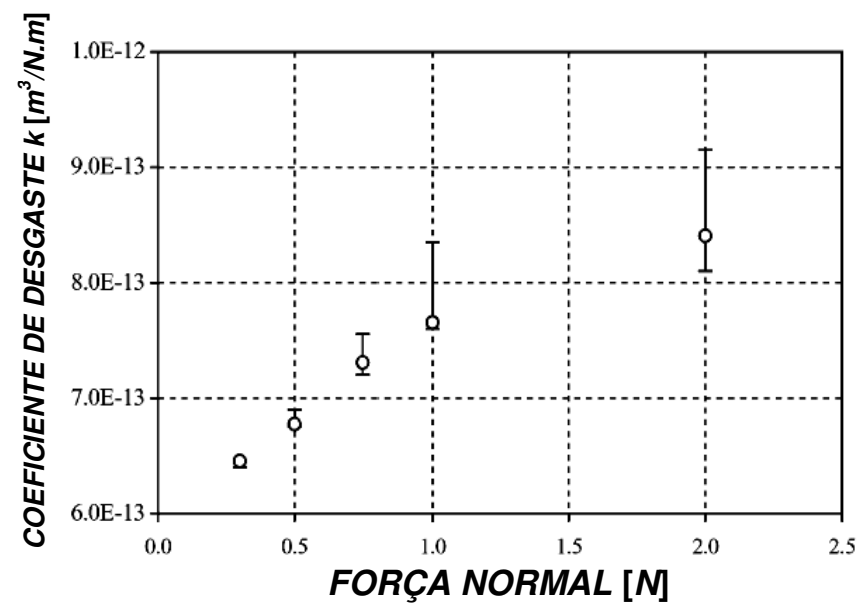

Figura 2.12: Variação do coeficiente de desgaste em função da carga normal, para um revestimento de carbeto de boro, esfera de aço AISI 52100 e partículas abrasivas de SiC (Bose e Wood, 2005).

Em ensaios utilizando substratos de aço carbono revestidos com $P A-11$ (poliamida - 11), com espessura de $400 \mu m$, Bello e Wood (2005) relataram que $\boldsymbol{k}$ diminuiu com o aumento da força normal (Figura 2.13). Entretanto, assim como na Figura 2.11, a taxa de desgaste apresentou uma relação linear com a força normal (Figura 2.14). O material abrasivo utilizado foi $\mathrm{SiC}$, com tamanho médio de partícula de $5 \mu \mathrm{m}$. A concentração da pasta abrasiva foi de $0,375 \frac{\mathrm{g}}{\mathrm{cm}^{3}}$ e as esferas foram de aço carbono, com diâmetro de 25 mm (Bello e Wood, 2005).

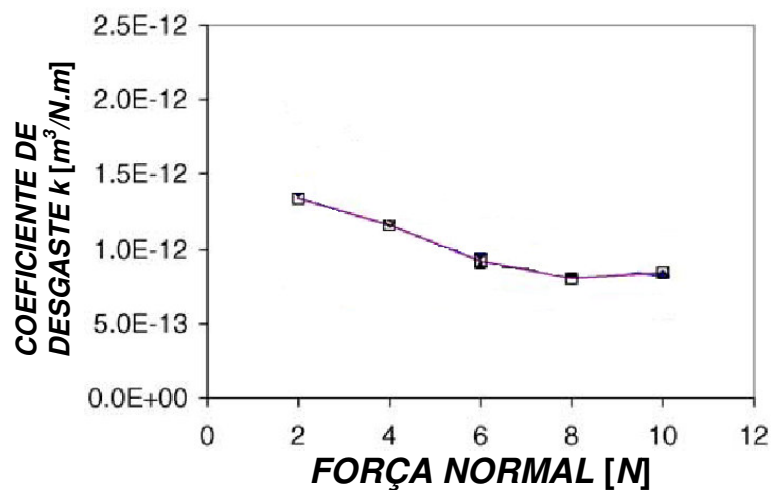

Figura 2.13: Variação do coeficiente de desgaste em função da carga normal, para revestimentos de PA-11, esferas de aço carbono e partículas abrasivas de SiC (Bello e Wood, 2005). 


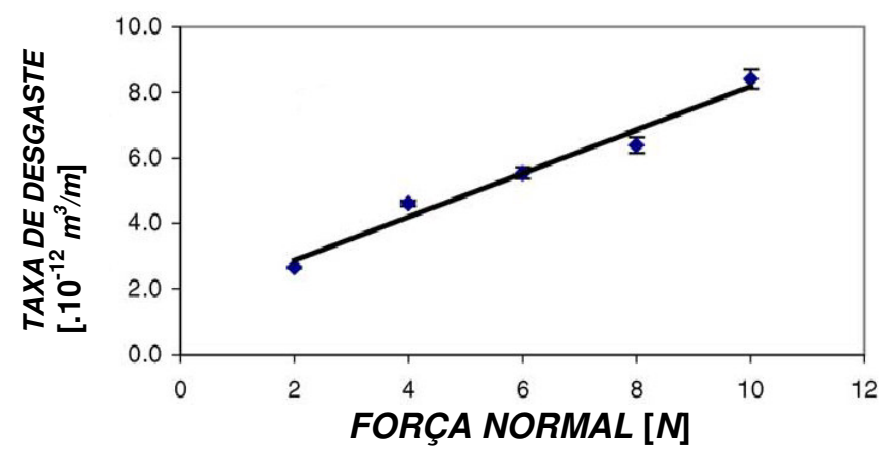

Figura 2.14: Variação da taxa de desgaste em função da carga norma, para revestimentos de PA-11, esferas de aço carbono e partículas abrasivas de SiC (Bello e Wood, 2005).

Nos casos apresentados nos parágrafos acima, mesmo obtendo-se uma variação linear da taxa de desgaste, em função da carga normal, $\boldsymbol{k}$ variou para cada ponto, onde aumentou ou diminuiu (Figuras 2.12 e 2.13, respectivamente). k não é uma propriedade do material que está sendo desgastado, e, na realidade, ele depende dos parâmetros de ensaio, conforme será descrito a seguir.

Em ensaio de micro-abrasão, $\boldsymbol{k}$ pode ser calculado pelas seguintes equações:

$$
\begin{gathered}
k=\frac{d^{4}}{128 \cdot t \cdot n_{E S F} \cdot F_{N} \cdot R^{2}} \\
k=\frac{A_{t}^{2}}{4 \cdot \pi \cdot F_{N} \cdot S \cdot R}
\end{gathered}
$$

$\mathrm{Na}$ Equação 2.5, e coerente com a nomenclatura do ANEXO II, $\boldsymbol{R}$ é o raio da esfera, $\boldsymbol{F}_{\boldsymbol{N}}, \boldsymbol{n}_{E S F}$ e $\boldsymbol{t}$ são os parâmetros de ensaio (força normal, rotação da esfera e tempo de ensaio, respectivamente). Mantendo-se $\boldsymbol{R}, \boldsymbol{n}_{\text {ESF }}$ e $\boldsymbol{t}$ constantes, e variando-se somente $\boldsymbol{F}_{\boldsymbol{N}}$, o diâmetro da cratera de desgaste $\boldsymbol{d}$ (Figura 2.10a) irá aumentar ou diminuir, com o aumento ou com a diminuição de $\boldsymbol{F}_{\boldsymbol{N}}$, respectivamente. A dedução da Equação 2.6 está no $A N E X O$ III. $\boldsymbol{A}_{t}$ é a área projetada total da calota esférica.

Com isso, para alguns materiais, $\boldsymbol{d}$ pode aumentar em proporção maior do que $\boldsymbol{F}_{\boldsymbol{N}}$, fazendo com que $\boldsymbol{k}$ aumente, como é o caso da Figura 2.12. Nessa situação, o material sofre maior intensidade de desgaste.

Em outros materiais, $\boldsymbol{d}$ pode aumentar em proporção menor do que $\boldsymbol{F}_{\boldsymbol{N}}$, fazendo com que $\boldsymbol{k}$ diminua, como é o caso da Figura 2.13. Nesse caso, o material apresentará menor intensidade de desgaste. 
Entretanto, $\boldsymbol{k}$ também pode permanecer constante. Mesmo que $\boldsymbol{F}_{\boldsymbol{N}}$ aumente ou diminua, o aumento ou a diminuição de $\boldsymbol{d}$ pode ser tal que o valor de $\boldsymbol{k}$ não se altere. Logo, pode-se dizer que a intensidade de desgaste permanecerá constante.

Ratificando o que foi dito no Item 2.2.1, sobre as limitações da equação de Archard para o desgaste abrasivo, $\boldsymbol{k}$ não considera a dureza, forma e tamanho dos grãos abrasivos, além da própria concentração da pasta abrasiva.

A Equação 2.5 foi deduzida com base nos trabalhos publicados por Baptista et al., 2000; Hutchings, 1998; Rutherford e Hutchings, 1996; Rutherford e Hutchings, 1997.

\subsubsection{Rotação da esfera de ensaio}

Pela Equação 2.5, nota-se que, assim como para o caso da força normal, variando-se a rotação da esfera de ensaio, $\boldsymbol{k}$ pode variar ou não, conforme discutido.

De forma diferente ao comportamento apresentado por $\boldsymbol{k}$ em função da carga normal, em ensaios de micro-abrasão em filmes finos de carbeto de boro, obtidos por $C V D$, o coeficiente de desgaste variou linearmente com a rotação da esfera de ensaio (Figura 2.15) (Bose e Wood, 2005).

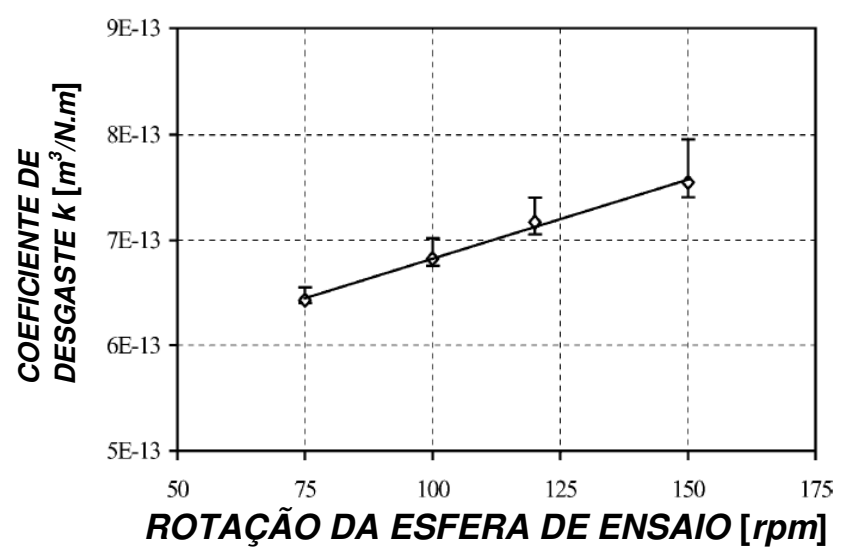

Figura 2.15: Variação do coeficiente de desgaste em função da carga normal, para um revestimento de carbeto de boro, esfera de aço AISI 52100 e partículas abrasivas de SiC (Bose e Wood, 2005).

Nota-se que, conforme a rotação da esfera aumentou, o valor de $\boldsymbol{k}$ aumentou proporcionalmente. Isso mostra que o revestimento apresentou maior intensidade de desgaste com o aumento da rotação da esfera. Entretanto, não é certo supor que todo revestimento apresenta esse comportamento.

$\mathrm{Na}$ literatura pesquisada, esse foi o único estudo envolvendo o efeito da rotação da esfera de ensaio no coeficiente de desgaste. 


\subsubsection{Distância de deslizamento entre a esfera e o corpo-de-prova}

Em um ensaio de desgaste micro-abrasivo por esfera rotativa, a distância de deslizamento entre a esfera e o corpo-de-prova apresenta influência fundamental para que o desgaste atinja, ou não, o regime permanente 1 . Além disso, a distância de deslizamento é um parâmetro que pode definir a completa formação da calota esférica.

Caso a distância de deslizamento definida para o ensaio seja relativamente baixa ( $\cong 6 m$ ), a cratera de desgaste poderá apresentar em sua borda, um aspecto difuso (Cozza et al., 2005). Isso pode ser um indício de que o ensaio não alcançou o regime permanente de desgaste. A Figura 2.16 mostra uma cratera de desgaste em que o regime permanente de desgaste não foi atingido (Trezona e Hutchings, 1999).

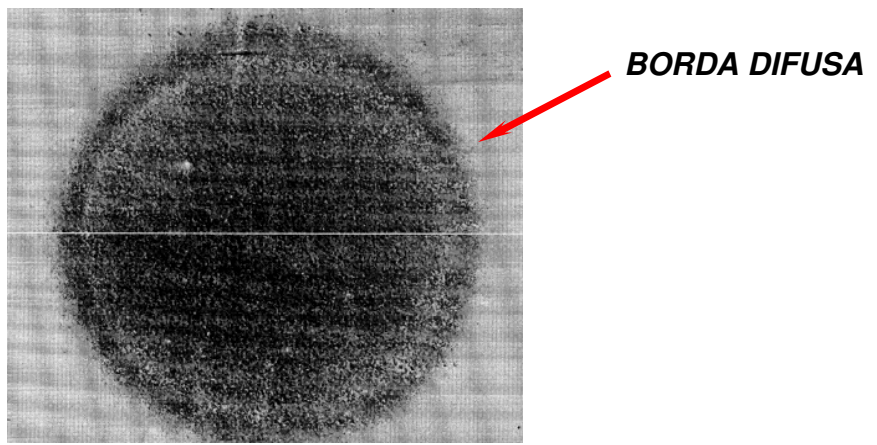

Figura 2.16: Cratera de desgaste com borda difusa (Trezona e Hutchings, 1999).

Porém, mesmo que i) o regime permanente de desgaste não tenha sido obtido e ii) a calota esférica apresente borda difusa, a mesma pode ter formação completa, caracterizada pelo contorno tendendo a uma circunferência, como é o caso da própria Figura 2.16.

A Figura 2.17 (Trezona e Hutchings, 1999) mostra uma cratera de desgaste nos estágios de formação, com suas respectivas distâncias de deslizamento. Notase que, conforme a distância de deslizamento aumenta, a forma da cratera torna-se mais definida. O corpo-de-prova foi de alumínio comercialmente puro e a esfera de aço AISI 52100, sob a ação de uma força normal de 0,25 N (Trezona e Hutchings, 1999). O material abrasivo foi SiC com tamanho médio de partícula de $4,25 \mu \mathrm{m}$.

\footnotetext{
${ }^{1}$ Diz-se que o processo de desgaste atingiu o regime permanente quando, a taxa de desgaste, para uma determinada condição de ensaio, permanece constante ao longo do tempo.
} 

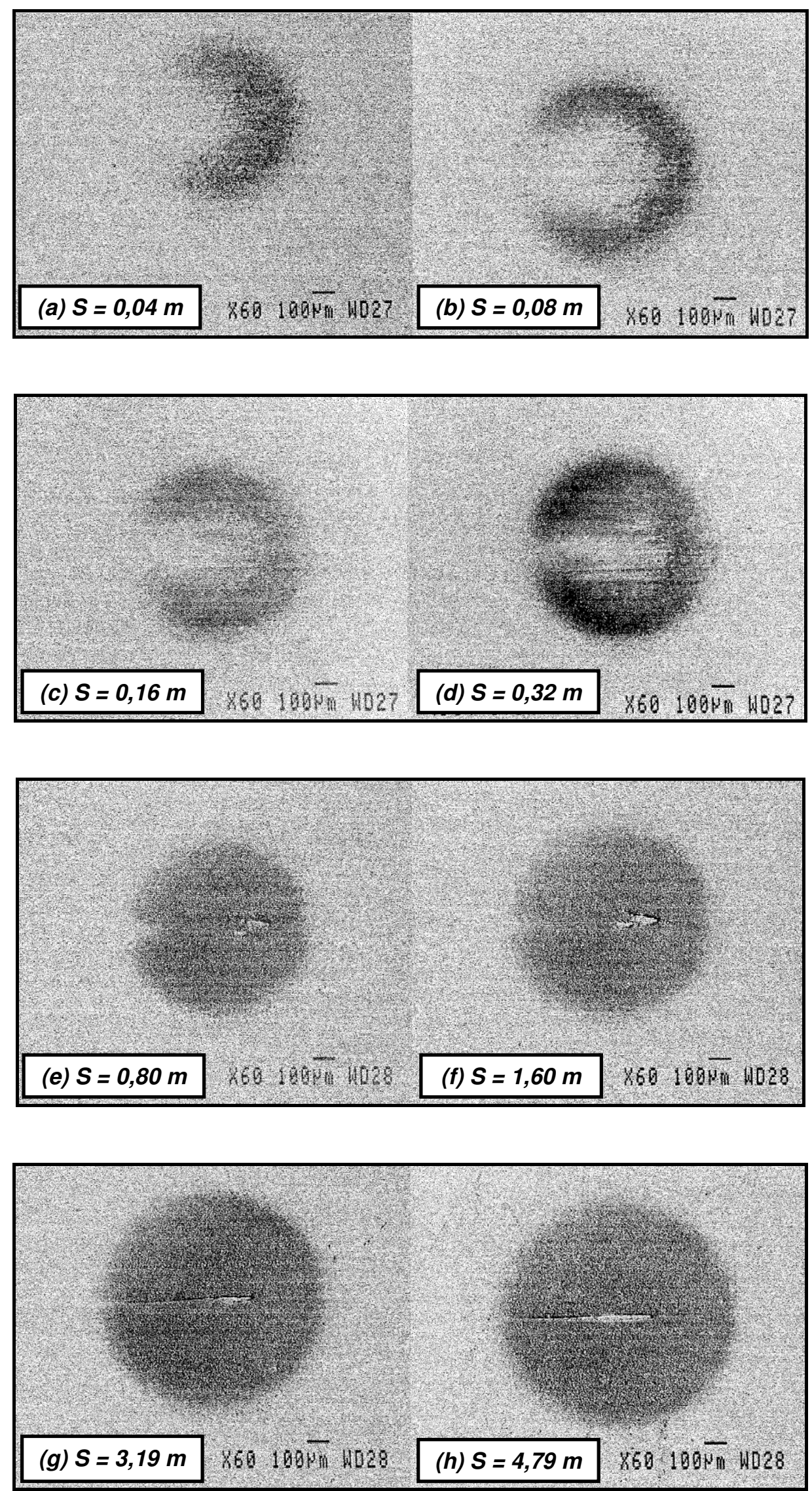

Figura 2.17: Diferentes estágios de formação de uma cratera de desgaste, com as respectivas distâncias de deslizamento (Trezona e Hutchings, 1999). 
A Figura 2.18 apresenta um gráfico do volume de desgaste em função do produto da distância de deslizamento pela força normal (Trezona e Hutchings, 1999). A relação linear entre $\boldsymbol{V}$ e $\boldsymbol{S} . \boldsymbol{F}_{\boldsymbol{N}}$ está de acordo com a Equação 2.7 (Hutchings, 1998; Rutherford e Hutchings, 1996), onde o volume de desgaste está em função do coeficiente de desgaste, distância de deslizamento e força normal.

$$
V=k \cdot S \cdot F_{N}
$$

O material do corpo-de-prova foi PMMA (polimetacrilato de metila). Com o uso de esfera de aço AISI 52100, ocorreu desgaste abrasivo por rolamento e, com esfera de PP (polipropileno), desgaste abrasivo por riscamento. Entretanto, nos dois casos o volume de desgaste apresentou uma variação linear em função do produto $\boldsymbol{S}_{\boldsymbol{N}} \boldsymbol{F}_{\boldsymbol{N}}$.

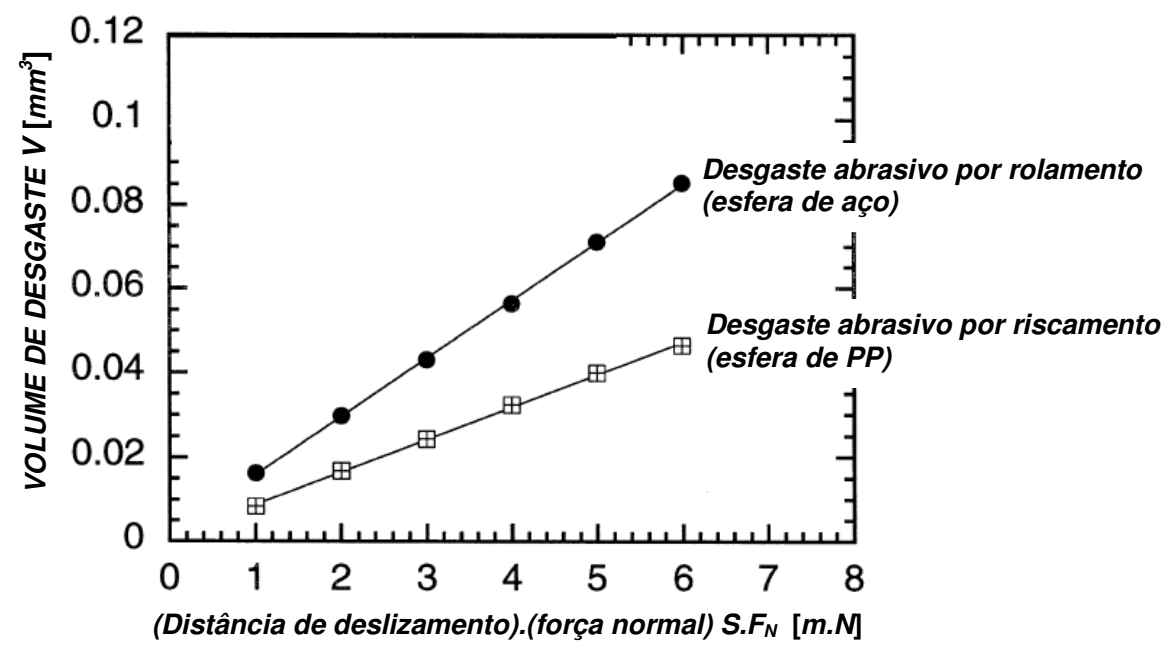

Figura 2.18: Volume de desgaste em função da distância de deslizamento e da força normal (Trezona e Hutchings, 1999).

\subsubsection{Concentração da pasta abrasiva}

Mergler e Huis in 't Veld (2003) estudaram a variação de $\boldsymbol{k}$ em função da concentração da pasta abrasiva para o PA-6,6 (Poliamida-6,6), PBT (Politereftalato de butileno) e POM (Polióxido de metileno).

A esfera de ensaio possuía diâmetro de $25,4 \mathrm{~mm}$, e foi fabricada em aço AISI 52100. Todos os ensaios foram realizados com a mesma esfera (foi desconsiderado o desgaste da mesma). Como material abrasivo, utilizou-se SiC com tamanho médio de partícula de 4,5 $\mu \mathrm{m}$. As concentrações da pasta abrasiva foram 
de $0,175,0,35$ e $0,7 \frac{\mathrm{g}}{\mathrm{cm}^{3}}$. Os valores das forças normais foram de 0,5 e $2 \mathrm{~N}$ e a rotação da esfera foi fixada em $80 \mathrm{rpm}$. Para esses mesmos materiais e condições de ensaio, foram verificadas variações lineares da taxa de desgaste, em função da força normal (Mergler e Huis in 't Veld, 2003).

As Figuras 2.19, 2.20 e 2.21 mostram a variação de $\boldsymbol{k}$ em função da concentração da pasta abrasiva, para o POM, PBT e $P A-6,6$, respectivamente.

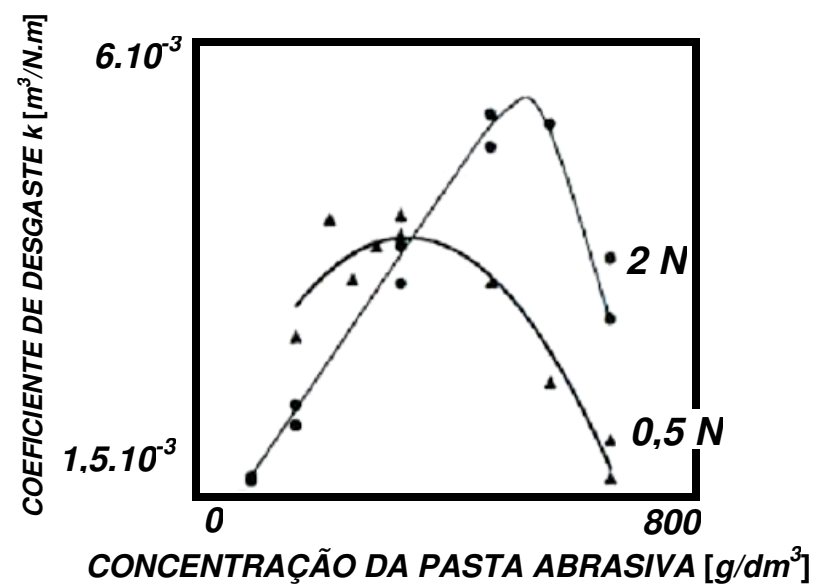

Figura 2.19: Variação do coeficiente de desgaste em função da concentração da pasta abrasiva para o POM (Mergler e Huis in 't Veld, 2003).

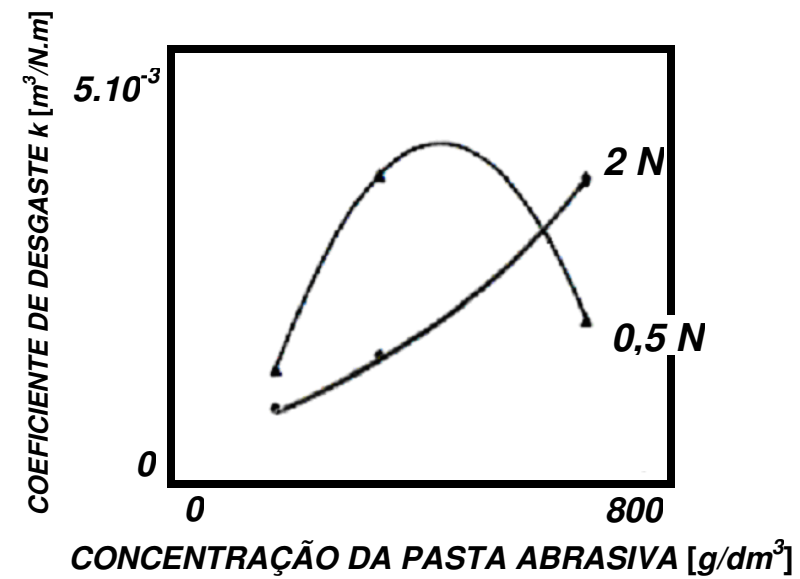

Figura 2.20: Variação do coeficiente de desgaste em função da concentração da pasta abrasiva para o PBT (Mergler e Huis in 't Veld, 2003). 


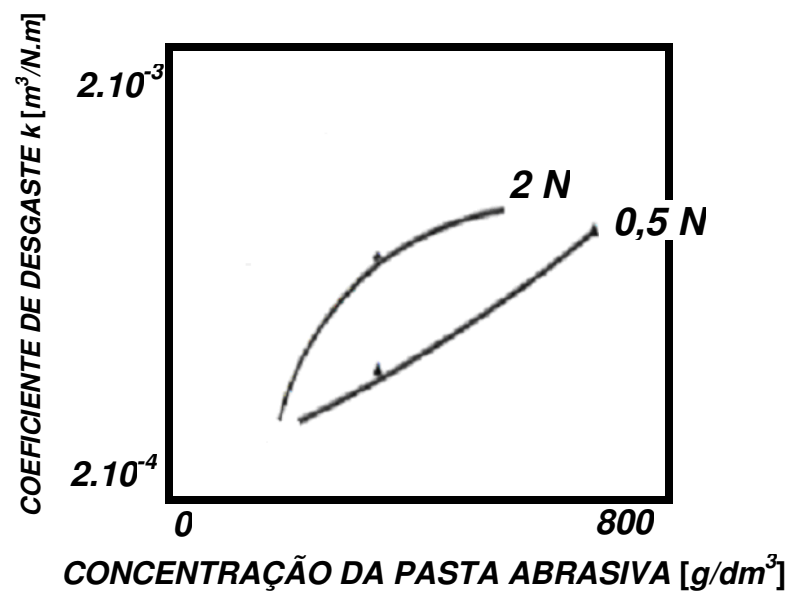

Figura 2.21: Variação do coeficiente de desgaste em função da concentração da pasta abrasiva para o PA-6,6 (Mergler e Huis in 't Veld, 2003).

As curvas levantadas para cada material e para cada valor de força normal se diferenciaram bastante. Embora as condições de ensaio tenham sido as mesmas, cada material apresentou uma curva característica.

A Figura 2.22 (Trezona et al., 1999) mostra um outro exemplo da variação do volume de desgaste em função da concentração da pasta abrasiva. O abrasivo utilizado foi SiC com tamanho médio de partícula de 4,25 $\mu \mathrm{m}$, em água destilada, junto com esferas de aço para rolamento e corpos-de-prova de aço ferramenta (1\% C, 1,2\% Mn, 0,2\% Si, 0,5\% Cr, 0,15\% V, 0,5\% W, em massa) temperado (dureza de $7,75 \mathrm{GPa}$ ).

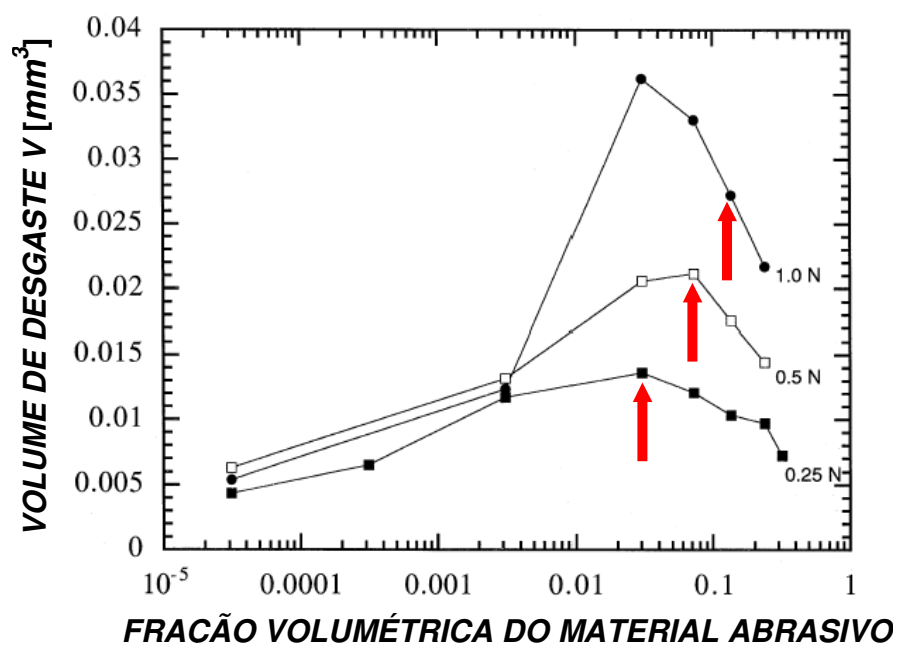

Figura 2.22: Volume de desgaste em função da porcentagem, em volume, de SiC na pasta abrasiva, para esferas de aço para rolamento e corpos-de-prova de aço ferramenta (Trezona et al., 1999). 
Para cada valor de força normal aplicada, foi levantada uma curva diferente. Observa-se que, quanto maior a força normal, maior o volume de desgaste, o que está de acordo com a Equação 2.6, quando considerada a mesma distância de deslizamento entre a esfera e o corpo-de-prova.

\subsubsection{Transição dos modos de desgaste abrasivo}

Geralmente, em ensaios de desgaste micro-abrasivo, considera-se que o modo de desgaste gerado é por rolamento. Porém, dependendo das condições de ensaio, pode-se ter a transição entre os modos de desgaste abrasivo, de rolamento para riscamento (Trezona et al., 1999).

Nos resultados apresentados nas Figuras 2.19, 2.20 e 2.21 (Mergler e Huis in 't Veld, 2003), conforme houve a variação da concentração da pasta abrasiva, observou-se a transição do modo de desgaste. Baixas cargas e altas concentrações de pasta abrasiva favoreceram o desgaste abrasivo por rolamento. Elevadas cargas e baixas concentrações de pasta abrasiva favoreceram o desgaste abrasivo por riscamento (Mergler e Huis in 't Veld, 2003).

Nos ensaios apresentados na Figura 2.22 (Trezona et al., 1999), também foi observada a transição entre os modos de desgaste. Os pontos marcados com setas indicam essa transição. À esquerda das setas, tem-se desgaste abrasivo por riscamento, que ocorre em baixas concentrações de pasta abrasiva e, à direita, desgaste abrasivo por rolamento, que ocorre em elevadas concentrações de pasta abrasiva.

Utilizando esferas de aço para rolamento e corpos-de-prova de aço-ferramenta e diferentes materiais abrasivos, Trezona et al. (1999) estudaram esse comportamento. A Figura 2.23 mostra a transição dos modos de desgaste, utilizando-se como material abrasivo, SiC, com tamanho médio de partícula de 4,25 $\mu \mathrm{m}$. Foi utilizada água destilada na mistura. $\mathrm{O}$ modo de desgaste ficou em função da combinação entre a força normal aplicada e a concentração da pasta abrasiva (Trezona et al., 1999). 


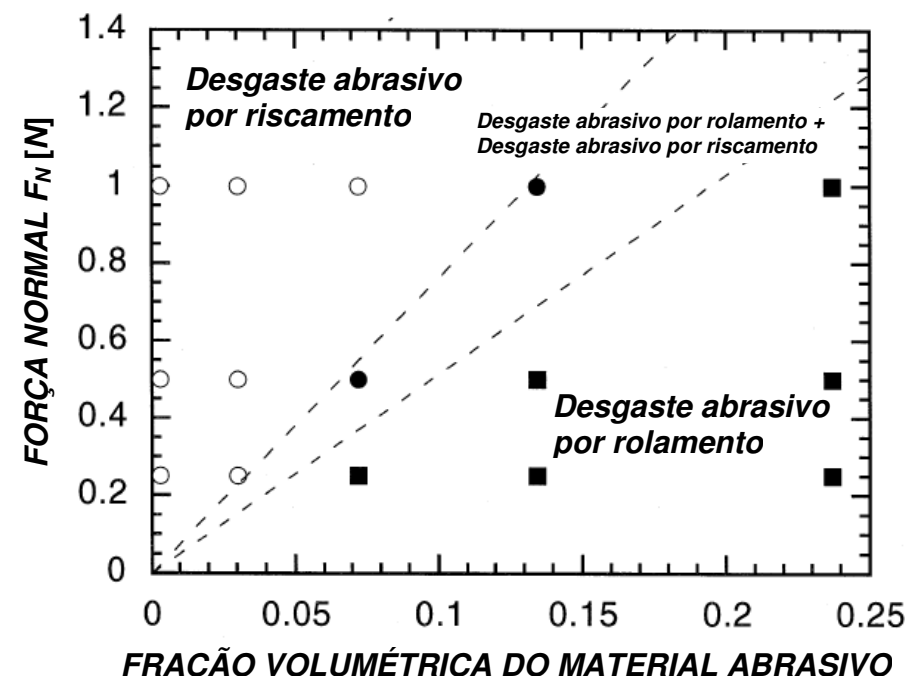

Figura 2.23: Transição dos modos de desgaste em função da força normal e da concentração da pasta abrasiva. Esfera de aço para rolamento, corpo-de-prova de aço ferramenta e partículas abrasivas de SiC (Trezona et al., 1999).

Percebe-se que, conforme foi relatado nos ensaios de Mergler e Huis in 't Veld (2003), para elevadas concentrações de pasta abrasiva, prevalece o desgaste abrasivo por rolamento e, para altas forças normais, predomina o desgaste abrasivo por riscamento (Trezona et al., 1999).

As Figuras 2.24 e 2.25 mostram, respectivamente, para os mesmos corposde-prova e esferas, a transição do modo de desgaste, utilizando-se como material abrasivo alumina com tamanho de partícula de 4,97 $\mu$ m e diamante com tamanho de partícula de 3,05 $\mu m$ (Trezona et al., 1999).

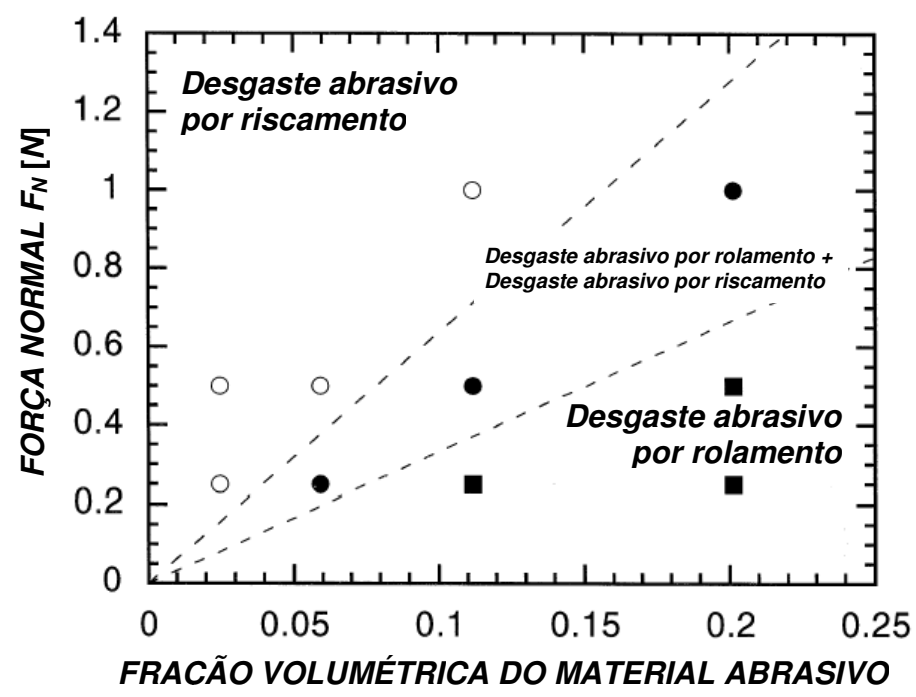

Figura 2.24: Transição dos modos de desgaste em função da força normal e da concentração da pasta abrasiva. Esfera de aço para rolamento, corpo-de-prova de aço ferramenta e partículas abrasivas de alumina (Trezona et al., 1999). 


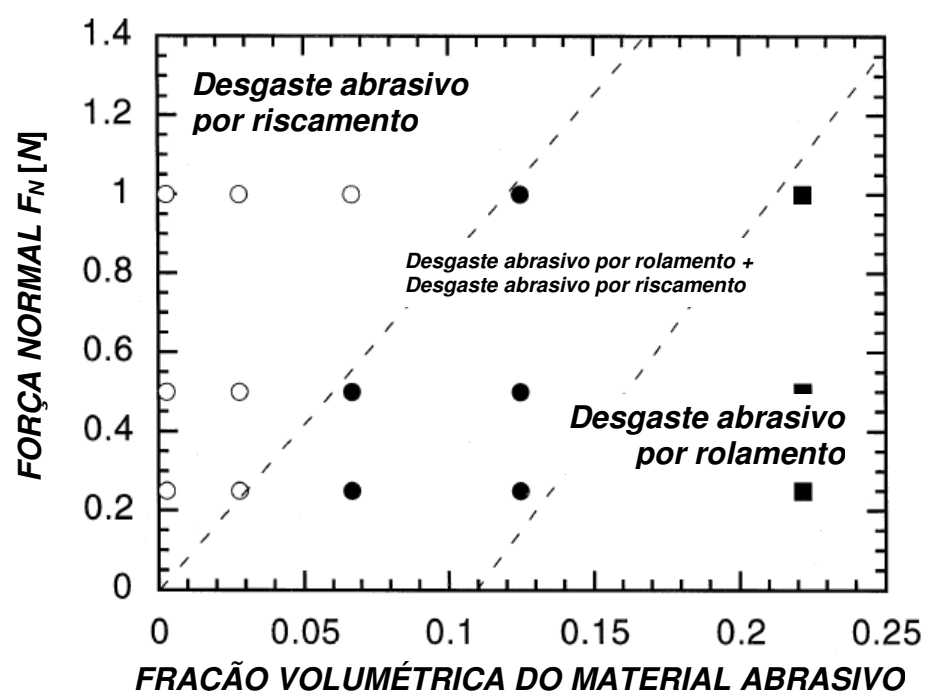

Figura 2.25: Transição dos modos de desgaste em função da força normal e da concentração da pasta abrasiva. Esfera de aço para rolamento, corpo-de-prova de aço ferramenta e partículas abrasivas de diamante (Trezona et al., 1999).

Nos ensaios utilizando-se alumina, obteve-se um gráfico semelhante ao da Figura 2.23. Novamente, em ambos os gráficos, o desgaste abrasivo por riscamento ocorreu na região de elevadas cargas e baixas concentrações de pasta abrasiva. Já o desgaste abrasivo por rolamento foi observado na região de baixas cargas e elevadas concentrações de pasta abrasiva (Trezona et al., 1999).

Nos três gráficos levantados (Figuras 2.23, 2.24 e 2.25), há uma região (central) em que os dois modos de desgaste ocorreram. Essa região foi maior nos ensaios em que foi utilizado diamante como material abrasivo (Figura 2.25) (Trezona et al., 1999).

Em ensaios de micro-abrasão por esfera rotativa, quando a superfície sofre os dois modos de desgaste (Figura 2.26), a mesma pode apresentar, em sua região central, ranhuras características de desgaste abrasivo por riscamento (Figura 2.4) e, nas extremidades, micro-impressões, deixadas pelo desgaste abrasivo por rolamento (Figura 2.5) (Adachi e Hutchings, 2003). 
Marcas de desgaste abrasivo por riscamento

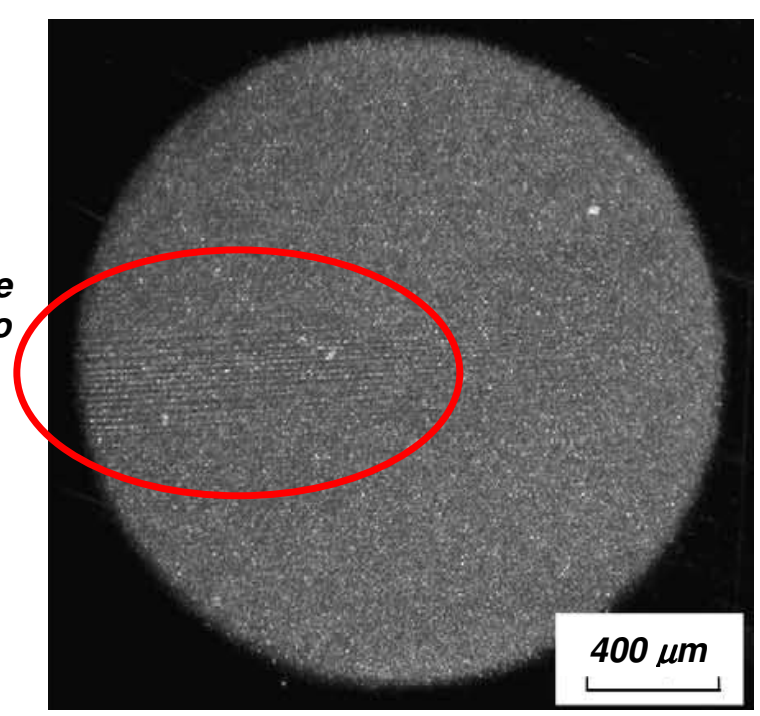

Figura 2.26: Corpo-de-prova de PMMA que sofreu desgaste abrasivo por riscamento na região central e desgaste abrasivo por rolamento nas extremidades. A força normal foi de 0,2 $\mathrm{N}$ e as partículas abrasivas foram de SiC, com uma fração volumétrica de $10 \%$ na pasta abrasiva (Adachi e Hutchings, 2003).

Considerando os efeitos da força normal e da concentração da pasta abrasiva, pode ser elaborado um gráfico, no qual são exibidas as superfícies características de cada modo de desgaste, em cada região (Figura 2.27).

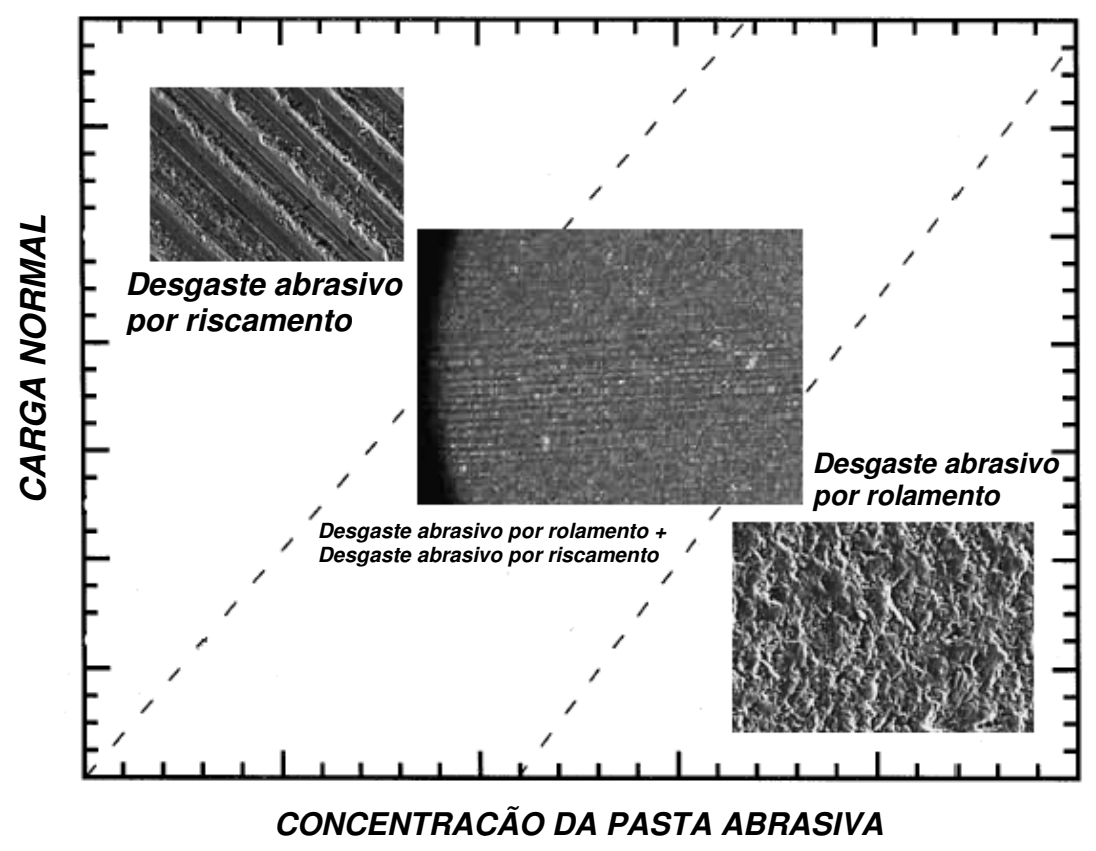

Figura 2.27: Superfícies características dos modos de desgaste, em função da carga normal e da concentração da pasta abrasiva.

A transição dos modos de desgaste também pode ser representada pela severidade de contato $\left(\boldsymbol{S}_{C}\right)$, definida pela Equação 2.8, em função de $\frac{H_{C P}}{H_{E}}$, em que 
$\boldsymbol{H}_{C P}$ é a dureza do corpo-de-prova e $\boldsymbol{H}_{E}$ é a dureza da esfera de ensaio (Figura 2.28) (Adachi e Hutchings, 2005).

$$
S_{C}=\frac{F_{N}\left(\frac{1}{H_{E}}+\frac{1}{H_{C P}}\right)}{\pi\left[\sqrt[3]{\left[0,75 \cdot F_{N} \cdot R \cdot\left(\frac{1-v_{E}^{2}}{E_{E}}+\frac{1-v_{C P}^{2}}{E_{C P}}\right)\right]^{2}}+2 \cdot R \cdot D_{P}\right] \cdot \vartheta}
$$

A Equação 2.7 foi deduzida a partir dos trabalhos de Adachi e Hutchings, 2005 e Hutchings, 1992.

Os índices $\boldsymbol{E}$ e $\boldsymbol{C P}$, referem-se, respectivamente, à esfera e ao corpo-deprova. Os demais itens da Equação 2.8 são:

- $F_{N} \Rightarrow$ Força normal entre a esfera e o corpo-de-prova;

- $\boldsymbol{H} \Rightarrow$ Dureza;

- $\boldsymbol{R} \Rightarrow$ Raio da esfera;

- $\boldsymbol{v} \Rightarrow$ Coeficiente de Poisson;

- $\boldsymbol{E} \Rightarrow$ Módulo de Elasticidade;

- $\boldsymbol{D}_{\boldsymbol{P}} \Rightarrow$ Tamanho médio das partículas abrasivas;

- $\vartheta \Rightarrow$ Porcentagem em volume, de material abrasivo na pasta abrasiva.

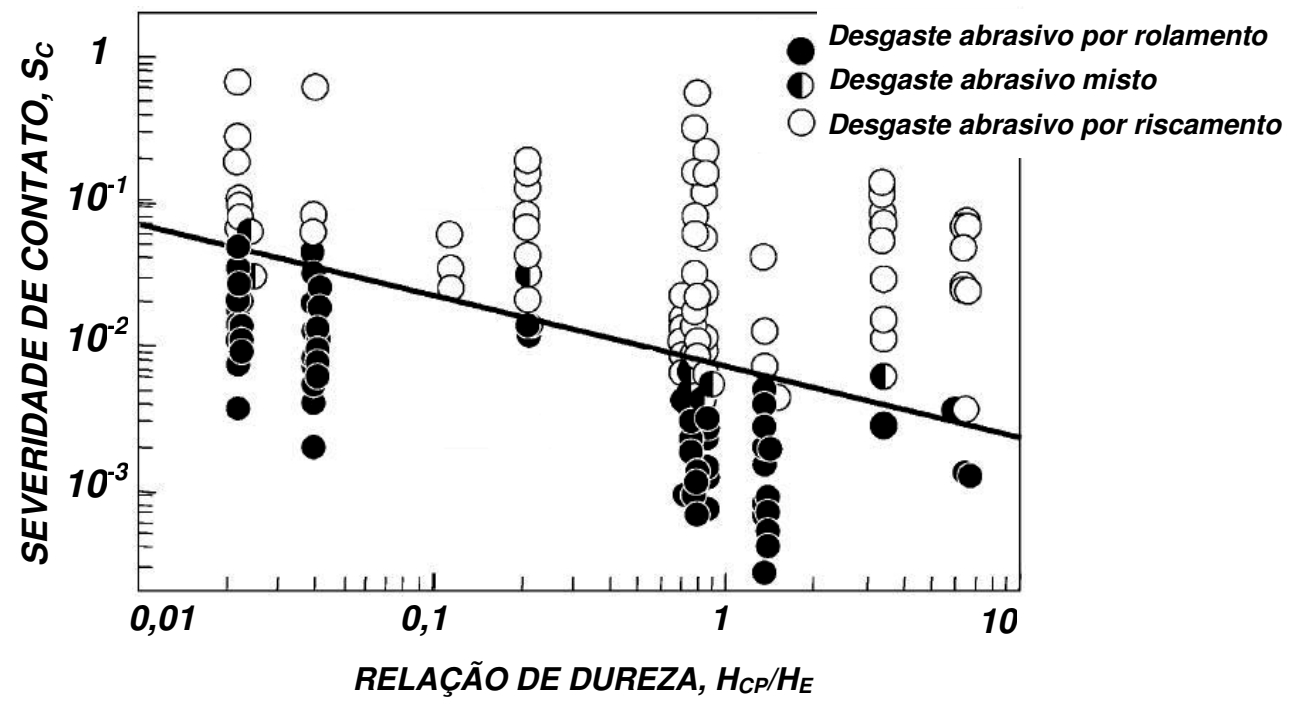

Figura 2.28: Transição dos modos de desgaste em função da severidade de contato $S_{C}$ e da razão $H_{C P} / H_{E}$ (Adachi e Hutchings, 2005). 
Para o levantamento da Figura 2.28, foram realizados ensaios microabrasivos, utilizando-se como esferas, $P P$ (polipropileno), bronze fosforoso e aço AISI 52100, com durezas de 0,062 GPa, 1,95 GPa e 9,9 GPa, respectivamente. Como corpos-de-prova, utilizou-se PMMA (polimetacrilato de metila), liga de alumínio S1C H4 e aço ferramenta (durezas de 0,22 GPa, 0,41 GPa e 7,75 GPa, respectivamente). Como material abrasivo, optou-se pelo SiC, com tamanho médio de partícula de 4,3 $\mu \mathrm{m}$. As concentrações das pastas abrasivas variaram de 0,003 a $20 \%$ SiC (em volume), e as cargas de 0,01 a $1 \mathrm{~N}$. A distância relativa total de deslizamento entre o corpo-de-prova e a esfera foi de $16 \mathrm{~m}$, e a velocidade tangencial periférica da esfera foi fixada em $0,05 \frac{\mathrm{m}}{\mathrm{s}}$.

\subsubsection{Dureza, forma e tamanho das partículas abrasivas}

\section{- Dureza}

A dureza do abrasivo desempenha papel fundamental durante o processo de desgaste. Para uma mesma dureza da superfície $\boldsymbol{H}_{\boldsymbol{S}}$, quanto maior a dureza do abrasivo, $\boldsymbol{H}_{\boldsymbol{A}}$, maior a taxa de desgaste da superfície e quanto menor a dureza do abrasivo, menor a taxa de desgaste. Entretanto, mesmo que $\boldsymbol{H}_{\boldsymbol{S}}>\boldsymbol{H}_{\boldsymbol{A}}$, ocorrerá desgaste.

A razão $\frac{H_{A}}{H_{S}}$ pode ser utilizada para prever os regimes de desgaste abrasivo (Kruschov, 1957 apud Pintaúde, 2002). Se $\frac{H_{A}}{H_{S}}<1$, o regime de desgaste será denominado moderado, ou também chamado de abrasão dútil. Se $\frac{H_{A}}{H_{S}}>1,2,0$ regime de desgaste abrasivo será classificado como severo, ou abrasão dura (Hutchings, 1992). As taxas de desgaste envolvidas no regime severo de desgaste abrasivo são relativamente maiores que as taxas de desgaste apresentadas no regime moderado de desgaste abrasivo.

A variação da taxa de desgaste em função de $\frac{H_{A}}{H_{S}}$ pode ser esquematizada através de um gráfico (Figura 2.29). 


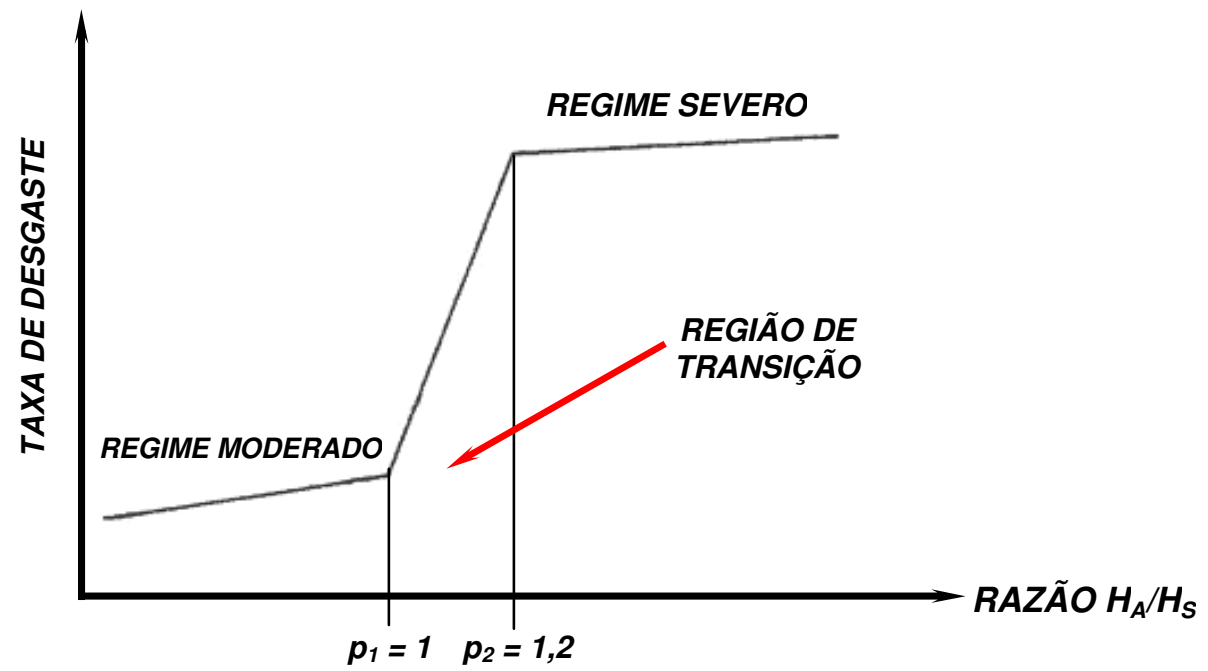

Figura 2.29: Relação esquemática entre a taxa de desgaste e a razão $H_{A} / H_{s}$. Os pontos $p_{1}$ e $p_{2}$ limitam a região de transição entre os regimes de desgaste (Kruschov, 1957 apud Pintaúde, 2002).

Na Figura 2.29, observa-se uma região de transição entre os dois regimes de desgaste abrasivo, limitada pelos pontos $p_{1}$ e $p_{2}$, nos quais a razão $\frac{H_{A}}{H_{S}}$ vale 1 e 1,2, respectivamente (Kruschov, 1957 apud Pintaúde, 2002).

No regime moderado de desgaste abrasivo $\left(\frac{H_{A}}{H_{S}}<1\right)$, a dureza do material que sofre desgaste é sempre maior que a dureza do abrasivo. Logo, mantendo-se $\boldsymbol{H}_{\boldsymbol{A}}$ constante, há pouca variação da taxa de desgaste com o aumento de $\boldsymbol{H}_{\boldsymbol{S}}$ (aumentando-se $\boldsymbol{H}_{\boldsymbol{S}}$, a razão $\frac{H_{A}}{H_{S}}$ diminui). Isso demonstra que, nessa região, a variação de $\boldsymbol{H}_{\boldsymbol{s}}$ apresenta pouca influência no processo de desgaste.

Na região de desgaste abrasivo severo $\left(\frac{H_{A}}{H_{S}}>1,2\right)$, é observado um efeito semelhante. Entretanto, aqui, o material abrasivo apresenta uma dureza, no mínimo, $20 \%$ maior que a dureza do material que sofre desgaste. Mantendo-se $\boldsymbol{H}_{\boldsymbol{s}}$ constante, é observada baixa variação da taxa de desgaste com o aumento de $\boldsymbol{H}_{\boldsymbol{A}}$. Nesse caso, o aumento da dureza do abrasivo apresenta pouca importância no processo de desgaste da superfície.

$\mathrm{Na}$ região de transição entre os regimes de desgaste abrasivo moderado e severo (região central do gráfico), é observada a seguinte condição: $1 \leq \frac{H_{A}}{H_{S}} \leq 1,2$. Nesse intervalo, a dureza do abrasivo é no mínimo, igual à dureza do material que 
sofre desgaste e, no máximo, 20\% maior. Sendo assim, mantendo-se $\boldsymbol{H}_{\boldsymbol{S}}$ constante, uma mínima variação de $\boldsymbol{H}_{\boldsymbol{A}}$ pode fazer com que o desgaste abrasivo saia do regime moderado e entre no regime severo e vice-versa. Nesse caso, a variação da taxa de desgaste torna-se extremamente sensível à variação da dureza do abrasivo.

\section{- Forma}

A forma dos abrasivos também é importante no processo de desgaste. Partículas pontiagudas podem ocasionar taxas de desgaste bem maiores do que partículas com pontas arredondadas (Hutchings, 1992).

Através de ensaios de desgaste por micro-abrasão, utilizando corpos-deprova de PMMA, Kelly e Hutchings (2001) analisaram a influência do formato do grão abrasivo no processo de desgaste. A Figura 2.30 mostra alguns formatos de partículas abrasivas utilizadas.
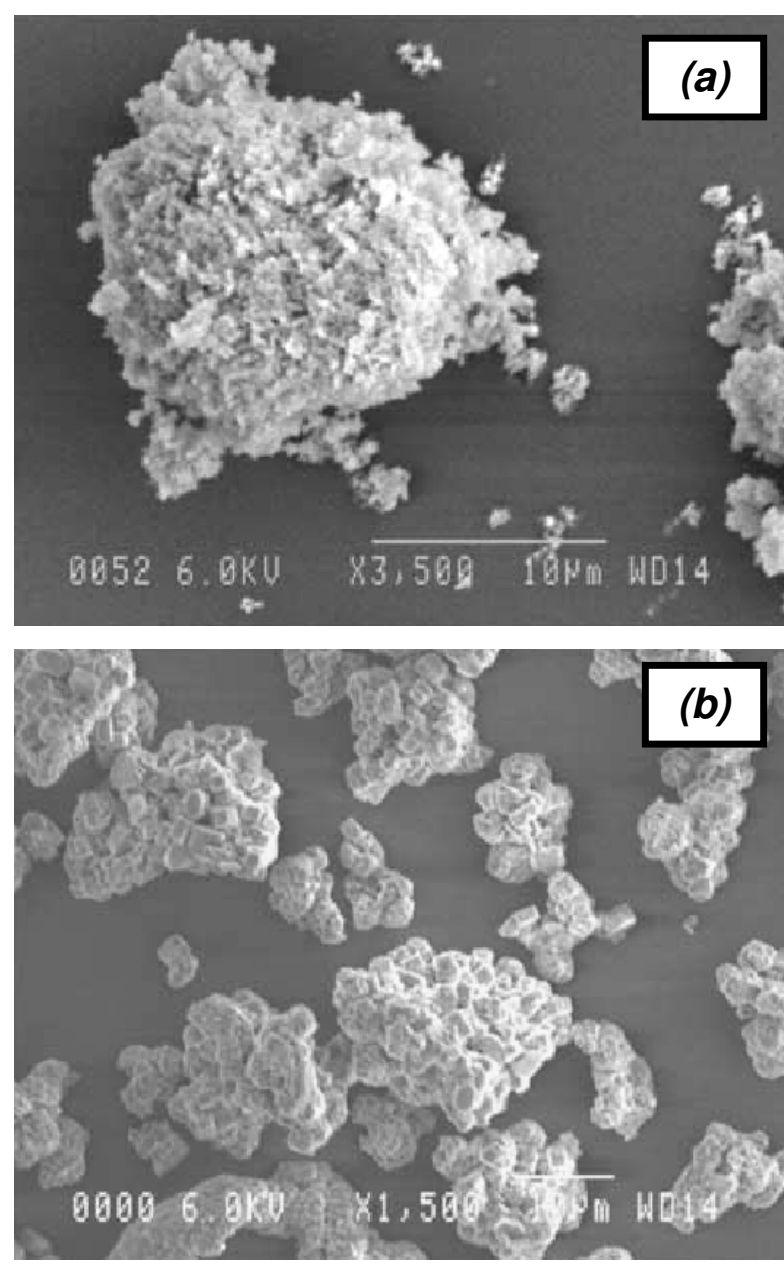

Figura 2.30: Alguns dos formatos de partículas abrasivas utilizadas por Kelly e Hutchings (2001). 
Todos os materiais abrasivos foram sílica. A Figura 2.30a corresponde à partículas com tamanho médio de $8,7 \mu \mathrm{m}$. Os grãos possuem pequenas pontas que envolvem toda sua superfície. O material abrasivo da Figura 2.30b possui tamanho médio de 14,62 $\mu \mathrm{m}$ e as partículas possuem faces relativamente planas, ao invés de possuírem um caráter pontiagudo, como o material da Figura 2.30a.

A Figura 2.31 mostra o volume de desgaste em função do produto da distância de deslizamento pela força normal, para os materiais das Figuras 2.30a e 2.30b. Foi utilizada uma concentração de pasta abrasiva de 0,4 $\mathrm{g}$ de abrasivo por $\mathrm{cm}^{3}$ de água destilada, em conjunto com uma força normal de 0,25 N. Devido à geometria de cada um dos abrasivos, as partículas (a) geraram maior desgaste que as partículas $(\boldsymbol{b})$.

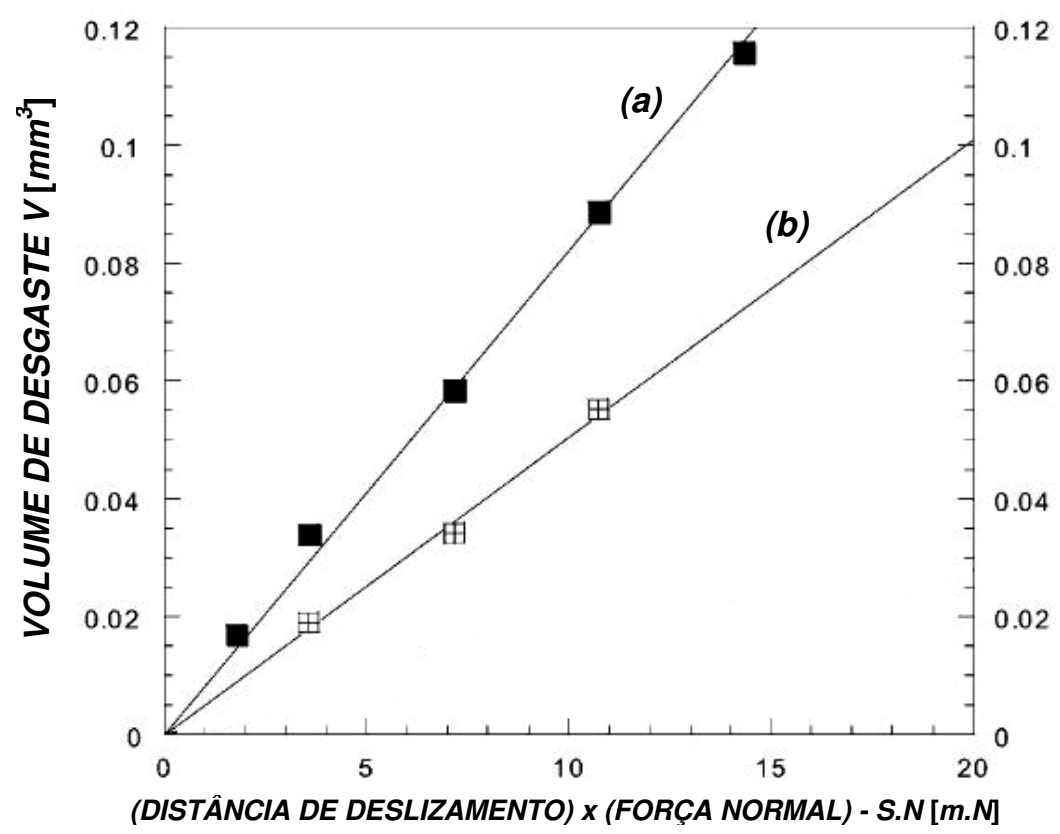

Figura 2.31: Volume de desgaste em função do produto da distância de deslizamento pela força normal, para os materiais (a) e (b) da Figura 2.30 (Kelly e Hutchings, 2001).

\section{- Tamanho}

$\mathrm{Na}$ análise do efeito do tamanho das partículas abrasivas sobre a taxa de desgaste, tanto para o desgaste abrasivo por riscamento, quanto para o desgaste abrasivo por rolamento, têm-se basicamente, duas regiões (Sasada et al., 1984), conforme a Figura 2.32.

Sasada et al. (1984) utilizaram corpos-de-prova de alumínio, cobre, níquel e zinco e partículas de SiC, com tamanho entre 3 e $150 \mu \mathrm{m}$. Para todos os ensaios, a 
força normal sobre as superfícies foi de $15,7 \mathrm{~N}$ e a velocidade relativa de deslizamento foi mantida em 52,8 $\frac{\mathrm{mm}}{\mathrm{s}}$. O gráfico apresentado na Figura 2.2 refere-se ao desgaste abrasivo por rolamento (a seco) de superfícies de cobre. Dentro da Região l, a taxa de desgaste é diretamente proporcional ao tamanho médio das partículas abrasivas $\left(\boldsymbol{D}_{P}\right)$, até o mesmo atingir um determinado valor, denominado tamanho crítico $\left(\boldsymbol{D}_{C}\right)$ (Gahlin e Jacobson, 1999; Sasada et al., 1984). Na Região II, observa-se uma taxa constante de desgaste, mostrando que a mesma, nessa região, é independente do tamanho dos grãos abrasivos. Para que o desgaste entre nesse regime, é necessário que os grãos abrasivos sejam maiores que $\boldsymbol{D}_{\boldsymbol{c}}$. Sasada et al., (1984) mostraram que, tanto para o desgaste abrasivo por riscamento, quanto para o desgaste abrasivo por rolamento, o valor de $\boldsymbol{D}_{\boldsymbol{c}}$ é de, aproximadamente, $50 \mu \mathrm{m}$. Gahlin e Jacobson (1999) mencionam que $\boldsymbol{D}_{C}$ vale aproximadamente $100 \mu \mathrm{m}$, para o desgaste abrasivo por riscamento.

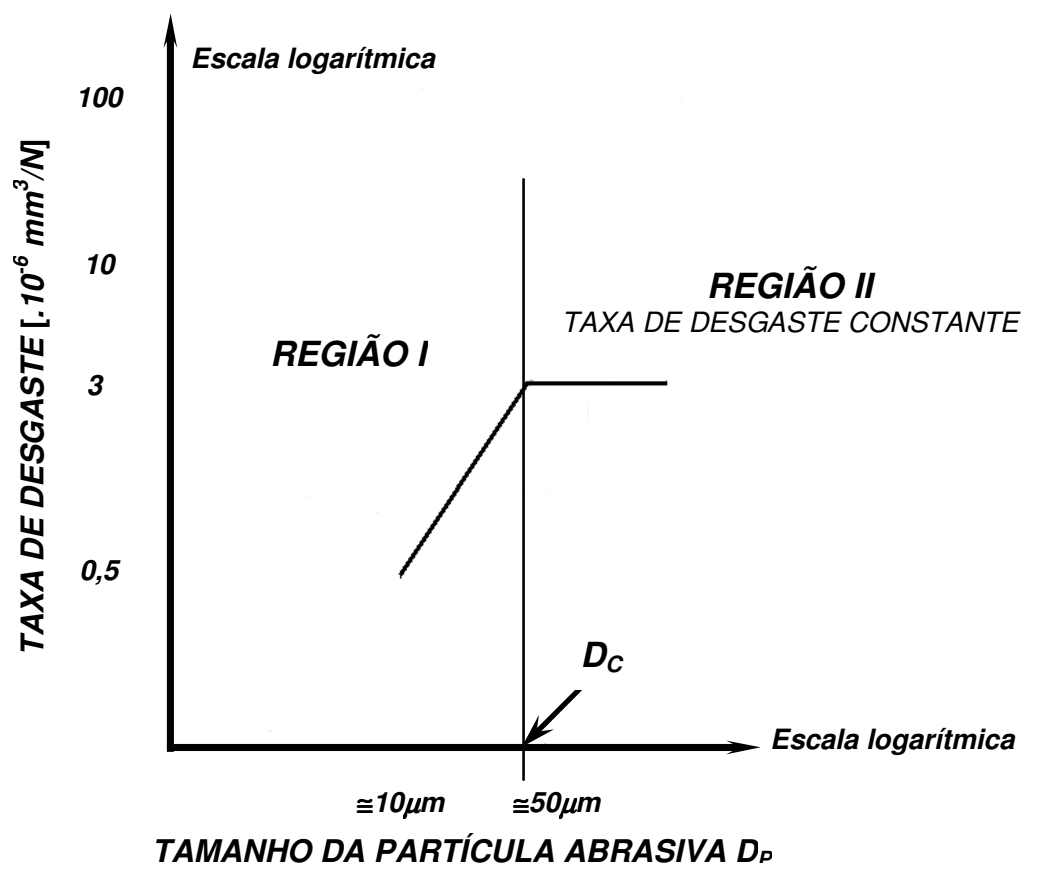

Figura 2.32: Variação da taxa de desgaste em função do tamanho das partículas abrasivas, para superfícies de cobre e grãos abrasivos de SiC (Sasada et al., 1984).

\subsection{REGIME PERMANENTE DE DESGASTE}

Diz-se que o processo de desgaste atingiu o regime permanente quando 0 coeficiente de desgaste permanece constante ao longo do tempo. 
As Figuras 2.33 e 2.34 mostram situações onde o regime permanente de desgaste foi alcançado.

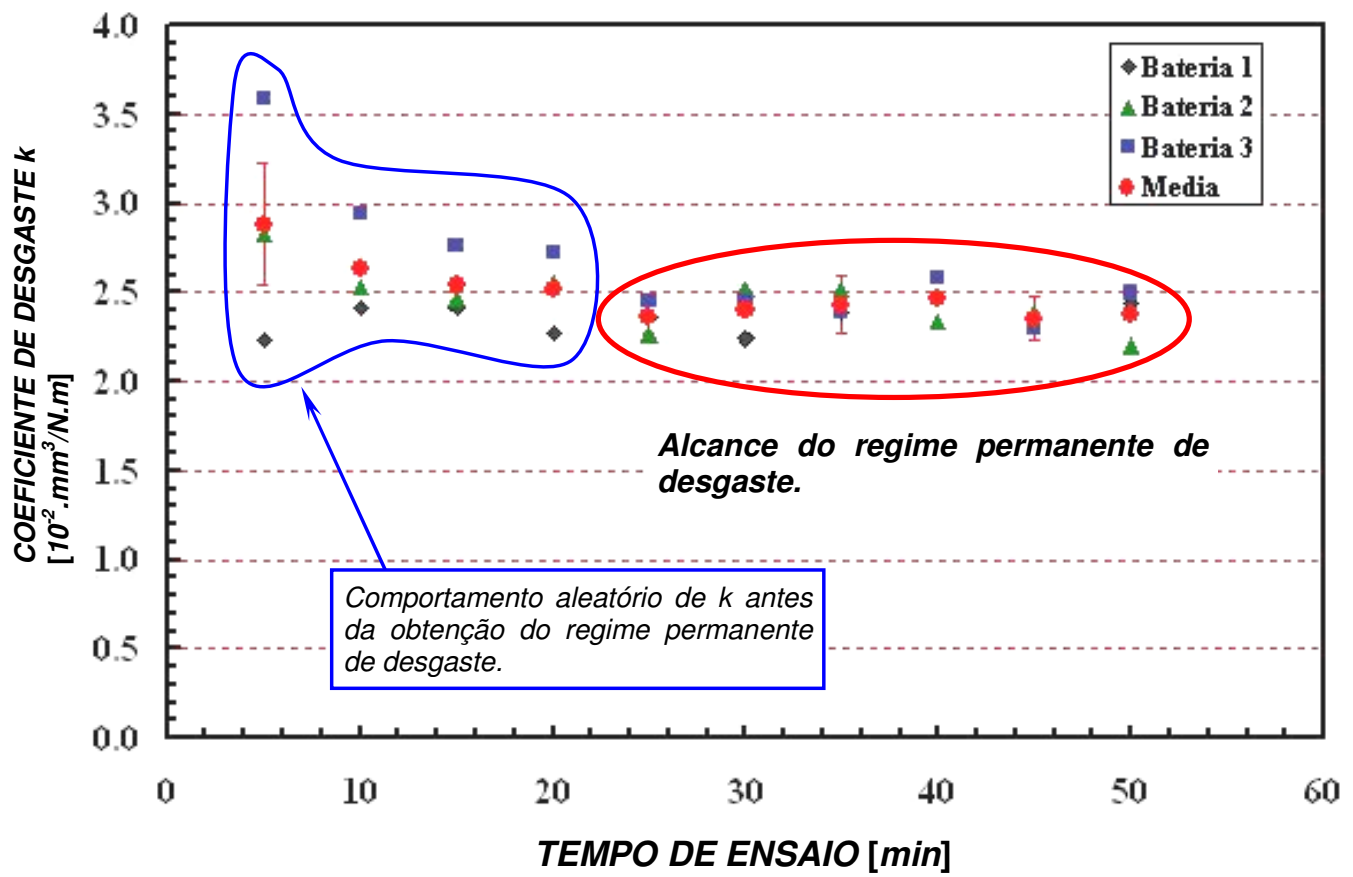

Figura 2.33: Gráfico exibindo o alcance do regime permanente de desgaste, que ocorreu a partir de 25 minutos de ensaio (Figura: Cortesia Prof. Dr. J. D. B. Mello - UFU - Faculdade de Engenharia Mecânica - LTM - Laboratório de Tribologia e Materiais).

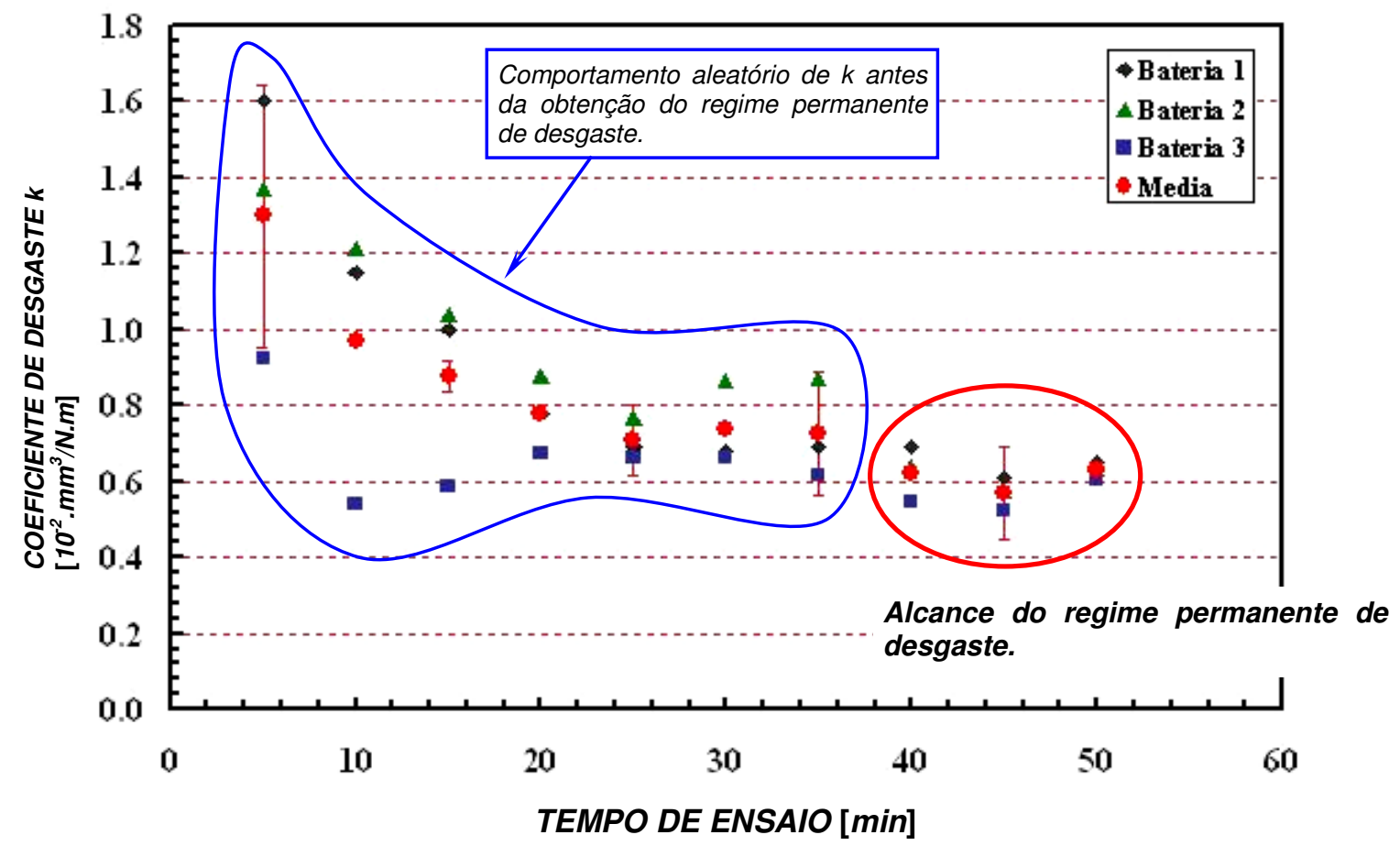

Figura 2.34: Gráfico exibindo o alcance do regime permanente de desgaste, que ocorreu a partir de 40 minutos de ensaio (Figura: Cortesia Prof. Dr. J. D. B. Mello - UFU - Faculdade de Engenharia Mecânica - LTM - Laboratório de Tribologia e Materiais). 
Nos resultados apresentados nas Figuras 2.33 e 2.34, foi utilizada uma esfera com $30 \mathrm{~mm}$ de diâmetro, a uma rotação de $150 \mathrm{rpm}$. Como material abrasivo, foi utilizado silíca $\left(\mathrm{SiO}_{2}\right)$, com tamanho médio de partícula de 1,83 $\mu \mathrm{m}$, forma esferoidal e dureza entre 7,4 e 12,4 GPa (750 e $1260 \mathrm{HV}$, respectivamente). A concentração da pasta abrasiva foi definida em $10 \%$ de água destilada e $90 \%$ de $\mathrm{SiO}_{2}$, em peso. A força normal foi de 0,45 $N$. Os tempos de ensaio adotados foram de 5, 10, 15, 20, 25, 30, 35, 40, 45 e 50 minutos. Para cada condição de ensaio, foram realizadas três repetições. Para o gráfico da Figura 2.33, o corpo-de-prova foi de aço rápido. Nesse caso, o regime permanente de desgaste foi obtido a partir de 353 metros de distância de deslizamento (25 minutos de ensaio). Para a Figura 2.34, o material do corpo-de-prova foi igualmente de aço rápido, mas com alteração na porcentagem de vanádio. Aqui, o regime permanente de desgaste foi atingido a partir de 565 metros de distância de deslizamento (40 minutos de ensaio).

Não existe uma distância de deslizamento ou um tempo de ensaio padrão, para o qual o processo de desgaste atinja o regime permanente. Isso depende, principalmente, dos materiais do corpo-de-prova e da esfera de ensaio. Além disso, a força normal, dureza, forma e tamanho médio das partículas abrasivas, concentração da pasta abrasiva e sua vazão no contato corpo-de-prova/esfera, podem influir na obtenção do regime permanente de desgaste. Ao longo da Revisão Bibliográfica desta Dissertação, não foi encontrado qualquer trabalho que abordasse especificamente esse assunto.

Até que o regime permanente de desgaste não tenha sido atingido, o gráfico do coeficiente de desgaste em função do tempo de ensaio $(k=f(t))$, ou o gráfico do coeficiente de desgaste em função da distância de deslizamento $(k=f(S))$, pode apresentar qualquer comportamento, como pode ser observado nas Figuras 2.33 e 2.34. Assim como no parágrafo anterior, não foi localizado qualquer artigo que versasse sobre esse tema.

Além dos gráficos de $k=f(t)$ e $k=f(S)$, a análise do regime permanente de desgaste pode ser feita pelos gráficos da taxa de desgaste em função do tempo de ensaio $(Q=f(t))$, e da taxa de desgaste em função da distância de deslizamento $(Q=f(S))$. Os gráficos de $Q=f(t)$ e $Q=f(S)$ apresentam o mesmo comportamento dos gráficos de $k=f(t)$ e $k=f(S)$, respectivamente. Isso porque, pela equação de Archard para o desgaste abrasivo, $Q=k . F_{N}$ (Equação 2.2) e, mantendo-se a força normal constante, a taxa de desgaste fica em função (somente) do coeficiente de 
desgaste. Logo, em todos os pontos, antes e após a obtenção do regime permanente de desgaste, a taxa de desgaste apresentará o mesmo comportamento do coeficiente de desgaste, seja em função do tempo de ensaio ou da distância de deslizamento.

Outra maneira de verificar se o regime permanente de desgaste foi alcançado é através das análises dos gráficos do volume de desgaste em função do tempo de ensaio $(V=f(t))$, ou do volume de desgaste em função da distância de deslizamento $(V=f(S))$. Caso o volume de desgaste apresente variação linear com o tempo de ensaio ou com a distância de deslizamento, pode-se dizer que o regime permanente de desgaste foi alcançado (Trezona et al., 1999). A Figura 2.35 apresenta um gráfico de $V=f(S)$, onde o volume de desgaste apresenta variação linear com a distância de deslizamento. Nesse caso, o regime permanente de desgaste foi obtido.

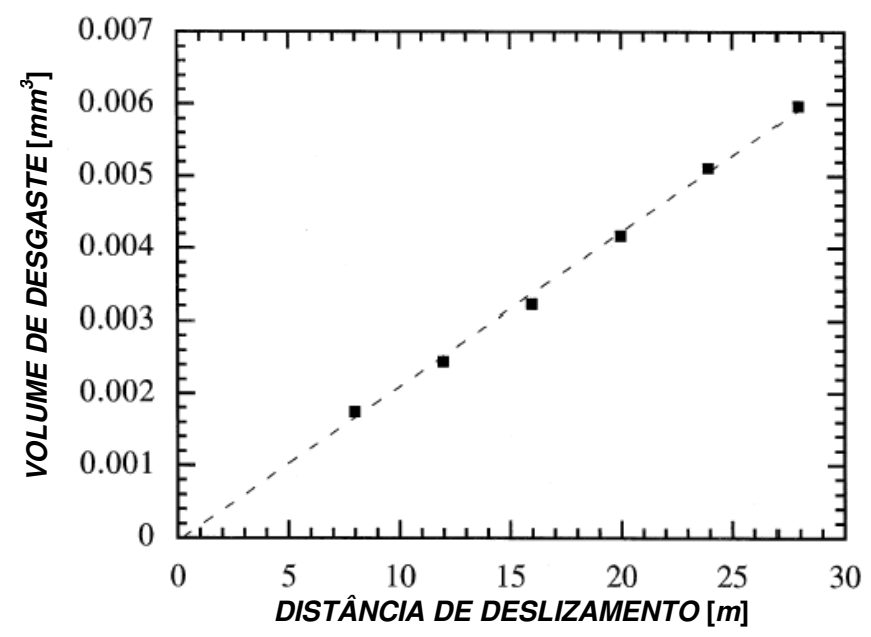

Figura 2.35: Variação linear do volume de desgaste com a distância de deslizamento (Trezona et al., 1999).

Para o estudo do regime permanente de desgaste, é possível conduzir os ensaios por dois procedimentos distintos (para a explicação abaixo, os mesmos foram denominados de Procedimento A e Procedimento B) (Baptista et al., 2000).

No Procedimento $A$, há paradas intermediárias após um determinado tempo de ensaio. Por exemplo, a cada 5 minutos, o ensaio é interrompido para a análise da calota esférica gerada. Em seguida, o ensaio é reiniciado na mesma posição. Com isso, ao final de todos os ensaios, tem-se somente uma cratera de desgaste. No Procedimento $B$, não há paradas intermediárias. Para cada tempo de ensaio, é obtida uma cratera de desgaste diferente. 
Ambos os procedimentos apresentam vantagens e desvantagens. No Procedimento $A$, há a sobreposição das calotas esféricas, fazendo com que reste somente a última. Porém, é um ensaio rápido, comparado com o Procedimento $B$, que é mais longo. Entretanto, no final dos ensaios pelo Procedimento $B$, tem-se todas as crateras de desgaste geradas. Além disso, no Procedimento $A$, durante o reinicio do ensaio, o corpo-de-prova pode deslocar-se de sua posição original, fazendo com que não haja um perfeito contato entre a esfera e a cratera de desgaste. 
Não julgue pequena demais sua tarefa.

Nenhuma obra de arte pode descurar dos pormenores.

Se as minúcias forem perfeitas, é que podemos denominar alguma coisa de obra-prima.

Não busque tarefas grandiosas e de evidência.

Procure dar conta integralmente do serviço pequenino que the foi confiado.

Da perfeição com que o executar dependerá sua oportunidade para receber uma incumbência maior. 


\section{CAPÍTULO 3 - OBJETIVOS DO TRABALHO}

Atualmente, observa-se um crescimento significativo no uso de equipamentos de ensaio de desgaste micro-abrasivo por esfera rotativa. O mesmo é aplicado nas mais diversas pesquisas envolvendo o estudo do desgaste micro-abrasivo de materiais metálicos (Trezona et al., 1999) e não-metálicos (Mergler e Huis in 't Veld, 2003), sob várias condições de ensaio.

Para a realização desta Dissertação, foi projetado e construído um equipamento de ensaio de desgaste micro-abrasivo por esfera rotativa fixa. Porém, como a máquina concebida ainda é recente, há muito que discutir e aprender a respeito, tanto em relação ao próprio equipamento, quanto em relação aos resultados que o mesmo pode fornecer. Com isso, inicialmente, foram traçados cinco objetivos:

\section{- OBJETIVO 1}

Verificar a reprodutibilidade do equipamento construído;

\section{- OBJETIVO 2}

Estudar a transição entre os modos de desgaste abrasivo para diferentes pares de materiais (corpo-de-prova/esfera);

\section{- OBJETIVO 3}

Estudar a relação do quociente $A_{R O L} / A_{R I S}{ }^{(1)}$ com a distância de deslizamento;

\section{- OBJETIVO 4}

Estudar a influência do desgaste da esfera na formação das calotas esféricas;

\section{- OBJETIVO 5}

Estudar a obtenção do regime permanente de desgaste para diferentes pares de materiais.

(1) $\boldsymbol{A}_{R O L}$ : Área projetada de atuação do desgaste abrasivo por rolamento na calota esférica; $\boldsymbol{A}_{R I S}$ : Área projetada de atuação do desgaste abrasivo por riscamento na calota esférica. 
Durante ensaios preliminares e discussões, levantaram-se três hipóteses:

\section{- HIPÓTESE 1}

A razão $A_{R O L} / A_{R I S}$ irá aumentar ou diminuir até uma determinada distância de deslizamento e, após isso, tenderá a permanecer constante;

\section{- HIPÓTESE 2}

Até certo nível, quanto maior o desgaste da esfera, melhor será a definição da calota esférica, caracterizada pelo contorno tendendo a uma circunferência. Entretanto, após um determinado número de ensaios realizados, o contorno da cratera de desgaste tenderá a uma elipse;

\section{- HIPÓTESE 3}

Para uma mesma condição de ensaio, diferentes pares de materiais não necessariamente irão atingir o regime permanente de desgaste em distâncias de deslizamento exatamente iguais.

As HIPÓTESES 1, 2 e 3 estão relacionadas com os OBJETIVOS 3, 4 e 5, respectivamente. 
Não desanime!

Aprenda a começar e a recomeçar!

Não se deixe arrastar pela indiferença: se caiu, levante-se e recomece.

Se errou, erga-se e recomece.

Se não consegue dominar-se, firme sua vontade e recomece.

Não desanime jamais!

Talvez chegue ao fim da luta cheio de cicatrizes, mas estas se transformarão em luzes, diante do Pai Todo-Compassivo. 


\section{CAPÍTULO 4 - MÁQUINA DE ENSAIO DE DESGASTE MICRO- ABRASIVO POR ESFERA ROTATIVA FIXA - MODELO LFS 2005}

\subsection{DESCRIÇÃO GERAL DO EQUIPAMENTO}

A Máquina de Ensaio de Desgaste Micro-Abrasivo por Esfera Rotativa Fixa - Modelo LFS 2005 foi inicialmente projetada pelo Eng. Renato Bergantin (2002), em seu projeto de formatura, sob orientação do Prof. Dr. Roberto Martins de Souza e participação dos Professores Deniol Katsuki Tanaka e Amilton Sinatora. Desde a sua concepção, a mesma sofreu modificações, chegando a sua atual configuração. Os desenhos do equipamento, e as empresas contatadas estão no ANEXO IV desta Dissertação.

Essa máquina realiza ensaios de desgaste abrasivo, sendo possível avaliar as propriedades de desgaste de materiais metálicos e não-metálicos, sob várias condições de ensaio.

O equipamento construído é do tipo esfera fixa. A Figura 4.1 apresenta uma visão geral da máquina.

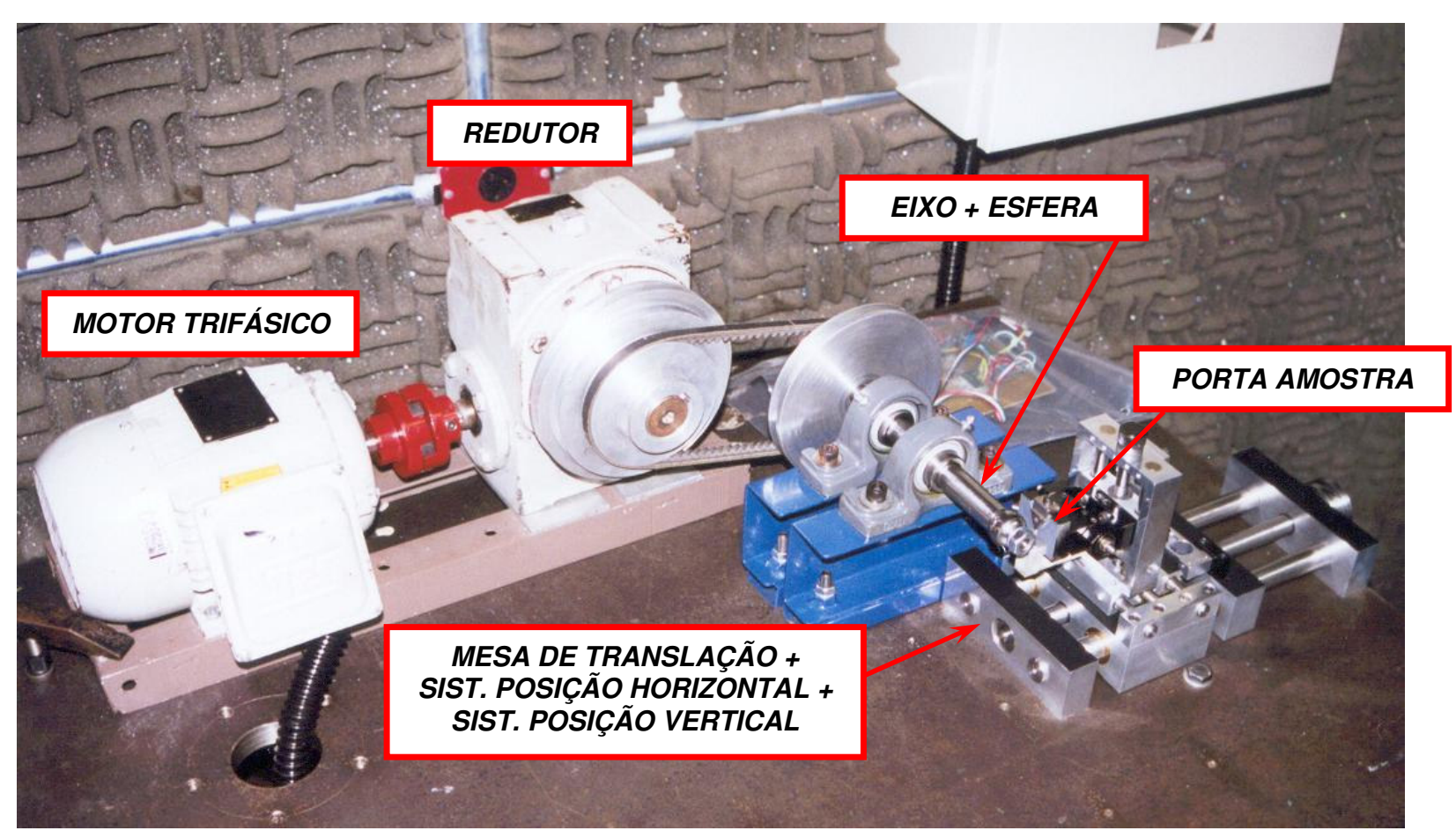

Figura 4.1: Visão geral do equipamento de ensaio de desgaste por micro-abrasão construído. 


\subsection{FUNCIONAMENTO DO EQUIPAMENTO}

A máquina está dividida em dois grupos básicos:

Grupo 1 - Sistema de controle de rotação da esfera de ensaio: Composto pelo motor, redutor, conjunto de polias escalonadas, inversor de freqüência e esfera de ensaio;

Grupo 2 - Sistema de avanço e posição do corpo-de-prova: Composto pela mesa de translação, sistema de posição horizontal, sistema de posição vertical, conjunto de fixação do corpo-de-prova e células de carga.

\subsubsection{Sistema de controle de rotação da esfera de ensaio}

O motor do equipamento é trifásico (220 V) de corrente alternada (Figura 4.2), potência de 552 We rotação síncrona de 1800 rpm.

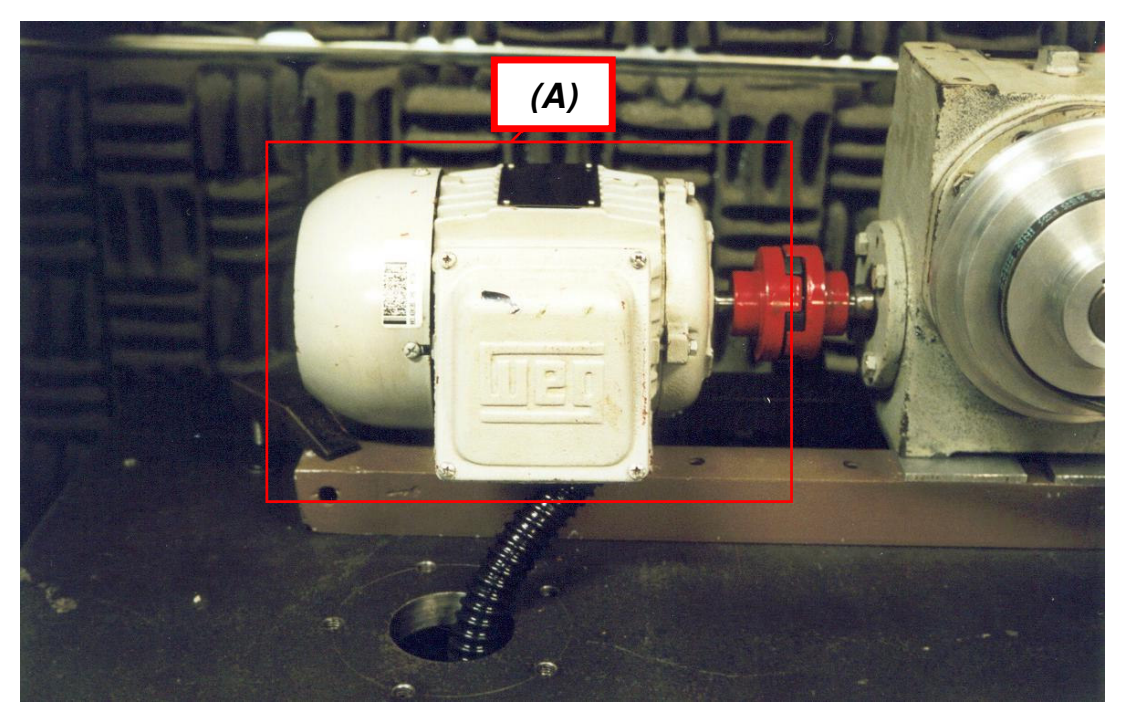

Figura 4.2: (A) Motor de corrente alternada.

No eixo de saída do motor, está acoplado um redutor de eixos reversos (sistema coroa-parafuso sem fim) com relação de transmissão 1:20. Com isso, a rotação de saída do redutor é de $90 \mathrm{rpm}$ (considerando a rotação síncrona do motor). No eixo de saída do redutor (eixo da coroa), está fixada uma polia escalonada (Figura 4.3). 


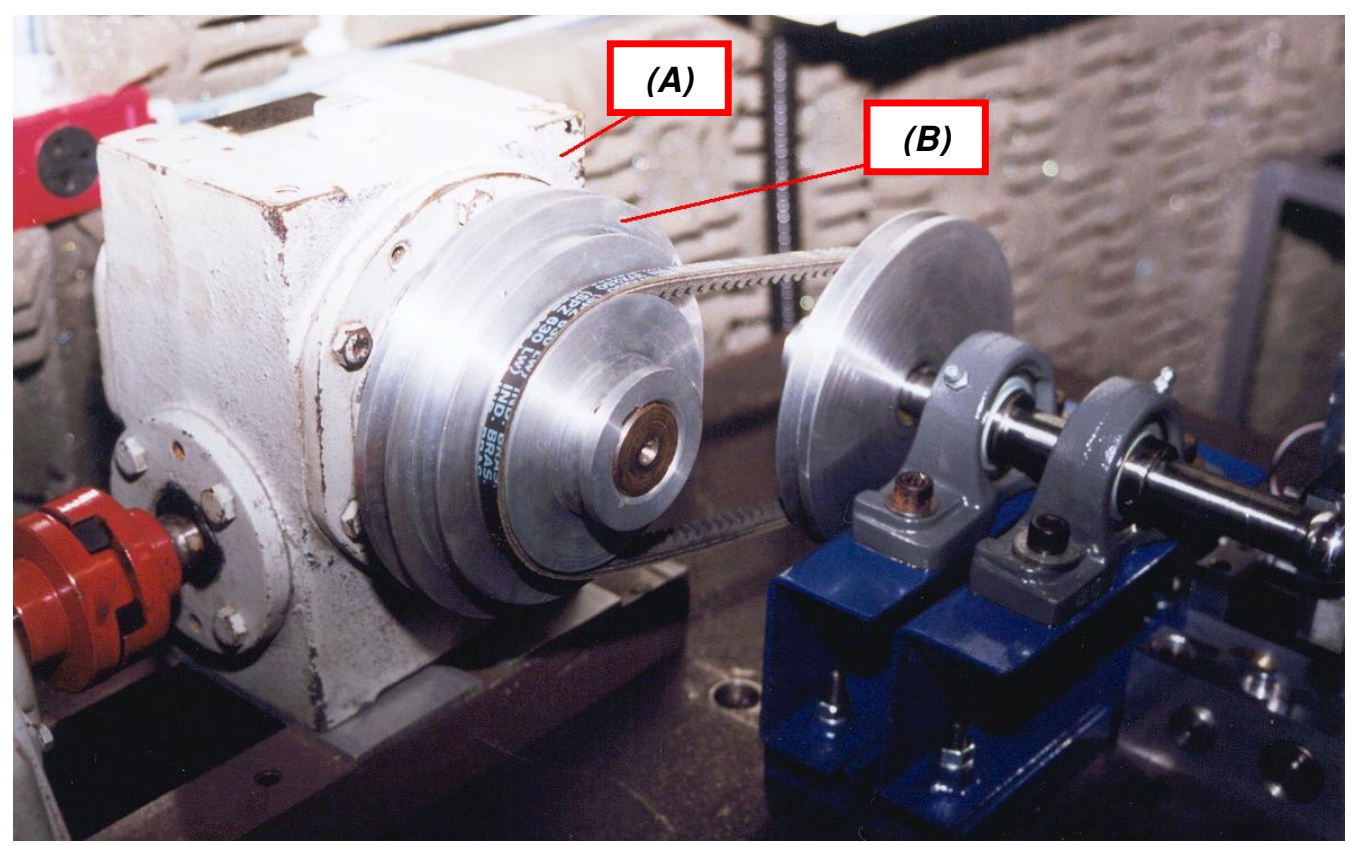

Figura 4.3: (A) Redutor de eixos reversos; (B) polia escalonada fixada no eixo de saída do redutor.

Essa polia trabalha com outra polia escalonada (Figura 4.4), localizada na extremidade do eixo de ensaio (eixo no qual a esfera de ensaio é fixa).

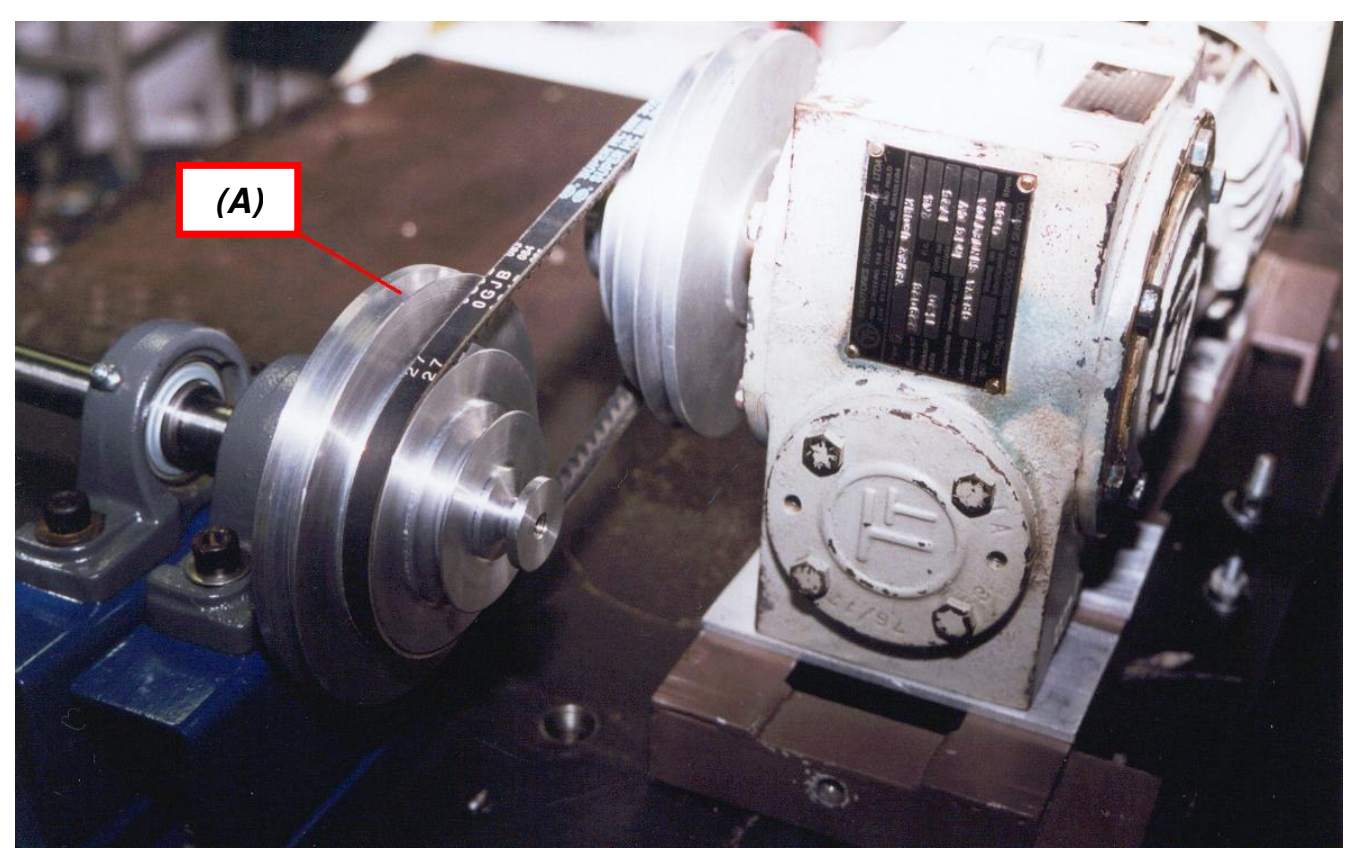

Figura 4.4: (A) Polia escalonada fixada na extremidade do eixo de ensaio.

A correia utilizada nas polias é a SUPER HC MN 3VX250 (SPZ 630 Lw). Através de quatro combinações entre essas polias (Figura 4.5) e, com o auxílio do 
inversor de freqüência (Figura 4.6), é possível obter uma faixa de rotações de 0 a $525 \mathrm{rpm}$.

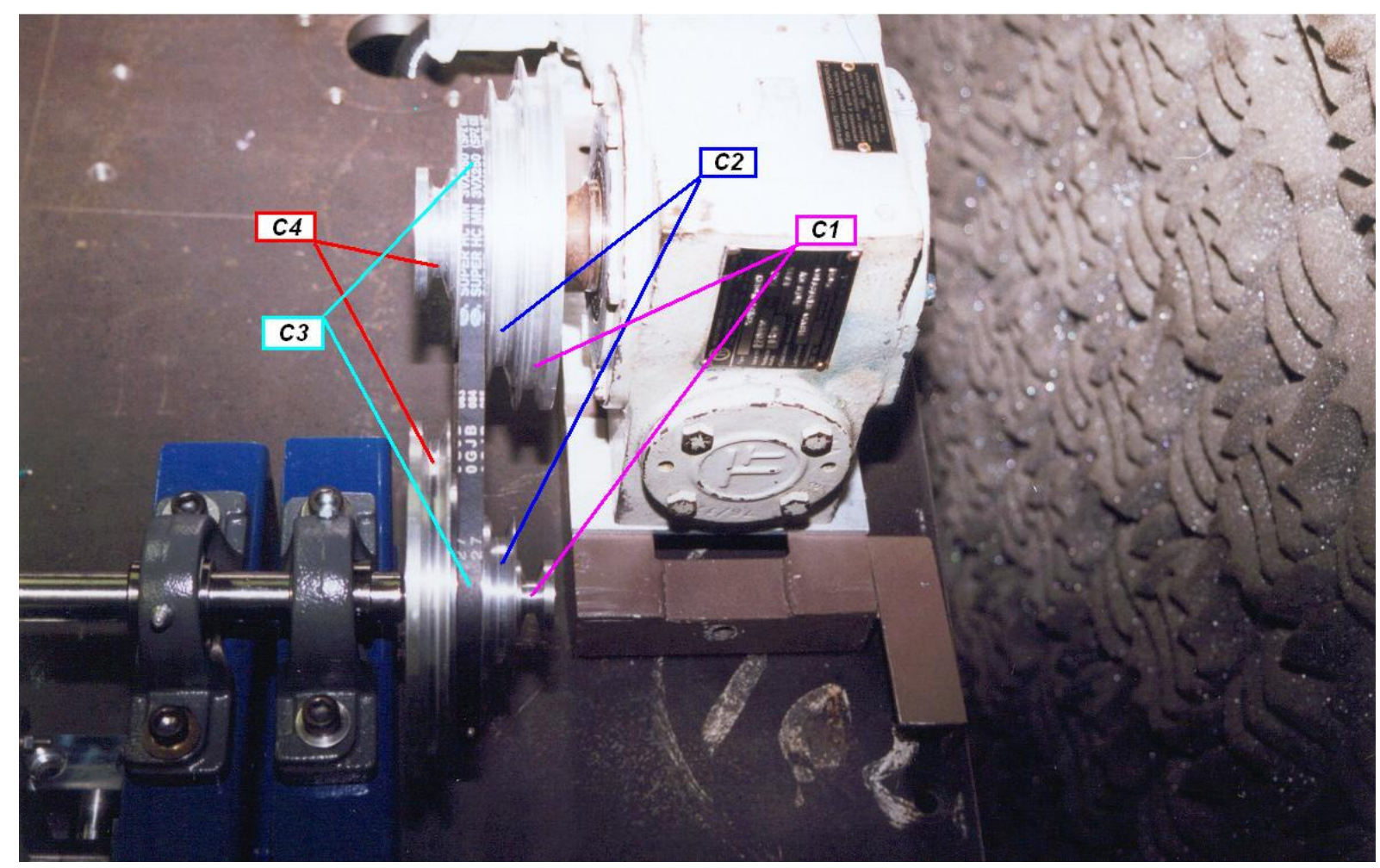

Figura 4.5: Combinações utilizadas, para a variação de rotação da esfera de ensaio.

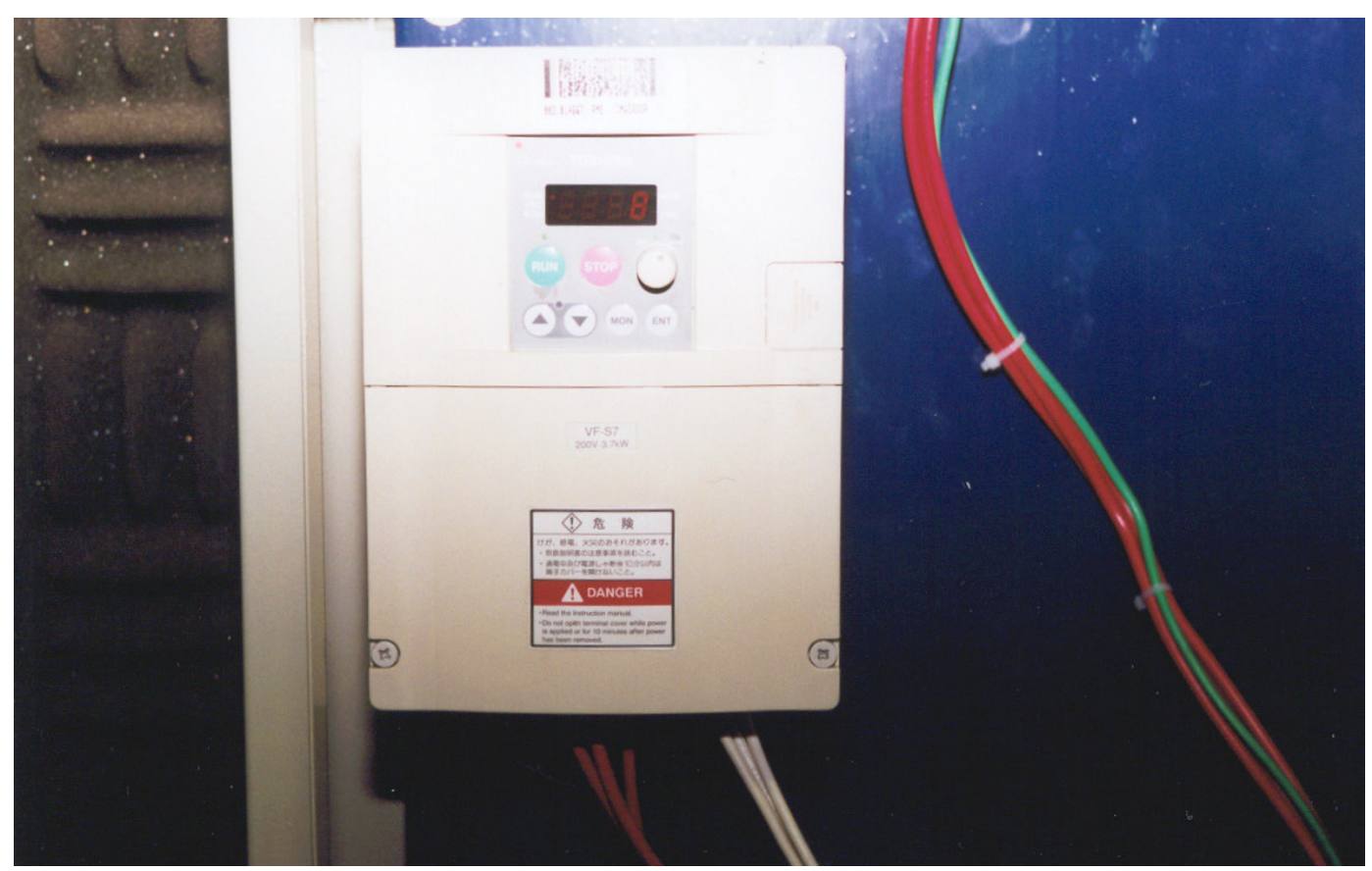

Figura 4.6: Inversor de freqüência, utilizado em conjunto com as polias escalonadas. 
Na primeira combinação (C1), a faixa de rotação varia de 150 a 525 rpm; na combinação $\boldsymbol{C 2}$ a faixa é de 60 a $210 \mathrm{rpm}$; na combinação $\boldsymbol{C 3}$, de 30 a $105 \mathrm{rpm}$ e na $\mathbf{C 4}$, de 12 a $42 \mathrm{rpm}$ (Tabela 4.1). A faixa de trabalho do inversor de freqüência é de 0 a $80 \mathrm{~Hz}$, com precisão de 0,1 Hz. Entretanto, as faixas de rotações foram calculadas, utilizando-se freqüências de 20 a $70 \mathrm{~Hz}$.

Tabela 4.1: Combinações entre as polias e as respectivas faixas de rotações.

\begin{tabular}{|c|c|c|}
\hline COMBINAÇÃO & $\begin{array}{c}\text { FAIXA DE ROTAÇÃO } \\
(\mathbf{r p m})\end{array}$ & $i_{P O L}$ \\
\hline C1 & $150-525$ & 5 \\
\hline C2 & $60-210$ & 2 \\
\hline C3 & $30-105$ & 1 \\
\hline C4 & $0^{(1)}-42$ & 0,4 \\
\hline
\end{tabular}

(1): A rotação $n_{E S F}=0 \mathrm{rpm}$ foi calculada para a freqüência de $0 \mathrm{~Hz}$.

A Figura 4.7 mostra a esfera de ensaio fixada no eixo de ensaio.

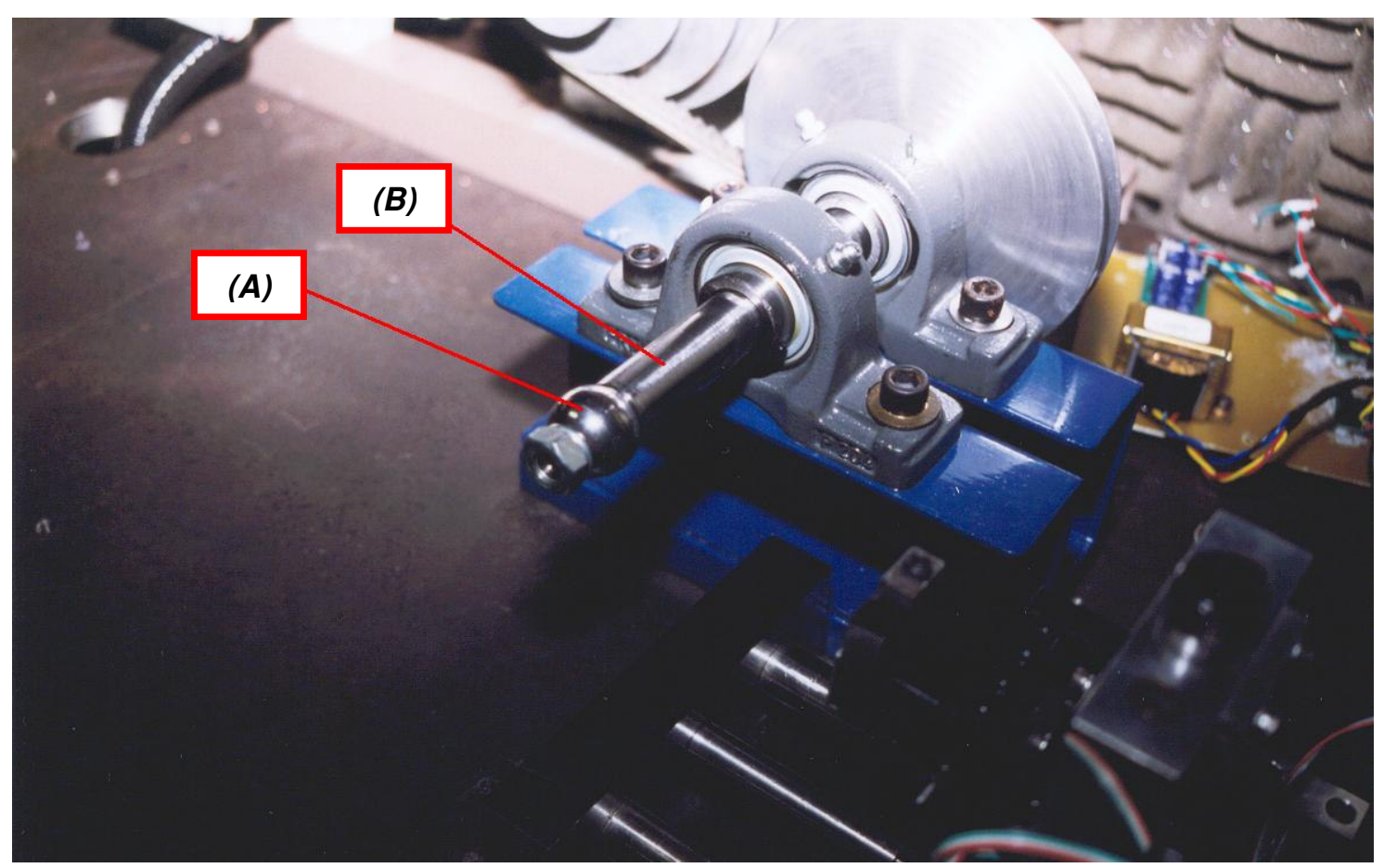

Figura 4.7: Esfera de ensaio (A) fixada no eixo de ensaio (B). 


\section{- Equação para estimativa da rotação da esfera de ensaio}

A Equação 4.1 é utilizada para o cálculo da rotação do rotor (do eixo de saída do motor):

$$
n=\frac{120 f}{p}(1-s)
$$

Sendo:

- $\boldsymbol{n} \Rightarrow$ Rotação do rotor (rpm);

- $f \Rightarrow$ Freqüência da rede $(60 \mathrm{~Hz})$;

- $\boldsymbol{p} \Rightarrow$ Número de pólos do motor;

$-s \Rightarrow$ Escorregamento do rotor (\%).

A rotação síncrona do rotor vale $\boldsymbol{n}_{\boldsymbol{s}}=1800 \mathrm{rpm}$. A plena carga, devido ao escorregamento, a rotação cai para $\boldsymbol{n}_{\boldsymbol{R}}=1750 \mathrm{rpm}$. Como a freqüência da rede vale $f=60 \mathrm{~Hz}$, tem-se um escorregamento de:

$$
\begin{gathered}
s=\frac{n_{S}-n_{R}}{n_{S}} 100 \% \\
s=\frac{1800 \mathrm{rpm}-1750 \mathrm{rpm}}{1800 \mathrm{rpm}} 100 \% \\
s=2,778 \%
\end{gathered}
$$

Esse valor de escorregamento só acontece a plena carga. Como a potência máxima consumida do motor, durante os ensaios, é muito pequena $(\cong 12,5 \mathrm{~W}$, com coeficiente de atrito cinético $\mu_{c}=1$ ), será desconsiderado esse efeito (embora, em freqüências relativamente baixas, tenha-se um aumento do escorregamento).

Conseqüentemente, desprezando $\boldsymbol{s}$, mas inserindo as relações de transmissão do redutor e das polias na Equação 4.1, chega-se à: 


$$
n_{E S F}=\frac{120 f_{i n v}}{p} i_{\text {red }} . i_{p o l}
$$

Sendo:

- $f_{\text {inv }} \Rightarrow$ Freqüência definida no inversor de freqüência $(H z)$;

- $\boldsymbol{p} \Rightarrow$ Número de pólos do motor (4 pólos);

- $\boldsymbol{i}_{\text {red }} \Rightarrow$ Relação de transmissão do redutor $(1 / 20)$;

- $\boldsymbol{i}_{\text {pol }} \Rightarrow$ Relação de transmissão das polias.

Logo, substituindo os valores de $\boldsymbol{p}$ e $\boldsymbol{i}_{\text {red }}$ na Equação 4.2:

$$
n_{E S F}=\frac{120 f_{i n v}}{4} \frac{1}{20} i_{p o l}
$$

$$
n_{E S F}=i_{p o l} 1,50 f_{i n v}
$$

\section{- Ajuste de rotação da esfera de ensaio}

O ajuste de rotação da esfera de ensaio é realizado da seguinte maneira:

- $\quad 1^{\circ}$. Depois de definida a rotação de ensaio, consultar a Tabela 4.1 e verificar qual das quatro combinações entre as polias deve ser utilizada, ou seja, em qual das combinações está incluída a rotação desejada;

- $2^{\circ}$. Utilizando a Equação 4.3, estimar o valor da rotação, em função da relação de transmissão das polias (Tabela 4.1) e do valor da freqüência, estabelecido no inversor de freqüência;

- $3^{\circ}$. Feita essa estimativa, com o auxílio de um tacômetro portátil, ajustar a rotação da esfera de ensaio, através da variação da freqüência. 


\subsubsection{Sistema de avanço e posição do corpo-de-prova}

A Figura 4.8 mostra a mesa de translação, também denominada mesa de transferência. Nesse conjunto, tem-se o berço movimentado (A) e o berço de movimentação (B). Entre esses dois elementos, está uma célula de carga ( $\boldsymbol{C})$, que faz a leitura da força normal definida para o ensaio. A carga normal é aplicada pela rotação de um fuso $(\boldsymbol{D})$.

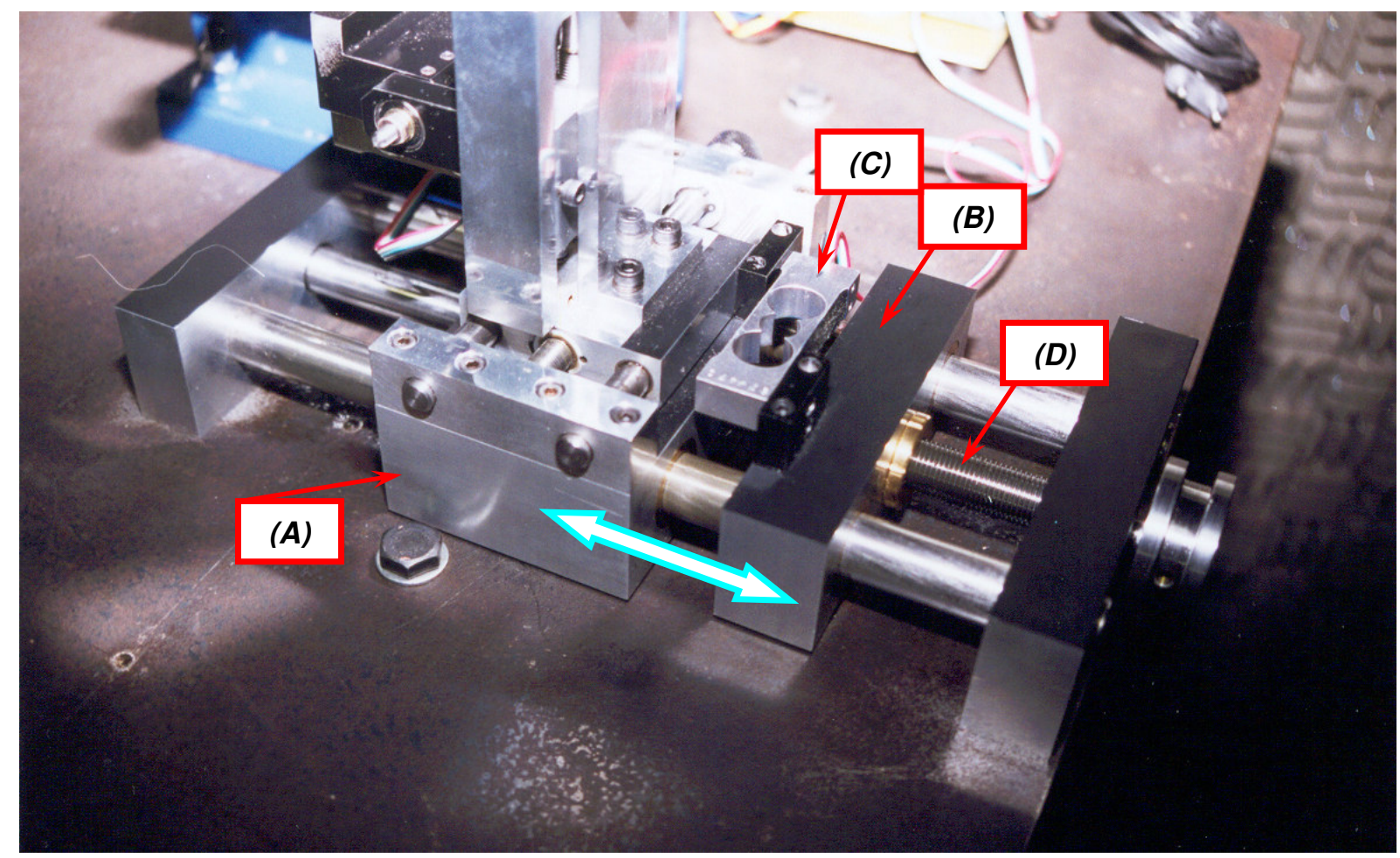

Figura 4.8: Entre o berço movimentado (A) e o berço de movimentação (B) está a célula de carga (C), que mede a força normal aplicada sobre o corpo-de-prova. $A$ carga normal é aplicada através de um fuso (D).

Em um mesmo corpo-de-prova, podem ser realizados vários ensaios. O equipamento possui um sistema de posição horizontal e um sistema de posição vertical (Figura 4.9). O controle de posição, para ambos os sistemas, pode ser realizado com uma precisão de $10 \mu \mathrm{m}$. Esses dois sistemas estão fixados sobre o berço movimentado. 


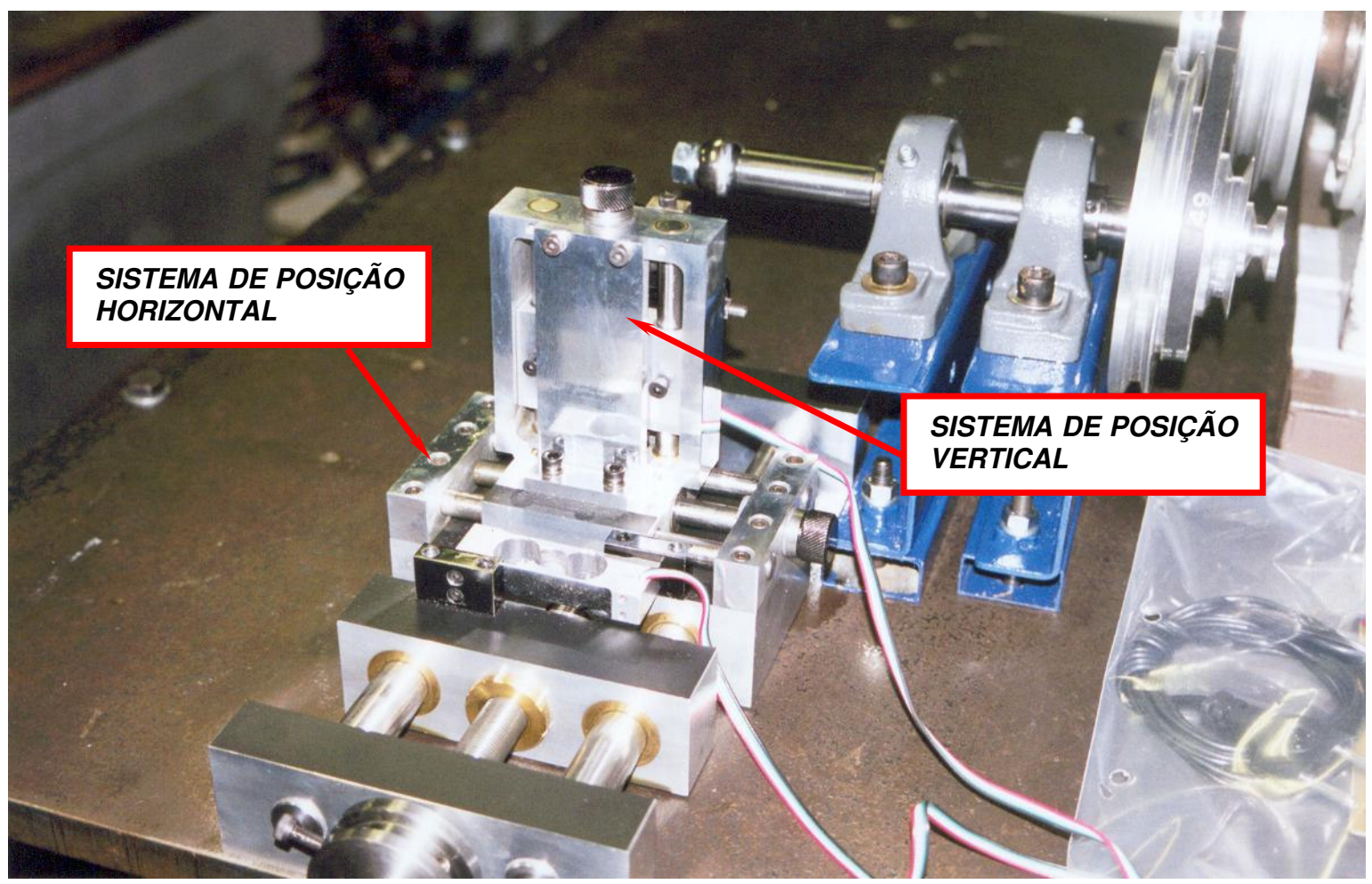

Figura 4.9: Sistema de posição horizontal e sistema de posição vertical.

O conjunto de fixação do corpo-de-prova está montado no sistema de posição vertical (Figura 4.10). No dispositivo mostrado na figura, é possível fixar apenas corpos-de-prova com formato triangular (triângulo eqüilátero de aresta $16 \mathrm{~mm}$ ), ou utilizar pastilhas intercambiáveis de metal duro (geometria TPGN 160308).

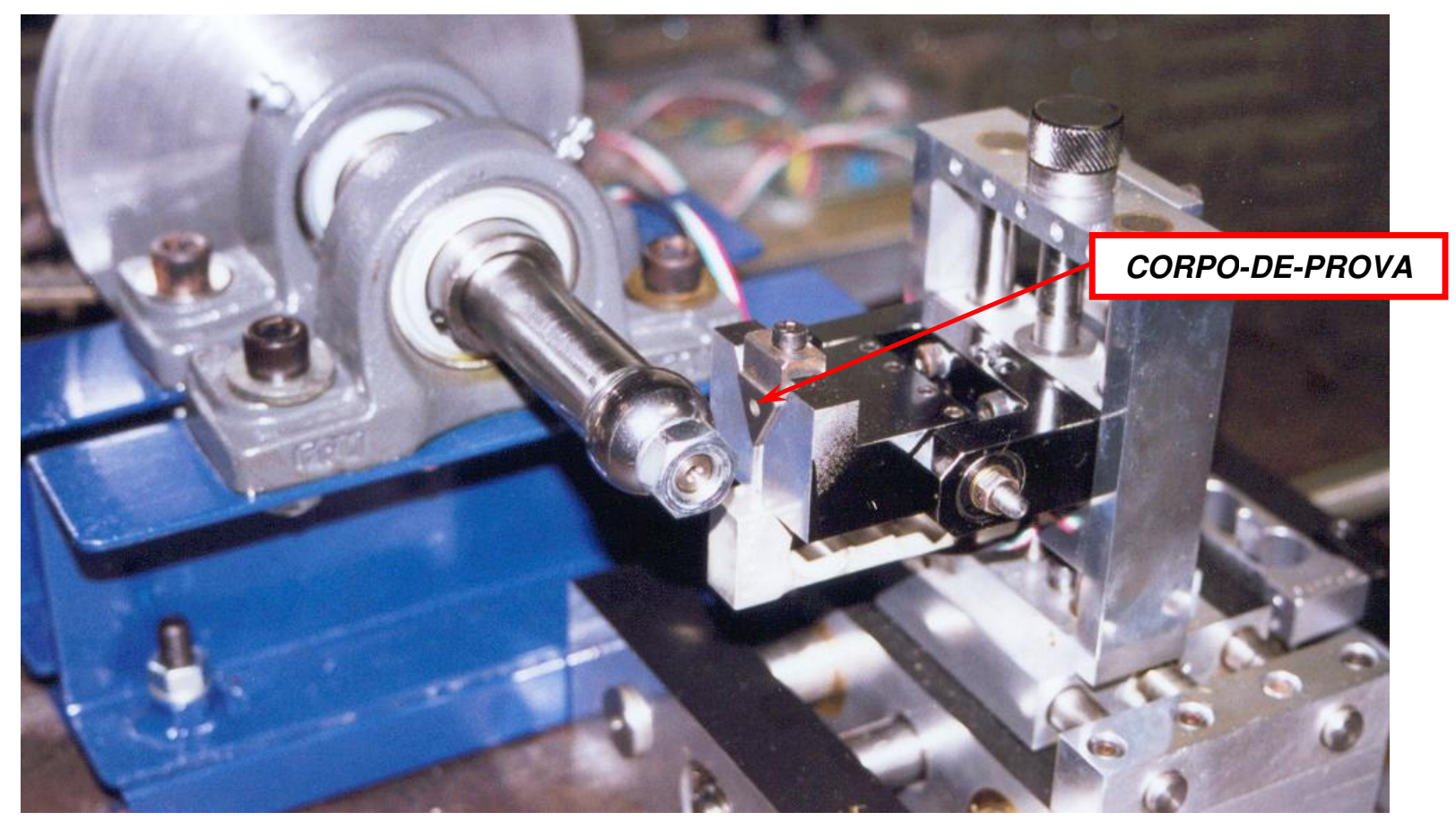

Figura 4.10: Pastilha intercambiável de metal duro fixada no porta-amostra. 
Abaixo do dispositivo de fixação do corpo-de-prova, está a célula de carga que realiza a medição da força tangencial (Figura 4.11).

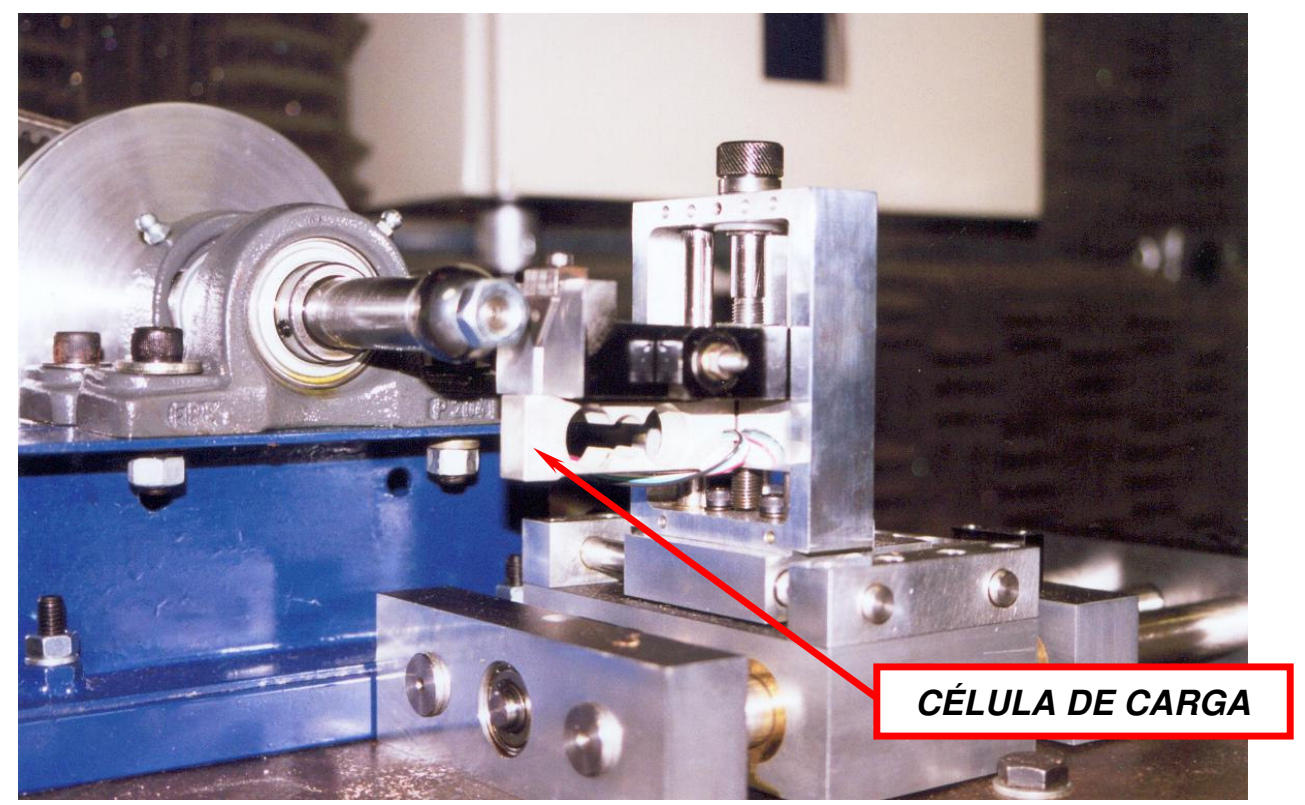

Figura 4.11: Célula de carga para medição da força tangencial desenvolvida durante o ensaio.

Tanto a força normal, quanto à força tangencial, são medidas de modo indireto, pela variação de tensão das células de carga, por um multímetro (Figura 4.12). As células de carga possuem capacidade nominal de $20 \mathrm{~N}$, suportando uma sobrecarga de $50 \%$.

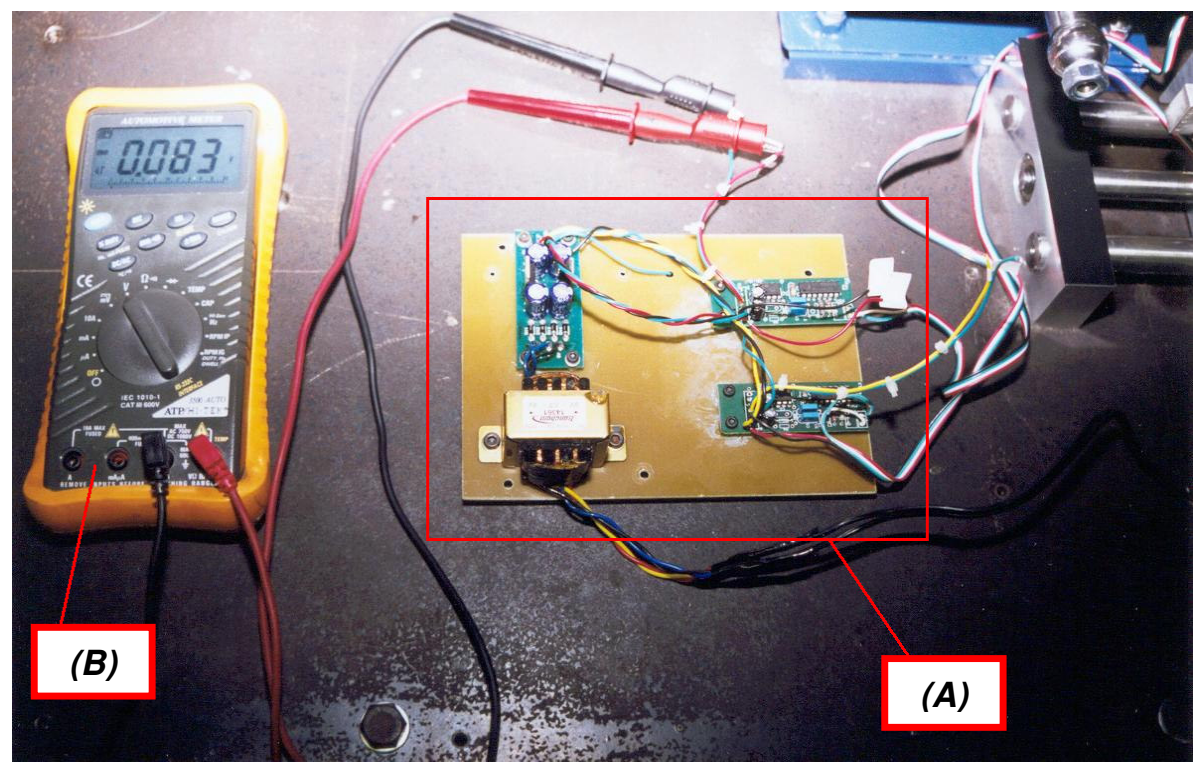

Figura 4.12: Circuito eletrônico (A) montado para trabalhar em conjunto com o multímetro (B). 
Tenha coragem em todas as circunstâncias da vida.

Por piores que the pareçam as dificuldades, tenha a certeza de que pode superá-las com a persistência e a força que provêm de seu íntimo.

Deus está dentro de cada um de nós, pronto a dar-nos energia e vigor, ânimo e incentivo.

Confie na bondade do Pai, que jamais desampara nenhum de seus filhos. 


\section{CAPÍTULO 5 - MATERIAIS E MÉTODOS}

\subsection{MATERIAIS UTILIZADOS}

Os corpos-de-prova foram de aço ferramenta M2 (temperado e revenido) e WC-Co P20. Todos possuíam forma de triângulo eqüilátero, com aresta de $16 \mathrm{~mm}$ e espessura de $3 \mathrm{~mm}$. Os corpos-de-prova de aço ferramenta $M 2$ foram usinados por eletroerosão a fio, pela empresa FEROSÃO J. C. R. Indústria e Comércio Ltda. As pastilhas de WC-Co P2O não possuíam qualquer tipo de revestimento e foram adquiridas junto à empresa ORDEPS Ferramentas, revendedora autorizada da SECO TOOLS S/A (empresa fabricante). As mesmas são encontradas sob a denominação ISO TPGN 160308 (aresta de $16 \mathrm{~mm}$, espessura de $3 \mathrm{~mm}$ e raio de ponta de $0,8 \mathrm{~mm}$ ).

Para a análise da microestrutura do aço ferramenta $M 2$, um dos corpos-deprova foi embutido em baquelita. Após o embutimento, a superfície do corpo-deprova foi lixada, obedecendo a seguinte seqüência de lixas: grão 220, 320, 400 e 600. Em seguida, a superfície foi polida com pastas diamantadas de diferentes granulometrias, na seqüência de 6,3 e 0,25 $\mu \mathrm{m}$. A última etapa foi o ataque químico da superfície com Nital $3 \%$.

A Figura 5.1 apresenta a microestrutura do aço ferramenta M2.

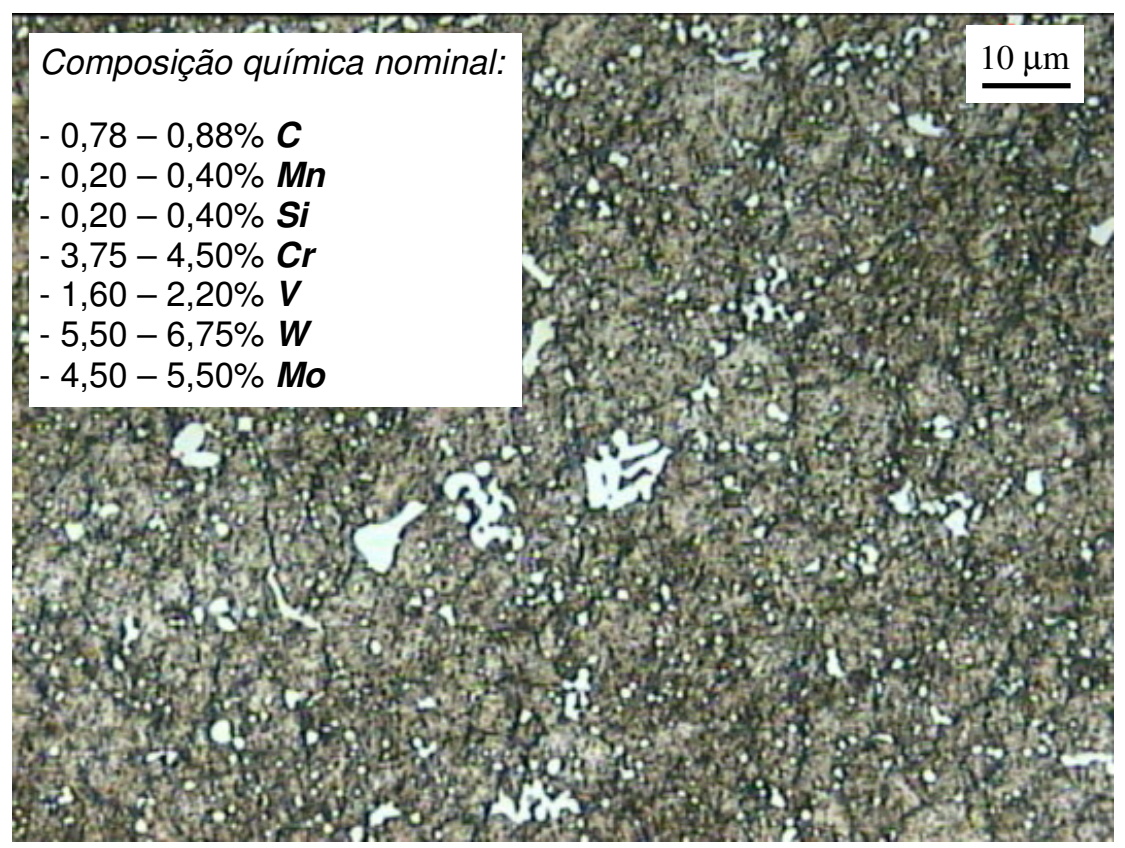

Figura 5.1: Microestrutura do aço ferramenta M2. Imagem obtida por microscopia óptica (Microscópio óptico OLYMPUS BX60M, pertencente ao Laboratório de Fenômenos de Superfície - LFS). 
Assim como no aço ferramenta $M 2$, para a análise da microestrutura do WC-Co P20, um corpo-de-prova foi embutido em baquelita e lixado. Em seguida, o mesmo foi submetido ao processo de polimento. $O$ ataque químico da superfície foi realizado com MURAKAMI, composto por 10 gramas de ferrocianeto de potássio $\left(K_{3} \mathrm{Fe}(\mathrm{CN})_{6}\right), 10$ gramas de hidróxido de potássio $(\mathrm{KOH})$ e $100 \mathrm{~m} /$ de água destilada.

A Figura 5.2 exibe a microestrutura do WC-Co P2O.

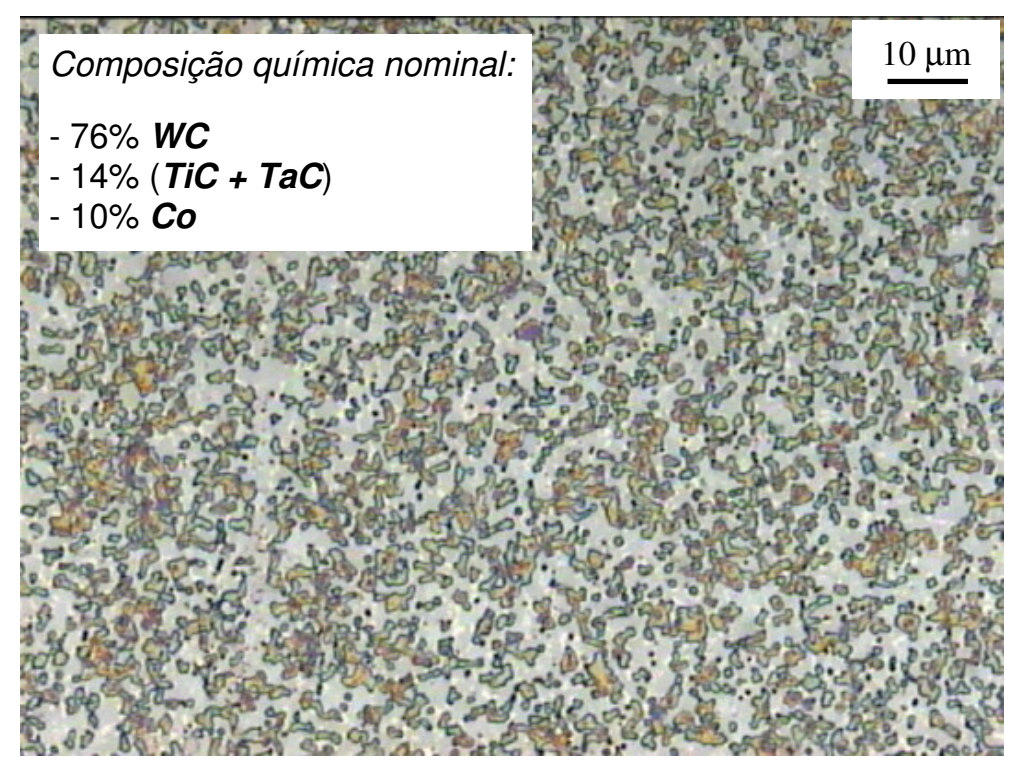

Figura 5.2: Microestrutura do WC-Co P20. Imagem obtida por microscopia óptica (Microscópio óptico OL YMPUS BX60M, pertencente ao LFS).

Foram utilizadas cinco esferas de aço AISI 1010 cementado e duas esferas de aço AISI 52100 temperado e revenido (totalizando assim, sete esferas de ensaio). Todas as esferas possuíam diâmetro de 25,4 $\mathrm{mm}$ (1") e foram adquiridas junto à empresa SÓ ESFERAS - Comércio de Esferas Ltda. Os furos de fixação (Desenho 02 - ANEXO IV) das esferas de aço AISI 1010 cementado foram usinados pela empresa $S A E$ - Componentes Industriais, por processos convencionais de usinagem (furação e posterior passagem de alargador). Nas esferas de aço AISI 52100, os furos de fixação foram usinados por eletroerosão por penetração, pela empresa FRATECH EROSÃO.

Cada esfera recebeu uma denominação, conforme a Tabela 5.1. 
Tabela 5.1: Denominações dadas às esferas de ensaio.

\begin{tabular}{|l|c|c|}
\hline \multicolumn{2}{|c|}{ Material } & Denominação \\
\hline 1 & Aço AISI 1010 cementado & E-1010C-1 \\
\hline 2 & Aço AISI 1010 cementado & E-1010C-2 \\
\hline 3 & Aço AISI 1010 cementado & E-1010C-3 \\
\hline 4 & Aço AISI 1010 cementado & E-1010C-4 \\
\hline 5 & Aço AISI 1010 cementado & E-1010C-5 \\
\hline 6 & Aço AISI 52100 & E-52100-1 \\
\hline 7 & Aço AISI 52100 & E-52100-2 \\
\hline
\end{tabular}

A esfera utilizada para a análise da microestrutura do aço AISI 52100 temperado e revenido não foi embutida em baquelita. A preparação de sua superfície foi realizada da mesma maneira e com os mesmos materiais utilizados para o aço ferramenta $M 2$.

A Figura 5.3 apresenta a microestrutura do aço AISI 52100 temperado e revenido.

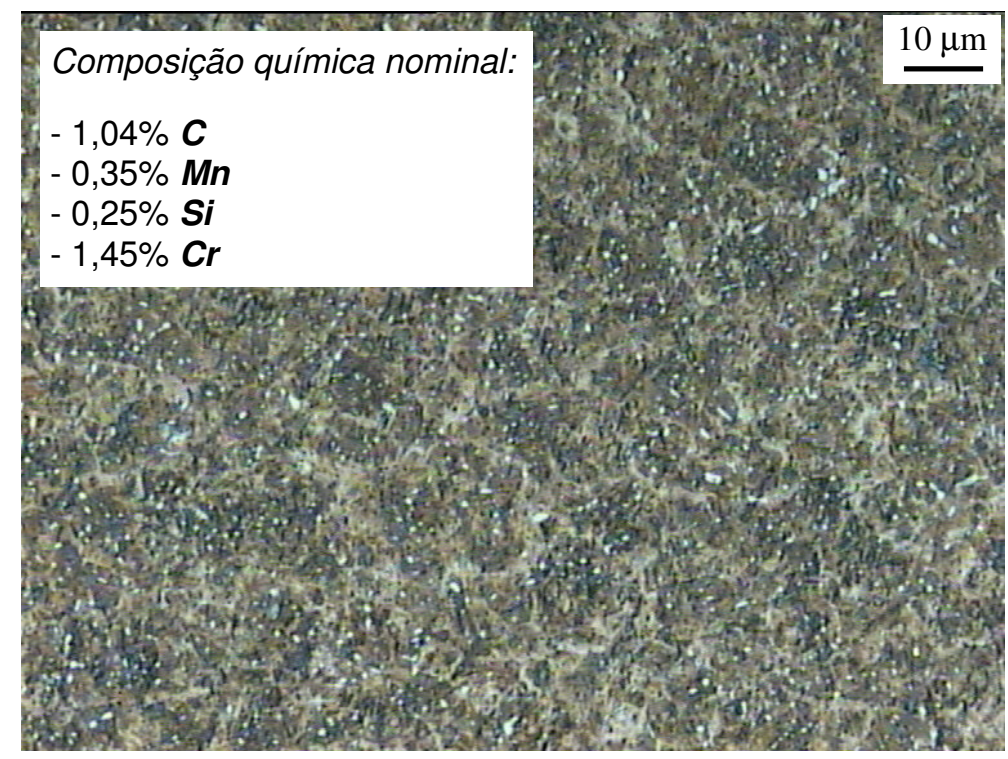

Figura 5.3: Microestrutura do aço AISI 52100 temperado e revenido. Imagem obtida por microscopia óptica (Microscópio óptico OL YMPUS BX60M, pertencente ao LFS).

A pasta abrasiva foi preparada com carbeto de silício preto SiC 1000, comercial de grau técnico, da Alcoa (Izhevskyi et al., 2004) e água destilada. A Figura 5.4 mostra uma micrografia eletrônica de varredura do abrasivo utilizado. 


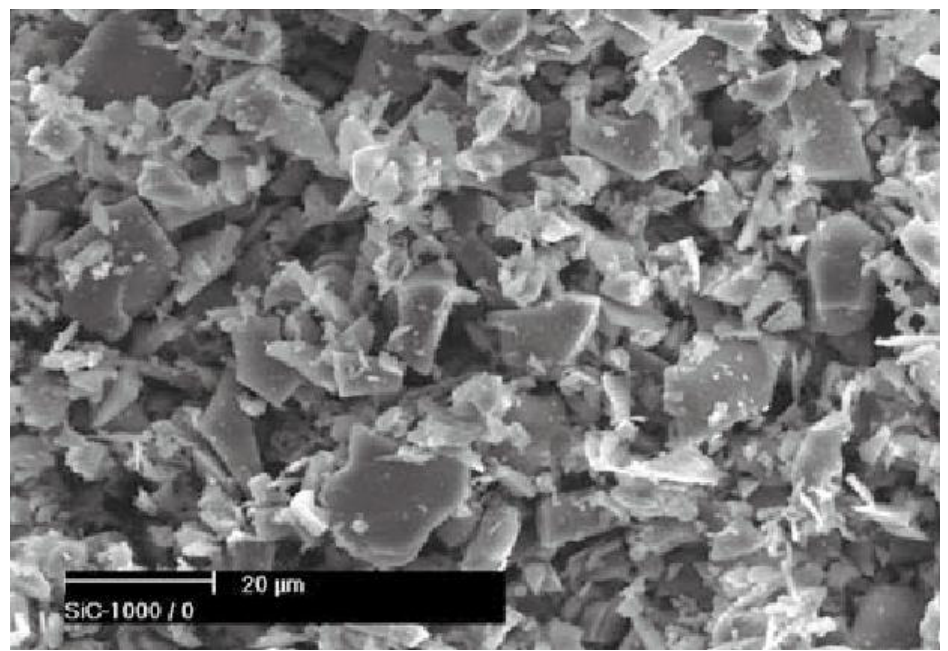

Figura 5.4: Micrografia eletrônica de varredura do pó abrasivo SiC 1000 (Izhevskyi et al., 2004).

A distribuição granulométrica desse material é apresentada na Figura 5.5 (Izhevskyi et al., 2004). Essa distribuição foi obtida a laser, utilizando o equipamento Granulometer 1064 - CILAS, de fabricação francesa (Izhevskyi et al., 2004).

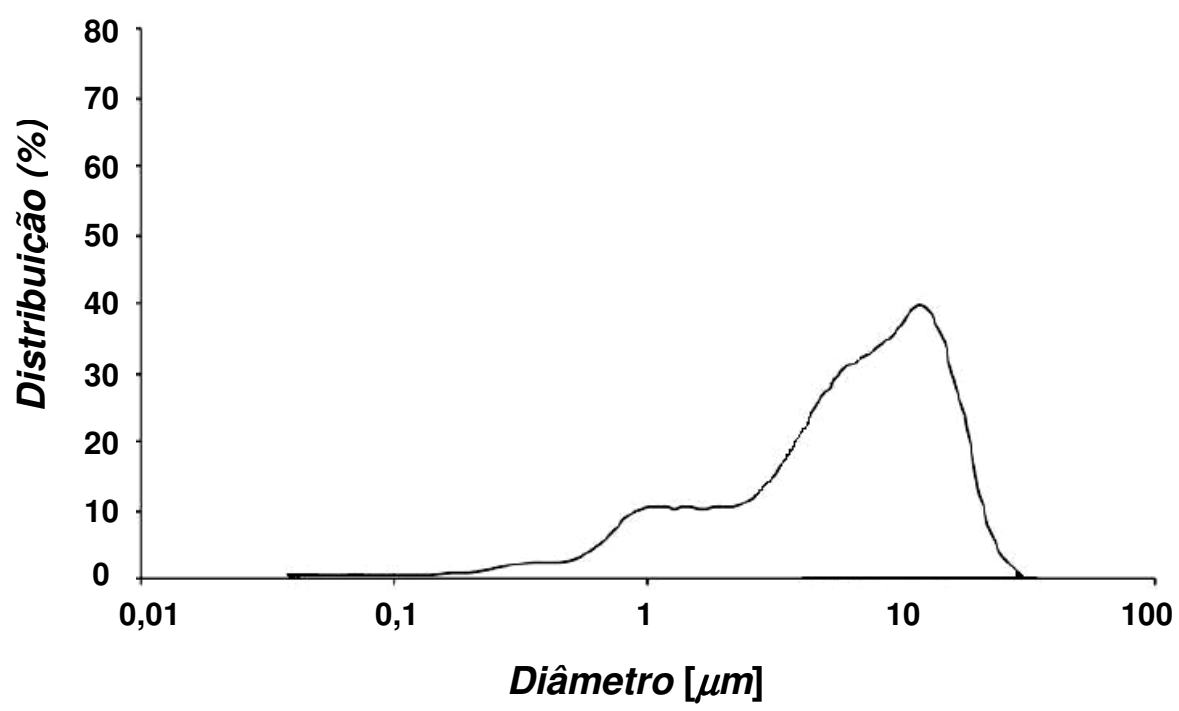

Figura 5.5: Distribuição granulométrica do SiC 1000 (Izhevskyi et al., 2004).

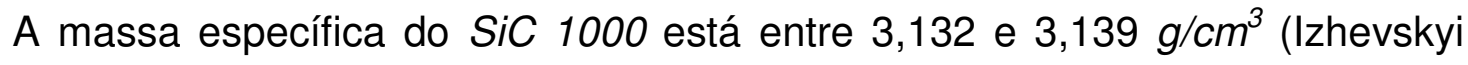
et al., 2004).

Para o cálculo da dureza do SiC 1000, uma porção do material foi sinterizada. Dez indentações Vickers foram conduzidas sob uma carga de $50 \mathrm{~N}$ e tempo de $15 \mathrm{~s}$ (Izhevskyi et al., 2004). Com os mesmos valores de força e tempo (50 N e $15 \mathrm{~s}$, respectivamente) adotados por Izhevskyi et al. (2004), foram medidas as durezas 
Vickers dos corpos-de-prova (HSS M2 e WC-Co P20) e das esferas de ensaio de aço AISI 52100. De forma aleatória, foram realizadas treze indentações na superfície de cada material. Após os ensaios, descartou-se o valor de dureza obtido na primeira indentação. Em seguida, a dureza do material foi determinada pela média aritmética dos dez valores mais próximos entre si. A dureza das esferas de aço AISI 1010 cementado foi obtida junto à empresa SÓ ESFERAS - Comércio de Esferas Ltda. Foi fornecida uma faixa de valores, correspondente à dureza na superfície da esfera.

A Tabela 5.2 reúne os valores das durezas dos materiais utilizados (corpos-de-prova, esferas de ensaio e material abrasivo). Originalmente, as unidades de todos os valores de dureza estavam em HV. Posteriormente, os valores foram convertidos para GPa. Todos os ensaios de dureza foram realizados no Durômetro Vickers VMT-7, fabricado pela Buehler e pertencente ao LFS.

Tabela 5.2: Dureza dos materiais utilizados nos ensaios.

\begin{tabular}{|c|c|c|}
\hline \multirow{2}{*}{ Corpo-de-prova } & Material & Dureza [GPa] \\
\cline { 2 - 3 } & HSS M2 & 6,4 \\
\hline \multirow{2}{*}{ Esfera de ensaio } & WC-Co P20 & 11,7 \\
\cline { 2 - 3 } & Aço AISI 1010 cementado & 8,4 \\
\hline Partícula abrasiva & SiC & $8-8,5^{(1)}$ \\
\hline
\end{tabular}

(1): Na superfície da esfera.

\subsection{PROCEDIMENTO EXPERIMENTAL}

Os ensaios foram divididos em dois grupos, denominados de "ensaios preliminares" e "ensaios definitivos". Os resultados dos ensaios preliminares estão relatados no Capítulo 6 e, dos ensaios definitivos, no Capítulo 7. Todos os ensaios foram realizados no equipamento descrito no Capítulo 4.

A finalidade da realização dos ensaios preliminares foi verificar 0 funcionamento do equipamento, além de se adquirir o "know-how" da operação do mesmo. Para tanto, foram realizados dois estudos distintos. O primeiro conjunto de ensaios preliminares foi conduzido com o objetivo de analisar a reprodutibilidade do equipamento. Por intermédio do segundo grupo de ensaios preliminares, foi verificado se o equipamento é capaz de proporcionar resultados em concordância 
qualitativa com a literatura. Para isso, foi analisada a transição entre os modos de desgaste abrasivo, para diferentes pares de materiais de corpo-de-prova e esfera.

Para alcançar os objetivos propostos no Capítulo 3, e validar (ou refutar) as hipóteses levantadas, foram realizados os ensaios definitivos. Nessa etapa, também foram realizados dois estudos distintos. No primeiro, foi analisada a relação do quociente $A_{R O L} / A_{\text {RIS }}$ com a distância de deslizamento. $\boldsymbol{A}_{R O L}$ é a área projetada de atuação do desgaste abrasivo por rolamento na calota esférica, e $\boldsymbol{A}_{\boldsymbol{R} I S}$ é a área projetada de atuação do desgaste abrasivo por riscamento. No segundo grupo de ensaios, foi analisada a obtenção do regime permanente de desgaste. Ambos os estudos foram realizados para diferentes pares de materiais de corpo-de-prova e esfera.

Os ensaios realizados nesta Dissertação podem ser organizados como apresentado na Figura 5.6.

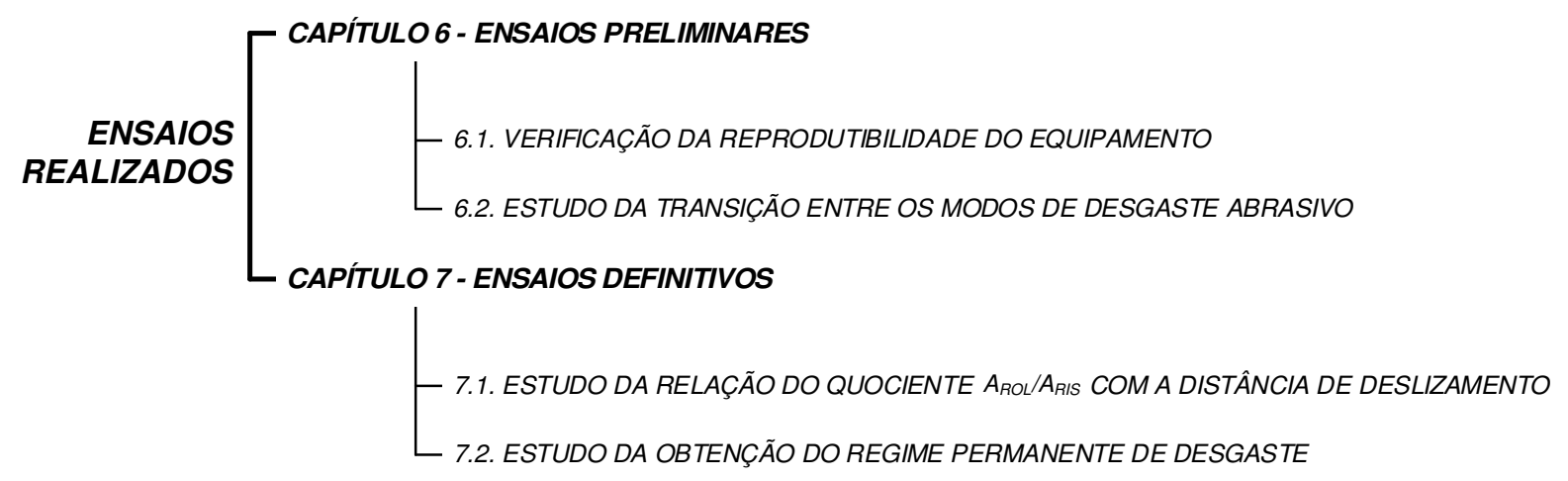

Figura 5.6: Organização dos ensaios realizados nesta Dissertação.

\subsection{ENSAIOS PRELIMINARES}

\subsubsection{Verificação da reprodutibilidade do equipamento}

A verificação da reprodutibilidade do Equipamento de Ensaio de Desgaste Micro-Abrasivo por Esfera Rotativa Fixa - Modelo LFS 2005 foi realizada através de medidas e cálculos das dimensões das calotas esféricas geradas. As dimensões analisadas foram diâmetro $(\boldsymbol{d})$, altura $(\boldsymbol{h})$ e volume $(\boldsymbol{V})$.

Foram estabelecidas três condições de ensaio. Na Tabela 5.3 estão os valores dos parâmetros definidos para os ensaios, assim como os materiais dos corpos-de-prova e das esferas utilizadas em cada condição de ensaio. 
Tabela 5.3: Parâmetros definidos para a verificação da reprodutibilidade do equipamento.

\begin{tabular}{|c|c|c|c|}
\hline Condição de ensaio & $\mathbf{1}$ & $\mathbf{2}$ & $\mathbf{3}$ \\
\hline Material do corpo-de-prova & WC-Co P20 & HSS M2 & HSS M2 \\
\hline Material da esfera & Aço AISI 52100 & Aço AISI 52100 & Aço AISI 1010 cemt. \\
\hline Esfera utilizada & E-52100-1 & E-52100-1 & E-1010C-1 \\
\hline Força Normal $[N]$ & 5 & 5 & 1,25 \\
\hline Rotação da esfera $[r p m]$ & 15 & 15 & 15 \\
\hline Distância de deslizamento $[m]$ & 8 & 8 & 8 \\
\hline Tempo de ensaio $[$ min $s]$ & 6 min $40 \mathrm{~s}$ & 6 min $40 \mathrm{~s}$ & 6 min $40 \mathrm{~s}$ \\
\hline Gotejamento da pasta abrasiva & 1 gota / $5 \mathrm{~s}$ & 1 gota $/ 5 \mathrm{~s}$ & 1 gota / $5 \mathrm{~s}$ \\
\hline Quantidade de repetições & 4 & 4 & 4 \\
\hline
\end{tabular}

Foi definida uma concentração de pasta abrasiva, conforme a Tabela 5.4. As duas colunas da esquerda mostram as porcentagens, em volume, de SiC e água destilada para a concentração. Na coluna da direita, está a massa de SiC por unidade de volume de água destilada $\left(\boldsymbol{g}_{\mathrm{Si}} / \mathbf{c m}^{3} \mathrm{H}_{2} \mathrm{O}\right.$-Dest. $)$.

Tabela 5.4: Concentração da pasta abrasiva.

\begin{tabular}{|c|c|c|}
\hline $\begin{array}{c}\text { \% SiC } \\
\text { (EM VOLUME) }\end{array}$ & $\begin{array}{c}\text { \% Água Destilada } \\
\text { (EM VOLUME) }\end{array}$ & $\frac{g_{\text {SiC }}}{\mathrm{cm}^{3} \mathrm{H}_{2} \mathrm{O}-\text { Dest. }}$ \\
\hline 25 & 75 & 1,045 \\
\hline
\end{tabular}

O gotejamento da pasta abrasiva foi realizado manualmente, por meio de um conta-gotas. Todos os ensaios foram realizados sem paradas intermediárias. A rotação das esferas de ensaio, força normal e a concentração da pasta abrasiva, foram definidas com base no trabalho de Trezona et al. (1999).

$\mathrm{Na}$ Tabela 5.3, foram mencionados, para cada condição de ensaio, os valores da rotação da esfera $\left(n_{E S F}\right)$ e da distância de deslizamento $(S)$. O tempo de ensaio $(t)$ foi conseqüência dos valores de $S, n_{E S F}$ e $R$, conforme é demonstrado a seguir.

O tempo de ensaio pode ser definido pelo quociente da velocidade tangencial periférica da esfera de ensaio $\left(v_{t}\right)$ pela distância de deslizamento, através da Equação 5.1:

$$
t=\frac{S}{v_{t}}
$$


Porém, $v_{t}$ pode ser escrito como $v_{t}=2 . \pi . n_{E S F} R$. Logo, a Equação 5.1 torna-se:

$$
t=\frac{S}{2 \cdot \pi \cdot n_{E S F} R}
$$

onde $S, n_{E S F}$ e $R$ são os valores definidos pelo pesquisador. Com isso, $t$ fica em função de $S, n_{E S F}$ e $R$.

Após os ensaios, o diâmetro de cada calota esférica foi medido por microscopia óptica, através do programa Leica Qwin ${ }^{(1)}$. Com os dados obtidos, foram calculados $\boldsymbol{h}$ e $\boldsymbol{V}$, pelas Equações 2.3 e 2.4, respectivamente. Durante a medição de $\boldsymbol{d}$, foram desconsideradas quaisquer irregularidades apresentadas pelo contorno da calota esférica. Considerou-se, portanto, o contorno de cada calota esférica como uma circunferência perfeita.

\subsubsection{Estudo da transição entre os modos de desgaste abrasivo}

O foco desse item foi o estudo da transição entre os modos de desgaste abrasivo, um fenômeno comumente observado durante ensaios de desgaste micro-abrasivo por esfera rotativa.

Foram estabelecidas quatro condições de ensaio. Na Tabela 5.5 estão os valores dos parâmetros definidos para os ensaios, assim como os materiais dos corpos-de-prova e das esferas utilizadas em cada condição.

Tabela 5.5: Parâmetros definidos para o estudo da transição entre os modos de desgaste abrasivo.

\begin{tabular}{|c|c|c|c|c|}
\hline Condição de ensaio & $\mathbf{1}$ & $\mathbf{2}$ & $\mathbf{3}$ & $\mathbf{4}$ \\
\hline Material do corpo-de-prova & WC-Co P20 & WC-Co P20 & HSS M2 & HSS M2 \\
\hline Material da esfera & $\begin{array}{c}\text { Aço AISI 1010 } \\
\text { cementado }\end{array}$ & $\begin{array}{c}\text { Aço AISI 1010 } \\
\text { cementado }\end{array}$ & $\begin{array}{c}\text { Aço AISI 1010 } \\
\text { cementado }\end{array}$ & $\begin{array}{c}\text { Aço AISI 1010 } \\
\text { cementado }\end{array}$ \\
\hline Esfera utilizada & E-1010C-2 & E-1010C-3 & E-1010C-4 & E-1010C-5 \\
\hline Força normal $[N]$ & 1,25 & 5 & 1,25 & 5 \\
\hline Rotação da esfera $[r p m]$ & 15 & 15 & 15 & 15 \\
\hline Distância de deslizamento $[m]$ & 6 & 6 & 6 & 6 \\
\hline Tempo de ensaio $[m i n]$ & 5 & 5 & 5 & 5 \\
\hline Gotejamento da pasta abrasiva & 1 gota / $5 \mathrm{~s}$ & 1 gota / $5 \mathrm{~s}$ & 1 gota / $5 \mathrm{~s}$ & 1 gota / $5 \mathrm{~s}$ \\
\hline Quantidade de repetições & 4 & 4 & 4 & 4 \\
\hline
\end{tabular}

\footnotetext{
${ }^{1}$ Nesta Dissertação, todas as imagens das crateras de desgaste exibidas nos Capítulos 6 e 7 foram obtidas através do Microscópio Óptico BX60M, pertencente ao LFS.
} 
Foi utilizada a mesma concentração de pasta abrasiva definida na Tabela 5.4. O gotejamento da mesma também foi realizado manualmente, por um conta-gotas. Todos os ensaios foram realizados sem paradas intermediárias. O valor do tempo de ensaio saiu em função de $S, n_{\text {esf }}$ e $R$, conforme foi demonstrado na Equação 5.2.

Após os ensaios, os diâmetros das crateras de desgaste foram medidos por microscopia óptica, pelo programa Leica QWin. Com o valor de $\boldsymbol{d}$, foram calculados $\boldsymbol{h}$ e $\boldsymbol{V}$, de cada calota esférica, pelas Equações 2.3 e 2.4, respectivamente. Aqui, também foi desconsiderada qualquer irregularidade no contorno da calota esférica.

Após as medições das calotas esféricas, foram analisadas as atuações dos modos de desgaste abrasivo. Aqui, não foram feitas as medições das áreas de atuação do desgaste abrasivo por riscamento e do desgaste abrasivo por rolamento. Os resultados obtidos foram comparados qualitativamente com os resultados apresentados por Adachi e Hutchings (2003), que relatam a transição entre os modos de desgaste abrasivo.

\subsection{ENSAIOS DEFINITIVOS}

\subsubsection{Estudo da relação do quociente $A_{R O L} / A_{R I S}$ com a distância de deslizamento}

O objetivo desse estudo foi analisar o comportamento de $A_{R O L} / A_{R I S}$ com a distância de deslizamento.

Para cada combinação corpo-de-prova/esfera, foram estabelecidas seis condições de ensaio, conforme mostram as Tabelas 5.6 e 5.7. A Tabela 5.6 apresenta os valores dos parâmetros definidos para os ensaios realizados nos corpos-de-prova de HSS M2. Na Tabela 5.7 estão os valores definidos para os ensaios conduzidos nos corpos-de-prova de WC-Co P20. 
Tabela 5.6: Valores dos parâmetros estabelecidos para os ensaios realizados nos corpos-de-prova de HSS M2.

\begin{tabular}{|c|c|c|c|c|c|c|}
\hline Condição de ensaio & 1 & 2 & 3 & 4 & 5 & 6 \\
\hline Material do corpo-de-prova & HSS M2 & HSS M2 & HSS M2 & HSS M2 & HSS M2 & HSS M2 \\
\hline Material da esfera & $\begin{array}{c}\text { Aço AISI } \\
52100\end{array}$ & $\begin{array}{c}\text { Aço AISI } \\
52100\end{array}$ & $\begin{array}{c}\text { Aço AISI } \\
52100\end{array}$ & $\begin{array}{c}\text { Aço AISI } \\
52100\end{array}$ & $\begin{array}{c}\text { Aço AISI } \\
52100\end{array}$ & $\begin{array}{c}\text { Aço AISI } \\
52100\end{array}$ \\
\hline Esfera utilizada & $E-52100-1$ & E-52100-1 & E-52100-1 & E-52100-1 & E-52100-1 & E-52100-1 \\
\hline Força Normal $[N]$ & 1,25 & 1,25 & 1,25 & 1,25 & 1,25 & 1,25 \\
\hline Rotação da esfera [rpm] & 37,6 & 37,6 & 37,6 & 37,6 & 37,6 & 37,6 \\
\hline Distância de deslizamento $[\mathrm{m}]$ & 8 & 15 & 20 & 25 & 35 & 40 \\
\hline Tempo de ensaio $[\min s]$ & $2 \min 40 s$ & $5 \mathrm{~min}$ & $6 \min 40 s$ & $8 \min 20 s$ & $11 \mathrm{~min} 40 \mathrm{~s}$ & $13 \min 20 \mathrm{~s}$ \\
\hline Gotejamento da pasta abrasiva & 1 gota $/ 10 \mathrm{~s}$ & 1 gota $/ 10 \mathrm{~s}$ & 1 gota $/ 10 \mathrm{~s}$ & 1 gota $/ 10 \mathrm{~s}$ & 1 gota / $10 \mathrm{~s}$ & 1 gota $/ 10 \mathrm{~s}$ \\
\hline Quantidade de repetições & 4 & 4 & 4 & 4 & 4 & 4 \\
\hline
\end{tabular}

Tabela 5.7: Valores dos parâmetros estabelecidos para os ensaios realizados nos corpos-de-prova de WC-Co P20.

\begin{tabular}{|c|c|c|c|c|c|c|}
\hline Condição de ensaio & $\mathbf{1}$ & $\mathbf{2}$ & $\mathbf{3}$ & $\mathbf{4}$ & $\mathbf{5}$ & $\mathbf{6}$ \\
\hline Material do corpo-de-prova & WC-Co P20 & WC-Co P20 & WC-Co P20 & WC-Co P20 & WC-Co P20 & WC-Co P20 \\
\hline Material da esfera & $\begin{array}{c}\text { Aço AISI } \\
52100\end{array}$ & $\begin{array}{c}\text { Aço AISI } \\
52100\end{array}$ & $\begin{array}{c}\text { Aço AISI } \\
52100\end{array}$ & $\begin{array}{c}\text { Aço AISI } \\
52100\end{array}$ & $\begin{array}{c}\text { Aço AISI } \\
52100\end{array}$ & $\begin{array}{c}\text { Aço AISI } \\
52100\end{array}$ \\
\hline Esfera utilizada & E-52100-1 & E-52100-1 & E-52100-1 & E-52100-1 & E-52100-1 & E-52100-1 \\
\hline Força Normal $[M]$ & 1,25 & 1,25 & 1,25 & 1,25 & 1,25 & 1,25 \\
\hline Rotação da esfera $[\mathrm{rpm}]$ & 37,6 & 37,6 & 37,6 & 37,6 & 37,6 & 37,6 \\
\hline Distância de deslizamento $[\mathrm{m}]$ & 8 & 15 & 20 & 25 & 35 & 40 \\
\hline Tempo de ensaio $[\mathrm{min} \mathrm{s}]$ & $2 \mathrm{~min} 40 \mathrm{~s}$ & $5 \mathrm{~min}$ & $6 \mathrm{~min} 40 \mathrm{~s}$ & $8 \mathrm{~min} 20 \mathrm{~s}$ & 11 min $40 \mathrm{~s}$ & $13 \mathrm{~min} 20 \mathrm{~s}$ \\
\hline Gotejamento da pasta abrasiva & 1 gota / $10 \mathrm{~s}$ & 1 gota / $10 \mathrm{~s}$ & 1 gota / $10 \mathrm{~s}$ & 1 gota / $10 \mathrm{~s}$ & 1 gota / $10 \mathrm{~s}$ & 1 gota / $10 \mathrm{~s}$ \\
\hline Quantidade de repetições & 4 & 4 & 4 & 4 & 4 & 4 \\
\hline
\end{tabular}

A rotação da esfera de ensaio $(37,6 \mathrm{rpm})$ foi a mesma adotada por Trezona et al. (1999). No trabalho de Trezona et al. (1999), a velocidade tangencial periférica da esfera de ensaio ficou definida em $v_{t}=0,05 \mathrm{~m} / \mathrm{s}$. Como a esfera possuía diâmetro de 25,4 mm, pela equação $n_{e s f}={ }^{v_{t}} / 2 . \pi \cdot R$ a rotação da mesma ficou em 37,6 rpm.

Todos os ensaios foram realizados sem paradas intermediárias. A concentração da pasta abrasiva foi a mesma mencionada na Tabela 5.4. A forma de gotejamento da pasta abrasiva também foi manual, por meio de um conta-gotas.

Com base na distância de deslizamento, para os ensaios com os corpos-de-prova de aço ferramenta $M 2$, foi estabelecida, por sorteio, a seguinte seqüência de ensaios: $20,15,20,25,25,20,15,15,15,25,25,20,35,40,35,8,40$, 8, 40, 8, 8, 35, 35 e 40 metros. Seguindo esse mesmo critério, para os ensaios com 
as pastilhas de $W C$-Co P20, a ordem de ensaios estabelecida ficou como: 8 , 15, 8 , $20,15,20,15,8,8,20,20,15,40,25,25,35,40,35,25,40,35,35,40$ e 25 metros.

As áreas $\boldsymbol{A}_{t}$ (área projetada total da cratera de desgaste), $\boldsymbol{A}_{\boldsymbol{R} I \mathbf{s}}$ (área projetada de atuação do desgaste abrasivo por riscamento) e $\boldsymbol{A}_{\boldsymbol{R}}$ (área projetada de atuação do desgaste abrasivo por rolamento) foram determinadas por dois métodos diferentes, denominados Método 1 e Método 2. A seguir, tem-se a explicação de cada um desses métodos.

\section{Método 1:}

Inicialmente, por microscopia óptica, foram realizadas as medições de $\boldsymbol{d}$ e $\boldsymbol{A}_{\boldsymbol{R} I \boldsymbol{S}}$, através do programa Leica $Q W i n$. Em função de $\boldsymbol{d}$, a área $\boldsymbol{A}_{\boldsymbol{t}}$ foi determinada pela equação $\boldsymbol{A}_{\boldsymbol{t}}=\pi \frac{\boldsymbol{d}^{2}}{4}$. Tendo-se $\boldsymbol{A}_{\boldsymbol{t}}$ e $\boldsymbol{A}_{\boldsymbol{R} I \boldsymbol{S}}, \boldsymbol{A}_{\boldsymbol{R} O L}$ foi determinada pela diferença entre $\boldsymbol{A}_{t}$ e $\boldsymbol{A}_{\boldsymbol{R} I S}$, ou seja, $\boldsymbol{A}_{\boldsymbol{R} O L}=\boldsymbol{A}_{t}-\boldsymbol{A}_{\boldsymbol{R} I \boldsymbol{S}}$. Com os valores de $\boldsymbol{A}_{\boldsymbol{R} I \boldsymbol{S}}$ e $\boldsymbol{A}_{\boldsymbol{R}}$, levantou-se o gráfico de $\frac{\boldsymbol{A}_{R O L}}{\boldsymbol{A}_{R I S}}=f(S)$.

\section{Método 2:}

As imagens das crateras de desgaste obtidas por microscopia óptica (pelo programa Leica $Q W i n)$ foram transferidas para o programa AutoCAD 2000. As áreas $\boldsymbol{A}_{t}, \boldsymbol{A}_{R I s} \mathrm{e}$ $\boldsymbol{A}_{R O L}$ foram medidas separadamente. A primeira área a ser medida foi $\boldsymbol{A}_{t}$. Em seguida, foram realizadas as medições de $\boldsymbol{A}_{\boldsymbol{R} I \boldsymbol{s}}$ e $\boldsymbol{A}_{\boldsymbol{R} O \boldsymbol{L}}$. Com os valores de $\boldsymbol{A}_{\boldsymbol{R} \boldsymbol{I} \boldsymbol{S}}$ e $\boldsymbol{A}_{\boldsymbol{R O L}}$, foi levantado o gráfico de $\frac{\boldsymbol{A}_{R O L}}{\boldsymbol{A}_{R I S}}=f(S)$. Na teoria, $\boldsymbol{A}_{\boldsymbol{t}}=\boldsymbol{A}_{\boldsymbol{R} \boldsymbol{S}}-\boldsymbol{A}_{\boldsymbol{R O L}}$. Entretanto, como as três áreas foram medidas de forma independente, foi esperado que houvesse diferença entre as parcelas.

Para cada material de corpo-de-prova (aço ferramenta M2 e WC-Co P20), foram levantados dois gráficos de $\frac{\boldsymbol{A}_{R O L}}{\boldsymbol{A}_{R I S}}=f(S)$. Um gráfico obtido pelo Método 1, e outro obtido pelo Método 2.

Após a construção dos quatro gráficos de $\frac{\boldsymbol{A}_{R O L}}{\boldsymbol{A}_{R I S}}=f(S)$, foram realizados novos ensaios nos corpos-de-prova de WC-Co P20, com os mesmos parâmetros 
mencionados na Tabela 5.7. Foram repetidos os ensaios para as distâncias de deslizamento de 15 e 35 metros, na seguinte seqüência: 15, 15, 35, 15, 35, 15, 35 e 35 metros. Após a finalização desses ensaios, as áreas $\boldsymbol{A}_{t}, \boldsymbol{A}_{\boldsymbol{R} I S}$ e $\boldsymbol{A}_{\boldsymbol{R} O L}$ foram medidas pelo Método 2. Com isso, foram obtidos dois pontos de $\frac{\boldsymbol{A}_{R O L}}{\boldsymbol{A}_{R I S}}=f(S)$, um para a distância de deslizamento de 15 metros, e outro para 35 metros. Esses pontos foram superpostos no gráfico anteriormente obtido pelo Método 2 para os corpos-de-prova de WC-Co P20.

\subsubsection{Estudo da obtenção do regime permanente de desgaste}

Para cada material de corpo-de-prova (aço ferramenta M2 e WC-Co P20), foi estudada a obtenção do regime permanente de desgaste, com base no gráfico de $\boldsymbol{k}=f(S)$. O coeficiente de desgaste foi calculado pela Equação 2.6 e a área $\boldsymbol{A}_{\boldsymbol{t}}$, medida pelo Método 2.

Para o HSS M2, foram utilizados os valores de $\boldsymbol{A}_{t}$ obtidos no Item 5.4.1. Nos corpos-de-prova de WC-Co P20, foram realizados novos ensaios, desta vez com a esfera E-52100-2 (não utilizada até então), para as distâncias de 25, 35 e 40 metros. Por sorteio, foi estabelecida a seguinte seqüência de ensaios: $25,35,25,35,35,40$, 25, 40, 35, 25, 40 e 40 metros.

Na Tabela 5.8 estão os parâmetros adotados para os ensaios realizados com a esfera E-52100-2, nos corpos-de-prova de WC-Co P20.

Tabela 5.8: Valores dos parâmetros estabelecidos para os ensaios realizados nos corpos-de-prova de WC-Co P20, com a esfera E-52100-2.

\begin{tabular}{|c|c|c|c|}
\hline Condição de ensaio & $\mathbf{4}$ & $\mathbf{5}$ & $\mathbf{6}$ \\
\hline Material do corpo-de-prova & WC-Co P20 & WC-Co P20 & WC-Co P20 \\
\hline Material da esfera & Aço AISI 52100 & Aço AISI 52100 & Aço AISI 52100 \\
\hline Esfera utilizada & E-52100-2 & E-52100-2 & E-52100-2 \\
\hline Força Normal $[N]$ & 1,25 & 1,25 & 1,25 \\
\hline Rotação da esfera $[r p m]$ & 37,6 & 37,6 & 37,6 \\
\hline Distância de deslizamento $[\mathrm{m}]$ & 25 & 35 & 40 \\
\hline Tempo de ensaio $[$ min $\mathrm{s}]$ & $8 \mathrm{~min} 20 \mathrm{~s}$ & $11 \mathrm{~min} 40 \mathrm{~s}$ & $13 \mathrm{~min} 20 \mathrm{~s}$ \\
\hline Gotejamento da pasta abrasiva & 1 gota / $10 \mathrm{~s}$ & 1 gota $/ 10 \mathrm{~s}$ & 1 gota $/ 10 \mathrm{~s}$ \\
\hline Quantidade de repetições & 4 & 4 & 4 \\
\hline
\end{tabular}


"...evite dizer o termo "eu preciso". Procure dizer "eu quero". Embora parecidos, são termos completamente diferentes. "Eu preciso" passa um conceito de obrigação. "Eu quero" transmite a sensação de "vou fazer, porque gosto"..."

Humberto's 


\section{CAPÍTULO 6 - ENSAIOS PRELIMINARES - RESULTADOS E DISCUSSÃO}

\subsection{VERIFICAÇÃO DA REPRODUTIBILIDADE DO EQUIPAMENTO}

A seguir, estão os resultados obtidos nos ensaios de desgaste por micro-abrasão, referentes à verificação da reprodutibilidade do equipamento.

\section{- RESULTADOS DA CONDIÇÃO DE ENSAIO 1}

A Figura 6.1 apresenta uma das quatro crateras de desgaste obtidas para a condição de ensaio 1 (Tabela 5.3).

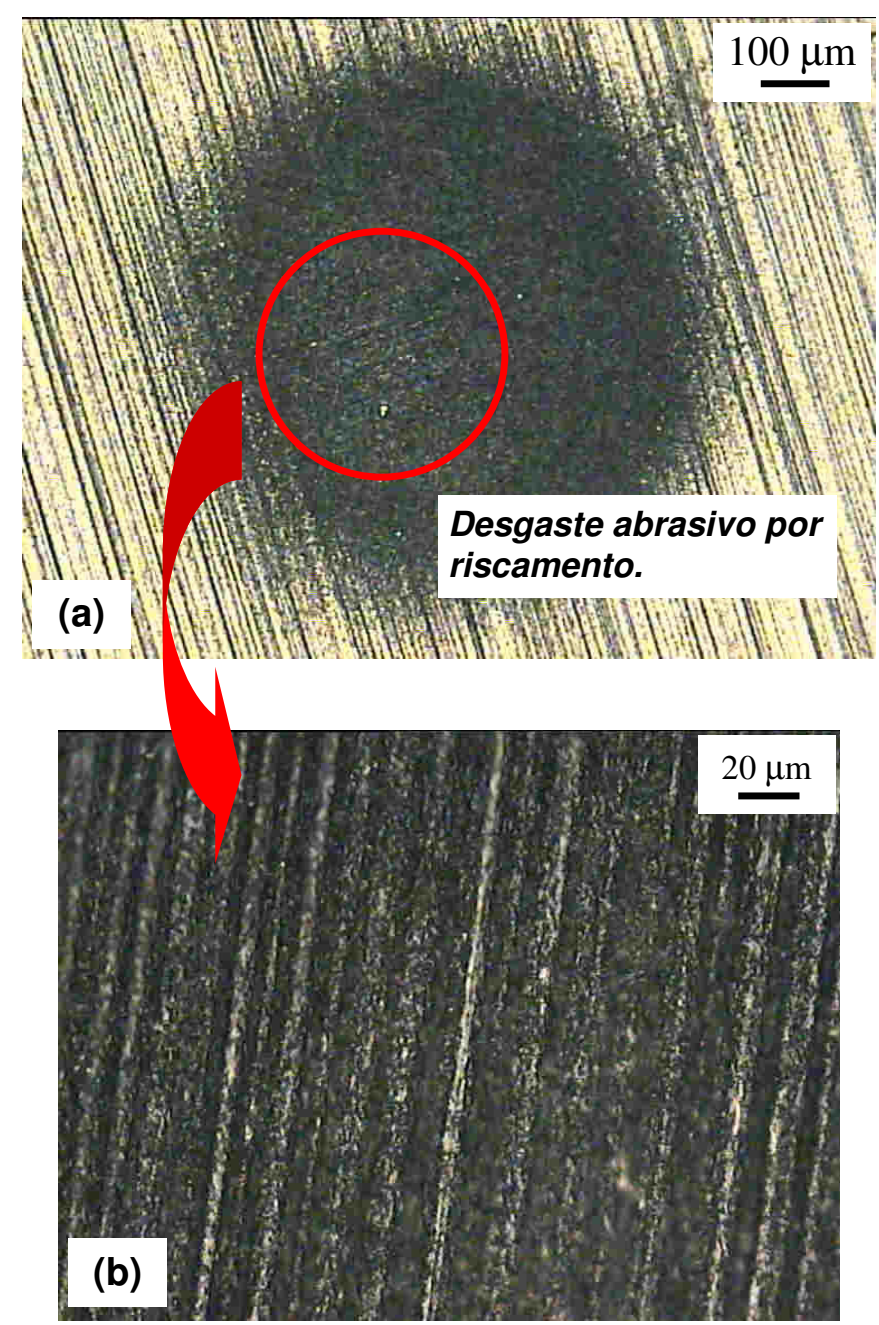

Figura 6.1: (a) Atuação de desgaste abrasivo misto. (b) Região de atuação de desgaste abrasivo por riscamento. Corpo-de-prova de WC-Co P20. 
A Tabela 6.1 apresenta as dimensões (diâmetro, altura e volume) das crateras de desgaste para os quatro ensaios realizados.

Tabela 6.1: Dimensões das crateras de desgaste para a condição de ensaio 1.

\begin{tabular}{|l|c|c|c|c|c|c|}
\hline GRANDEZA & ENSAIO 1 & ENSAIO 2 & ENSAIO 3 & ENSAIO 4 & MÉDIA & DESVIO-PADRÃO \\
\hline $\boldsymbol{d}[\mathrm{mm}]$ & 0,637 & 0,657 & 0,669 & 0,647 & 0,652 & 0,014 \\
\hline $\boldsymbol{h}[\mu \mathrm{m}]$ & 4,0 & 4,2 & 4,4 & 4,1 & 4,2 & $(1)$ \\
\hline $\boldsymbol{V}\left[10^{-3} \mathrm{~mm}^{3}\right]$ & 0,636 & 0,72 & 0,774 & 0,677 & 0,702 & $(1)$ \\
\hline
\end{tabular}

(1): Na Tabela 6.1, foi calculado o desvio-padrão $\left(\sigma_{P}\right)$ somente da dimensão que foi medida no microscópio óptico (no caso, o diâmetro da cratera de desgaste). Para os cálculos dos desvios-padrão da altura e do volume da calota esférica, deve-se utilizar o conceito de Propagação de Erros. As dimensões altura e volume, não foram obtidos diretamente por medições realizadas no microscópio óptico, mas sim pelas Equações 2.3 e 2.4, respectivamente.

\section{- RESULTADOS DA CONDIÇÃO DE ENSAIO 2}

A Figura 6.2 apresenta uma das quatro crateras de desgaste obtidas com a condição de ensaio 2 (Tabela 5.3).

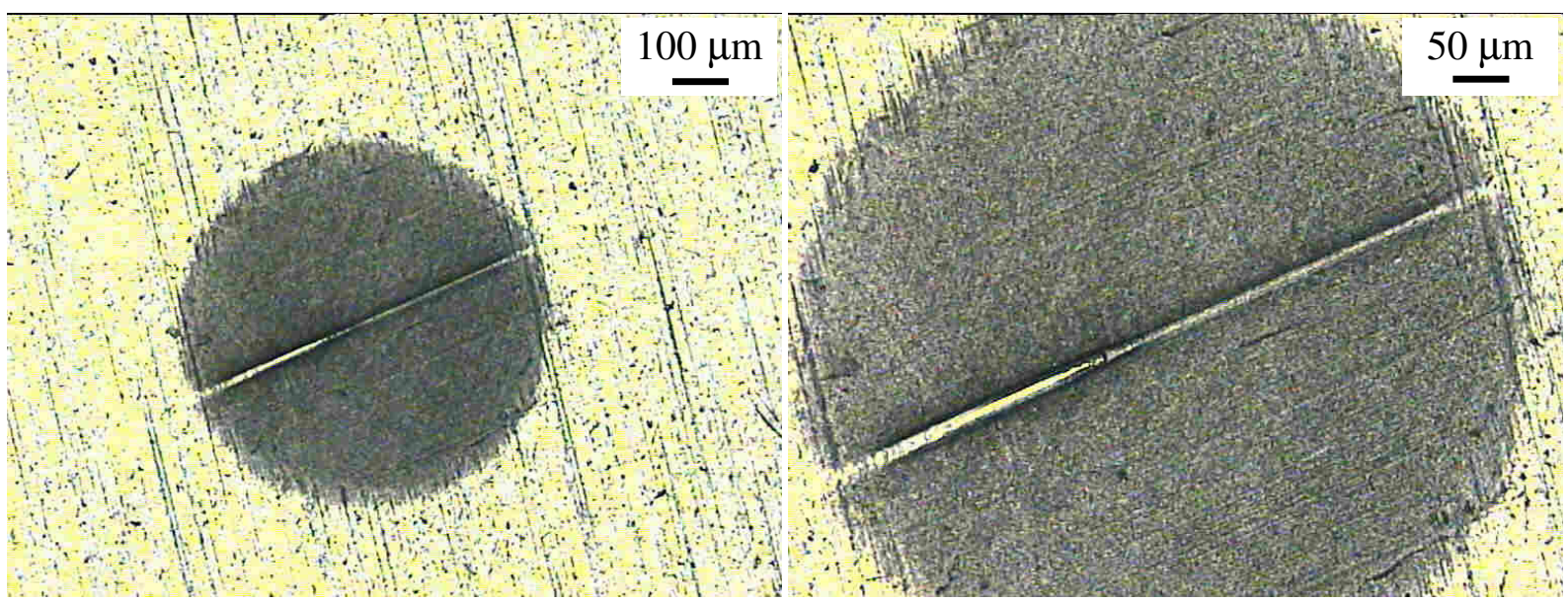

Figura 6.2: Forma padrão de cratera de desgaste obtida na condição de ensaio 2. Corpos-de-prova de aço ferramenta M2.

$\mathrm{Na}$ Tabela 6.2 estão as grandezas $\boldsymbol{d}$, $\boldsymbol{h}$ e $\boldsymbol{V}$, obtidas com a condição de ensaio 2.

Tabela 6.2: Dimensões das crateras de desgaste para a condição de ensaio 2.

\begin{tabular}{|l|c|c|c|c|c|c|}
\hline GRANDEZA & ENSAIO 1 & ENSAIO 2 & ENSAIO 3 & ENSAIO 4 & MÉDIA & DESVIO-PADRÃO \\
\hline $\boldsymbol{d}[\mathrm{mm}]$ & 0,649 & 0,662 & 0,658 & 0,685 & 0,664 & 0,015 \\
\hline $\boldsymbol{h}[\mu \mathrm{m}]$ & 4,1 & 4,3 & 4,3 & 4,6 & 4,3 & $(1)$ \\
\hline $\boldsymbol{V}\left[10^{-3} \mathrm{~mm}^{3}\right]$ & 0,686 & 0,742 & 0,725 & 0,851 & 0,751 & $(1)$ \\
\hline
\end{tabular}

(1): Ver observações da Tabela 6.1. 


\section{RESULTADOS DA CONDIÇÃO DE ENSAIO 3}

A Figura 6.3 mostra a primeira cratera de desgaste obtida. Nesse caso, a mesma não foi considerada. Nessa situação, foram realizados cinco ensaios.

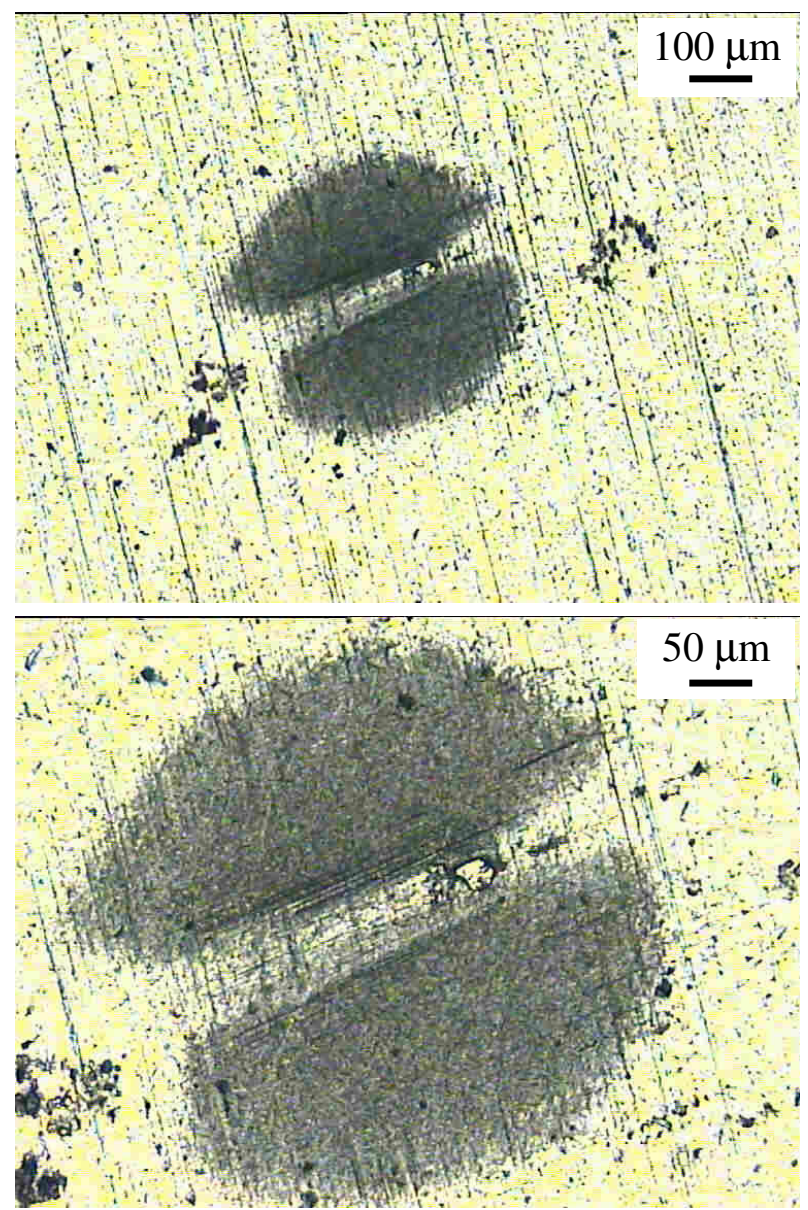

Figura 6.3: Forma da primeira cratera de desgaste obtida com a esfera E-1010C-1. Essa cratera de desgaste não foi considerada na análise dos resultados.

$\mathrm{Na}$ Tabela 6.3 estão as grandezas $\boldsymbol{d}, \boldsymbol{h}$ e $\boldsymbol{V}$, obtidas com a condição de ensaio 3.

Tabela 6.3: Dimensões das crateras de desgaste para a condição de ensaio 3.

\begin{tabular}{|l|c|c|c|c|c|c|}
\hline GRANDEZA & ENSAIO 1 & ENSAIO 2 & ENSAIO 3 & ENSAIO 4 & MÉDIA & DESVIO-PADRÃO \\
\hline $\boldsymbol{d}[\mathrm{mm}]$ & 0,403 & 0,382 & 0,413 & 0,391 & 0,397 & 0,014 \\
\hline $\boldsymbol{h}[\mu \mathrm{m}]$ & 1,6 & 1,4 & 1,7 & 1,5 & 1,6 & $(1)$ \\
\hline $\boldsymbol{V}\left[10^{-3} \mathrm{~mm}^{3}\right]$ & 0,102 & 0,082 & 0,112 & 0,09 & 0,097 & $(1)$ \\
\hline
\end{tabular}

(1): Ver observações da Tabela 6.1. 
A discussão a seguir, está baseada, além dos resultados obtidos com as condições de ensaio 1, 2 e 3, que visam relatar a reprodutibilidade do equipamento, em observações referentes ao funcionamento do mesmo.

Inicialmente, vale ressaltar que, as forças normais $(1,25 N$ e $5 \mathrm{~N}$ e a concentração da pasta abrasiva $\left(1,045 \mathrm{~g} / \mathrm{cm}^{3}\right)$ adotadas nesses ensaios foram similares aos valores utilizados por Trezona et al. (1999). Porém, a rotação da esfera de ensaio, $15 \mathrm{rpm}$, definida para o Item 6.1, foi menor que a utilizada por Trezona et al. (1999), 37,6 rpm. Além disso, a distância de deslizamento percorrida nesses ensaios (8 metros) foi relativamente pequena. A menor distância de deslizamento adotada por Trezona et al. (1999) foi de 15 metros.

A forma de cada cratera de desgaste gerada, apresentou similaridades com os resultados apresentados por Trezona e Hutchings (1999), que tendiam a uma circunferência. Por exemplo, a forma da calota esférica apresentada na Figura 6.2 é semelhante à da cratera da Figura $2.17 \mathrm{~h}$, retirada do trabalho de Trezona e Hutchings (1999).

Pelos valores dos diâmetros das crateras de desgaste exibidos nas Tabelas 6.1, 6.2 e 6.3, referentes às condições de ensaio 1, 2 e 3, respectivamente, pode-se dizer que, mesmo em pequenas distâncias de deslizamento, o equipamento está proporcionando resultados reprodutíveis. Esta afirmação está baseada nos valores de desvios-padrão relatados, 0,014, 0,015 e 0,014, para as condições de ensaio 1, 2 e 3, respectivamente. Entretanto, atualmente, não há uma norma para o ensaio de desgaste micro-abrasivo, na qual poderia se ter uma referência de valores de desvios-padrão, para julgar se os valores obtidos no Item 6.1, estão "altos" ou "baixos".

Em relação à utilização do equipamento de desgaste micro-abrasivo, devem ser seguidos alguns cuidados. Antes da realização dos ensaios de micro-abrasão, é necessário que as guias da mesa de translação sejam lubrificadas (Figura 6.4). Em ensaios adicionais (não descritos nesta Dissertação) realizados sem esse procedimento, foram registradas diferenças significativas nos valores dos diâmetros das calotas esféricas obtidas, o que, conseqüentemente, conduziu a valores de desvios-padrão relativamente altos, quando comparados aos valores mencionados nas Tabelas 6.1, 6.2 e 6.3 . 


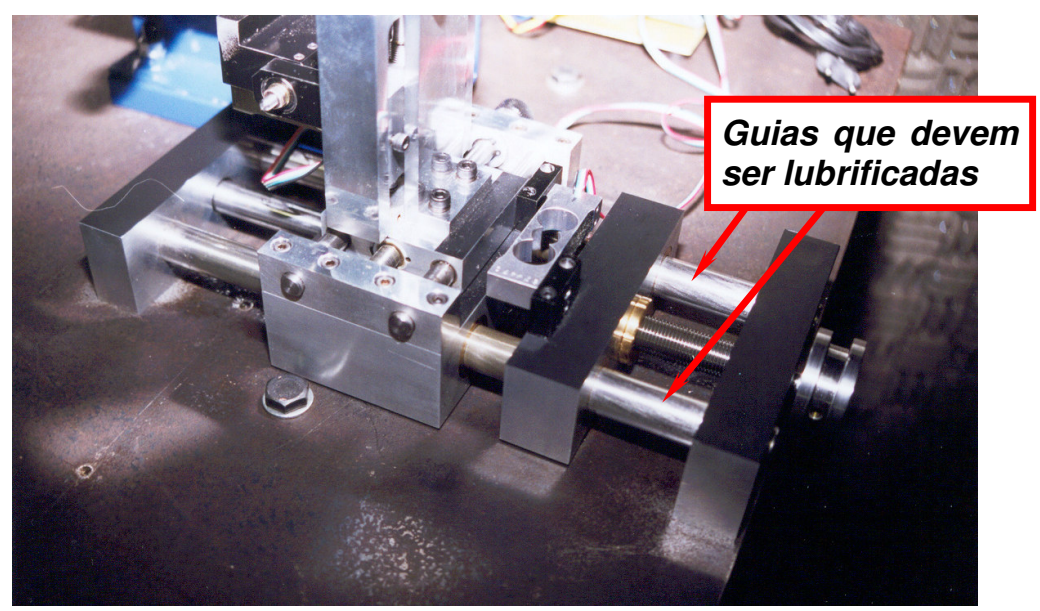

Figura 6.4: Guias da mesa de translação que devem ser lubrificadas antes do início dos ensaios.

Em cada corpo-de-prova, as duas faces podem ser utilizadas para a realização dos ensaios. Aliada a essa vantagem, tanto o sistema de posição horizontal quanto o sistema de posição vertical (Figura 4.9), mostraram-se bastante úteis, pois, através dos mesmos, foi possível realizar diversos ensaios em cada corpo-de-prova (aproximadamente 10 ensaios em cada face, dependendo do diâmetro de cada cratera de desgaste).

Para a montagem utilizada na obtenção dos resultados desta Dissertação, o conjunto de fixação do corpo-de-prova apresentou um problema. Quando a força normal é aplicada na pastilha, dependendo do local onde o esforço é aplicado, surge um momento que tende a girar o corpo-de-prova (Figura 6.5).

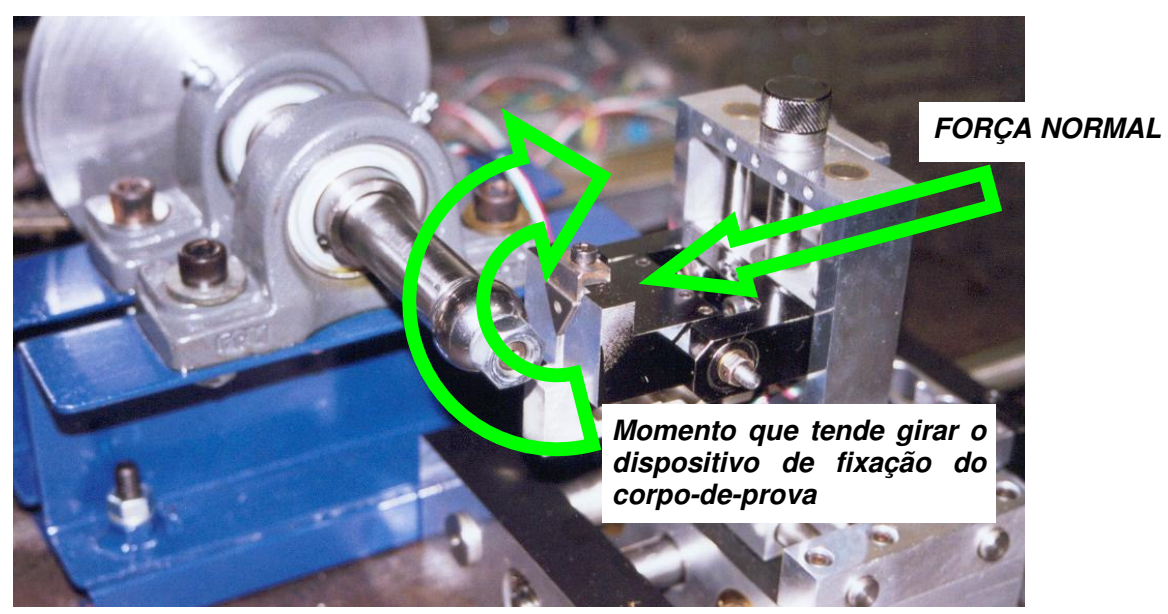

Figura 6.5: Momento que tende girar o corpo-de-prova quando a força normal é aplicada no mesmo. 
Para a realização dos ensaios apresentados acima, esse problema foi resolvido (provisoriamente) através da união da peça na qual é fixado o corpo-de-prova (Peça 31 - ANEXO IV) com a célula de carga utilizada para a medição da força tangencial (Figura 6.6). Esse problema ocorreu devido a um erro de projeto. Com isso, o correto é refazer o desenho desse conjunto, embora os resultados acima mostrem que é possível utilizar o sistema dessa forma. Adicionalmente, é possível descontar na célula de carga qualquer força agindo em sentido oposto à força tangencial desenvolvida durante os ensaios.

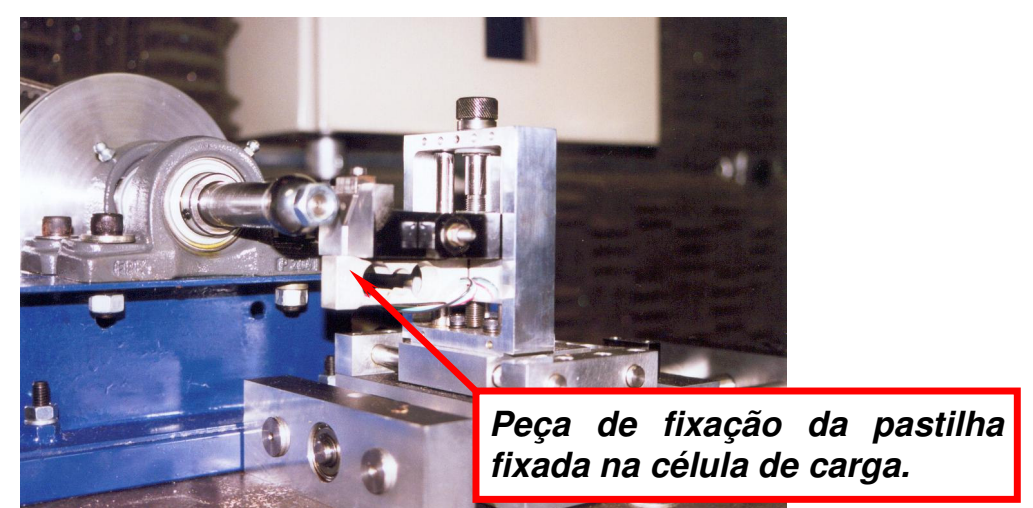

Figura 6.6: Componente de fixação do corpo-de-prova unido à célula de carga.

O eixo de ensaio está com uma excentricidade de 0,05 $\mathrm{mm}$. Esse valor foi obtido com um relógio comparador. Esse valor não está interferindo nos resultados, mas seria de extrema importância, refazer esse componente, com uma excentricidade menor. Nesse caso, o problema ocorreu na usinagem e não no projeto. Além disso, em alguns ensaios foi observado que, caso o furo da esfera de ensaio esteja excêntrico, a mesma perderá a utilidade, pois somente uma parte da circunferência de trabalho entrará em contato com o corpo-de-prova.

Todo o sistema de controle de rotação do eixo de ensaio (Figuras 4.2, 4.3 e 4.6) mostrou-se bastante eficaz. Além de cobrir uma ampla faixa de rotações, não apresentou qualquer tipo de problema. Entretanto, se o usuário adotar rotações relativamente elevadas (100 rpm ou maior), é importante, para a segurança da própria pessoa, que seja construída uma proteção para a correia e o conjunto de polias (Figura 4.4).

Tanto a maneira pela qual a força normal é aplicada no corpo-de-prova, quanto a forma com que é lida, embora trabalhosa, estão confiáveis. Para as experiências realizadas no âmbito desta Dissertação, o maior problema do 
equipamento, foi a forma com que a pasta abrasiva foi inserida no contato entre 0 corpo-de-prova e a esfera. Por ser uma tarefa totalmente manual, a mesma exige do usuário, extrema atenção. Isso porque, a pessoa deve gotejar a mistura em tempos constantes ao mesmo que não deve deixar o abrasivo decantar.

\subsection{ESTUDO DA TRANSIÇÃO ENTRE OS MODOS DE DESGASTE ABRASIVO}

Todos os ensaios conduzidos no corpo-de-prova de aço ferramenta M2 resultaram em desgaste abrasivo misto (desgaste abrasivo por riscamento + desgaste abrasivo por rolamento). Em contrapartida, nos ensaios realizados no corpo-de-prova de WC-Co $P 20$, não foi observada a total predominância de desgaste abrasivo por rolamento. O desgaste abrasivo por riscamento foi observado quando aplicou-se a força normal elevada, $5 \mathrm{~N}$. Para a carga normal mais baixa, 1,25 N, foi observada a atuação do modo misto de desgaste abrasivo. Nesse caso, no centro da cratera de desgaste, houve a ocorrência de desgaste abrasivo por riscamento e, nas bordas, desgaste abrasivo por rolamento (Figura 6.7). Adachi e Hutchings (2003) observaram o mesmo comportamento. Entretanto, os corpos-de-prova usados por esses autores foram de PMMA.

A borda difusa da cratera de desgaste apresentada na Figura 6.7 pode ser um indício de que o regime permanente de desgaste não foi atingido.

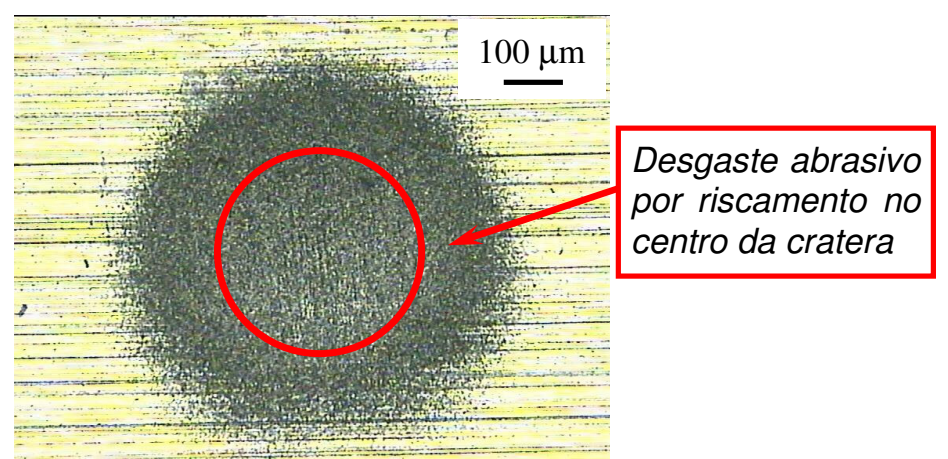

Figura 6.7: Ação de desgaste abrasivo por riscamento (centro) e desgaste abrasivo por rolamento (extremidades), para uma força normal de 1,25 $\mathrm{N}$ e uma concentração de pasta abrasiva de $1,045 \mathrm{~g} / \mathrm{cm}^{3}$ (25\% SiC / 75\% água destilada).

Em cada corpo-de-prova, para cada condição, todas as crateras foram similares. Entretanto, para a força normal de $5 \mathrm{~N}$, a quarta repetição para ambos corpos-de-prova resultou em uma pequena diferença na forma da cratera de desgaste, quando comparada às outras três. A Figura 6.8 mostra a forma da cratera de desgaste obtida na quarta repetição, no corpo-de-prova de aço ferramenta M2. 


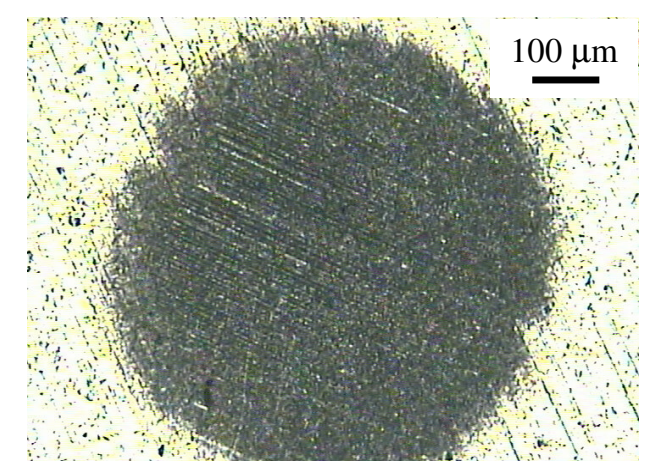

Figura 6.8: Cratera de desgaste no corpo-de-prova de aço ferramenta M2, para uma força normal de $5 \mathrm{~N}$ e uma concentração de pasta abrasiva de $1,045 \mathrm{~g} / \mathrm{cm}^{3}$ (25\% SiC / $75 \%$ água destilada). Esta cratera de desgaste foi gerada durante o quarto ensaio.

Trezona et al. (1999) mencionam que, para elevadas concentrações de pasta abrasiva e baixas forças normais, há o predomínio do desgaste abrasivo por rolamento e, para elevadas forças normais e baixas concentrações de pasta abrasiva, há o domínio do desgaste abrasivo por riscamento. Neste trabalho, foi observado um comportamento similar. Para a força normal de 1,25 $\mathrm{N}$, ocorreu desgaste abrasivo misto. Entretanto, para a força normal de $5 N$ (relativamente alta quando comparada com 1,25 $\mathrm{N}$ ), foi observado desgaste abrasivo por riscamento no corpo-de-prova de WC-Co P20. A Figura 6.9 reproduz um resultado originalmente publicado por Adachi e Hutchings (2003), onde os resultados obtidos neste trabalho estão superpostos.

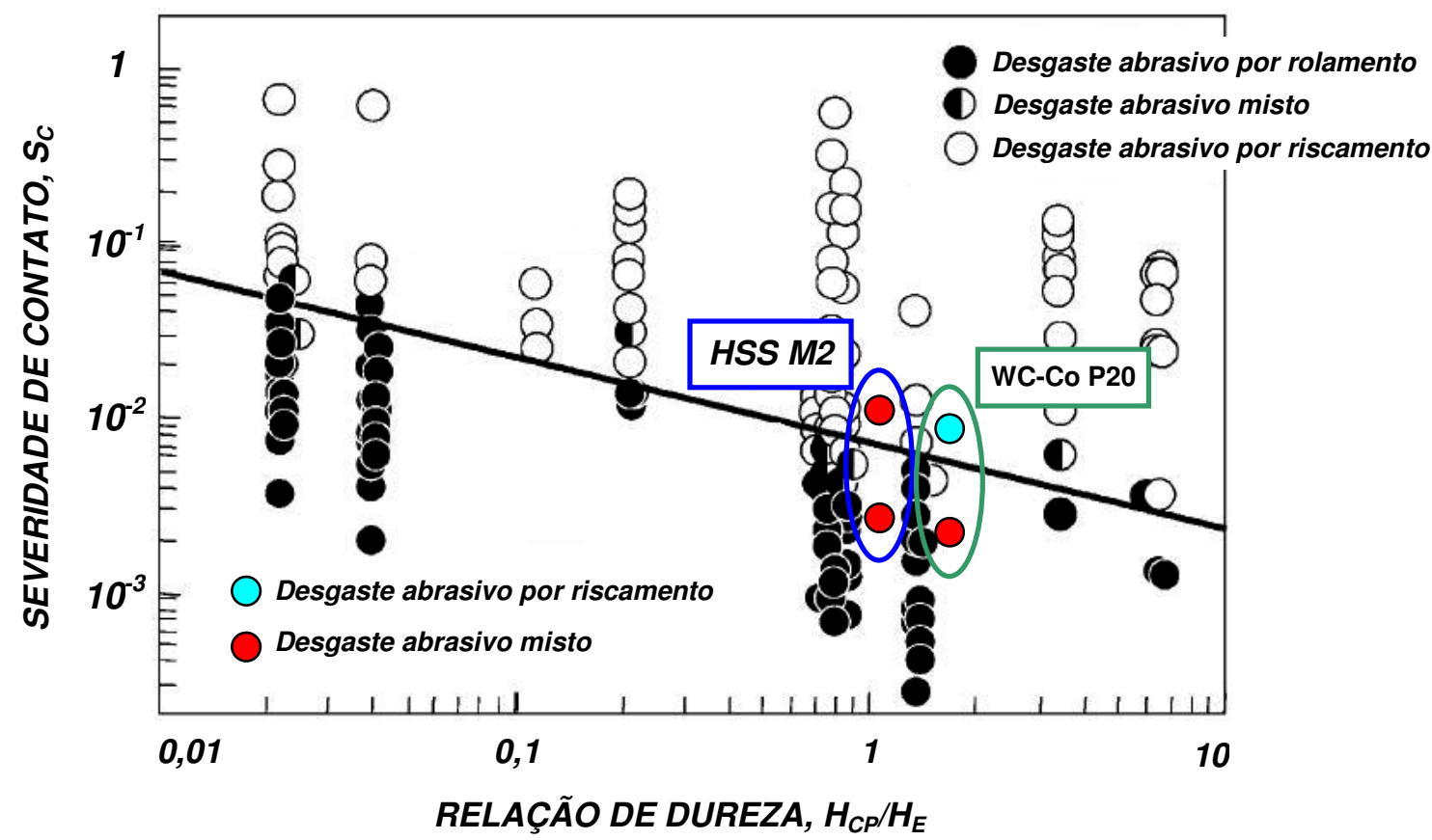

Figura 6.9: Transição dos modos de desgaste em função da severidade de contato $S_{C}$ e da razão $H_{C P} / H_{E}$ (Adachi e Hutchings, 2005). 
A severidade de contato (Sc), é expressa pela Equação 2.7 (Adachi e Hutchings, 2003; Hutchings, 1992).

Os resultados obtidos estão em concordância qualitativa com os trabalhos apresentados por Adachi e Hutchings (2003) e Trezona et al. (1999), em relação à transição do modo de desgaste durante o desgaste micro-abrasivo. Em ambos os casos, o desgaste abrasivo por riscamento foi favorecido quando a severidade de contato $(\mathbf{S c})$ aumentou.

As Tabelas 6.4 e 6.5 apresentam os resultados de duas condições de ensaio da segunda série de ensaios preliminares (Tabela 5.5). Na Tabela 6.4 estão as dimensões das calotas esféricas geradas no corpo-de-prova de aço ferramenta $M 2$, para a força normal de $5 \mathrm{~N}$. Na Tabela 6.5 estão as dimensões das crateras de desgaste geradas no corpo-de-prova de $W C$-Co P20, para a força normal de 1,25 N.

Tabela 6.4: Dimensões das crateras de desgaste geradas no corpo-de-prova de aço ferramenta M2, para a força normal de $5 \mathrm{~N}$.

\begin{tabular}{|l|c|c|c|c|c|c|}
\hline GRANDEZA & ENSAIO 1 & ENSAIO 2 & ENSAIO 3 & ENSAIO 4 & MÉDIA & DESVIO-PADRÃO \\
\hline $\boldsymbol{d}[\mathrm{mm}]$ & 0,662 & 0,667 & 0,647 & 0,682 & 0,665 & 0,014 \\
\hline $\boldsymbol{h}[\mu \mathrm{m}]$ & 4,3 & 4,4 & 4,1 & 4,6 & 4,3 & $(1)$ \\
\hline $\boldsymbol{V}\left[10^{-3} \mathrm{~mm}^{3}\right]$ & 0,742 & 0,765 & 0,677 & 0,836 & 0,755 & $(1)$ \\
\hline
\end{tabular}

(1): Ver observações da Tabela 6.1.

Tabela 6.5: Dimensões das crateras de desgaste geradas no corpo-de-prova de WC-Co P20, para a força normal de 1,25 $\mathrm{N}$.

\begin{tabular}{|l|c|c|c|c|c|c|}
\hline GRANDEZA & ENSAIO 1 & ENSAIO 2 & ENSAIO 3 & ENSAIO 4 & MÉDIA & DESVIO-PADRÃO \\
\hline $\boldsymbol{d}[\mathrm{mm}]$ & 0,587 & 0,605 & 0,619 & 0,611 & 0,606 & 0,014 \\
\hline $\boldsymbol{h}[\mu \mathrm{m}]$ & 3,4 & 3,6 & 3,8 & 3,7 & 3,6 & $(1)$ \\
\hline $\boldsymbol{V}\left[10^{-3} \mathrm{~mm}^{3}\right]$ & 0,459 & 0,518 & 0,567 & 0,539 & 0,521 & $(1)$ \\
\hline
\end{tabular}

(1): Ver observações da Tabela 6.1.

Nota-se, pelos resultados apresentados nas Tabelas 6.4 e 6.5, que o equipamento está proporcionando resultados reprodutíveis, mesmo quando observou-se uma pequena diferença na forma da cratera de desgaste (Figura 6.8 - quarta repetição com carga de $5 \mathrm{~N}$ ). Os valores dos desvios-padrão relatados nas Tabelas 6.4 e 6.5 foram os mesmos observados nas Tabelas $6.1 \mathrm{e}$ 6.3, no Item 6.1. 
A distância de deslizamento adotada nesses ensaios foi de 6 metros. Esse valor é menor do que o definido para os ensaios do Item 6.1. Devido a essa baixa distância de deslizamento, as crateras de desgaste apresentaram borda difusa, como pode ser observado na Figura 6.7. Isso pode ser um indício de que o processo de desgaste não atingiu o regime permanente. Nesse item (Item 6.2), essa questão não foi estudada (todos os ensaios foram conduzidos com a mesma distância de deslizamento).

O material da esfera de ensaio pode vir a ser um fator limitante durante os ensaios. O aço AISI 1010 cementado pode não ser um bom material para estes ensaios, pois a dureza de sua superfície diminui gradualmente com o decorrer do ensaio. Mesmo com a similaridade nos volumes de desgaste ao longo das quatro repetições, as pequenas diferenças na circularidade das crateras de ensaio observadas na quarta repetição (para ambos corpos-de-prova) podem ser uma indicação do desgaste da esfera. No caso de superfícies cementadas, o desgaste resulta em uma diminuição da dureza da superfície durante cada ensaio, que pode introduzir erros experimentais. 
Você pode ter defeitos, viver ansioso e ficar irritado algumas vezes, mas não se esqueça de que sua vida é a maior empresa do mundo. Só você pode evitar que ela vá à falência. Há muitas pessoas que precisam, admiram e torcem por você.

Gostaria que você sempre se lembrasse de que ser feliz não é ter um céu sem tempestades, caminhos sem acidentes, trabalhos sem fadigas, relacionamentos sem decepções.

Ser feliz é encontrar força no perdão, esperança nas batalhas, segurança no palco do medo, amor nos desencontros.

Ser feliz não é apenas valorizar o sorriso, mas refletir sobre a tristeza. Não é apenas comemorar o sucesso, mas aprender lições nos fracassos. Não é apenas ter júbilo nos aplausos, mas encontrar alegria no anonimato.

Ser feliz é reconhecer que vale a pena viver a vida, apesar de todos os desafios, incompreensões e períodos de crise.

Ser feliz não é uma fatalidade do destino, mas uma conquista de quem sabe viajar para dentro do seu próprio ser.

Ser feliz é deixar de ser vítima dos problemas e se tornar um autor da própria história. É atravessar desertos fora de si, mas ser capaz de encontrar um oásis no recôndito da sua alma. É agradecer a Deus a cada manhã pelo milagre da vida.

Ser feliz é não ter medo dos próprios sentimentos. É saber falar de si mesmo. É ter coragem para ouvir um "não". É ter segurança para receber uma crítica, mesmo que injusta. É beijar os filhos, curtir os pais e ter momentos poéticos com os amigos, mesmo que eles nos magoem.

Ser feliz é deixar viver a criança livre, alegre e simples que mora dentro de cada um de nós. É ter maturidade para falar "eu errei". É ter ousadia para dizer "me perdoe". É ter sensibilidade para expressar "eu preciso de você". É ter capacidade de dizer "eu te amo".

Desejo que a vida se torne um canteiro de oportunidades para você ser feliz. Que nas suas primaveras, você seja amante da alegria. Que nos seus invernos, você seja amigo da sabedoria e, quando você errar o caminho, recomece tudo de novo. Pois assim, você será cada vez mais apaixonado pela vida e descobrirá que ser feliz não é ter uma vida perfeita, mas usar as lágrimas para irrigar a tolerância. Usar as perdas para refinar a paciência. Usar as falhas para esculpir a serenidade. Usar a dor para lapidar o prazer. Usar os obstáculos para abrir as janelas da inteligência.

Jamais desista de si mesmo. Jamais desista das pessoas que você ama. Jamais desista de ser feliz, pois a vida é um espetáculo imperdível. E você é um ser humano especial! 


\section{CAPÍTULO 7 - ENSAIOS DEFINITIVOS - RESULTADOS E DISCUSSÃO}

\subsection{ESTUDO DA RELAÇÃO DO QUOCIENTE $A_{R O L} / A_{R I S}$ COM A DISTÂNCIA DE DESLIZAMENTO}

\subsubsection{Corpos-de-prova de HSS M2 - Resultados obtidos pelo Método 1}

A Tabela 7.1 apresenta os valores de $\boldsymbol{d}, \boldsymbol{A}_{\boldsymbol{t}}, \boldsymbol{A}_{\boldsymbol{R I S}}, \boldsymbol{A}_{\boldsymbol{R O L}}$ e $\boldsymbol{A}_{\boldsymbol{R O L}} / \boldsymbol{A}_{\boldsymbol{R} I S}$, para cada distância de deslizamento. As áreas $\boldsymbol{A}_{t}, \boldsymbol{A}_{R I S}$ e $\boldsymbol{A}_{\boldsymbol{R} O L}$ foram obtidas pelo Método 1 .

Tabela 7.1: Resultados obtidos com os corpos-de-prova de HSS M2, pelo Método 1.

\begin{tabular}{|c|c|c|c|c|c|c|c|}
\hline DIST. DESL. (S) & GRANDEZA & ENSAIO 1 & ENSAIO 2 & ENSAIO 3 & ENSAIO 4 & MÉDIA & DESV. PAD. \\
\hline \multirow{5}{*}{8 metros } & $\boldsymbol{d}[\mathrm{mm}]$ & 1,023 & 1,090 & 1,055 & 1,105 & 1,068 & $0,037^{(1)}$ \\
\hline & $\boldsymbol{A}_{t}\left[\mathrm{~mm}^{2}\right]$ & 0,822 & 0,933 & 0,874 & 0,959 & 0,897 & - \\
\hline & $\boldsymbol{A}_{\boldsymbol{R} I S}\left[\mathrm{~mm}^{2}\right]$ & $0^{(2)}$ & $0^{(2)}$ & $0^{(2)}$ & $0^{(2)}$ & $0^{(2)}$ & $0^{(1)}$ \\
\hline & $\boldsymbol{A}_{\boldsymbol{R O L}}\left[\mathrm{mm}^{2}\right]$ & 0,822 & 0,933 & 0,874 & 0,959 & 0,897 & - \\
\hline & $A_{R O L} / A_{R I S}$ & $\rightarrow \infty$ & $\rightarrow \infty$ & $\rightarrow \infty$ & $\rightarrow \infty$ & $\rightarrow \infty$ & - \\
\hline \multirow{5}{*}{15 metros } & $\boldsymbol{d}[\mathrm{mm}]$ & 1,354 & 1,341 & 1,368 & 1,377 & 1,360 & $0,016^{(1)}$ \\
\hline & $\boldsymbol{A}_{t}\left[\mathrm{~mm}^{2}\right]$ & 1,440 & 1,412 & 1,470 & 1,489 & 1,453 & - \\
\hline & $\boldsymbol{A}_{\boldsymbol{R} I S}\left[\mathrm{~mm}^{2}\right]$ & 0,615 & 0,979 & 0,875 & 0,772 & 0,810 & $0,155^{(1)}$ \\
\hline & $\boldsymbol{A}_{\boldsymbol{R O L}}\left[\mathrm{mm}^{2}\right]$ & 0,825 & 0,433 & 0,595 & 0,717 & 0,643 & - \\
\hline & $A_{R O L} / A_{R I S}$ & 1,341 & 0,443 & 0,680 & 0,929 & 0,848 & - \\
\hline \multirow{5}{*}{20 metros } & $\boldsymbol{d}[\mathrm{mm}]$ & 1,441 & 1,399 & 1,408 & 1,423 & 1,418 & $0,018^{(1)}$ \\
\hline & $\boldsymbol{A}_{t}\left[\mathrm{~mm}^{2}\right]$ & 1,631 & 1,537 & 1,557 & 1,590 & 1,579 & - \\
\hline & $\boldsymbol{A}_{\boldsymbol{R} I S}\left[\mathrm{~mm}^{2}\right]$ & 0,194 & 0,135 & 0,149 & 0,162 & 0,160 & $0,025^{(1)}$ \\
\hline & $\boldsymbol{A}_{R O L}\left[\mathrm{~mm}^{2}\right]$ & 1,437 & 1,402 & 1,408 & 1,428 & 1,419 & - \\
\hline & $A_{R O L} / A_{R I S}$ & 7,407 & 10,387 & 9,450 & 8,817 & 9,015 & - \\
\hline \multirow{5}{*}{25 metros } & $\boldsymbol{d}[\mathrm{mm}]$ & 1,455 & 1,487 & 1,458 & 1,477 & 1,469 & $0,015^{(1)}$ \\
\hline & $\boldsymbol{A}_{t}\left[\mathrm{~mm}^{2}\right]$ & 1,663 & 1,737 & 1,670 & 1,713 & 1,696 & - \\
\hline & $\boldsymbol{A}_{R I S}\left[\mathrm{~mm}^{2}\right]$ & 0,455 & 0,660 & 0,682 & 0,578 & 0,594 & $0,103^{(1)}$ \\
\hline & $\boldsymbol{A}_{R O L}\left[\mathrm{~mm}^{2}\right]$ & 1,208 & 1,077 & 0,988 & 1,135 & 1,102 & - \\
\hline & $A_{R O L} / A_{R I S}$ & 2,654 & 1,631 & 1,448 & 1,964 & 1,924 & - \\
\hline \multirow{5}{*}{35 metros } & $\boldsymbol{d}[\mathrm{mm}]$ & 1,426 & 1,507 & 1,391 & 1,451 & 1,444 & $0,049^{(1)}$ \\
\hline & $\boldsymbol{A}_{\boldsymbol{t}}\left[\mathrm{mm}^{2}\right]$ & 1,597 & 1,784 & 1,520 & 1,654 & 1,639 & - \\
\hline & $\boldsymbol{A}_{\boldsymbol{R} I S}\left[\mathrm{~mm}^{2}\right]$ & $0^{(2)}$ & $0^{(2)}$ & $0^{(2)}$ & $0^{(2)}$ & $0^{(2)}$ & $0^{(1)}$ \\
\hline & $\boldsymbol{A}_{R O L}\left[\mathrm{~mm}^{2}\right]$ & 1,597 & 1,784 & 1,520 & 1,654 & 1,639 & - \\
\hline & $A_{R O L} / A_{R I S}$ & $\rightarrow \infty$ & $\rightarrow \infty$ & $\rightarrow \infty$ & $\rightarrow \infty$ & $\rightarrow \infty$ & - \\
\hline \multirow{5}{*}{40 metros } & $\boldsymbol{d}[\mathrm{mm}]$ & 1,911 & 1,955 & 1,990 & 1,994 & 1,963 & $0,039^{(1)}$ \\
\hline & $\boldsymbol{A}_{t}\left[\mathrm{~mm}^{2}\right]$ & 2,868 & 3,002 & 3,110 & 3,123 & 3,026 & - \\
\hline & $\boldsymbol{A}_{R I S}\left[\mathrm{~mm}^{2}\right]$ & $0^{(2)}$ & $0^{(2)}$ & $0^{(2)}$ & $0^{(2)}$ & $0^{(2)}$ & $0^{(1)}$ \\
\hline & $\boldsymbol{A}_{\boldsymbol{R O L}}\left[\mathrm{mm}^{2}\right]$ & 2,868 & 3,002 & 3,110 & 3,123 & 3,026 & - \\
\hline & $A_{R O L} / A_{R I S}$ & $\rightarrow \infty$ & $\rightarrow \infty$ & $\rightarrow \infty$ & $\rightarrow \infty$ & $\rightarrow \infty$ & - \\
\hline
\end{tabular}

(1): O desvio-padrão foi calculado somente para as grandezas que foram medidas no microscópio óptico ( $\boldsymbol{d}$ e $\left.\boldsymbol{A}_{\boldsymbol{R I S}}\right)$; (2): O modo de desgaste abrasivo foi totalmente por rolamento. 
A Figura 7.1 apresenta a dependência do quociente $\boldsymbol{A}_{R O L} / \boldsymbol{A}_{\boldsymbol{R} I S}$ com a distância de deslizamento, para os corpos-de-prova de aço ferramenta M2. Os resultados foram obtidos pelo Método 1.

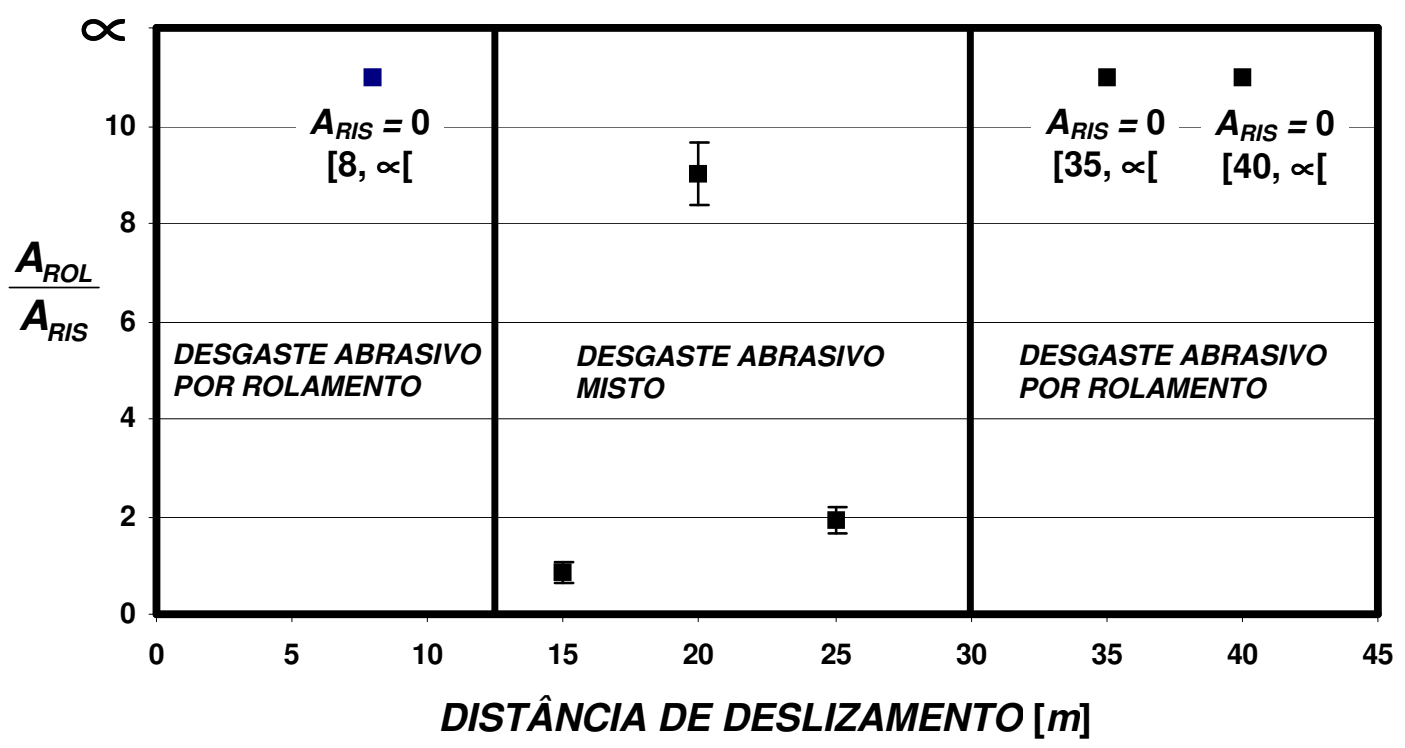

Figura 7.1: Dependência de $A_{R O L} / A_{R I S}$ com a distância de deslizamento, para os corpos-de-prova de aço ferramenta M2. Resultados obtidos pelo Método 1.

As Figuras 7.2 à 7.11 mostram algumas crateras de desgaste geradas durante os ensaios com os corpos-de-prova de aço ferramenta M2.

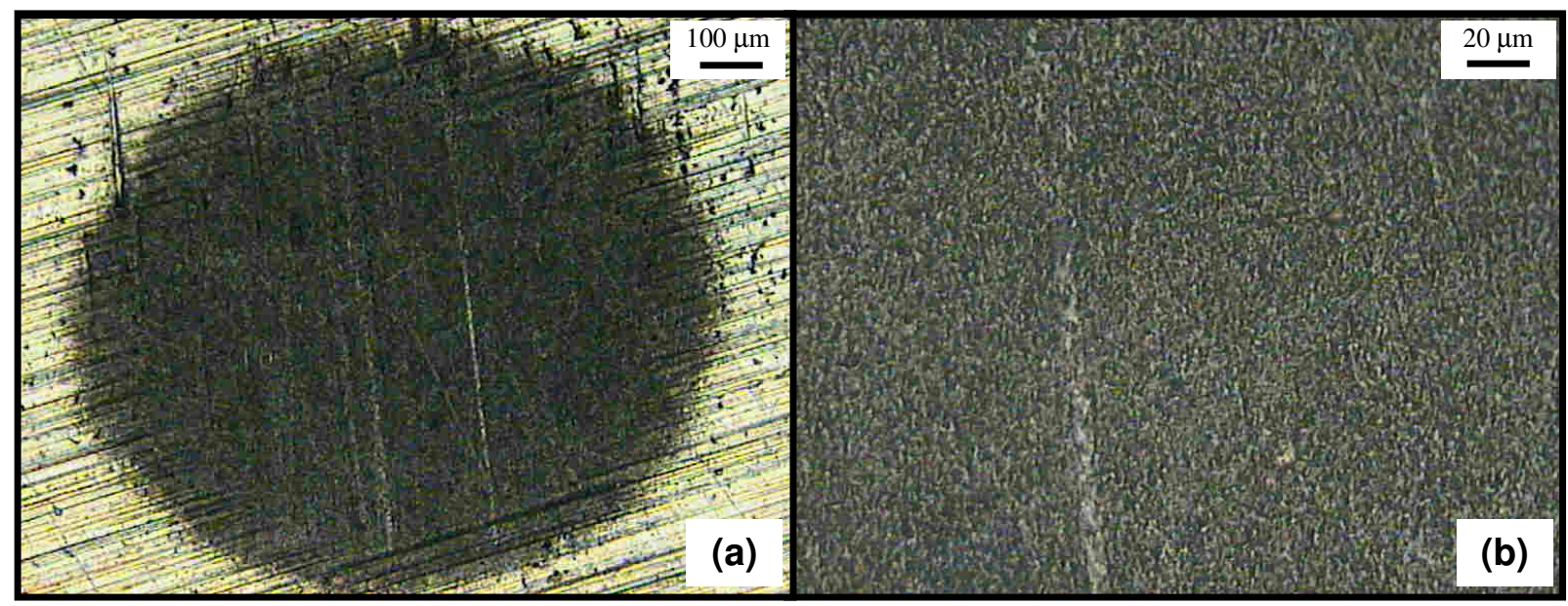

Figura 7.2: Corpo-de-prova de aço ferramenta M2. (a) Cratera de desgaste gerada com uma distância de deslizamento de 8 metros. (b) Ampliação de (a), exibindo a atuação de desgaste abrasivo por rolamento. 


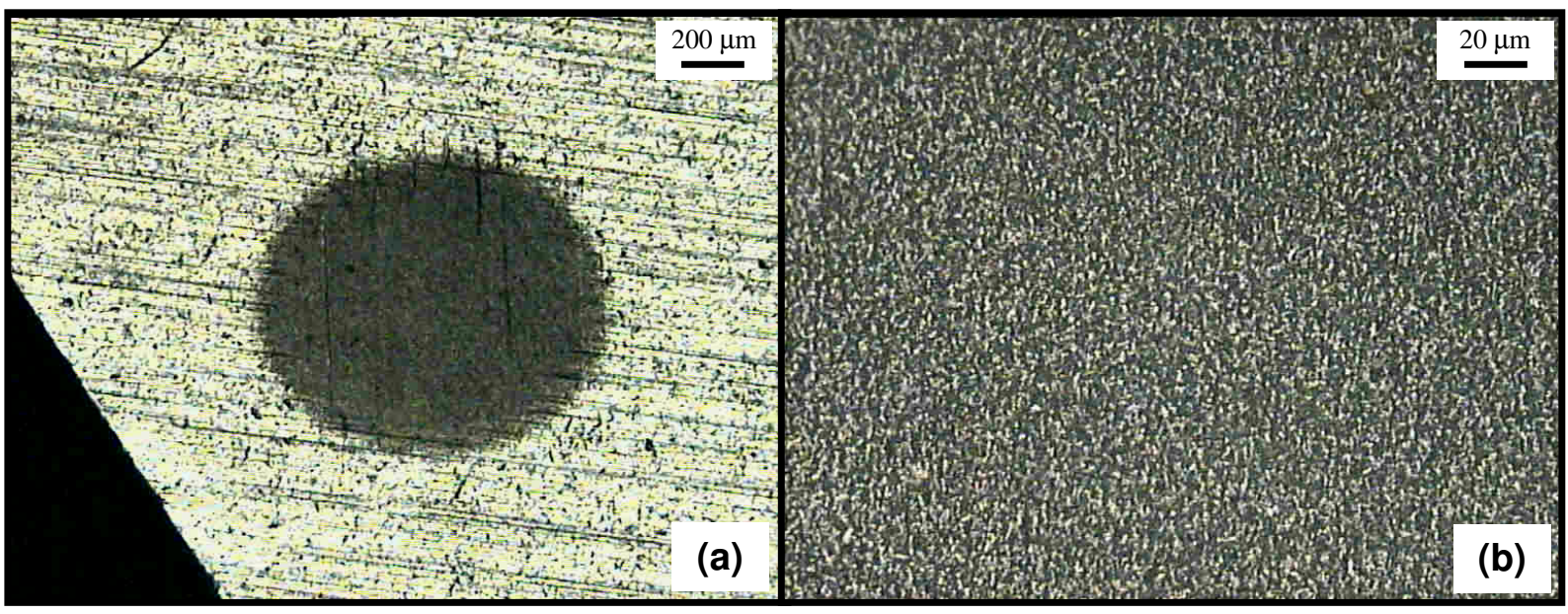

Figura 7.3: Corpo-de-prova de aço ferramenta M2. (a) Cratera de desgaste gerada com uma distância de deslizamento de 8 metros. (b) Ampliação de (a), exibindo a atuação de desgaste abrasivo por rolamento.

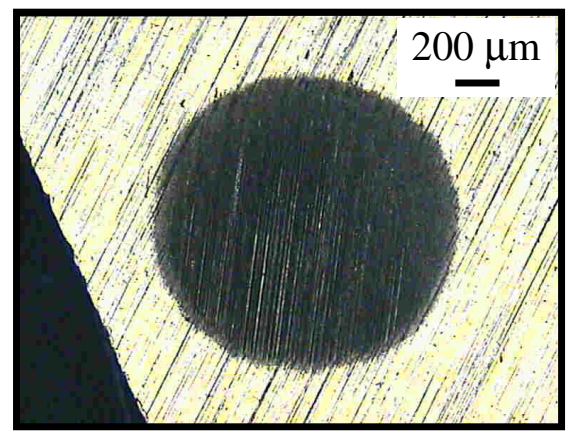

Figura 7.4: Corpo-de-prova de aço ferramenta M2. Cratera de desgaste gerada com uma distância de deslizamento de 15 metros. Atuação de desgaste abrasivo misto.

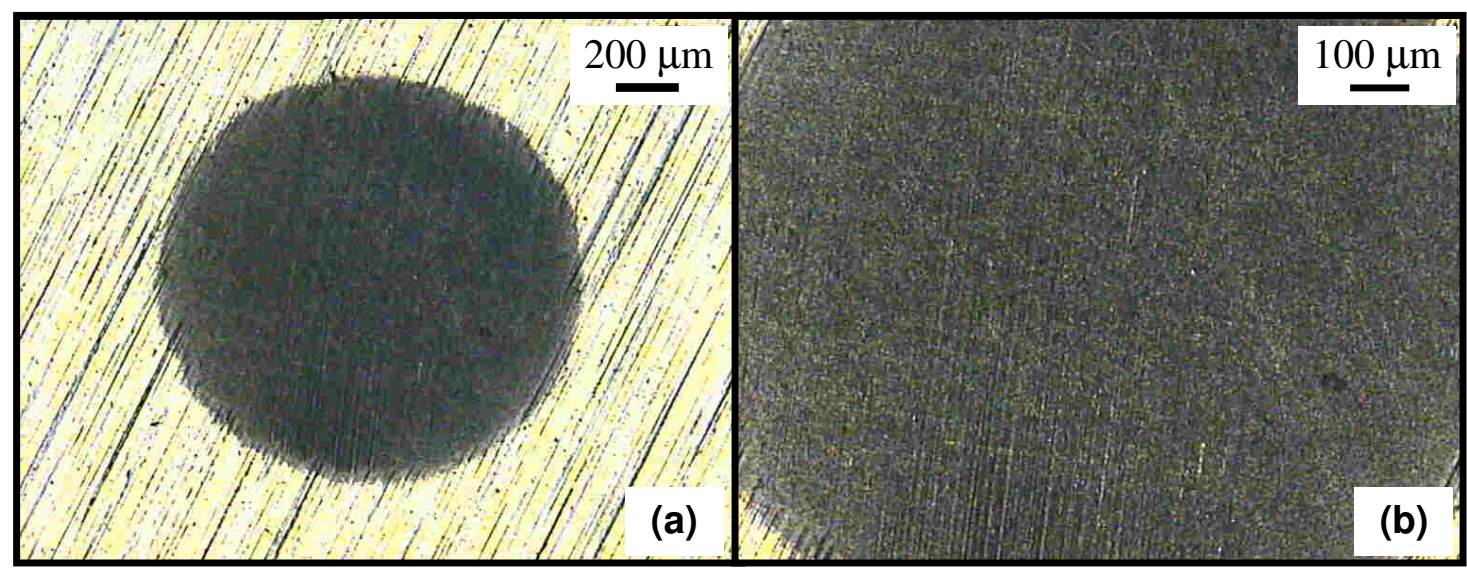

Figura 7.5: Corpo-de-prova de aço ferramenta M2. (a) Cratera de desgaste gerada com uma distância de deslizamento de 20 metros. (b) Ampliação de (a), exibindo a atuação de desgaste abrasivo misto. 


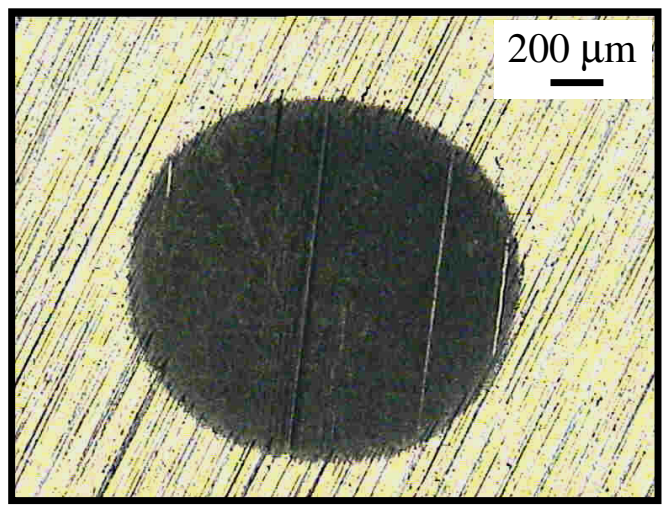

Figura 7.6: Corpo-de-prova de aço ferramenta M2. Cratera de desgaste gerada com uma distância de deslizamento de 25 metros. Atuação de desgaste abrasivo misto.

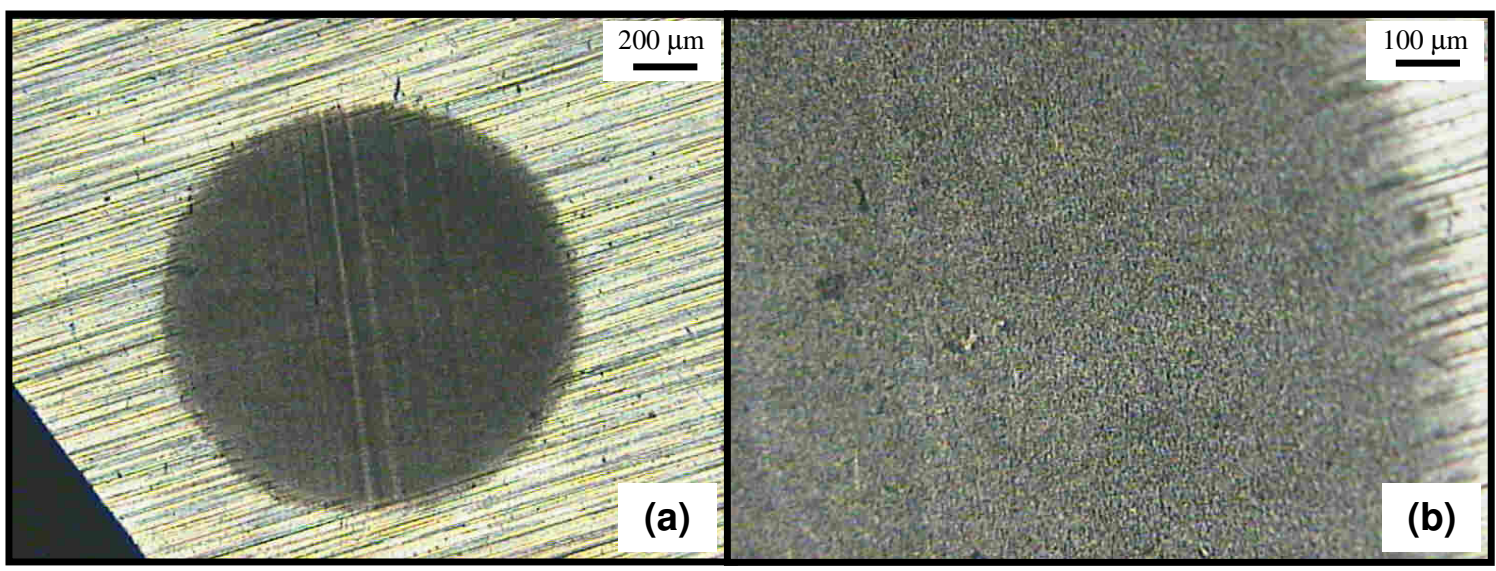

Figura 7.7: Corpo-de-prova de aço ferramenta M2. (a) Cratera de desgaste gerada com uma distância de deslizamento de 35 metros. (b) Ampliação de (a), exibindo a atuação de desgaste abrasivo por rolamento.

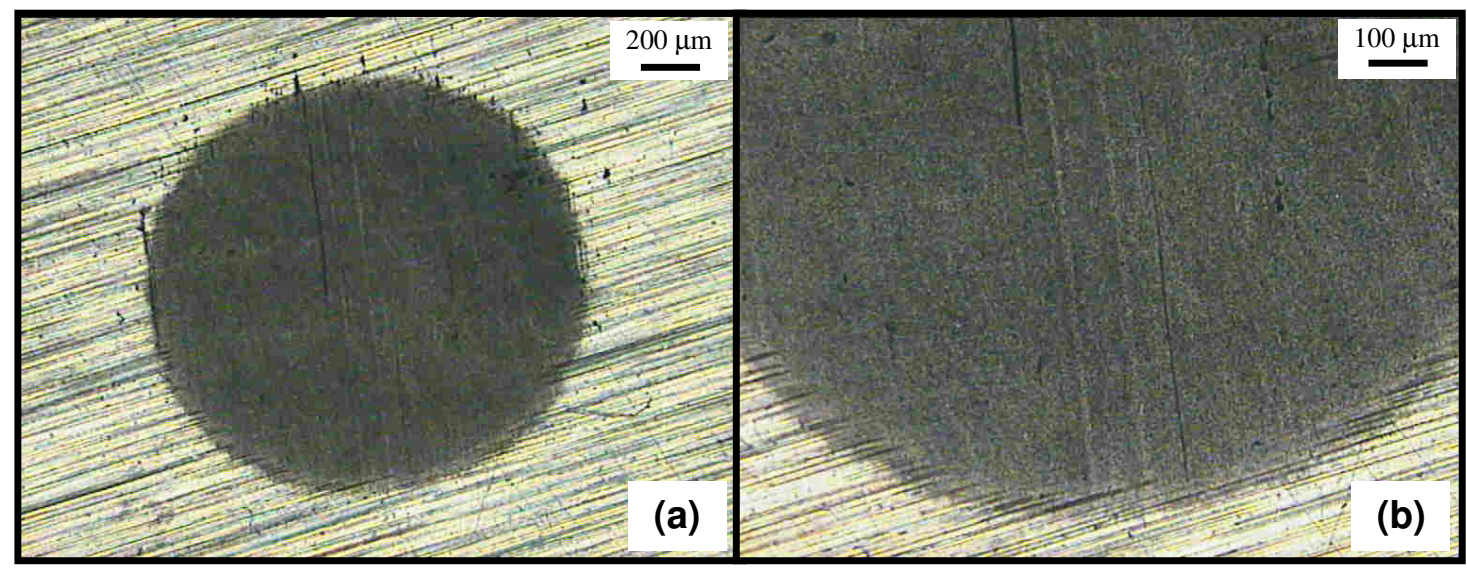

Figura 7.8: Corpo-de-prova de aço ferramenta M2. (a) Cratera de desgaste gerada com uma distância de deslizamento de 35 metros. (b) Ampliação de (a), exibindo a atuação de desgaste abrasivo por rolamento. 


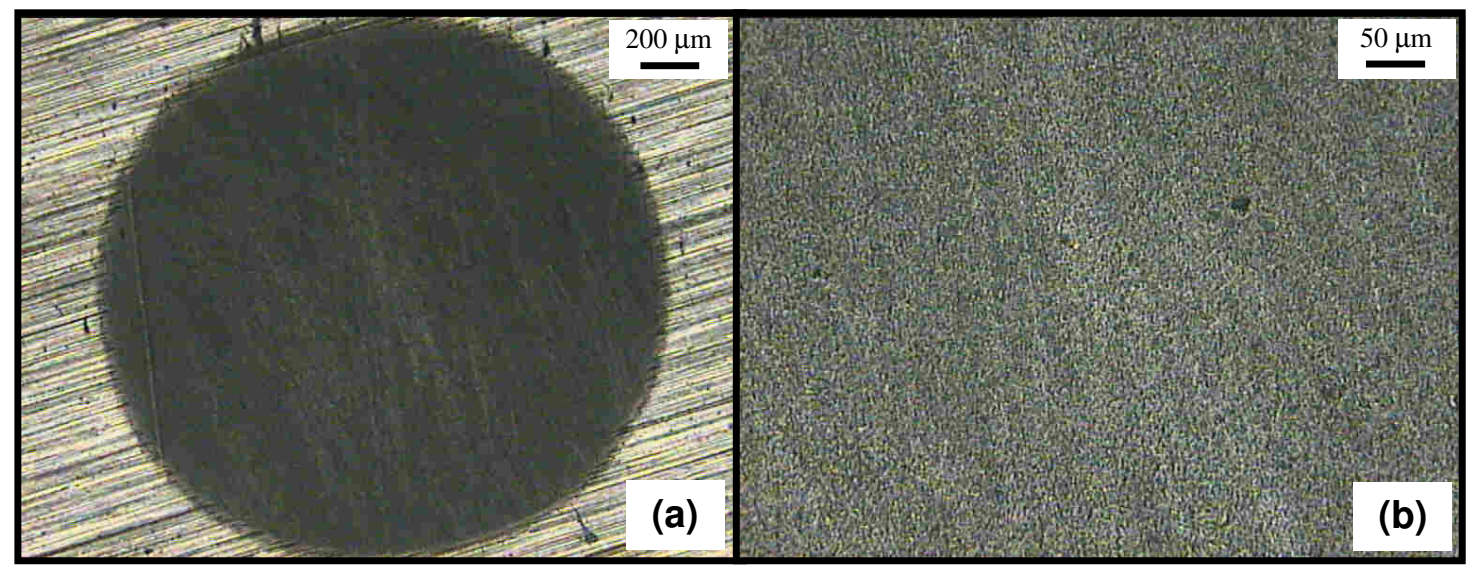

Figura 7.9: Corpo-de-prova de aço ferramenta M2. (a) Cratera de desgaste gerada com uma distância de deslizamento de 40 metros. (b) Ampliação de (a), exibindo a atuação de desgaste abrasivo por rolamento.

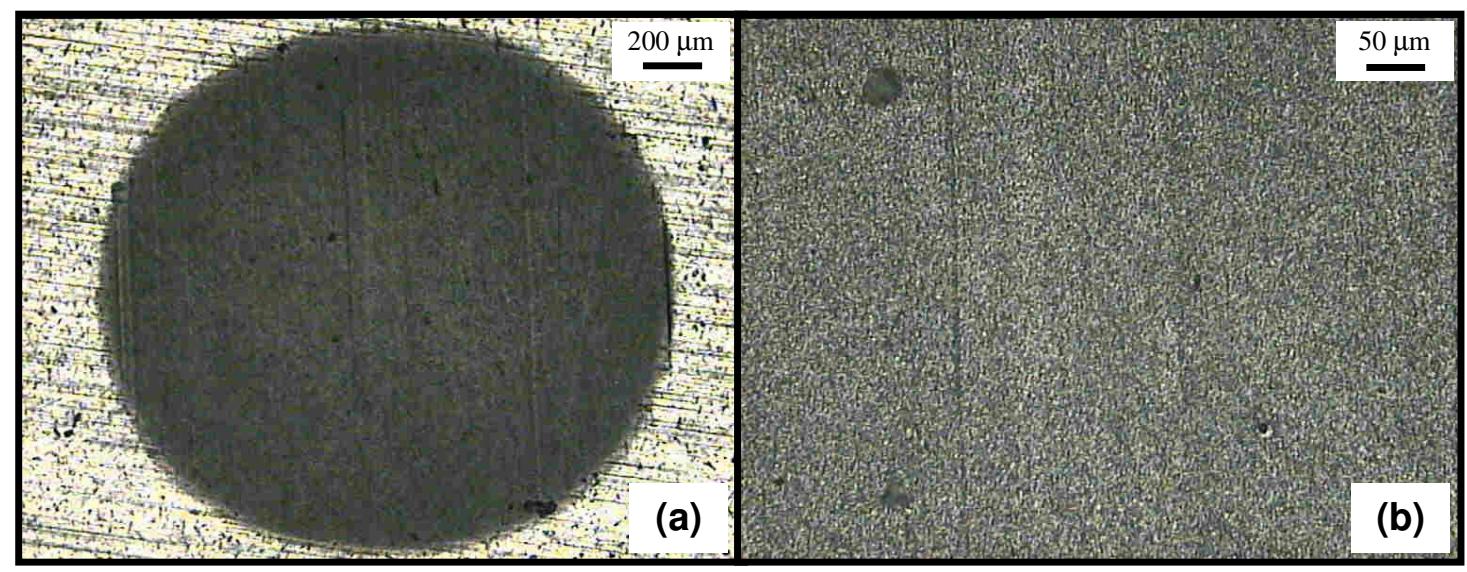

Figura 7.10: Corpo-de-prova de aço ferramenta M2. (a) Cratera de desgaste gerada com uma distância de deslizamento de 40 metros. (b) Ampliação de (a), exibindo a atuação de desgaste abrasivo por rolamento.

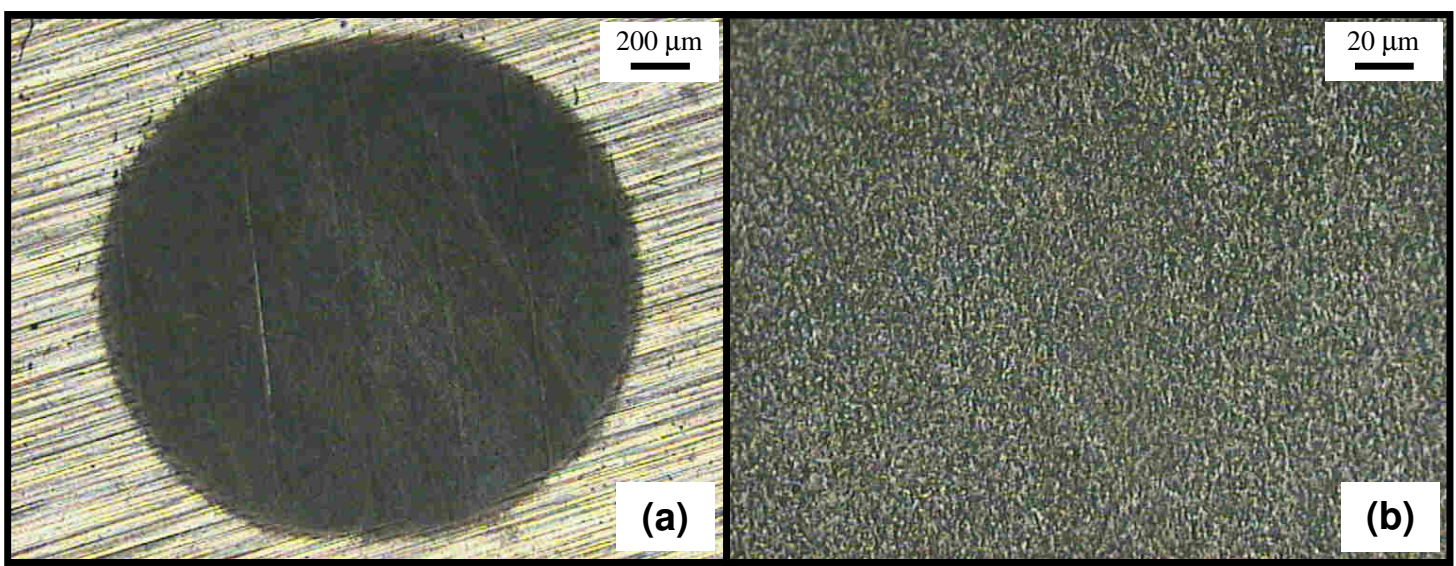

Figura 7.11: Corpo-de-prova de aço ferramenta M2. (a) Cratera de desgaste gerada com uma distância de deslizamento de 40 metros. (b) Ampliação de (a), exibindo a atuação de desgaste abrasivo por rolamento. 


\subsubsection{Corpos-de-prova de HSS M2 - Resultados obtidos pelo Método 2}

A Tabela 7.2 apresenta os valores de $\boldsymbol{A}_{\boldsymbol{t}}, \boldsymbol{A}_{\boldsymbol{R} \boldsymbol{S}}, \boldsymbol{A}_{\boldsymbol{R} O L}$ e $\boldsymbol{A}_{\boldsymbol{R O L}} / \boldsymbol{A}_{\boldsymbol{R} I \boldsymbol{S}}$, para cada distância de deslizamento. As áreas $\boldsymbol{A}_{\boldsymbol{t}}, \boldsymbol{A}_{\boldsymbol{R} \boldsymbol{s}}$ e $\boldsymbol{A}_{\boldsymbol{R} O L}$ foram medidas pelo Método 2.

Tabela 7.2: Resultados obtidos para os corpos-de-prova de HSS M2, pelo Método 2.

\begin{tabular}{|c|c|c|c|c|c|c|c|c|}
\hline DIST. DESL. (S) & GRANDEZA & ENSAIO 1 & ENSAIO 2 & ENSAIO 3 & ENSAIO 4 & MÉDIA & DESV. PAD. & ERRO \\
\hline \multirow{4}{*}{8 metros } & $\boldsymbol{A}_{t}\left[\mathrm{~mm}^{2}\right]$ & 0,709 & 0,811 & 0,669 & 0,601 & 0,698 & 0,088 & 0,044 \\
\hline & $\boldsymbol{A}_{\boldsymbol{R I S}}\left[\mathrm{mm}^{2}\right]$ & $0^{(1)}$ & $0^{(1)}$ & $0^{(1)}$ & $0^{(1)}$ & $0^{(1)}$ & 0 & 0 \\
\hline & $\boldsymbol{A}_{\boldsymbol{R O L}}\left[\mathrm{mm}^{2}\right]$ & 0,709 & 0,811 & 0,669 & 0,601 & 0,698 & 0,088 & 0,044 \\
\hline & $A_{R O L} / A_{R I S}$ & $\rightarrow \infty$ & $\rightarrow \infty$ & $\rightarrow \infty$ & $\rightarrow \infty$ & $\rightarrow \infty$ & - & - \\
\hline \multirow{4}{*}{15 metros } & $\boldsymbol{A}_{t}\left[\mathrm{~mm}^{2}\right]$ & 1,478 & 1,323 & 1,401 & - & 1,401 & 0,078 & 0,045 \\
\hline & $\boldsymbol{A}_{\boldsymbol{R I S}}\left[\mathrm{mm}^{2}\right]$ & 0,611 & 0,433 & 0,567 & - & 0,537 & 0,093 & 0,054 \\
\hline & $\boldsymbol{A}_{R O L}\left[\mathrm{~mm}^{2}\right]$ & 0,925 & 0.945 & 0,759 & - & 0,876 & 0,102 & 0,059 \\
\hline & $A_{R O L} / A_{R I S}$ & 1,514 & 2,182 & 1,339 & - & 1,678 & 0,445 & 0,257 \\
\hline \multirow{4}{*}{20 metros } & $\boldsymbol{A}_{t}\left[\mathrm{~mm}^{2}\right]$ & 1,604 & 1,523 & 1,401 & 1,387 & 1,479 & 0,103 & 0,052 \\
\hline & $\boldsymbol{A}_{\boldsymbol{R I S}}\left[\mathrm{mm}^{2}\right]$ & 0,184 & 0,254 & 0,403 & 0,224 & 0,266 & 0,096 & 0,048 \\
\hline & $\boldsymbol{A}_{\boldsymbol{R O L}}\left[\mathrm{mm}^{2}\right]$ & 1,413 & 1,265 & 1,002 & 1,188 & 1,217 & 0,171 & 0,086 \\
\hline & $A_{R O L} / A_{R I S}$ & 7,679 & 4,980 & 2,486 & 5,304 & 5,112 & 2,124 & 1,062 \\
\hline \multirow{4}{*}{25 metros } & $\boldsymbol{A}_{t}\left[\mathrm{~mm}^{2}\right]$ & 1,686 & 1,711 & 1,650 & - & 1,682 & 0,031 & 0,018 \\
\hline & $\boldsymbol{A}_{R I S}\left[\mathrm{~mm}^{2}\right]$ & 0,255 & 0,412 & 0,338 & - & 0,335 & 0,079 & 0,045 \\
\hline & $\boldsymbol{A}_{R O L}\left[\mathrm{~mm}^{2}\right]$ & 1,436 & 1,277 & 1,289 & - & 1,334 & 0,089 & 0,051 \\
\hline & $A_{R O L} / A_{R I S}$ & 5,631 & 3,100 & 3,814 & - & 4,181 & 1,305 & 0,754 \\
\hline \multirow{4}{*}{35 metros } & $\boldsymbol{A}_{t}\left[\mathrm{~mm}^{2}\right]$ & 1,696 & 1,563 & 1,433 & 1,501 & 1,548 & 0,112 & 0,056 \\
\hline & $\boldsymbol{A}_{\boldsymbol{R} I S}\left[\mathrm{~mm}^{2}\right]$ & $0^{(1)}$ & $0^{(1)}$ & $0^{(1)}$ & $0^{(1)}$ & $0^{(1)}$ & 0 & 0 \\
\hline & $\boldsymbol{A}_{R O L}\left[\mathrm{~mm}^{2}\right]$ & 1,696 & 1,563 & 1,433 & 1,501 & 1,548 & 0,109 & 0,054 \\
\hline & $A_{R O L} / A_{R I S}$ & $\rightarrow \infty$ & $\rightarrow \infty$ & $\rightarrow \infty$ & $\rightarrow \infty$ & $\rightarrow \infty$ & - & - \\
\hline \multirow{4}{*}{40 metros } & $\boldsymbol{A}_{t}\left[\mathrm{~mm}^{2}\right]$ & 2,963 & 2,901 & 2,610 & 2,738 & 2,816 & 0,155 & 0,078 \\
\hline & $\boldsymbol{A}_{\boldsymbol{R I S}}\left[\mathrm{mm}^{2}\right]$ & $0^{(1)}$ & $0^{(1)}$ & $0^{(1)}$ & $0^{(1)}$ & $0^{(1)}$ & 0 & 0 \\
\hline & $\boldsymbol{A}_{\boldsymbol{R O L}}\left[\mathrm{mm}^{2}\right]$ & 2,963 & 2,901 & 2,610 & 2,738 & 2,816 & 0,155 & 0,078 \\
\hline & $A_{R O L} / A_{R I S}$ & $\rightarrow \infty$ & $\rightarrow \infty$ & $\rightarrow \infty$ & $\rightarrow \infty$ & $\rightarrow \infty$ & - & - \\
\hline
\end{tabular}

(1): O modo de desgaste abrasivo foi totalmente por rolamento.

A Figura 7.12 apresenta a dependência do quociente $\boldsymbol{A}_{R O L} / \boldsymbol{A}_{R I S}$ com a distância de deslizamento, para os corpos-de-prova de aço ferramenta M2. Os resultados foram obtidos pelo Método 2. 


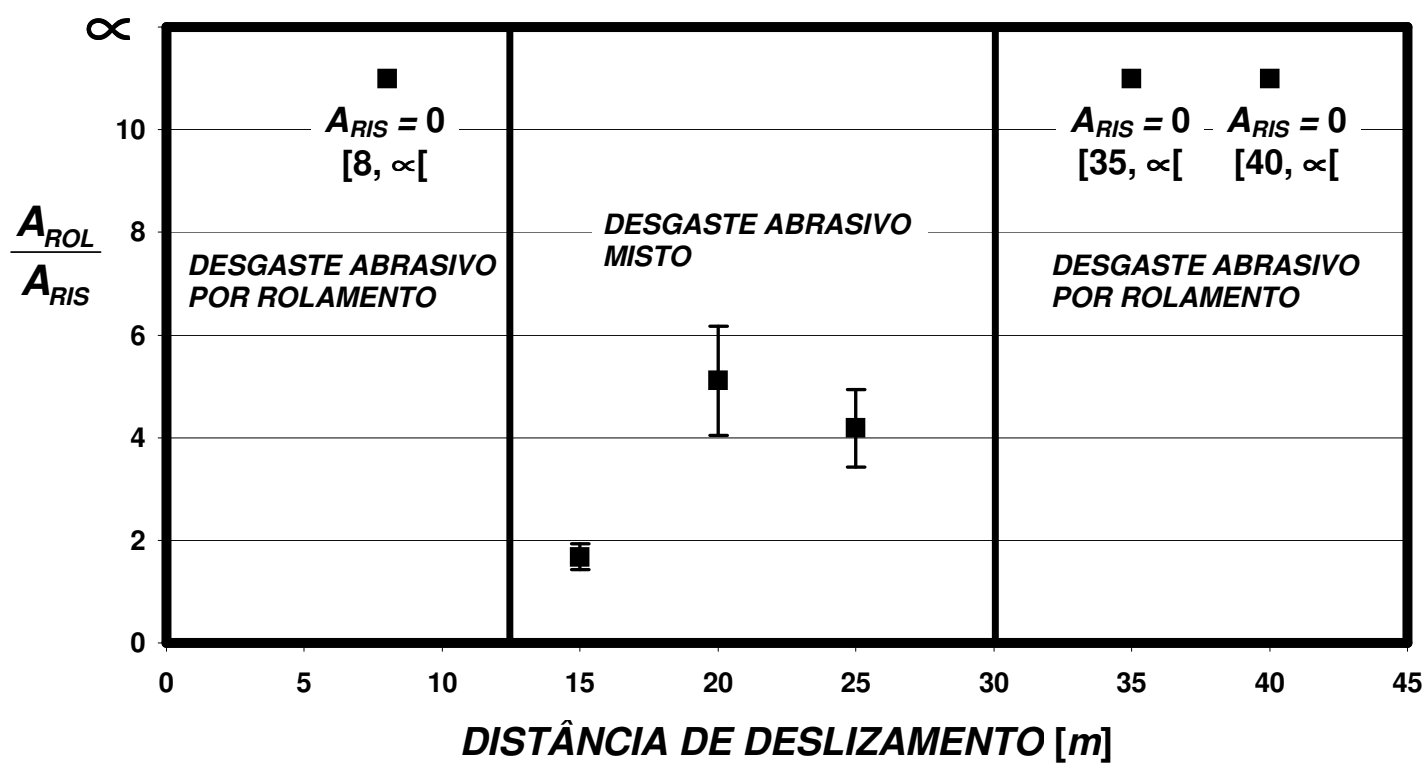

Figura 7.12: Dependência de $A_{R O L} / A_{R I S}$ com a distância de deslizamento, para os corpos-de-prova de aço ferramenta M2. Resultados obtidos pelo Método 2.

As Figuras 7.13 à 7.21 apresentam as áreas $\boldsymbol{A}_{\boldsymbol{t}}, \boldsymbol{A}_{\boldsymbol{R} O L}$ e $\boldsymbol{A}_{\boldsymbol{R} \boldsymbol{S}}$ das crateras de desgaste, medidas pelo Método 2.
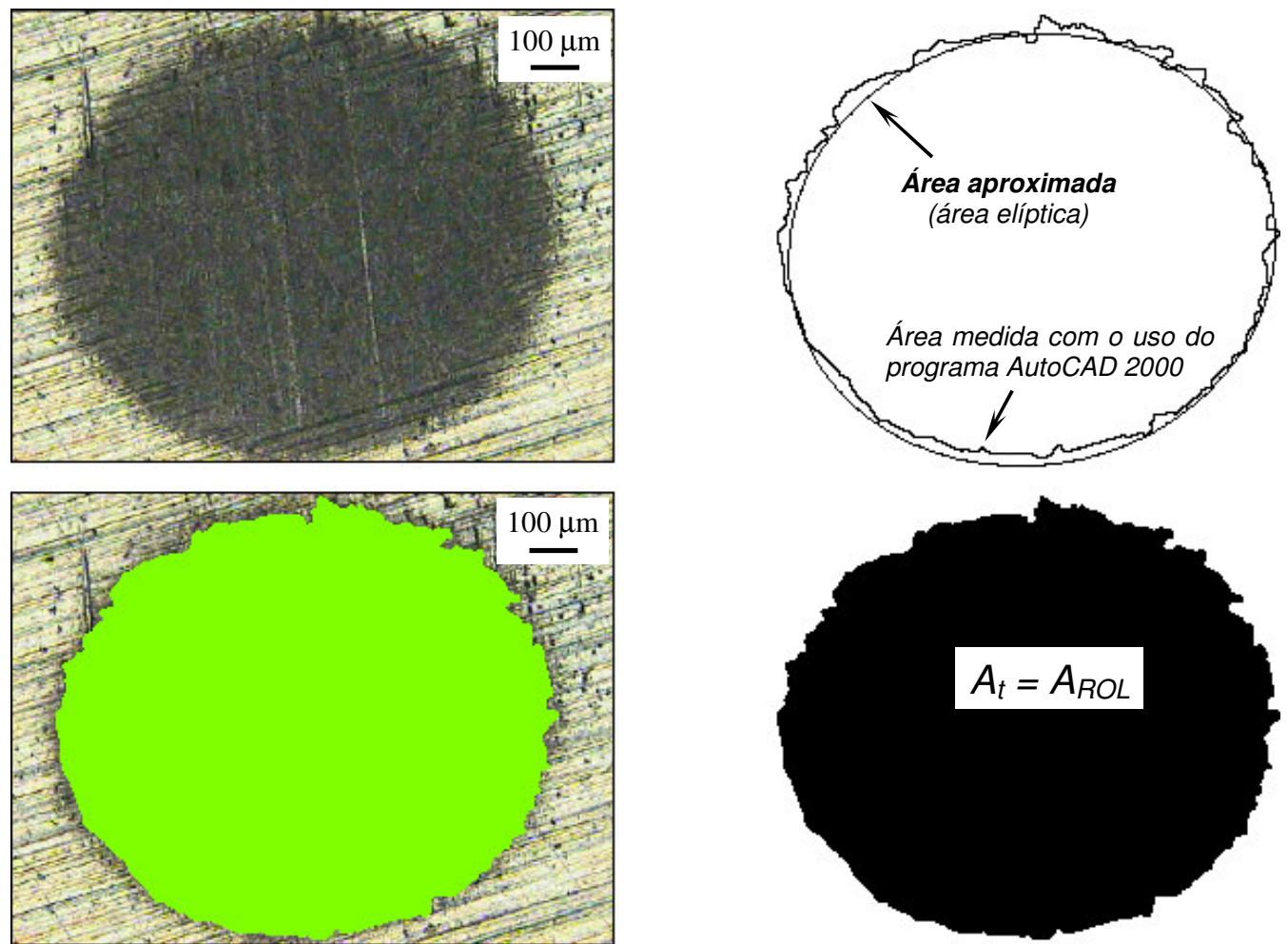

Figura 7.13: Corpo-de-prova de aço ferramenta M2. Distância de deslizamento de 8 metros. A área $A_{t}$ foi medida pelo Método 2. Atuação de desgaste abrasivo por rolamento $\left(A_{t}=A_{R O L}\right)$. 

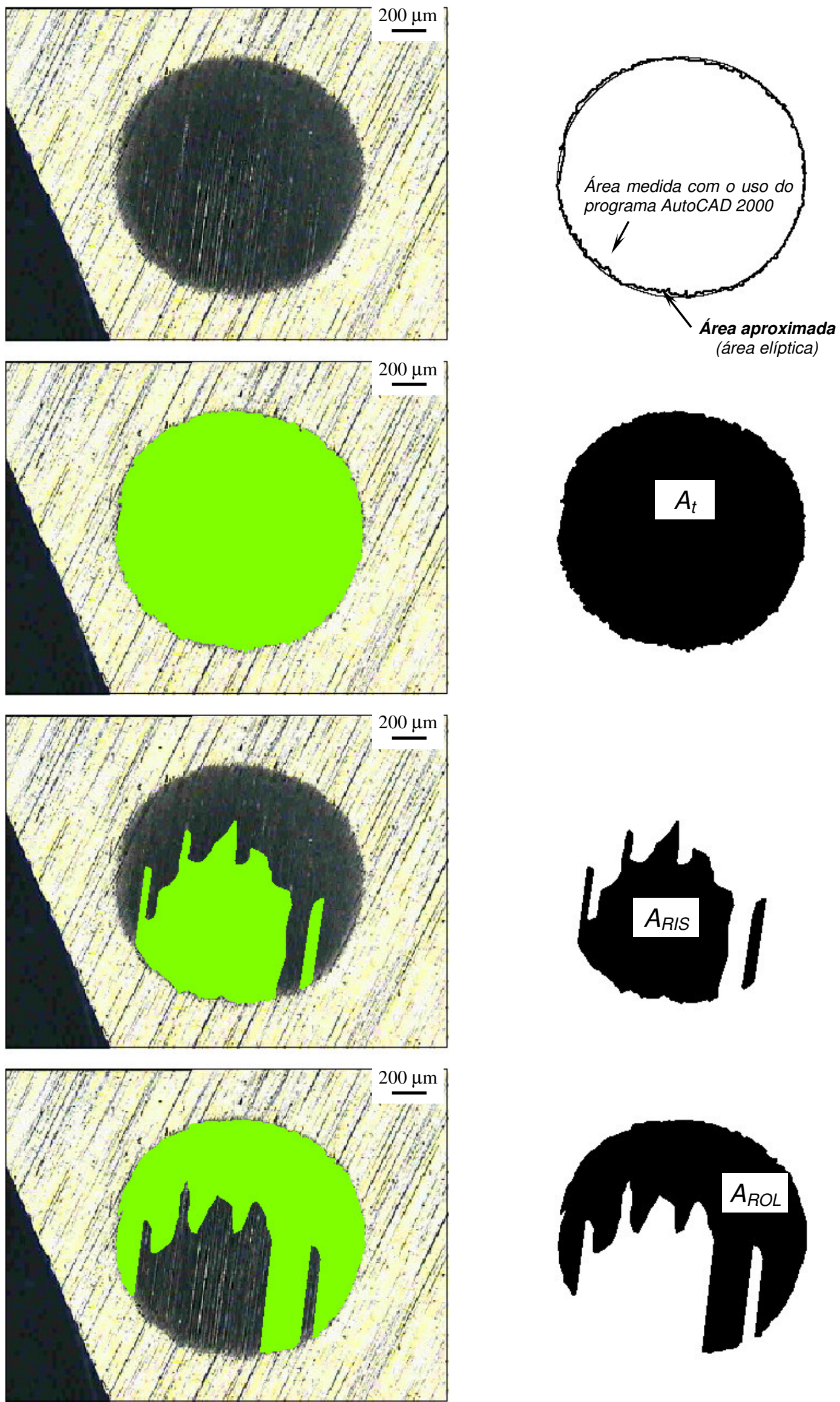

Figura 7.14: Corpo-de-prova de aço ferramenta M2. Distância de deslizamento de 15 metros. As áreas At, $A_{R I S}$ e $A_{R O L}$ foram medidas pelo Método 2. Atuação de desgaste abrasivo misto. 

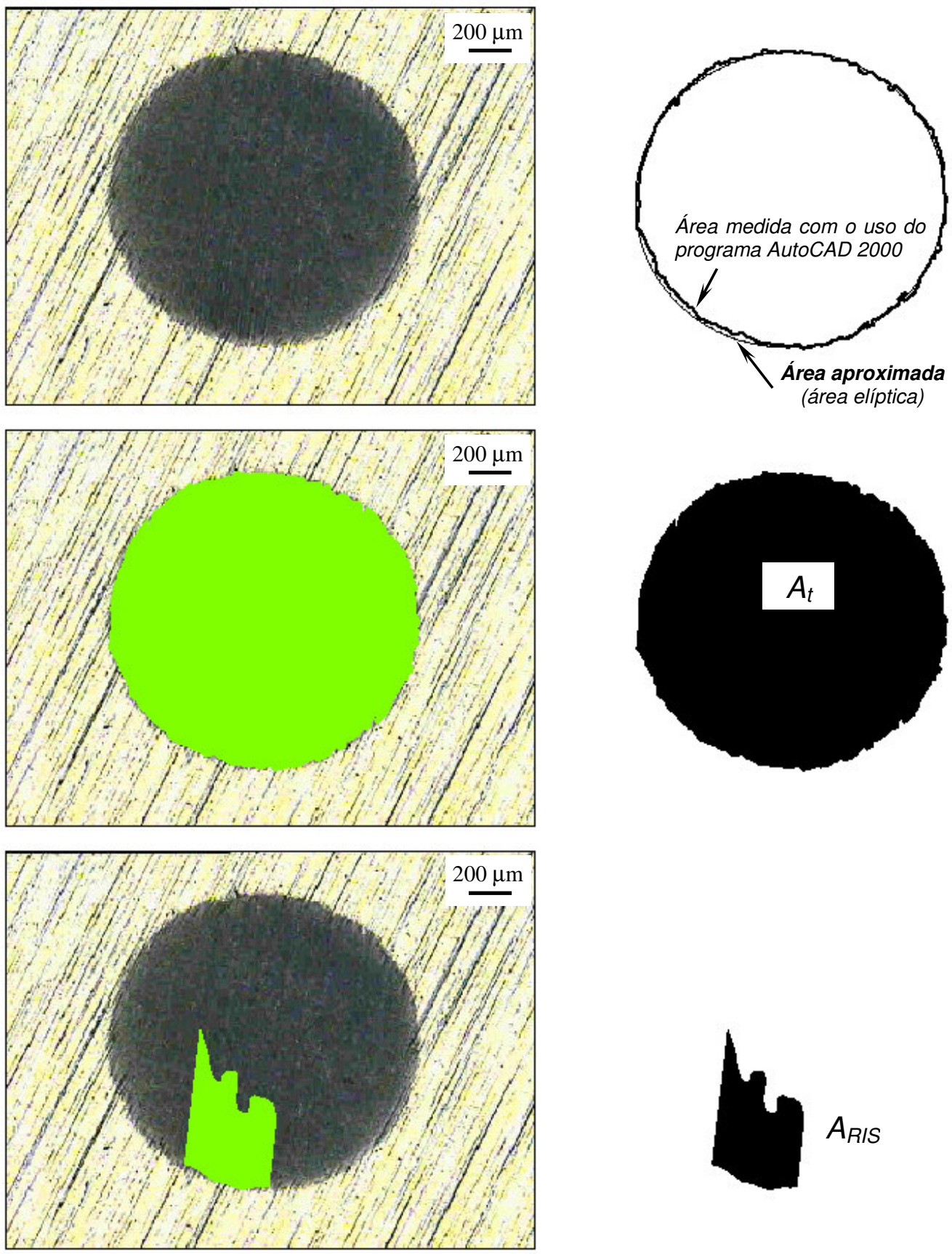

$A_{R I S}$
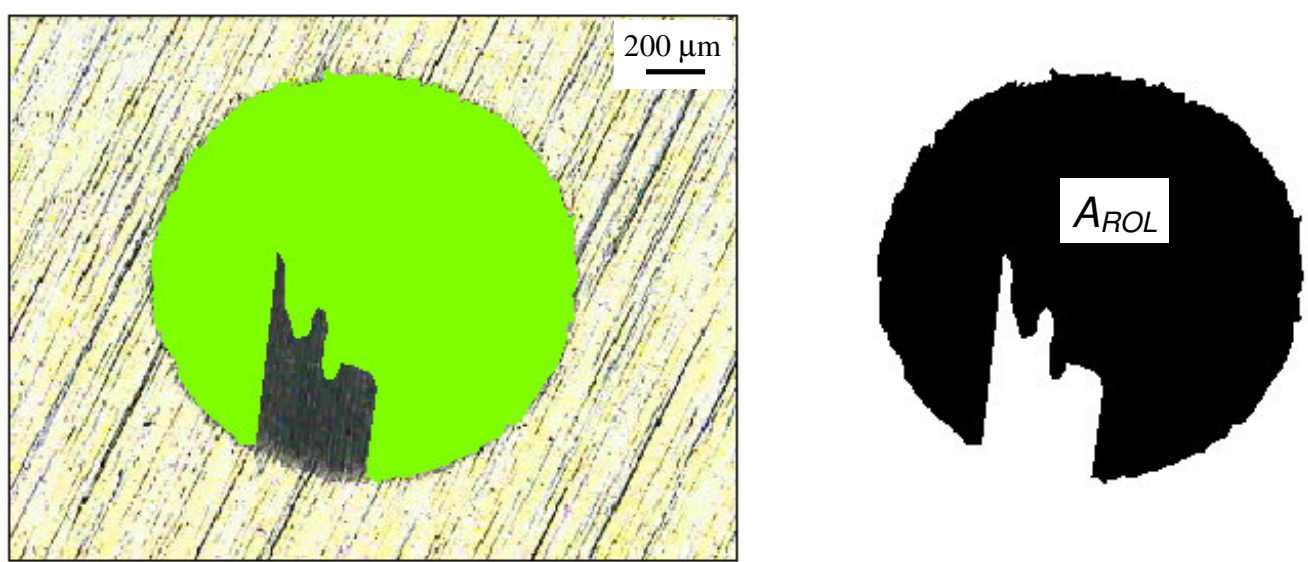

Figura 7.15: Corpo-de-prova de aço ferramenta M2. Distância de deslizamento de 20 metros. As áreas $A_{t}, A_{R I S}$ e $A_{R O L}$ foram medidas pelo Método 2. Atuação de desgaste abrasivo misto. 

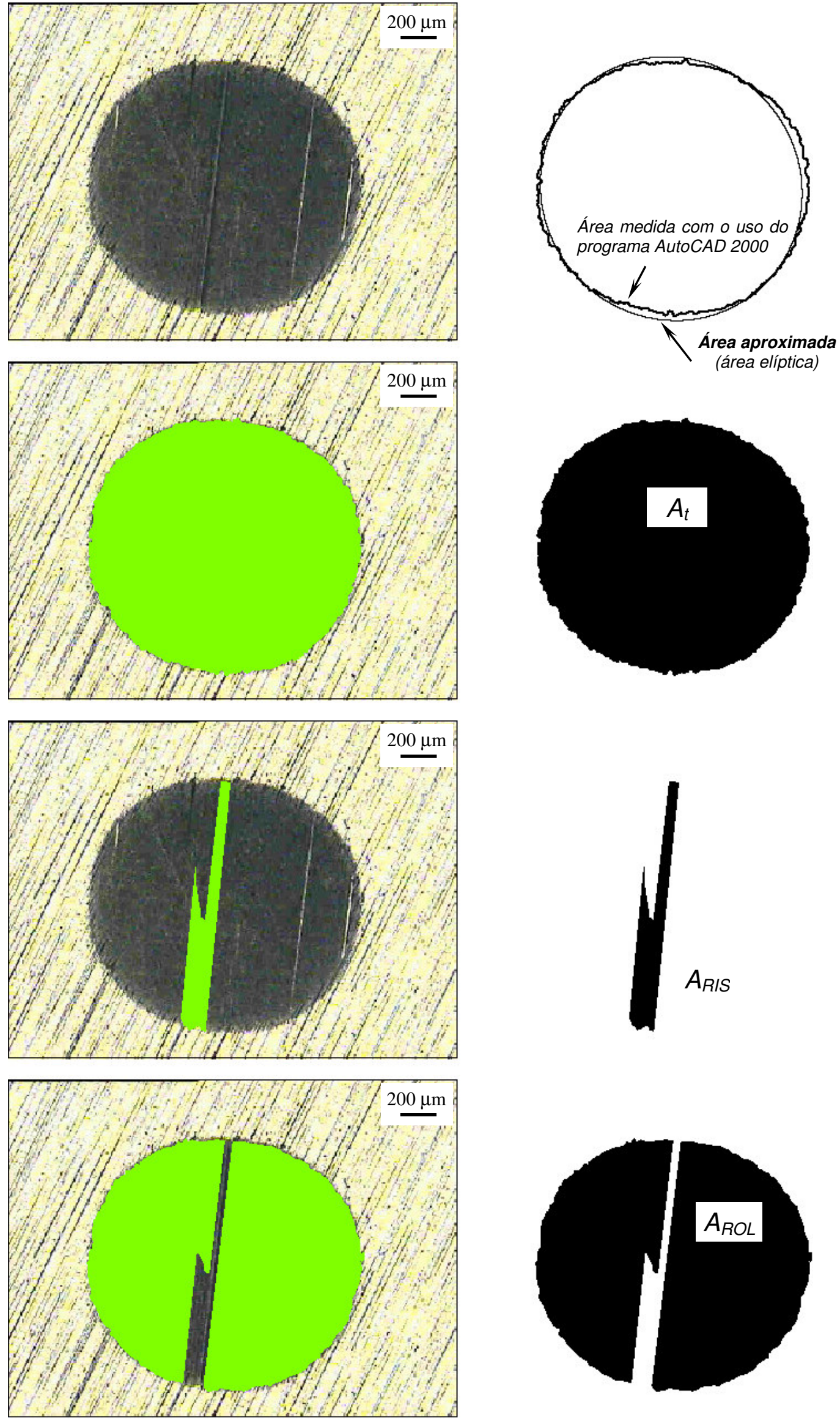

Figura 7.16: Corpo-de-prova de aço ferramenta M2. Distância de deslizamento de 25 metros. As áreas $A_{t}, A_{R I S}$ e $A_{R O L}$ foram medidas pelo Método 2. Atuação de desgaste abrasivo misto. 

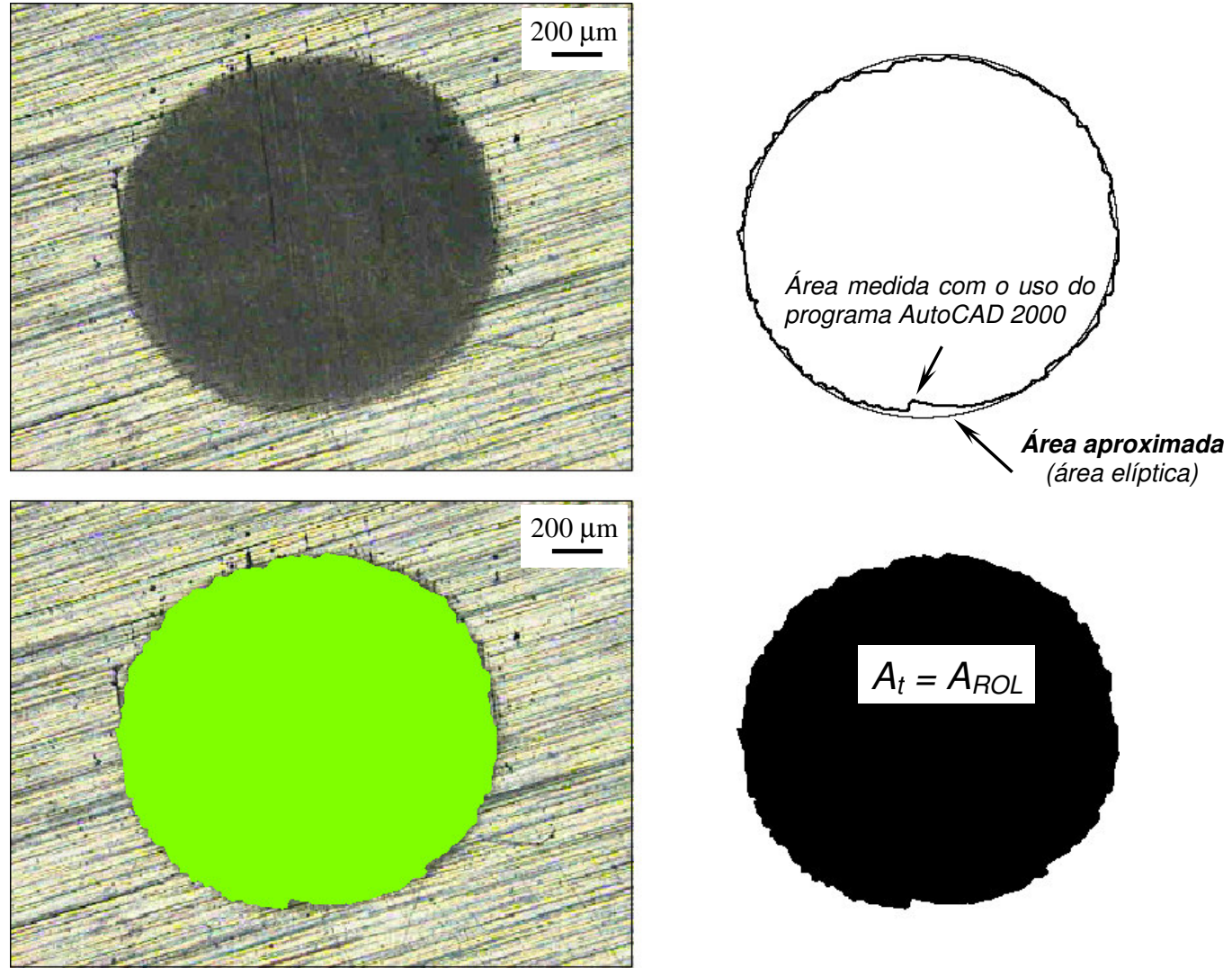

Figura 7.17: Corpo-de-prova de aço ferramenta M2. Distância de deslizamento de 35 metros. $A$ área $A_{t}$ foi medida pelo Método 2. Atuação de desgaste abrasivo por rolamento $\left(A_{t}=A_{R O L}\right)$.
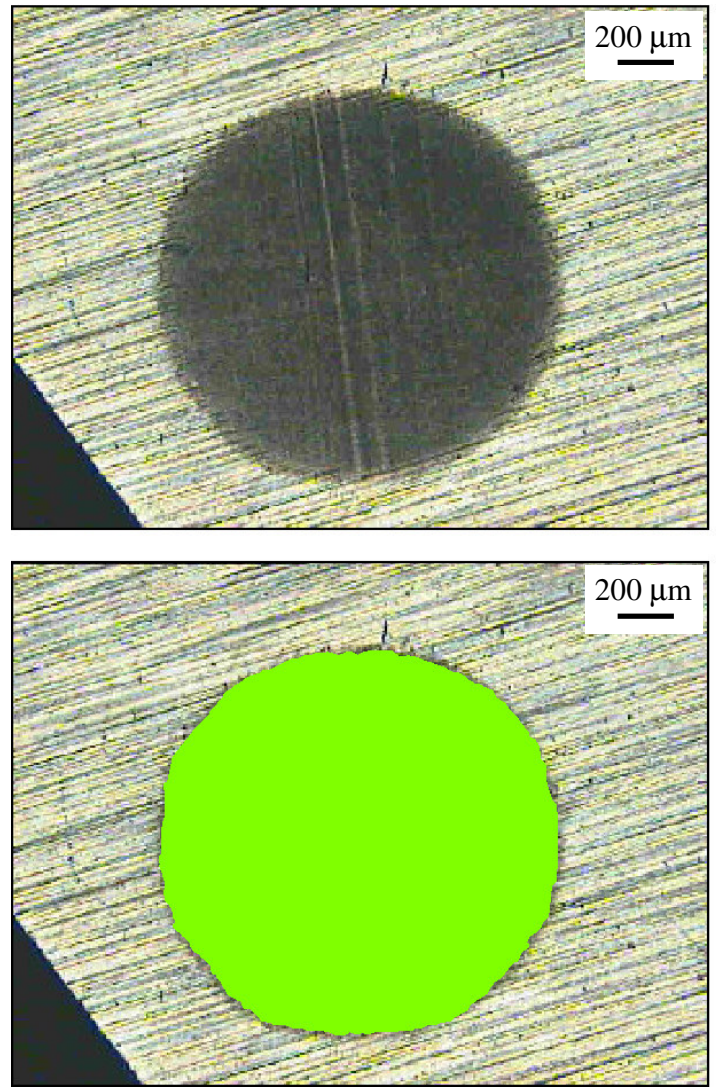

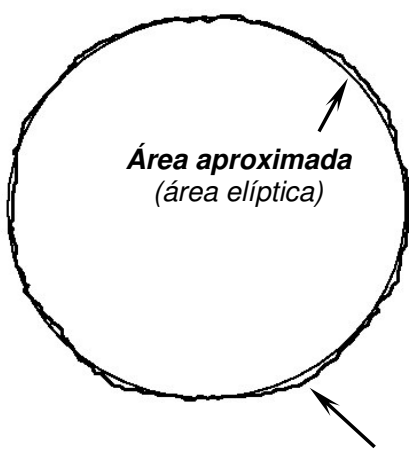

Área medida com o uso do programa AutoCAD 2000

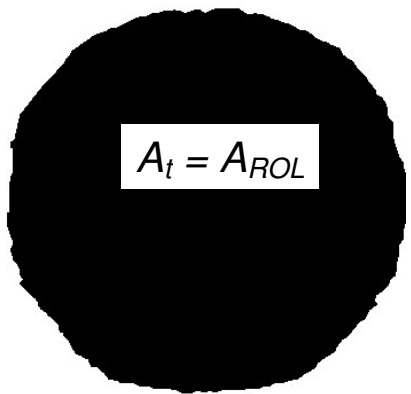

Figura 7.18: Corpo-de-prova de aço ferramenta M2. Distância de deslizamento de 35 metros. $A$ área $A_{t}$ foi medida pelo Método 2. Atuação de desgaste abrasivo por rolamento $\left(A_{t}=A_{R O L}\right)$. 

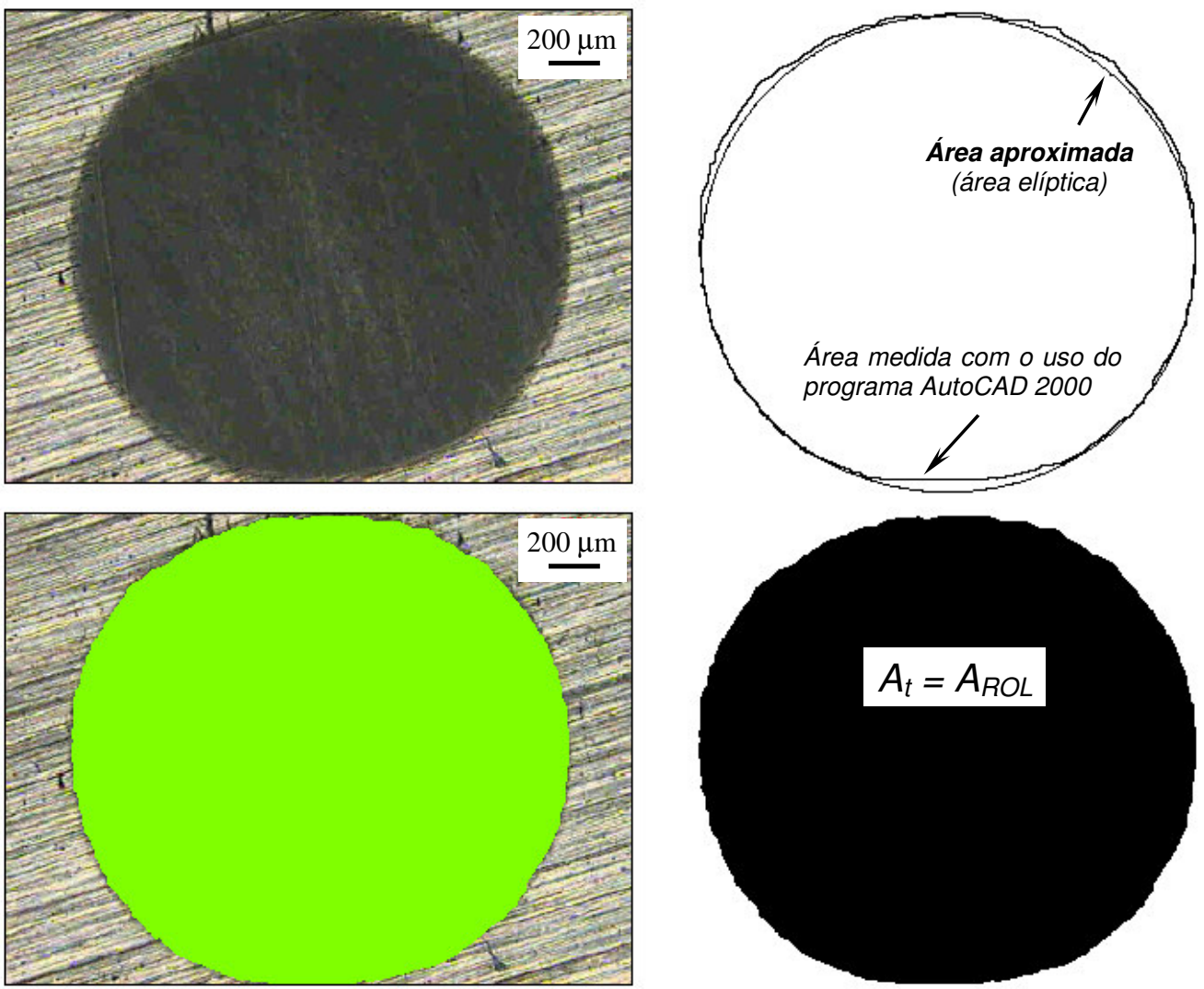

Figura 7.19: Corpo-de-prova de aço ferramenta M2. Distância de deslizamento de 40 metros. $A$ área $A_{t}$ foi medida pelo Método 2. Atuação de desgaste abrasivo por rolamento $\left(A_{t}=A_{R O L}\right)$.
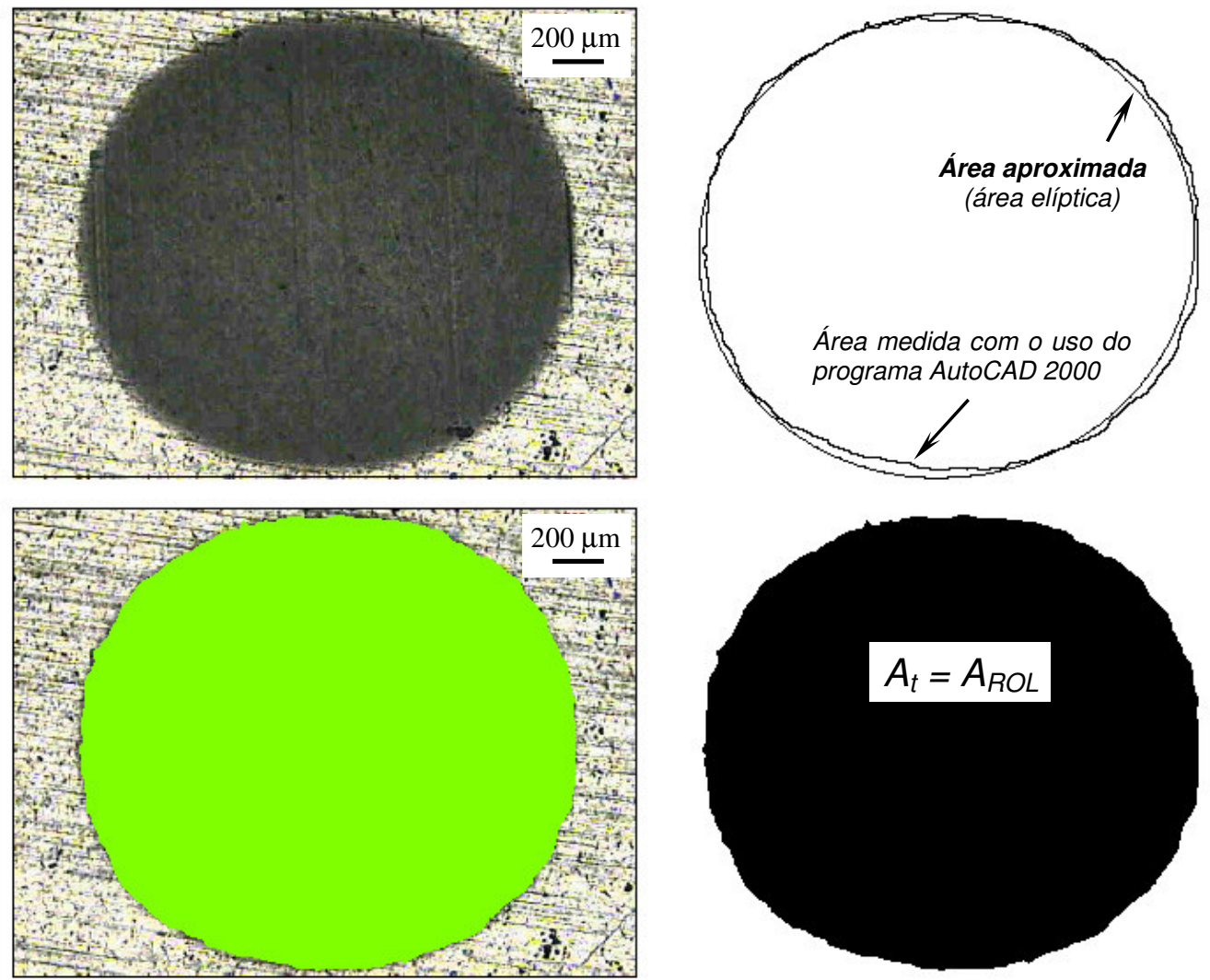

Figura 7.20: Corpo-de-prova de aço ferramenta M2. Distância de deslizamento de 40 metros. $A$ área $A_{t}$ foi medida pelo Método 2. Atuação de desgaste abrasivo por rolamento $\left(A_{t}=A_{R O L}\right)$. 

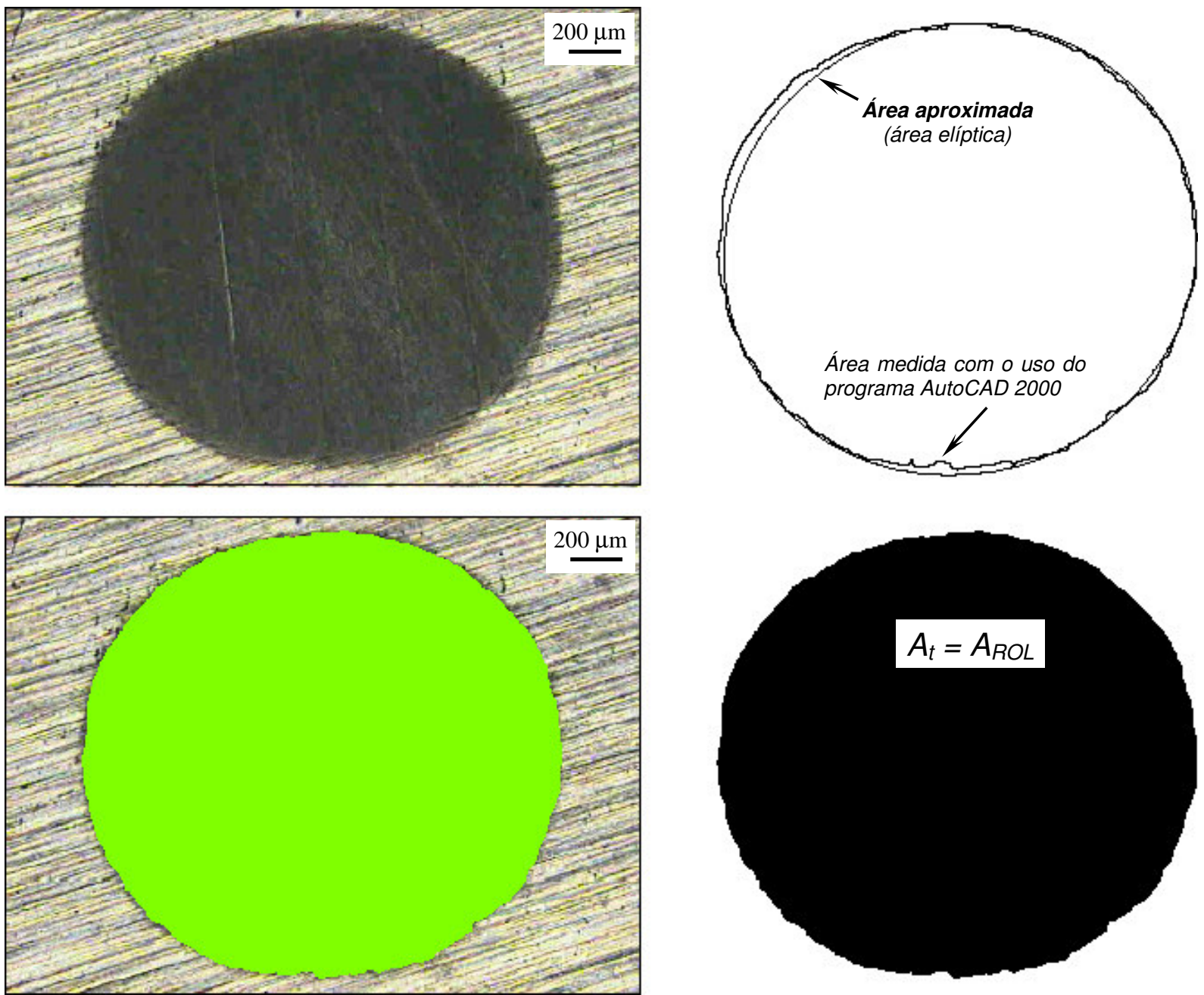

Figura 7.21: Corpo-de-prova de aço ferramenta M2. Distância de deslizamento de 40 metros. A área $A_{t}$ foi medida pelo Método 2. Atuação de desgaste abrasivo por rolamento $\left(A_{t}=A_{R O L}\right)$. 


\subsubsection{Corpos-de-prova de WC-Co P20 - Resultados obtidos pelo Método 1}

A Tabela 7.3 apresenta os valores de $\boldsymbol{d}, \boldsymbol{A}_{\boldsymbol{t}}, \boldsymbol{A}_{\boldsymbol{R} \boldsymbol{I}}, \boldsymbol{A}_{\boldsymbol{R} O L}$ e $\boldsymbol{A}_{\boldsymbol{R O L}} / \boldsymbol{A}_{\boldsymbol{R} \boldsymbol{S}}$, para cada distância de deslizamento. As áreas $\boldsymbol{A}_{t}, \boldsymbol{A}_{\boldsymbol{R} I S}$ e $\boldsymbol{A}_{\boldsymbol{R} O L}$ foram obtidas pelo Método 1.

Tabela 7.3: Resultados obtidos para os corpos-de-prova de WC-Co P20, pelo Método 1.

\begin{tabular}{|c|c|c|c|c|c|c|c|}
\hline DIST. DESL. (S) & GRANDEZA & ENSAIO 1 & ENSAIO 2 & ENSAIO 3 & ENSAIO 4 & MÉDIA & DESV. PAD. \\
\hline \multirow{5}{*}{8 metros } & $\boldsymbol{d}[\mathrm{mm}]$ & 1,210 & 1,433 & 1,374 & 1,452 & 1,367 & $0,110^{(1)}$ \\
\hline & $\boldsymbol{A}_{t}\left[\mathrm{~mm}^{2}\right]$ & 1,150 & 1,613 & 1,483 & 1,656 & 1,475 & - \\
\hline & $\boldsymbol{A}_{\text {RIS }}\left[\mathrm{mm}^{2}\right]$ & 0,058 & 0,118 & $0^{(2)}$ & $0^{(2)}$ & $0,088^{(3)}$ & $0,042^{(1)(3)}$ \\
\hline & $\boldsymbol{A}_{R O L}\left[\mathrm{~mm}^{2}\right]$ & 1,092 & 1,495 & 1,483 & 1,656 & 1,431 & - \\
\hline & $A_{R O L} / A_{R I S}$ & 18,830 & 12,670 & $\rightarrow \infty$ & $\rightarrow \infty$ & $15,75^{(4)}$ & - \\
\hline \multirow{5}{*}{15 metros } & $\boldsymbol{d}[\mathrm{mm}]$ & 1,455 & 1,290 & 1,601 & 1,425 & 1,443 & $0,128^{(1)}$ \\
\hline & $\boldsymbol{A}_{t}\left[\mathrm{~mm}^{2}\right]$ & 1,663 & 1,307 & 2,013 & 1,595 & 1,644 & - \\
\hline & $\boldsymbol{A}_{R I S}\left[\mathrm{~mm}^{2}\right]$ & 0,330 & 0,113 & 0,174 & 0,108 & 0,181 & $0,104^{(1)}$ \\
\hline & $\boldsymbol{A}_{R O L}\left[\mathrm{~mm}^{2}\right]$ & 1,333 & 1,194 & 1,839 & 1,487 & 1,463 & - \\
\hline & $A_{R O L} / A_{R I S}$ & 4,039 & 10,566 & 10,570 & 13,767 & 9,735 & - \\
\hline \multirow{5}{*}{20 metros } & $\boldsymbol{d}[\mathrm{mm}]$ & 1,476 & 1,325 & 1,608 & 1,348 & 1,439 & $0,131^{(1)}$ \\
\hline & $\boldsymbol{A}_{t}\left[\mathrm{~mm}^{2}\right]$ & 1,711 & 1,379 & 2,031 & 1,427 & 1,637 & - \\
\hline & $\boldsymbol{A}_{R I S}\left[\mathrm{~mm}^{2}\right]$ & 0,224 & 0,207 & 0,438 & $0^{(2)}$ & $0,29^{(3)}$ & $0,129^{(1)(3)}$ \\
\hline & $\boldsymbol{A}_{R O L}\left[\mathrm{~mm}^{2}\right]$ & 1,487 & 1,172 & 1,593 & 1,427 & 1,420 & - \\
\hline & $A_{R O L} / A_{R I S}$ & 6,639 & 5,661 & 3,636 & $\rightarrow \infty$ & 5,312 & - \\
\hline \multirow{5}{*}{25 metros } & $\boldsymbol{d}[\mathrm{mm}]$ & 1,991 & 1,902 & 1,934 & 1,843 & 1,918 & $0,062^{(1)}$ \\
\hline & $\boldsymbol{A}_{t}\left[\mathrm{~mm}^{2}\right]$ & 3,113 & 2,841 & 2,938 & 2,668 & 2,890 & - \\
\hline & $\boldsymbol{A}_{R I S}\left[\mathrm{~mm}^{2}\right]$ & $0^{(2)}$ & $0^{(2)}$ & $0^{(2)}$ & $0^{(2)}$ & $0^{(2)}$ & $0^{(1)}$ \\
\hline & $\boldsymbol{A}_{R O L}\left[\mathrm{~mm}^{2}\right]$ & 3,113 & 2,841 & 2,938 & 2,668 & 2,89 & - \\
\hline & $A_{R O L} / A_{R I S}$ & $\rightarrow \infty$ & $\rightarrow \infty$ & $\rightarrow \infty$ & $\rightarrow \infty$ & $\rightarrow \infty$ & - \\
\hline \multirow{5}{*}{35 metros } & $\boldsymbol{d}[\mathrm{mm}]$ & 1,918 & 1,869 & 1,955 & 1,895 & 1,909 & $0,036^{(1)}$ \\
\hline & $\boldsymbol{A}_{t}\left[\mathrm{~mm}^{2}\right]$ & 2,889 & 2,744 & 3,002 & 2,820 & 2,864 & - \\
\hline & $\boldsymbol{A}_{\boldsymbol{R I S}}\left[\mathrm{mm}^{2}\right]$ & $0^{(2)}$ & $0^{(2)}$ & $0^{(2)}$ & $0^{(2)}$ & $0^{(2)}$ & $0^{(1)}$ \\
\hline & $\boldsymbol{A}_{R O L}\left[\mathrm{~mm}^{2}\right]$ & 2,889 & 2,744 & 3,002 & 2,820 & 2,864 & - \\
\hline & $A_{R O L} / A_{R I S}$ & $\rightarrow \infty$ & $\rightarrow \infty$ & $\rightarrow \infty$ & $\rightarrow \infty$ & $\rightarrow \infty$ & - \\
\hline \multirow{5}{*}{40 metros } & $\boldsymbol{d}[\mathrm{mm}]$ & 1,910 & 1,922 & 1,833 & 1,801 & 1,867 & 0,059 \\
\hline & $\boldsymbol{A}_{t}\left[\mathrm{~mm}^{2}\right]$ & 2,865 & 2,901 & 2,639 & 2,548 & 2,738 & - \\
\hline & $\boldsymbol{A}_{R I S}\left[\mathrm{~mm}^{2}\right]$ & $0^{(2)}$ & $0^{(2)}$ & $0^{(2)}$ & $0^{(2)}$ & $0^{(2)}$ & $0^{(1)}$ \\
\hline & $\boldsymbol{A}_{\boldsymbol{R O L}}\left[\mathrm{mm}^{2}\right]$ & 2,865 & 2,901 & 2,639 & 2,548 & 2,738 & - \\
\hline & $A_{R O L} / A_{R I S}$ & $\rightarrow \infty$ & $\rightarrow \infty$ & $\rightarrow \infty$ & $\rightarrow \infty$ & $\rightarrow \infty$ & - \\
\hline
\end{tabular}

(1): O desvio-padrão foi calculado somente para as grandezas que foram medidas no microscópio óptico ( $\boldsymbol{d}$ e $\left.\boldsymbol{A}_{\boldsymbol{R} I S}\right)$;

(2): O modo de desgaste abrasivo foi totalmente por rolamento;

(3): Para o cálculo da média e do desvio-padrão de $\boldsymbol{A}_{\boldsymbol{R} I S}$, não foram considerados os ensaios onde $\boldsymbol{A}_{\text {RIS }}=0$;

(4): Para o cálculo da média de $\boldsymbol{A}_{R O L} / \boldsymbol{A}_{R I S}$, não foram considerados os ensaios onde $\boldsymbol{A}_{R O L} / \boldsymbol{A}_{R I S} \rightarrow \infty$. 
A Figura 7.22 apresenta a dependência do quociente $\boldsymbol{A}_{\text {ROL }} / \boldsymbol{A}_{\text {RIS }}$ com a distância de deslizamento, para os corpos-de-prova de WC-Co P20. Os resultados foram obtidos pelo Método 1.

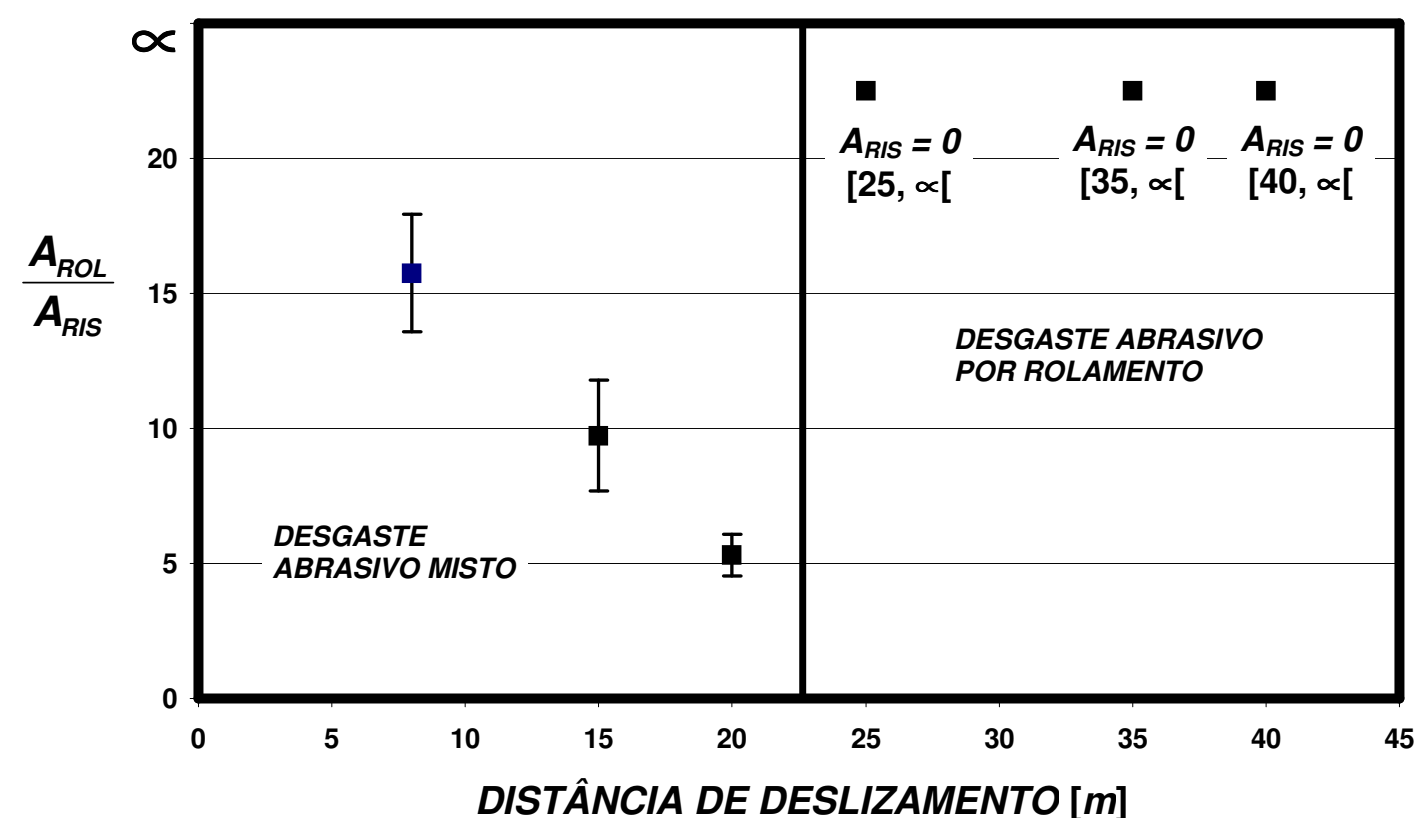

Figura 7.22: Dependência de $A_{R O L} / A_{R I S}$ com a distância de deslizamento, para os corpos-de-prova de WC-Co P20. Resultados obtidos pelo Método 1.

As Figuras 7.23 à 7.36 mostram algumas crateras de desgaste geradas nos ensaios com os corpos-de-prova de WC-Co P20.

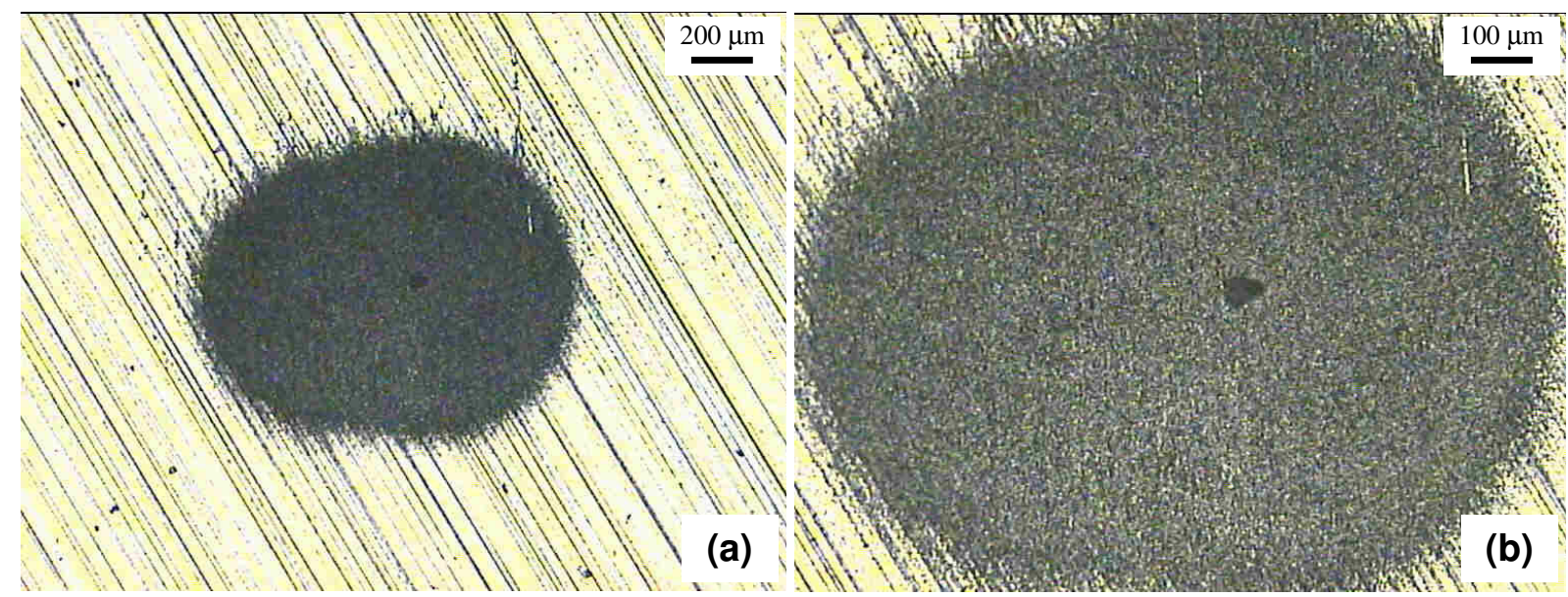

Figura 7.23: Corpo-de-prova de WC-Co P20. (a) Cratera de desgaste gerada com uma distância de deslizamento de 8 metros. (b) Ampliação de (a), exibindo a atuação de desgaste abrasivo por rolamento. 

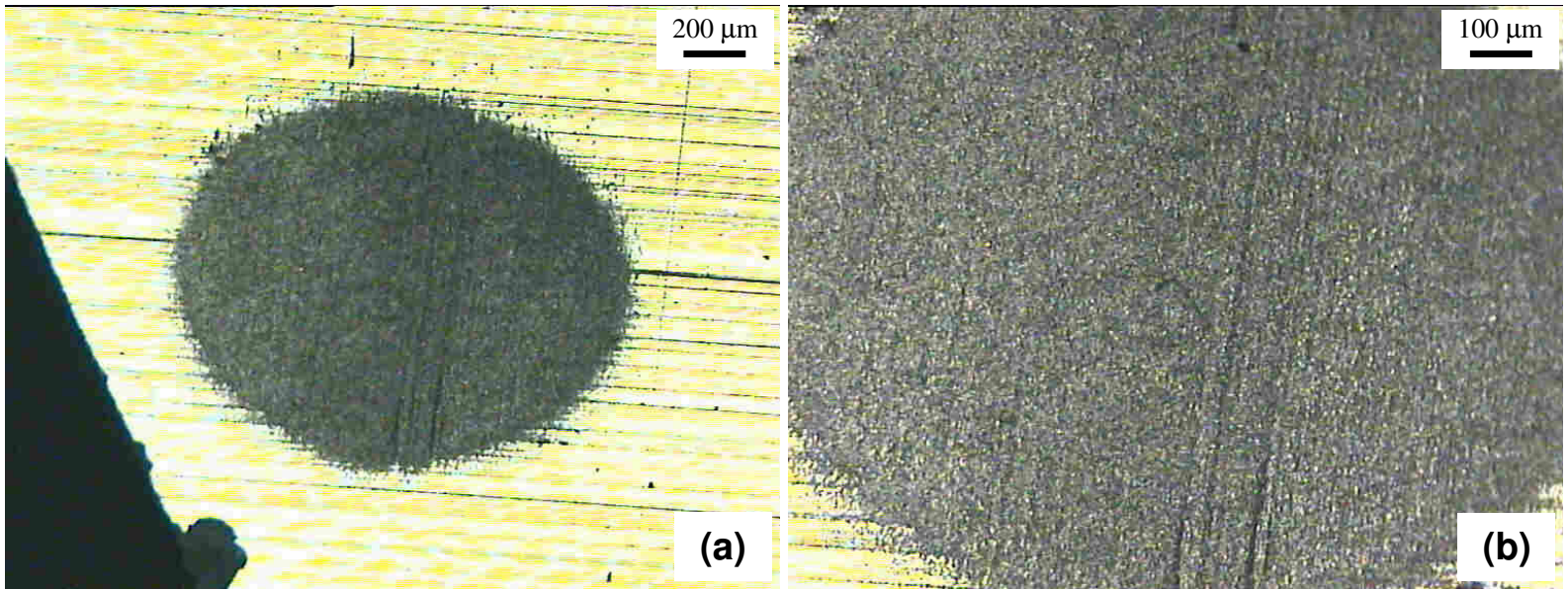

Figura 7.24: Corpo-de-prova de WC-Co P20. (a) Cratera de desgaste gerada com uma distância de deslizamento de 8 metros. (b) Ampliação de (a), exibindo a atuação de desgaste abrasivo misto.

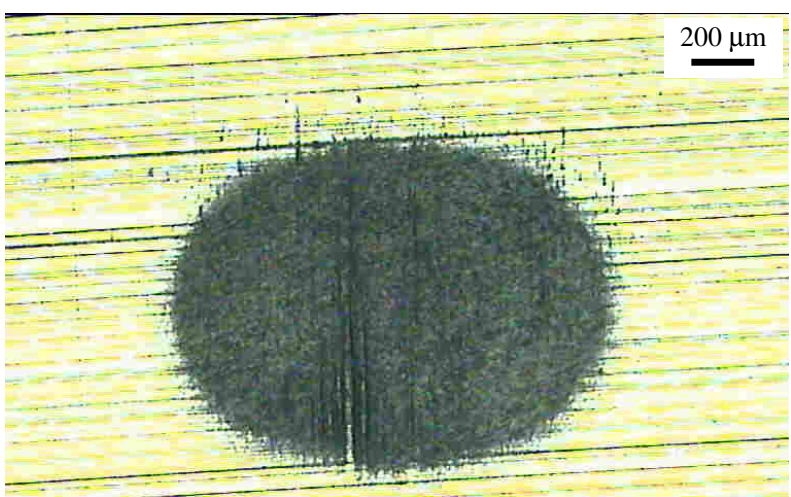

(a)

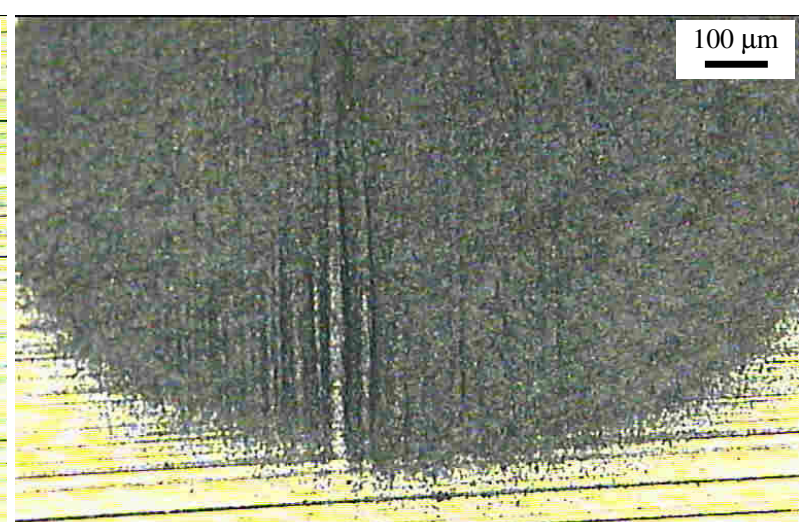

(b)

Figura 7.25: Corpo-de-prova de WC-Co P20. (a) Cratera de desgaste gerada com uma distância de deslizamento de 8 metros. (b) Ampliação de (a), exibindo a atuação de desgaste abrasivo misto.

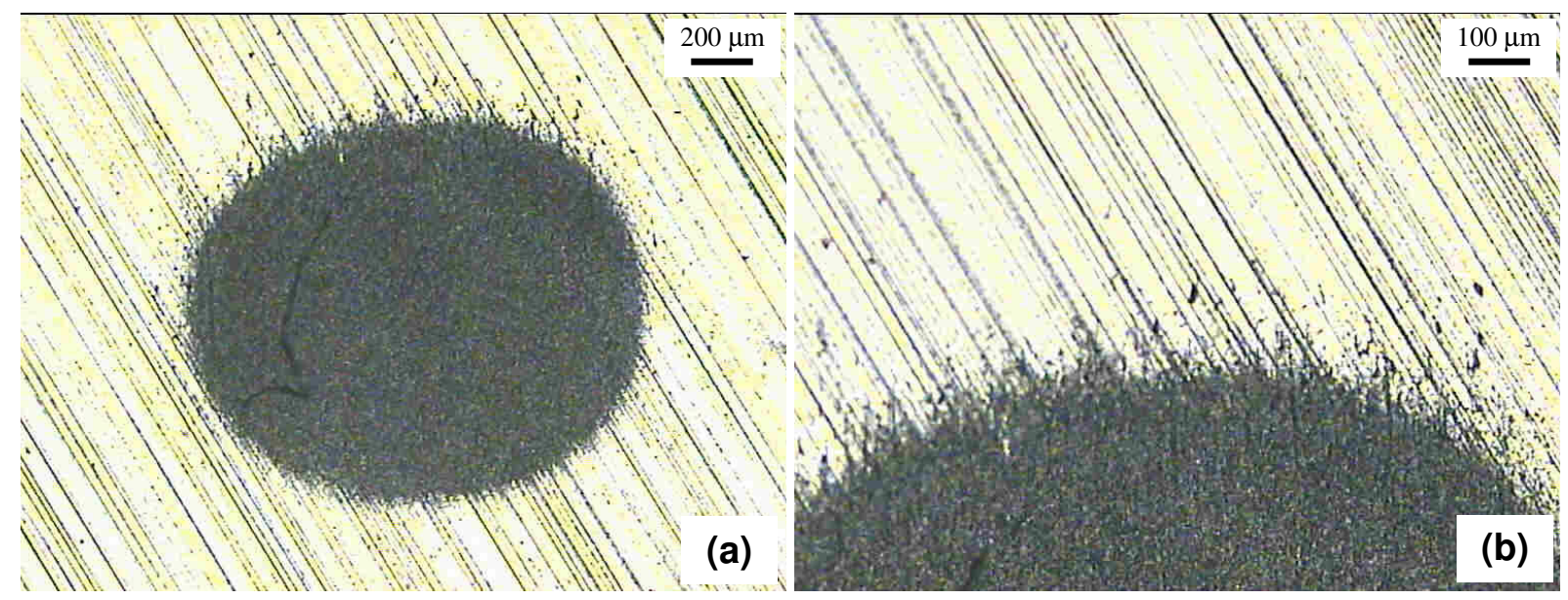

Figura 7.26: Corpo-de-prova de WC-Co P20. (a) Cratera de desgaste gerada com uma distância de deslizamento de 15 metros. (b) Ampliação de (a), exibindo a atuação de desgaste abrasivo misto. 


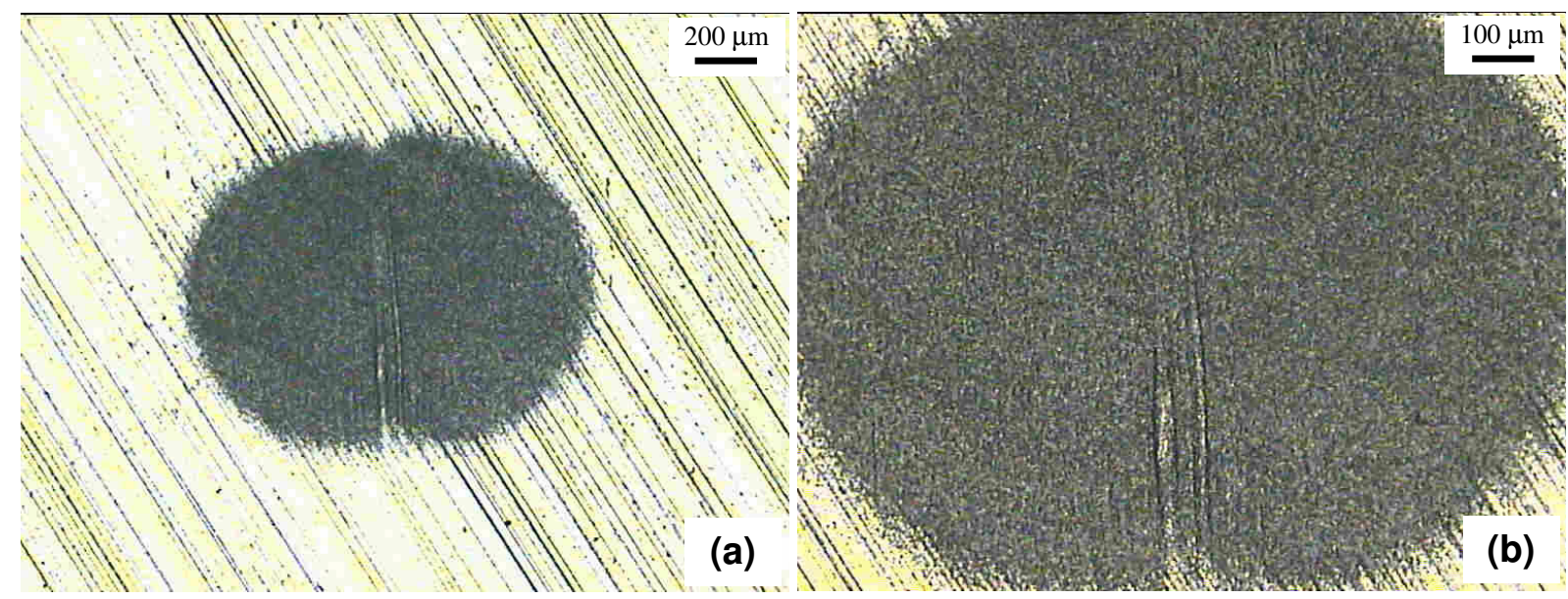

Figura 7.27: Corpo-de-prova de WC-Co P20. (a) Cratera de desgaste gerada com uma distância de deslizamento de 15 metros. (b) Ampliação de (a), exibindo a atuação de desgaste abrasivo misto.

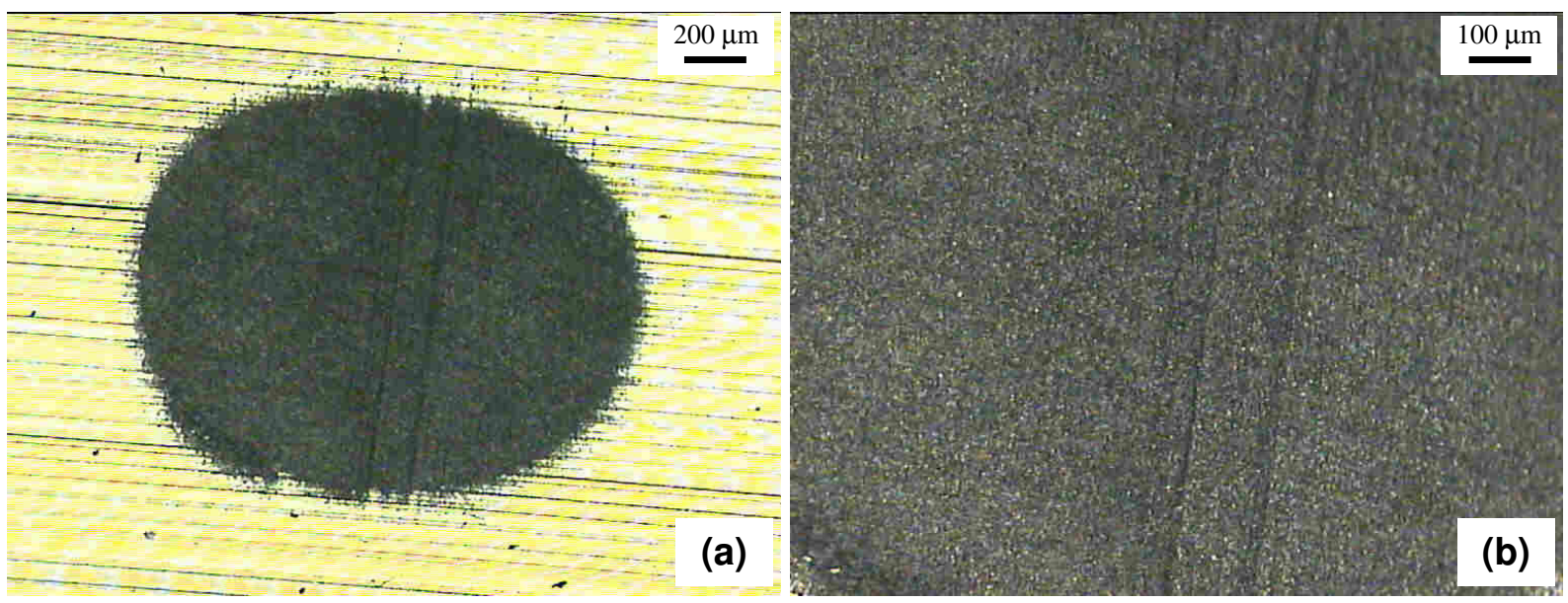

Figura 7.28: Corpo-de-prova de WC-Co P20. (a) Cratera de desgaste gerada com uma distância de deslizamento de 15 metros. (b) Ampliação de (a), exibindo a atuação de desgaste abrasivo misto.
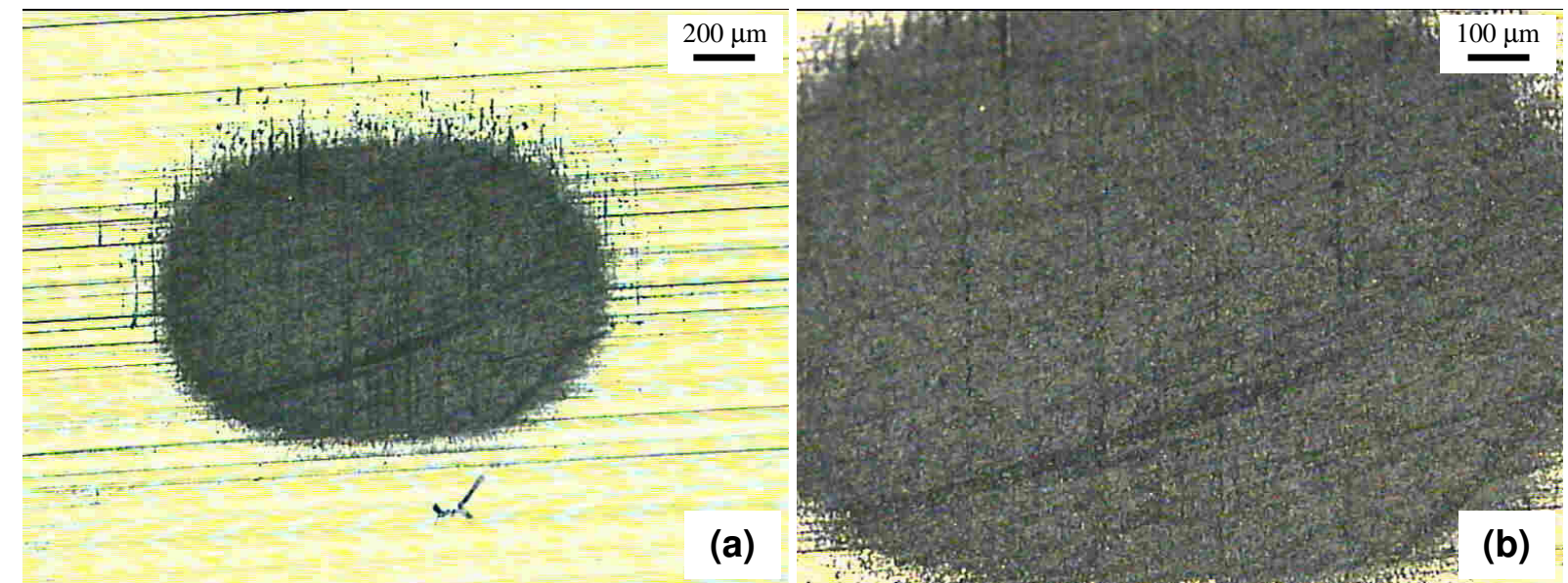

Figura 7.29: Corpo-de-prova de WC-Co P20. (a) Cratera de desgaste gerada com uma distância de deslizamento de 15 metros. (b) Ampliação de (a), exibindo a atuação de desgaste abrasivo misto. 


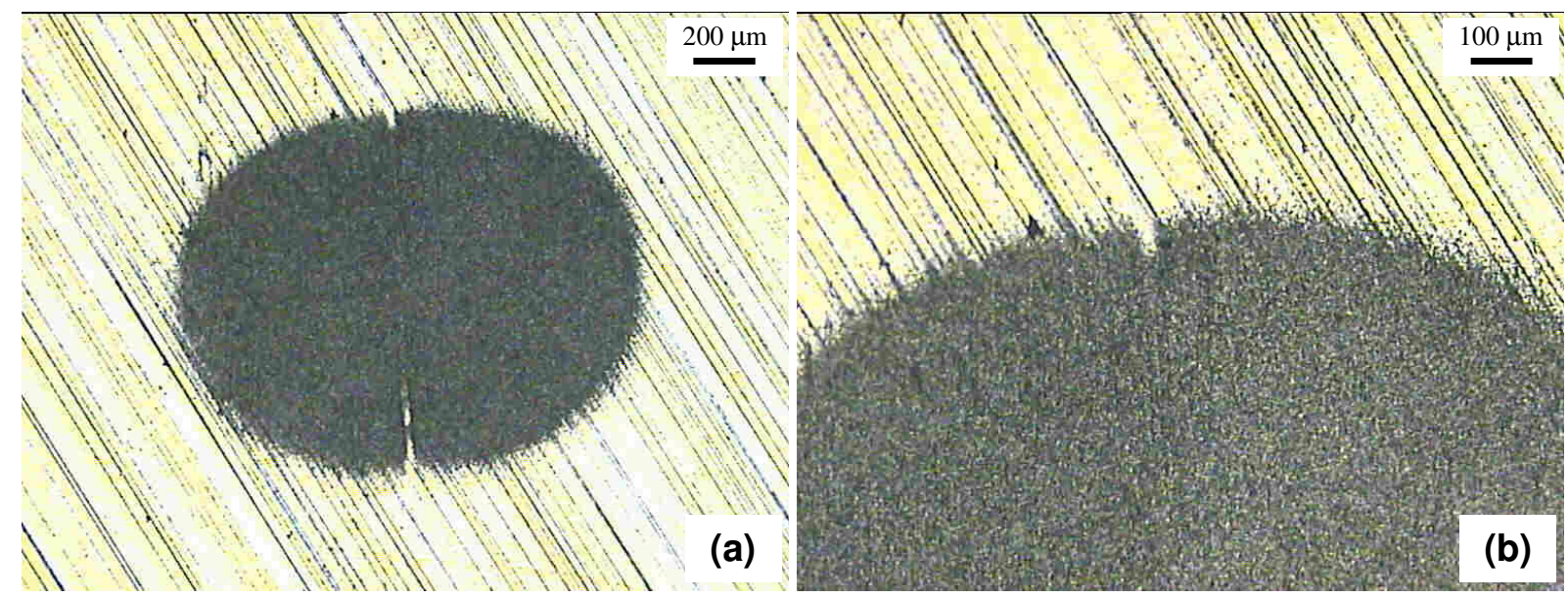

Figura 7.30: Corpo-de-prova de WC-Co P20. (a) Cratera de desgaste gerada com uma distância de deslizamento de 20 metros. (b) Ampliação de (a), exibindo a atuação de desgaste abrasivo misto.

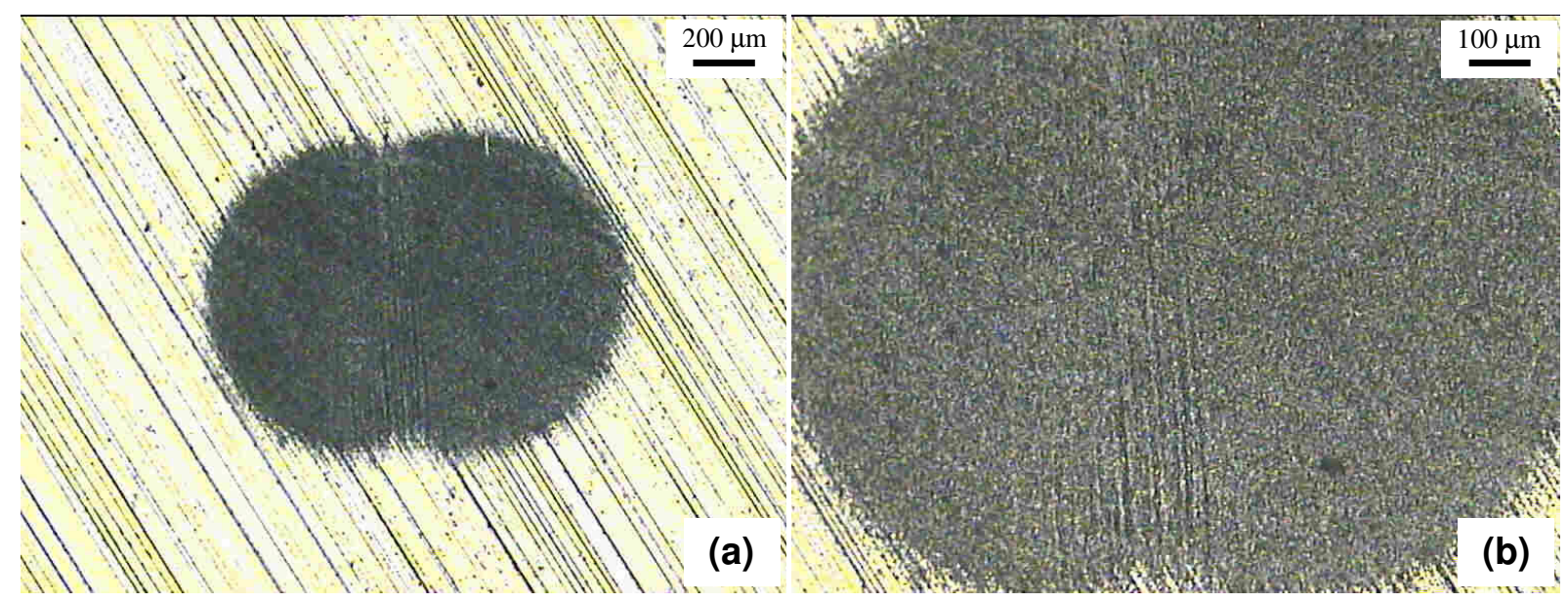

Figura 7.31: Corpo-de-prova de WC-Co P20. (a) Cratera de desgaste gerada com uma distância de deslizamento de 20 metros. (b) Ampliação de (a), exibindo a atuação de desgaste abrasivo misto.
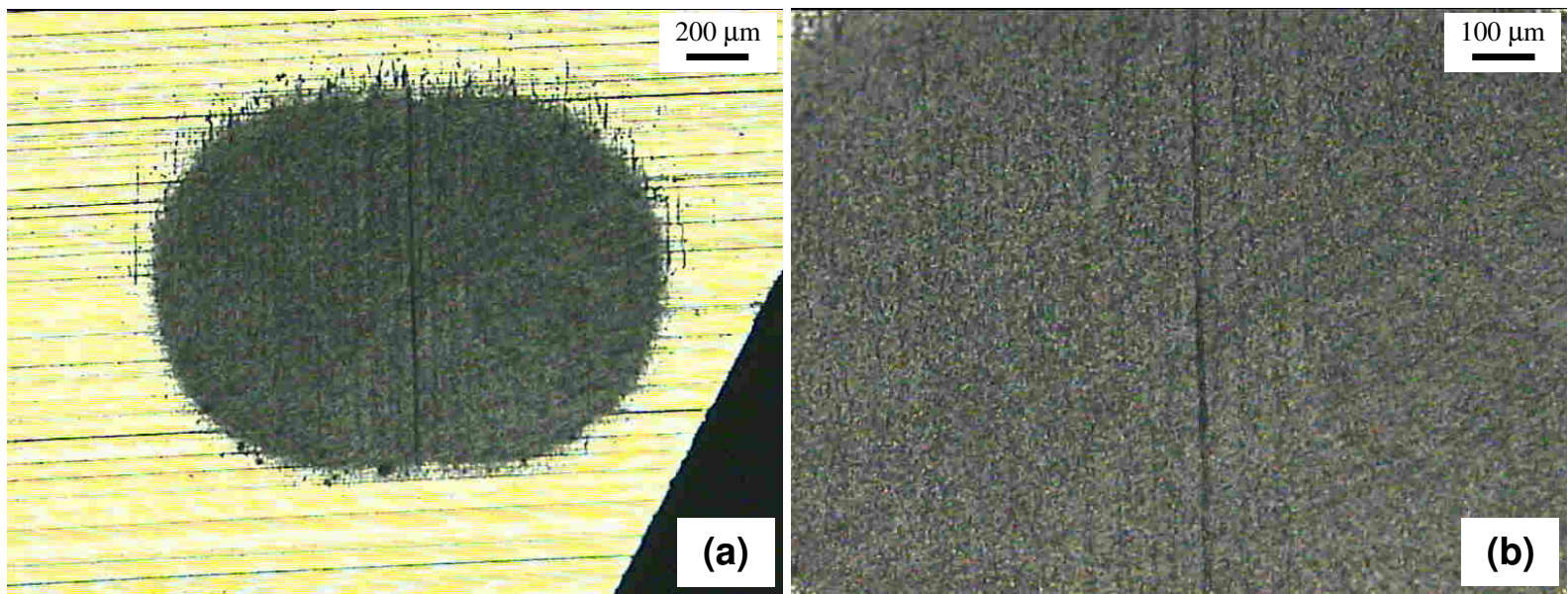

Figura 7.32: Corpo-de-prova de WC-Co P20. (a) Cratera de desgaste gerada com uma distância de deslizamento de 20 metros. (b) Ampliação de (a), exibindo a atuação de desgaste abrasivo misto. 


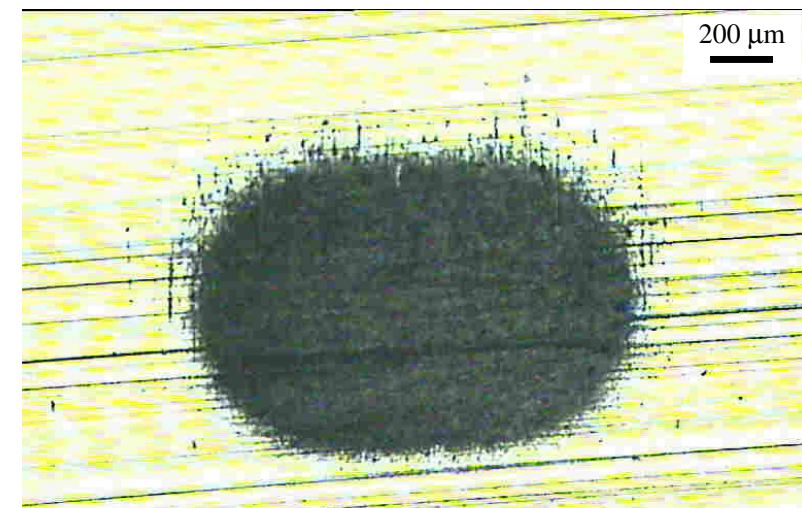

(a)

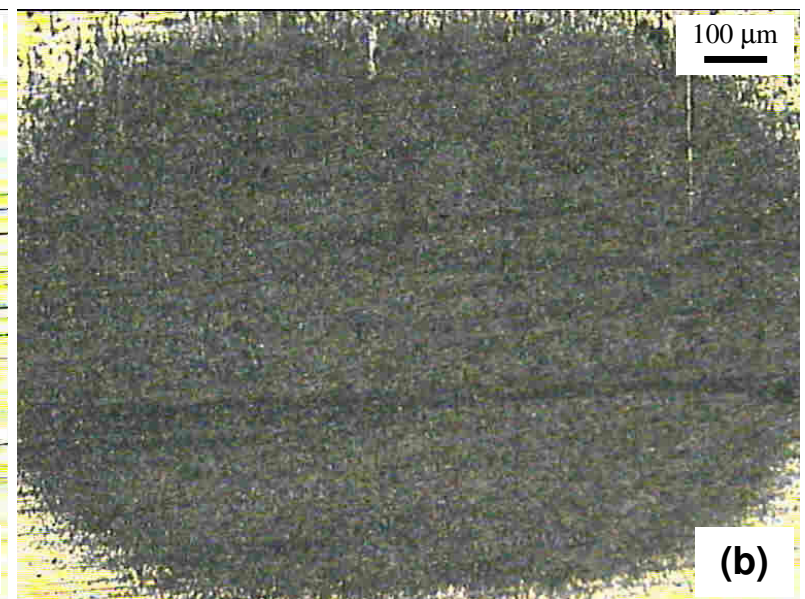

Figura 7.33: Corpo-de-prova de WC-Co P20. (a) Cratera de desgaste gerada com uma distância de deslizamento de 20 metros. (b) Ampliação de (a), exibindo a atuação de desgaste abrasivo por rolamento.

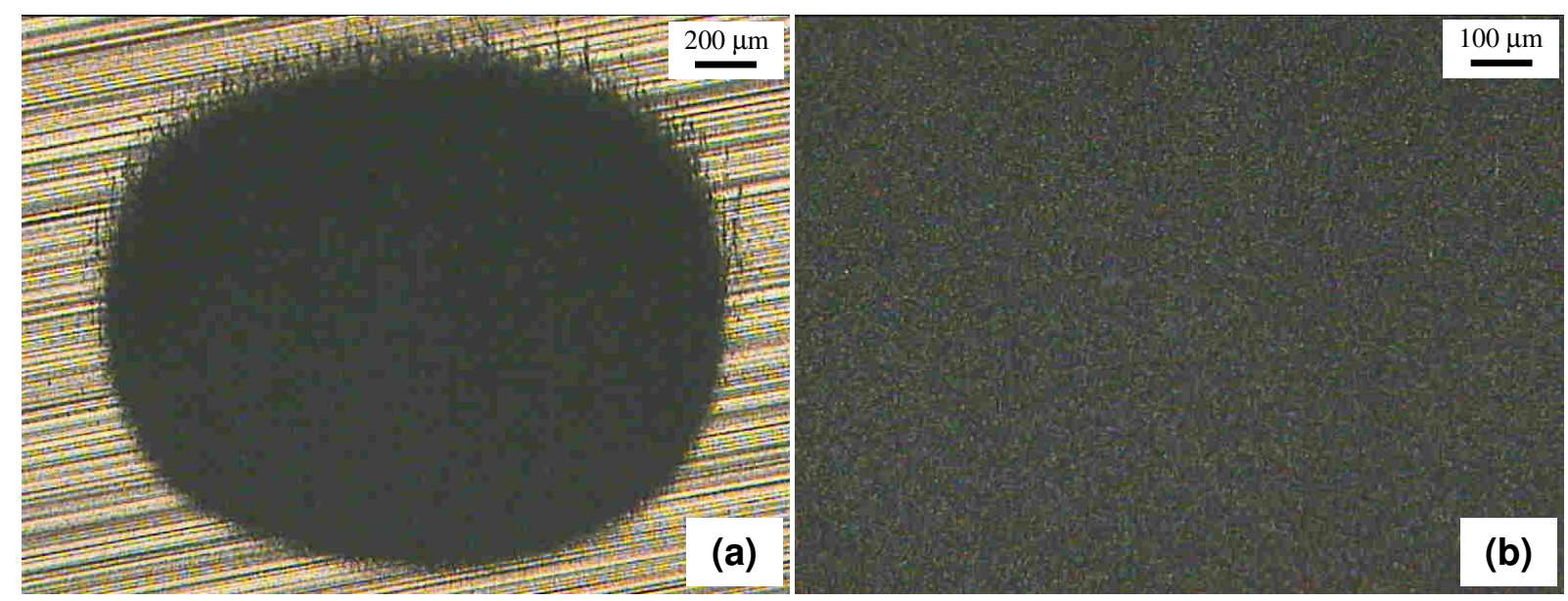

Figura 7.34: Corpo-de-prova de WC-Co P20. (a) cratera de desgaste obtida com uma distância de deslizamento de 25 metros. (b) Ampliação de (a), exibindo a atuação de desgaste abrasivo por rolamento.

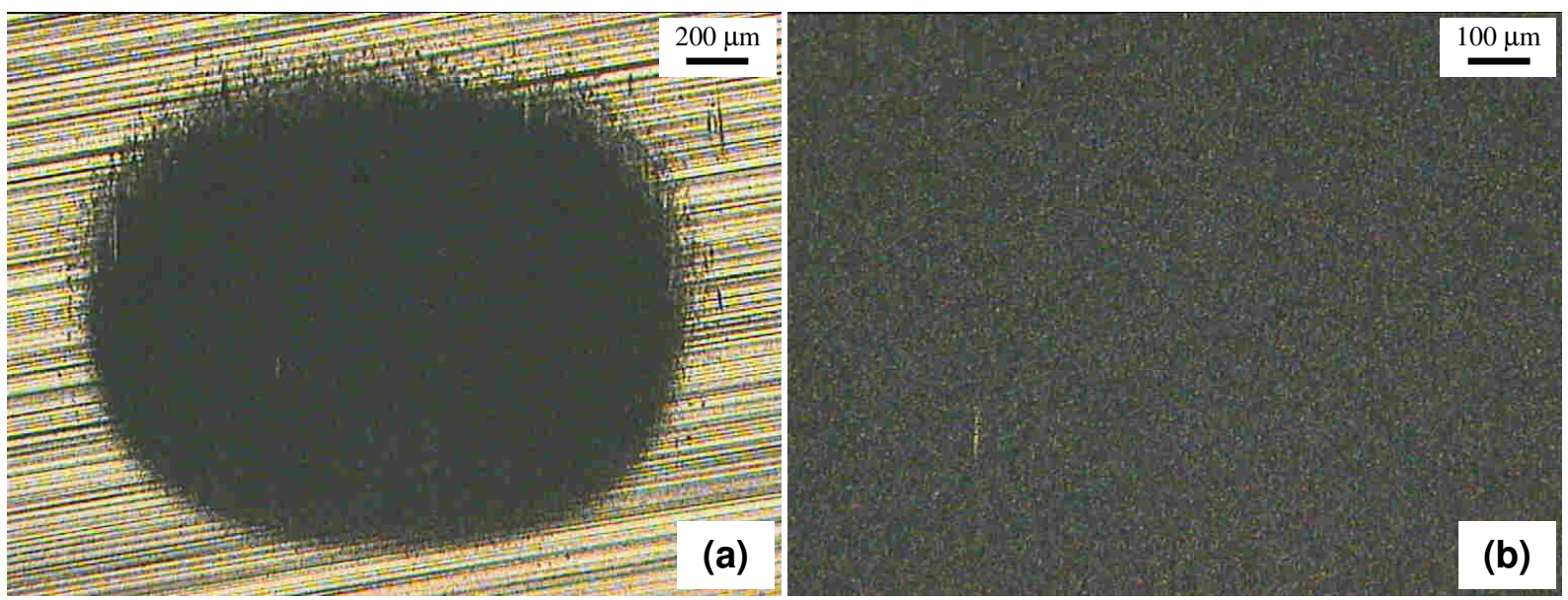

Figura 7.35: Corpo-de-prova de WC-Co P20. (a) Cratera de desgaste gerada com uma distância de deslizamento de 35 metros. (b) Ampliação de (a), exibindo a atuação de desgaste abrasivo por rolamento. 

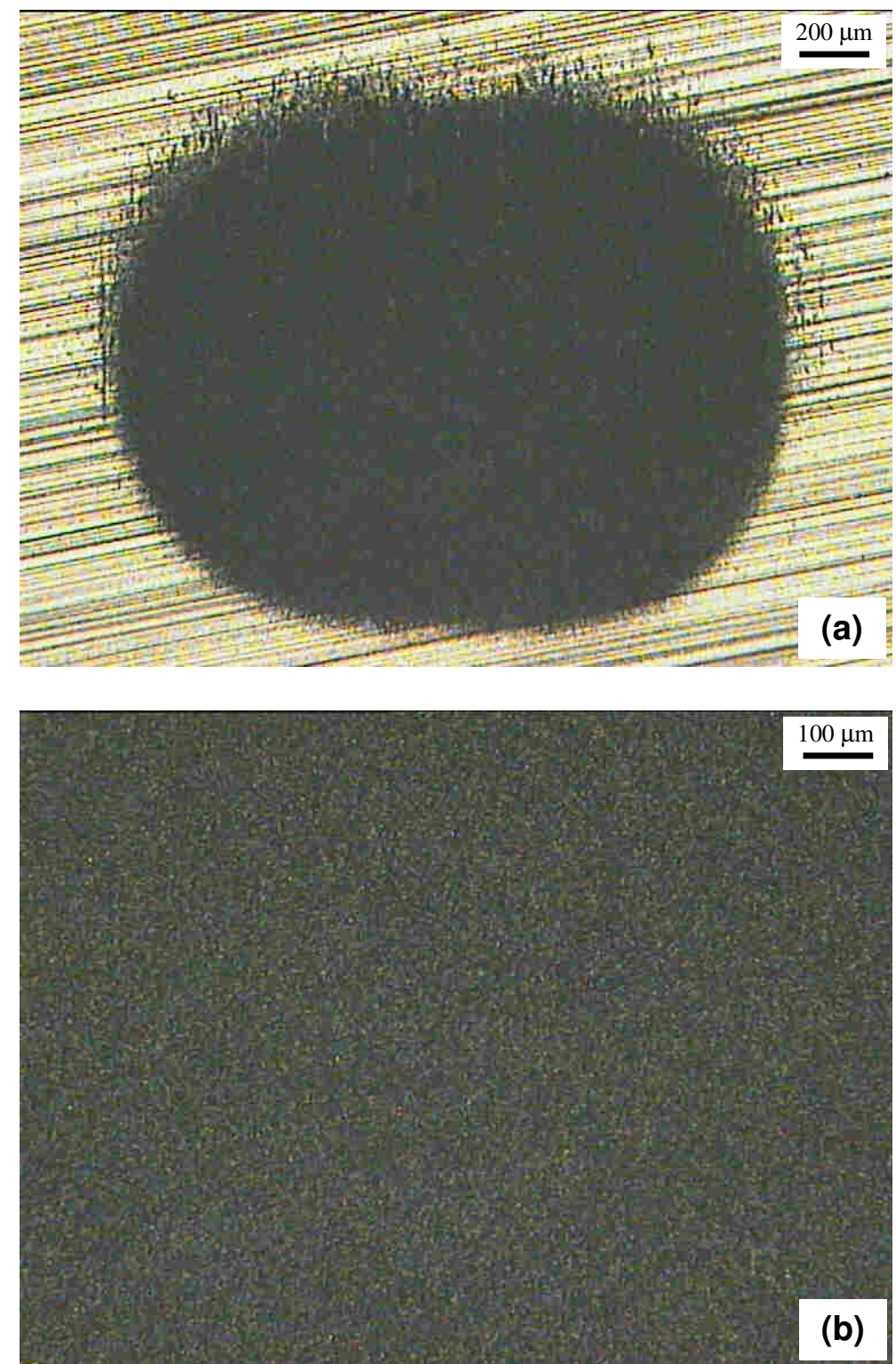

Figura 7.36: Corpo-de-prova de WC-Co P20. (a) Cratera de desgaste gerada com uma distância de deslizamento de 40 metros. (b) Ampliação de (a), exibindo a atuação de desgaste abrasivo por rolamento. 


\subsubsection{Corpos-de-prova de WC-Co P20 - Resultados obtidos pelo Método 2}

A Tabela 7.4 apresenta os valores de $\boldsymbol{A}_{\boldsymbol{t}}, \boldsymbol{A}_{\boldsymbol{R} \boldsymbol{S}}, \boldsymbol{A}_{\boldsymbol{R} O L}$ e $\boldsymbol{A}_{\boldsymbol{R O L}} / \boldsymbol{A}_{\boldsymbol{R} I \boldsymbol{S}}$, para cada distância de deslizamento. As áreas $\boldsymbol{A}_{\boldsymbol{t}}, \boldsymbol{A}_{\boldsymbol{R} \boldsymbol{s}}$ e $\boldsymbol{A}_{\boldsymbol{R} O L}$ foram medidas pelo Método 2.

Tabela 7.4: Resultados obtidos para os corpos-de-prova de WC-Co P20, pelo Método 2.

\begin{tabular}{|c|c|c|c|c|c|c|c|c|}
\hline DIST. DESL. (S) & GRANDEZA & ENSAIO 1 & ENSAIO 2 & ENSAIO 3 & ENSAIO 4 & MÉDIA & DESV. PAD. & ERRO \\
\hline \multirow{4}{*}{8 metros } & $\boldsymbol{A}_{t}\left[\mathrm{~mm}^{2}\right]$ & 1,120 & 1,298 & 0,930 & - & 1,116 & 0,184 & 0,106 \\
\hline & $\boldsymbol{A}_{R I S}\left[\mathrm{~mm}^{2}\right]$ & 0,113 & 0,068 & $0^{(1)}$ & - & $0,091^{(2)}$ & $0,032^{(2)}$ & 0,023 \\
\hline & $\boldsymbol{A}_{\boldsymbol{R} O L}\left[\mathrm{~mm}^{2}\right]$ & 1,001 & 1,227 & 0,930 & - & 1,053 & 0,155 & 0,090 \\
\hline & $A_{R O L} / A_{R I S}$ & 8,858 & 18,044 & $\rightarrow \infty$ & - & $13,451^{(3)}$ & $6,495^{(3)}$ & 4,593 \\
\hline \multirow{4}{*}{15 metros } & $\boldsymbol{A}_{t}\left[\mathrm{~mm}^{2}\right]$ & 1,406 & 1,002 & 1,656 & 1,148 & 1,303 & 0,289 & 0,144 \\
\hline & $\boldsymbol{A}_{\boldsymbol{R} I S}\left[\mathrm{~mm}^{2}\right]$ & 0,279 & 0,070 & 0,132 & 0,073 & 0,139 & 0,098 & 0,050 \\
\hline & $\boldsymbol{A}_{R O L}\left[\mathrm{~mm}^{2}\right]$ & 1,184 & 0,934 & 1,551 & 1,077 & 1,187 & 0,264 & 0,132 \\
\hline & $A_{R O L} / A_{R I S}$ & 4,244 & 13,343 & 11,750 & 14,753 & 11,023 & 4,683 & 2,342 \\
\hline \multirow{4}{*}{20 metros } & $\boldsymbol{A}_{t}\left[\mathrm{~mm}^{2}\right]$ & 1,368 & 1,104 & 1,619 & 1,044 & 1,274 & 0,277 & 0,138 \\
\hline & $\boldsymbol{A}_{R I S}\left[\mathrm{~mm}^{2}\right]$ & $0^{(1)}$ & 0,097 & 0,497 & $0^{(1)}$ & $0,297^{(2)}$ & $0,283^{(2)}$ & 0,200 \\
\hline & $\boldsymbol{A}_{\boldsymbol{R O L}}\left[\mathrm{mm}^{2}\right]$ & 1,368 & 0,998 & 1,322 & 1,044 & 1,173 & 0,200 & 0,100 \\
\hline & $A_{R O L} / A_{R I S}$ & $\rightarrow \infty$ & 10,289 & 2,660 & $\rightarrow \infty$ & $6,474^{(3)}$ & $5,394^{(3)}$ & 3,814 \\
\hline \multirow{4}{*}{25 metros } & $\boldsymbol{A}_{t}\left[\mathrm{~mm}^{2}\right]$ & 2,680 & 2,442 & 2,808 & - & 2,643 & 0,186 & 0,107 \\
\hline & $\boldsymbol{A}_{\boldsymbol{R I S}}\left[\mathrm{mm}^{2}\right]$ & $0^{(1)}$ & $0^{(1)}$ & $0^{(1)}$ & - & 0 & 0 & 0 \\
\hline & $\boldsymbol{A}_{R O L}\left[\mathrm{~mm}^{2}\right]$ & 2,680 & 2,442 & 2,808 & - & 2,643 & 0,186 & 0,107 \\
\hline & $A_{R O L} / A_{R I S}$ & $\rightarrow \infty$ & $\rightarrow \infty$ & $\rightarrow \infty$ & - & $\rightarrow \infty$ & - & - \\
\hline \multirow{4}{*}{35 metros } & $\boldsymbol{A}_{t}\left[\mathrm{~mm}^{2}\right]$ & 2,356 & 2,811 & 2,665 & - & 2,611 & 0,232 & 0,134 \\
\hline & $\boldsymbol{A}_{R I S}\left[\mathrm{~mm}^{2}\right]$ & $0^{(1)}$ & $0^{(1)}$ & $0^{(1)}$ & - & 0 & 0 & 0 \\
\hline & $\boldsymbol{A}_{R O L}\left[\mathrm{~mm}^{2}\right]$ & 2,356 & 2,811 & 2,665 & - & 2,611 & 0,232 & 0,134 \\
\hline & $A_{R O L} / A_{R I S}$ & $\rightarrow \infty$ & $\rightarrow \infty$ & $\rightarrow \infty$ & - & $\rightarrow \infty$ & - & - \\
\hline \multirow{4}{*}{40 metros } & $\boldsymbol{A}_{t}\left[\mathrm{~mm}^{2}\right]$ & 2,409 & 2,781 & 2,352 & - & 2,514 & 0,233 & 0,135 \\
\hline & $\boldsymbol{A}_{\boldsymbol{R I S}}\left[\mathrm{mm}^{2}\right]$ & $0^{(1)}$ & $0^{(1)}$ & $0^{(1)}$ & - & 0 & 0 & 0 \\
\hline & $\boldsymbol{A}_{\boldsymbol{R O L}}\left[\mathrm{mm}^{2}\right]$ & 2,409 & 2,781 & 2,352 & - & 2,514 & 0,233 & 0,135 \\
\hline & $A_{R O L} / A_{R I S}$ & $\rightarrow \infty$ & $\rightarrow \infty$ & $\rightarrow \infty$ & - & $\rightarrow \infty$ & - & 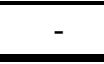 \\
\hline
\end{tabular}

(1):O modo de desgaste abrasivo foi totalmente por rolamento;

(2):Para os cálculos da média e do desvio-padrão de $\boldsymbol{A}_{\boldsymbol{R} I \boldsymbol{S}}$, não foram considerados os ensaios onde $\boldsymbol{A}_{\text {RIS }}=0$;

(3):Para os cálculos da média e do desvio-padrão de $\boldsymbol{A}_{\boldsymbol{R} O L} / \boldsymbol{A}_{\boldsymbol{R} I S}$, não foram considerados os ensaios onde $\boldsymbol{A}_{R O L} / \boldsymbol{A}_{R I S} \rightarrow \infty$.

A Figura 7.37 apresenta a dependência do quociente $\boldsymbol{A}_{R O L} / \boldsymbol{A}_{R I S}$ com a distância de deslizamento, para os corpos-de-prova de WC-Co P20. Os resultados foram obtidos pelo Método 2. 


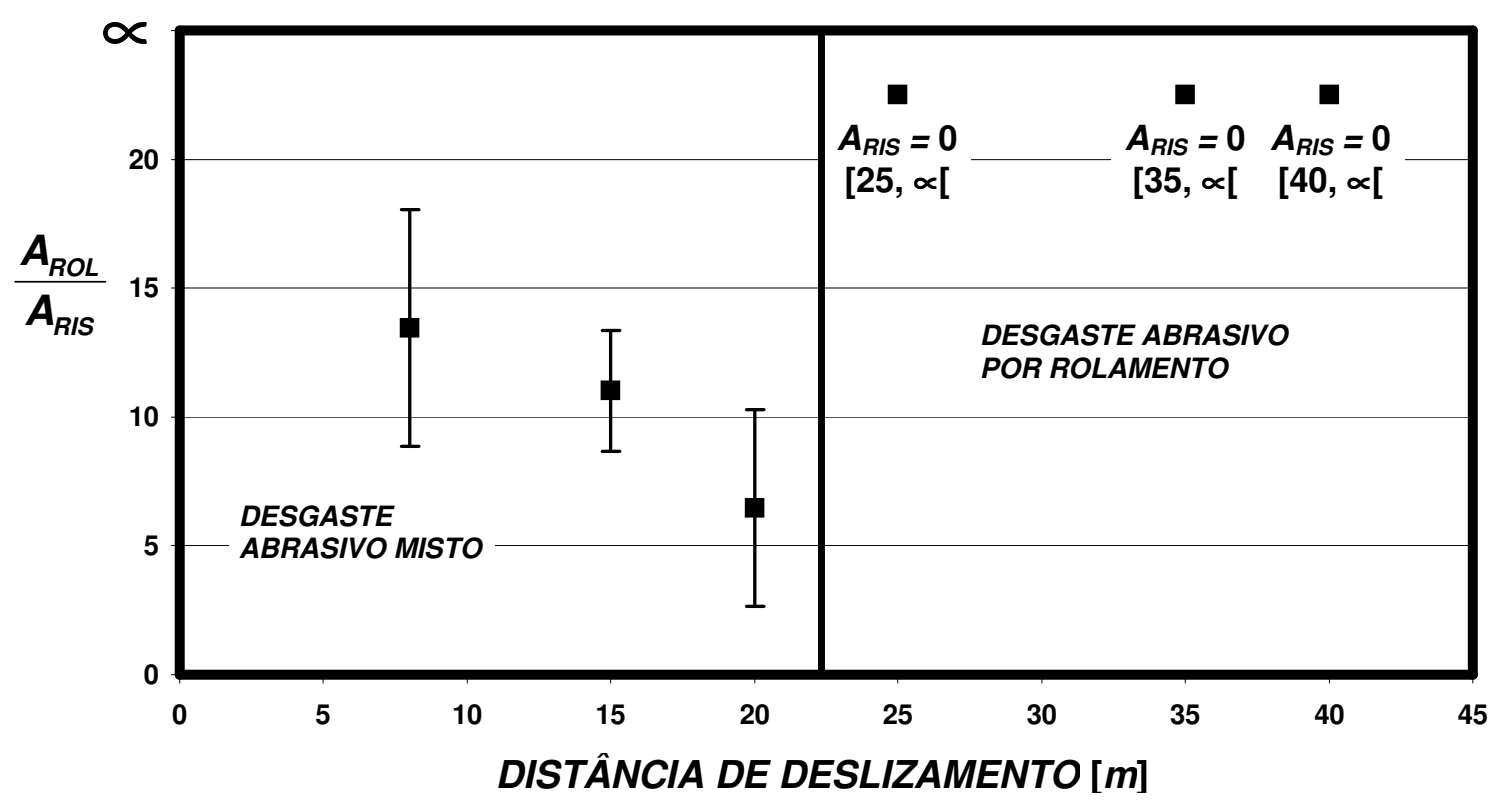

Figura 7.37: Dependência de $A_{R O L} / A_{R I S}$ com a distância de deslizamento, para os corpos-de-prova de WC-Co P20. Resultados obtidos pelo Método 2.

As Figuras 7.38 à 7.51 apresentam as áreas $\boldsymbol{A}_{\boldsymbol{t}}, \boldsymbol{A}_{\boldsymbol{R} O L}$ e $\boldsymbol{A}_{\boldsymbol{R} \boldsymbol{S}}$ das crateras de desgaste, medidas pelo Método 2.
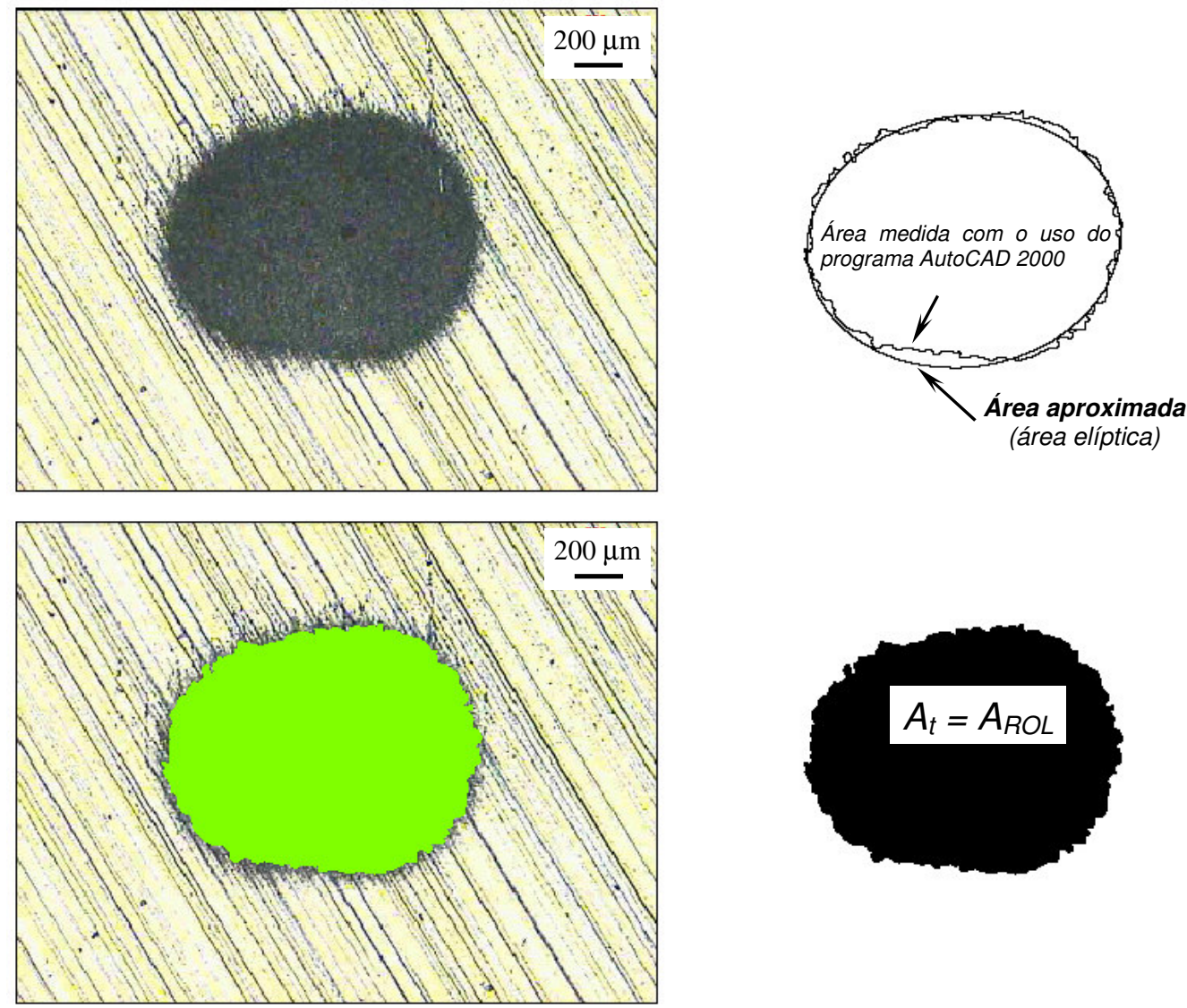

Figura 7.38: Corpo-de-prova de WC-Co P20. Distância de deslizamento de 8 metros. $A$ área $A_{t}$ foi medida pelo Método 2. Atuação de desgaste abrasivo por rolamento $\left(A_{t}=A_{R O L}\right)$. 

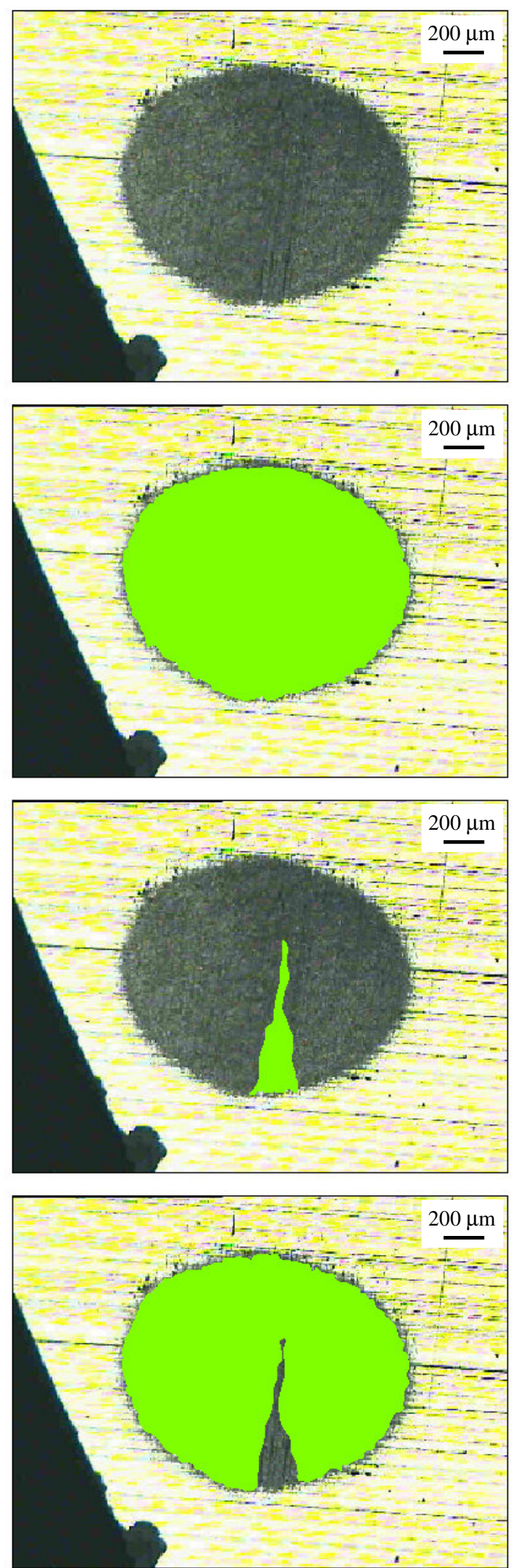
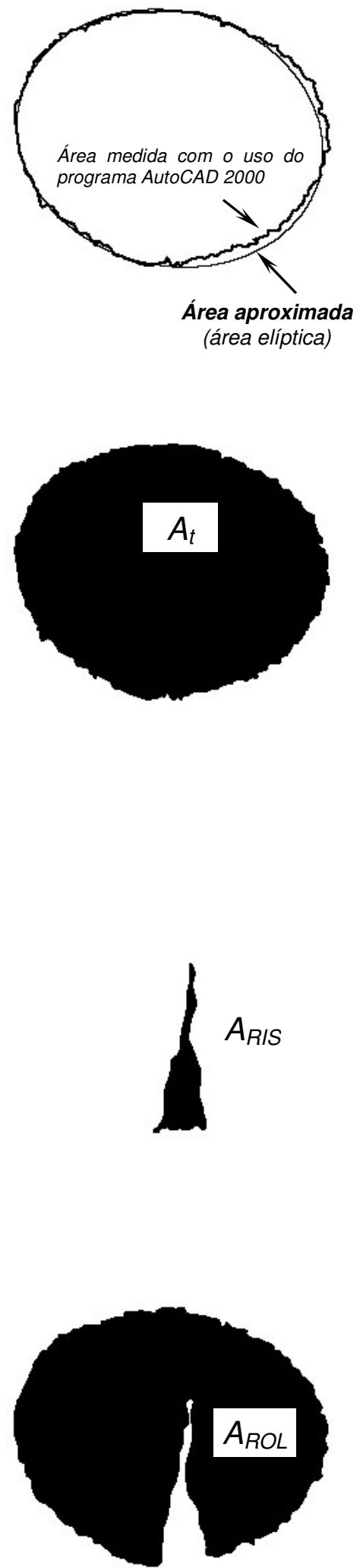

Figura 7.39: Corpo-de-prova de WC-Co P20. Distância de deslizamento de 8 metros. As áreas $A_{t}, A_{R I S}$ e $A_{R O L}$ foram medidas pelo Método 2. Atuação de desgaste abrasivo misto. 

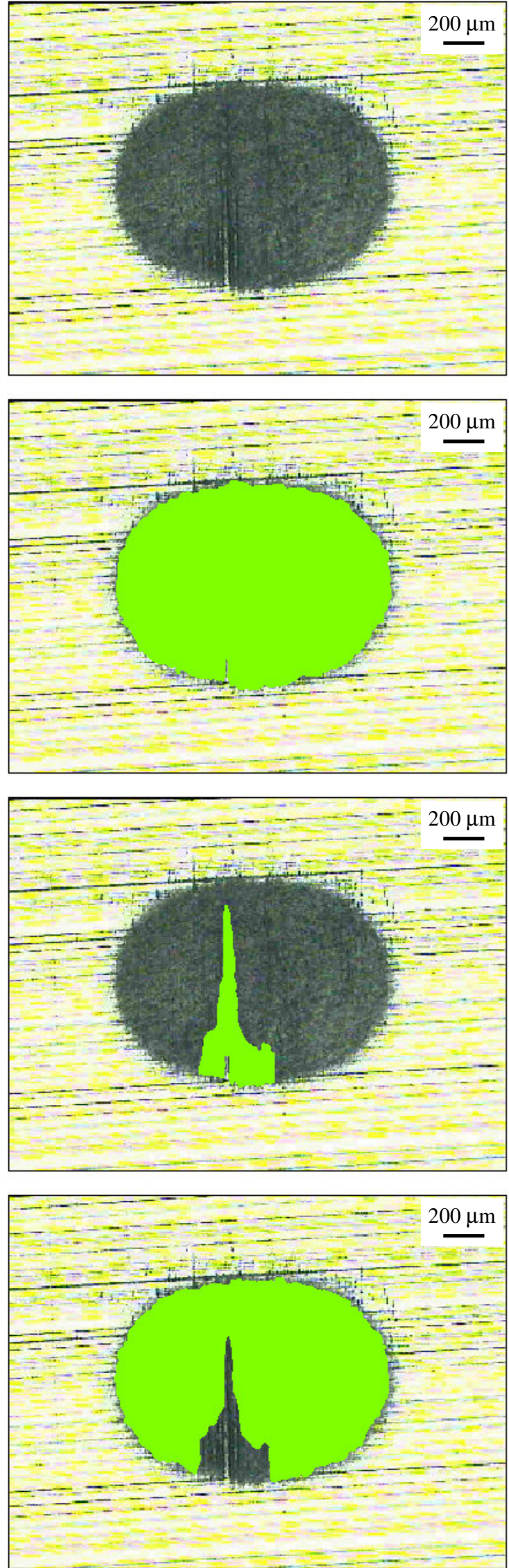

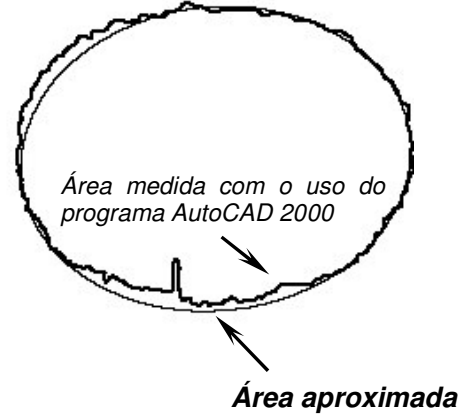

(área elíptica)
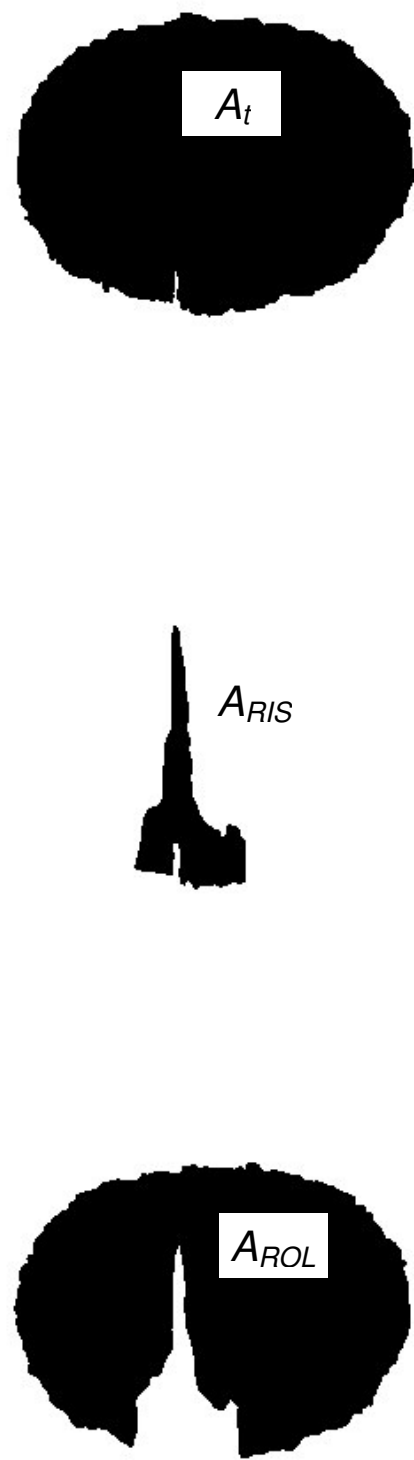

Figura 7.40: Corpo-de-prova de WC-Co P20. Distância de deslizamento de 8 metros. As áreas $A_{t}, A_{R I S}$ e $A_{R O L}$ foram medidas pelo Método 2. Atuação de desgaste abrasivo misto. 

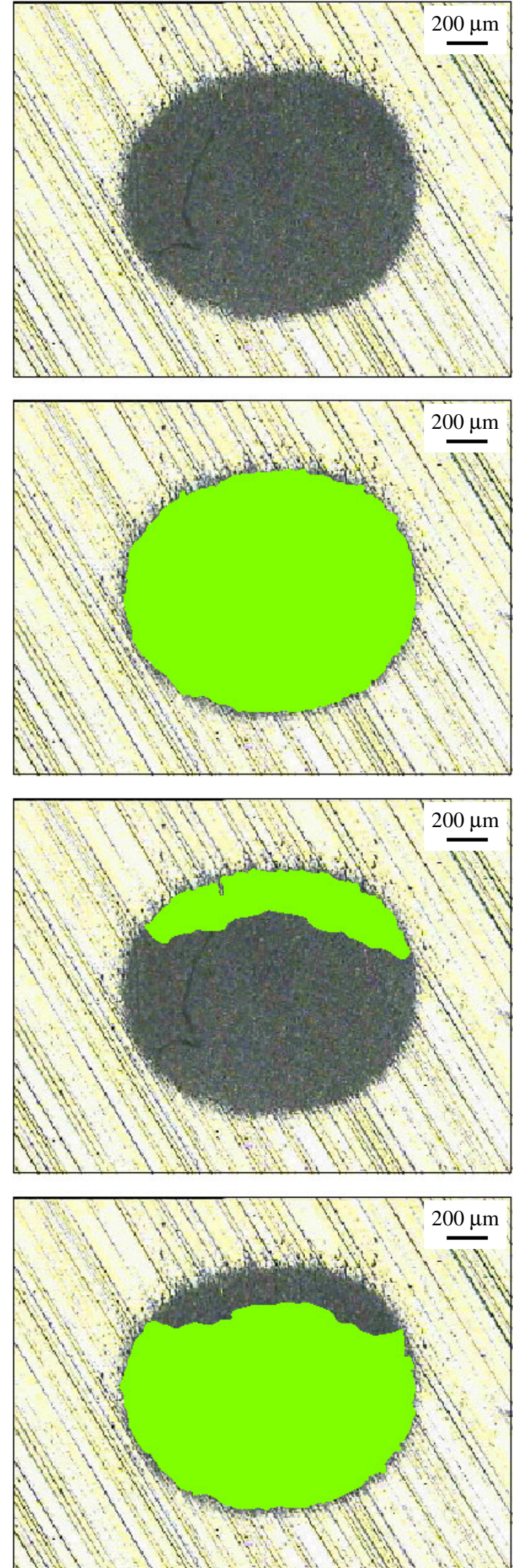

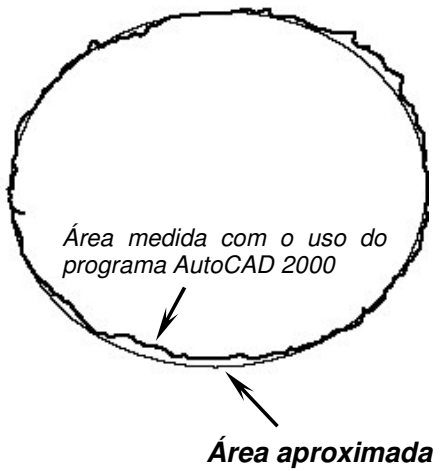

(área elíptica)
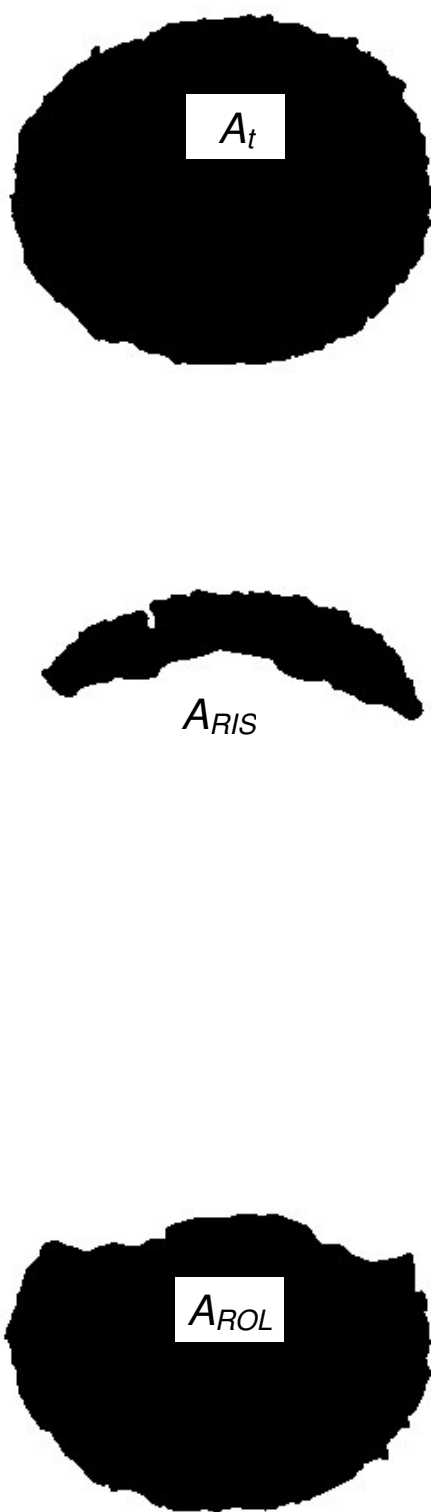

Figura 7.41: Corpo-de-prova de WC-Co P20. Distância de deslizamento de 15 metros. As áreas $A_{t}, A_{R I S}$ e $A_{R O L}$ foram medidas pelo Método 2. Atuação de desgaste abrasivo misto. 

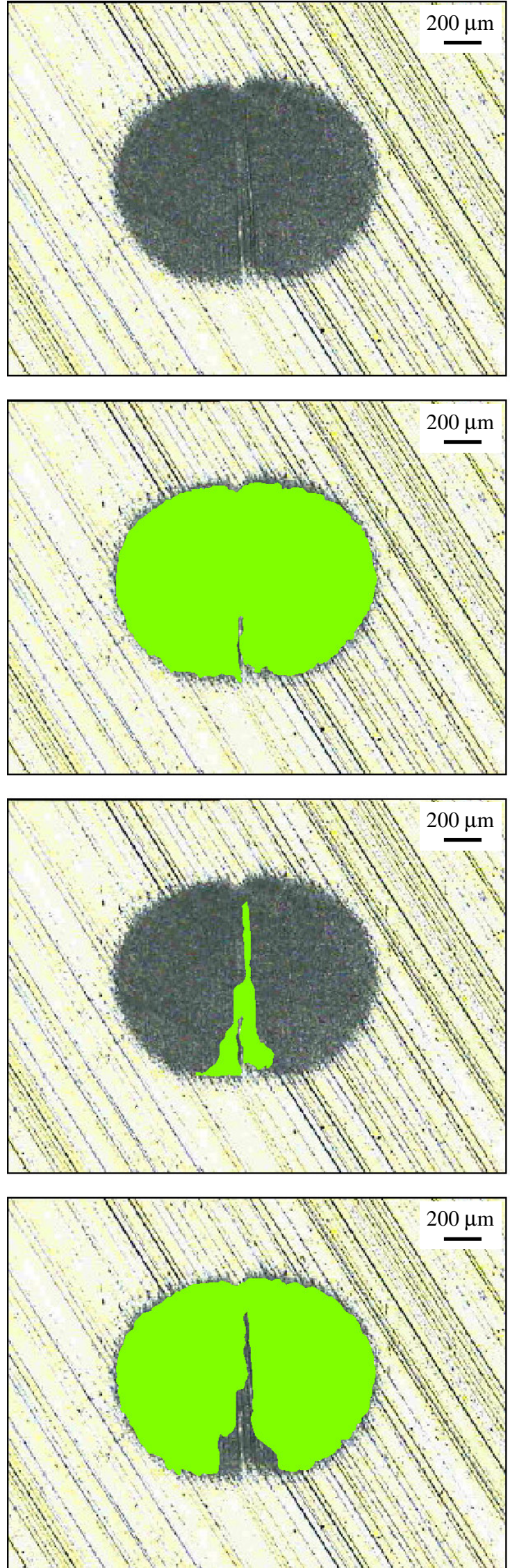

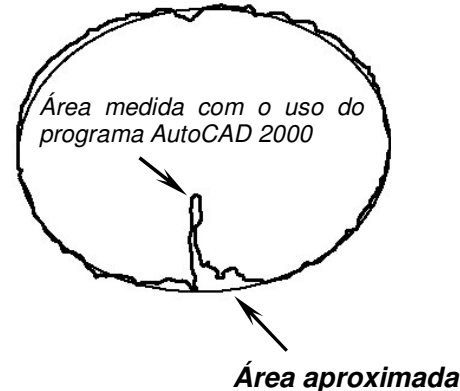

(área elíptica)
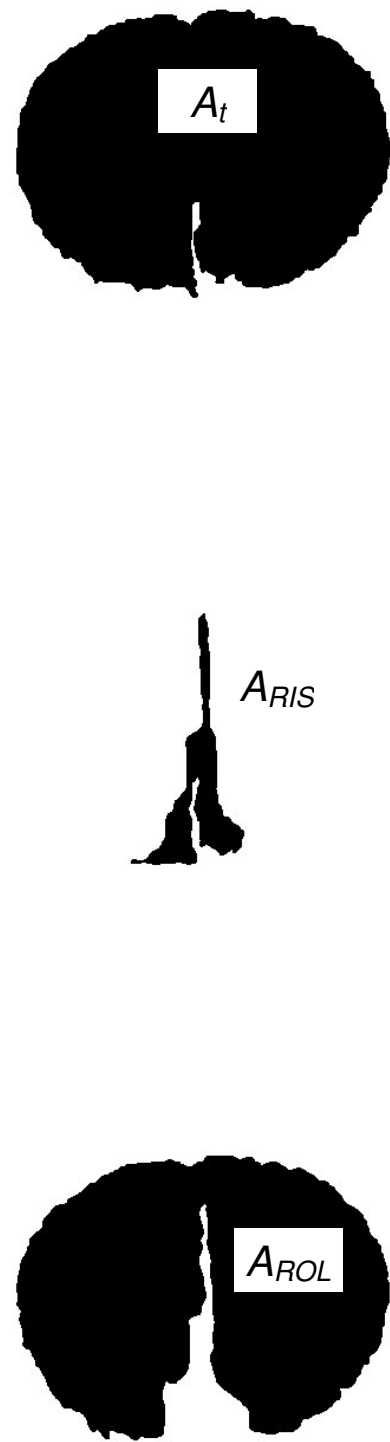

Figura 7.42: Corpo-de-prova de WC-Co P20. Distância de deslizamento de 15 metros. As áreas $A_{t}, A_{R I S}$ e $A_{R O L}$ foram medidas pelo Método 2. Atuação de desgaste abrasivo misto. 

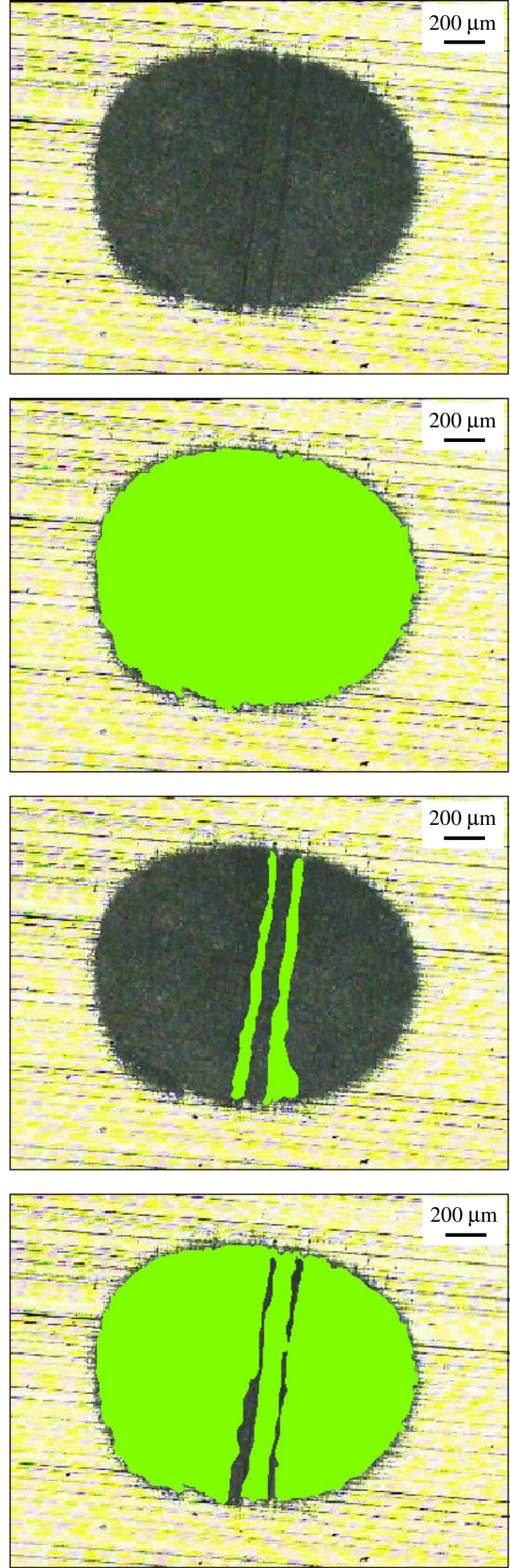

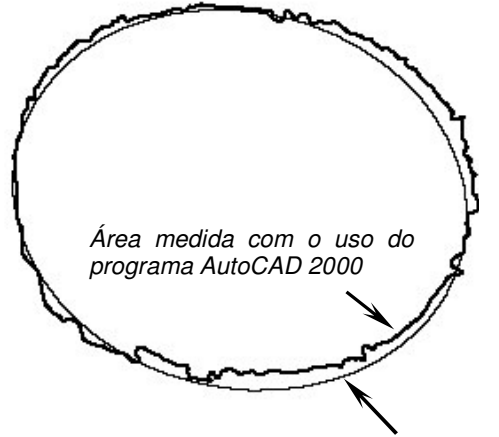

Área aproximada (área elíptica)
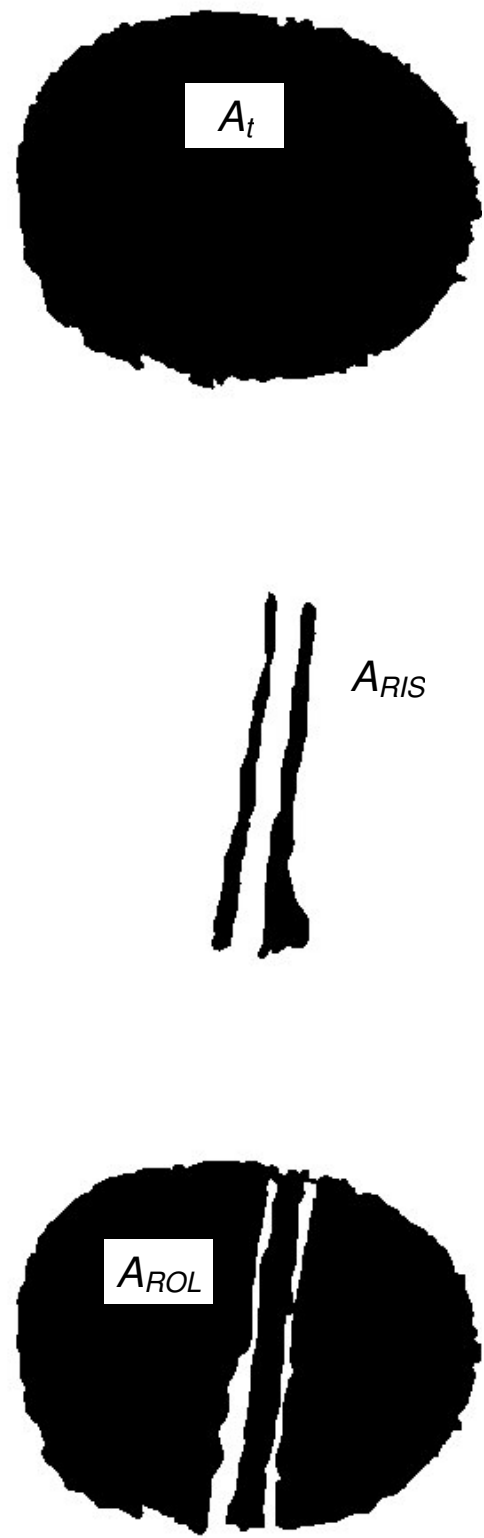

Figura 7.43: Corpo-de-prova de WC-Co P20. Distância de deslizamento de 15 metros. As áreas $A_{t}, A_{R I S}$ e $A_{R O L}$ foram medidas pelo Método 2. Atuação de desgaste abrasivo misto. 

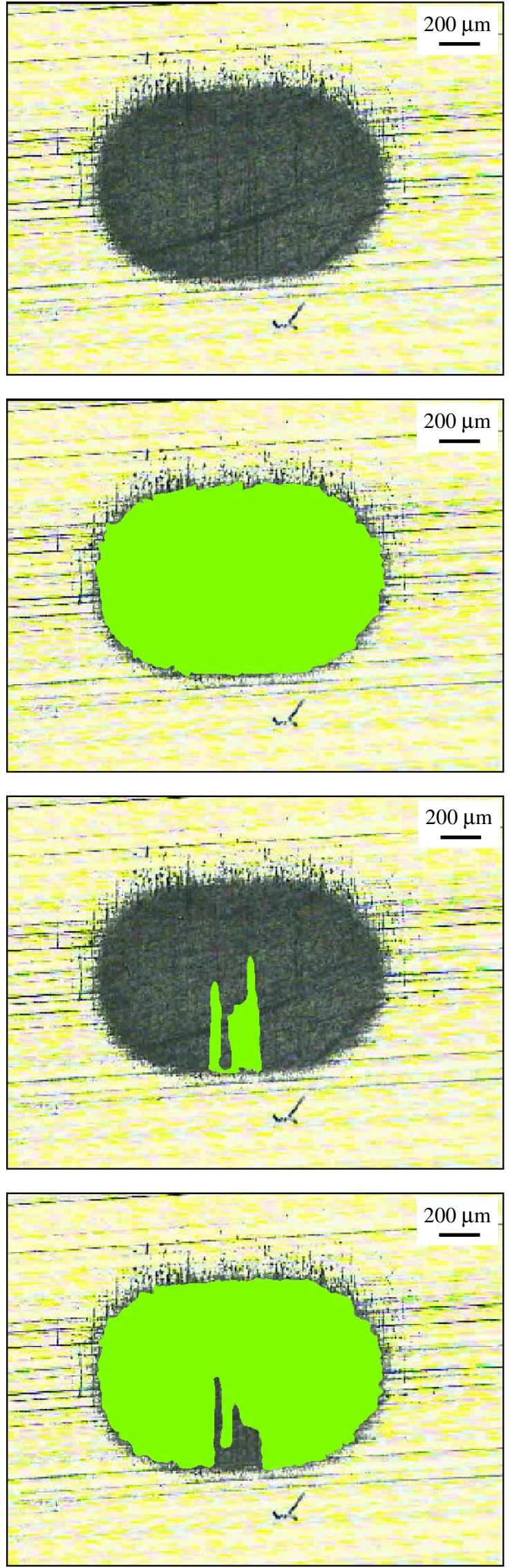

Figura 7.44: Corpo-de-prova de WC-Co P20. Distância de deslizamento de 15 metros. As áreas $A_{t}, A_{R I S}$ e $A_{R O L}$ foram medidas pelo Método 2. Atuação de desgaste abrasivo misto.
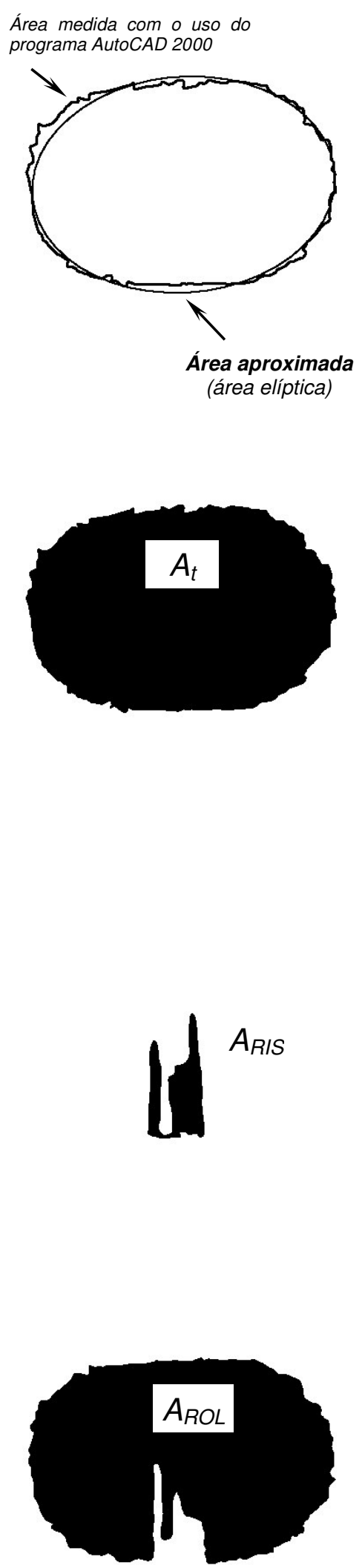

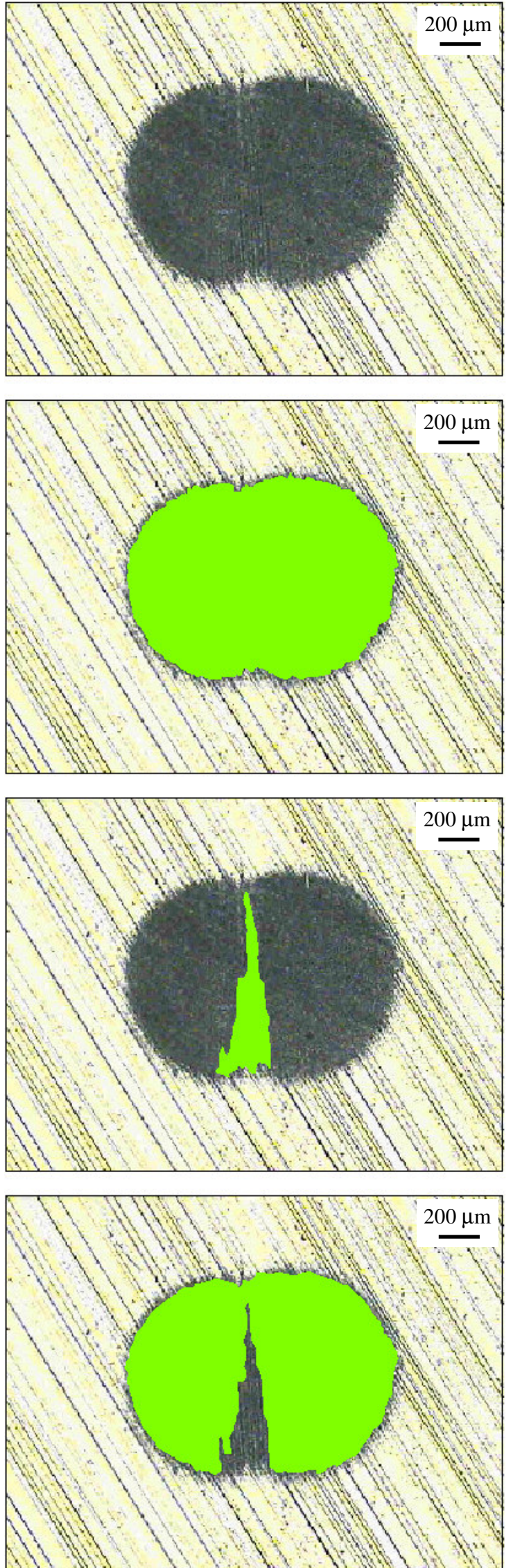
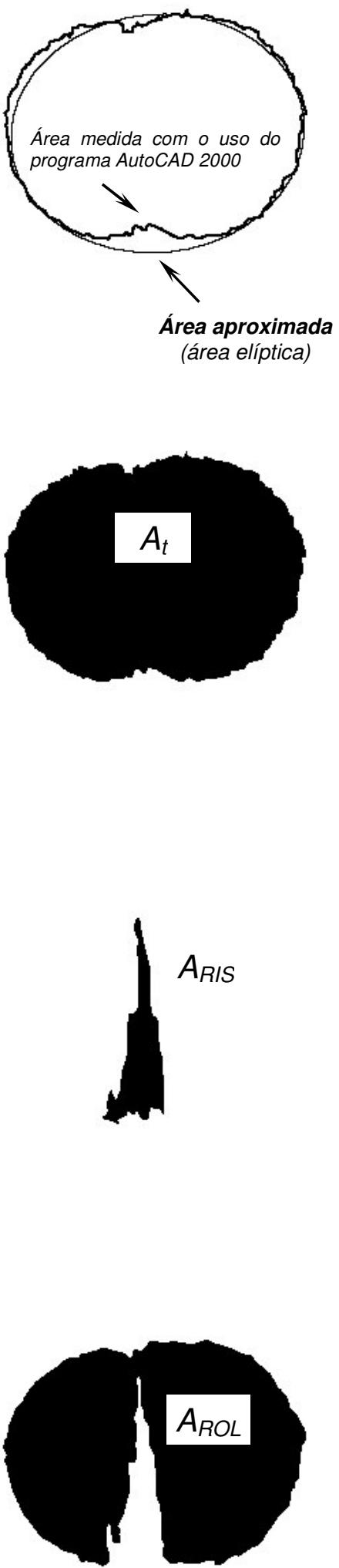

Figura 7.45: Corpo-de-prova de WC-Co P20. Distância de deslizamento de 20 metros. As áreas $A_{t}, A_{R I S}$ e $A_{R O L}$ foram medidas pelo Método 2. Atuação de desgaste abrasivo misto. 

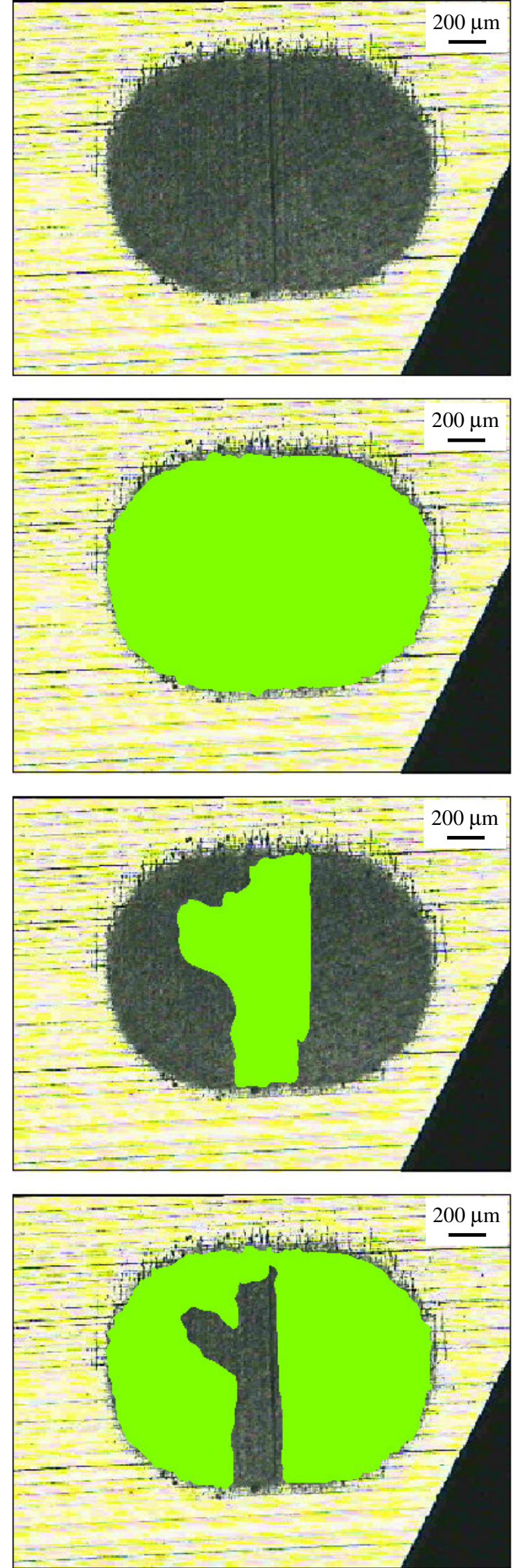

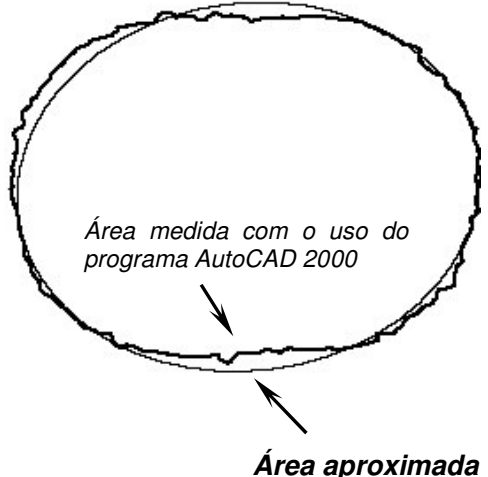

(área elíptica)
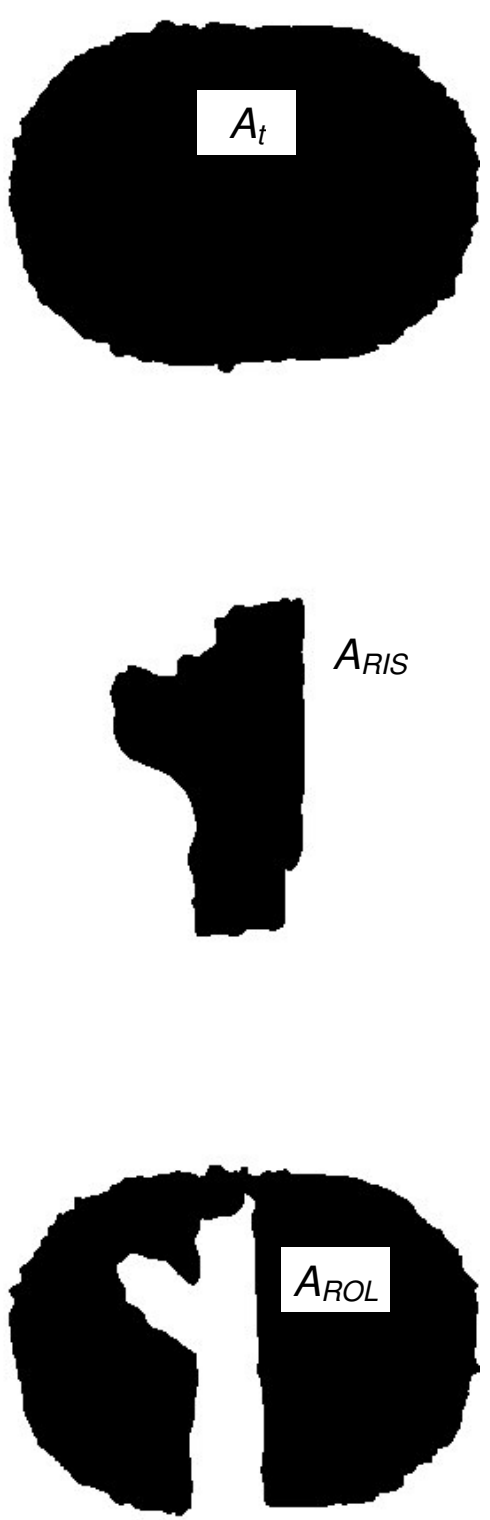

Figura 7.46: Corpo-de-prova de WC-Co P20. Distância de deslizamento de 20 metros. As áreas $A_{t}, A_{R I S}$ e $A_{R O L}$ foram medidas pelo Método 2. Atuação de desgaste abrasivo misto. 

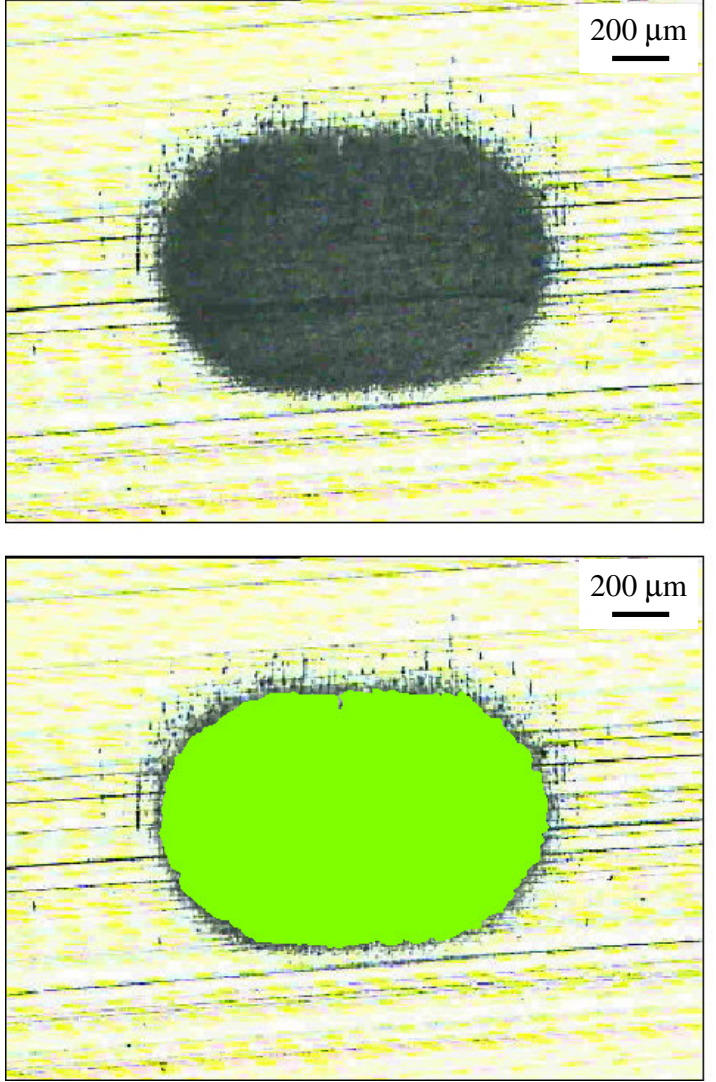

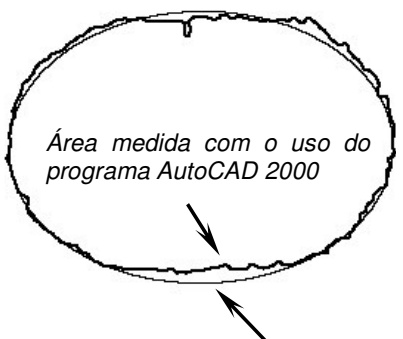

Área aproximada (área elíptica)

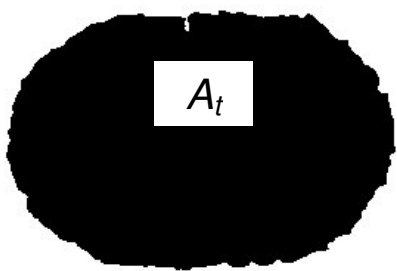

Figura 7.47: Corpo-de-prova de WC-Co P20. Distância de deslizamento de 20 metros. $A$ área $A_{t}$ foi medida pelo Método 2. Atuação de desgaste abrasivo por rolamento $\left(A_{t}=A_{R O L}\right)$.
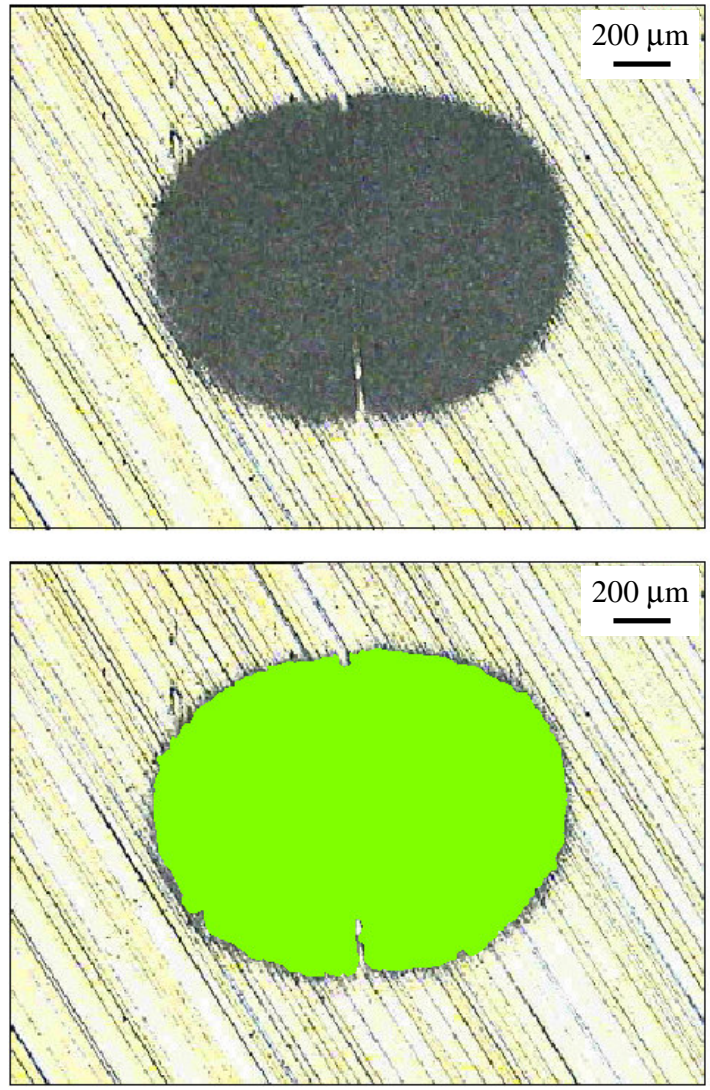
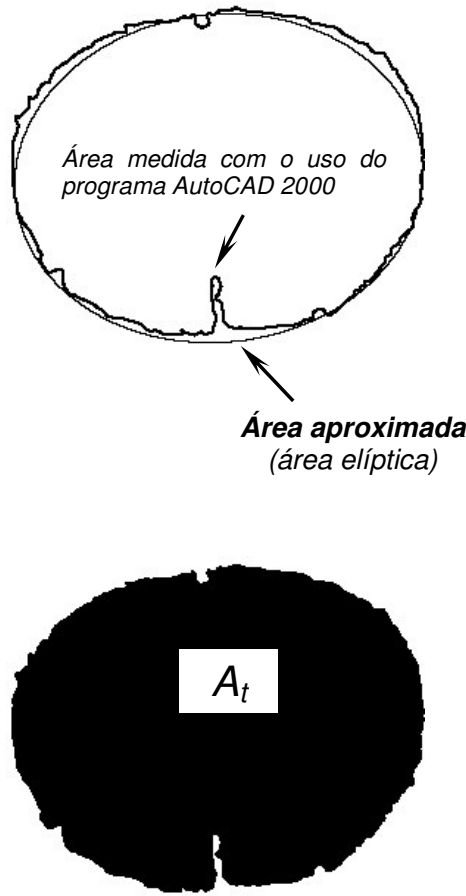

Figura 7.48: Corpo-de-prova de WC-Co P20. Distância de deslizamento de 20 metros. $A$ área $A_{t}$ foi medida pelo Método 2. Atuação de desgaste abrasivo por rolamento $\left(A_{t}=A_{R O L}\right)$. 

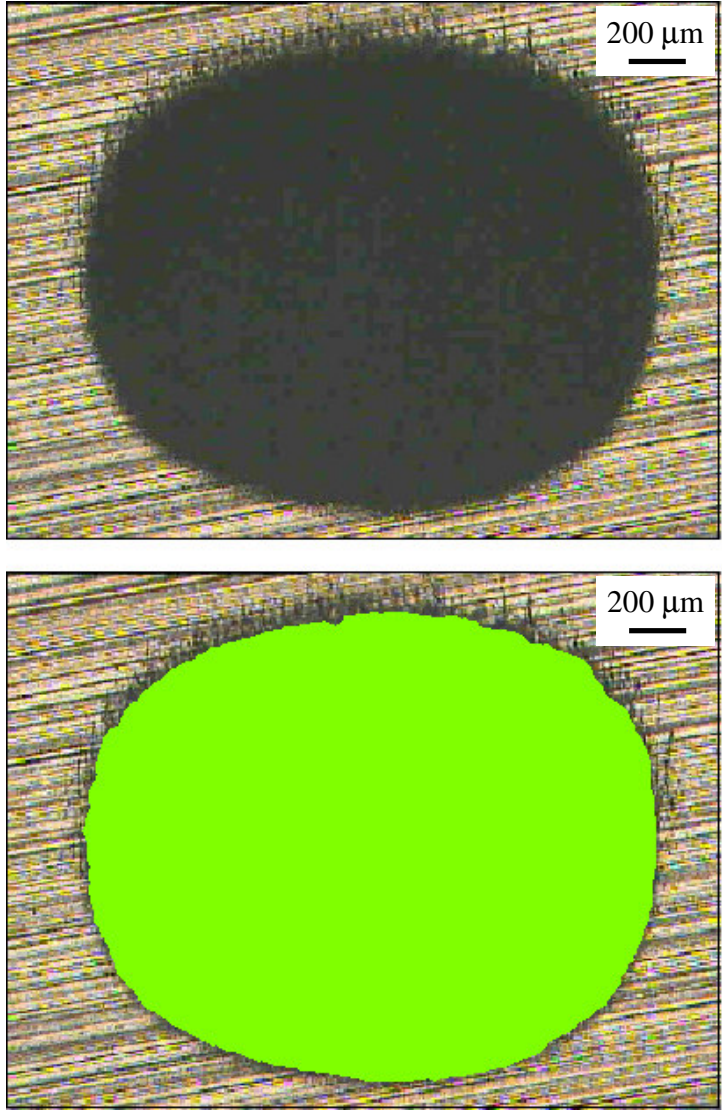

Figura 7.49: Corpo-de-prova de WC-Co P20. Distância de deslizamento de 25 metros. $A$ área $A_{t}$ foi medida pelo Método 2. Atuação de desgaste abrasivo por rolamento $\left(A_{t}=A_{R O L}\right)$.
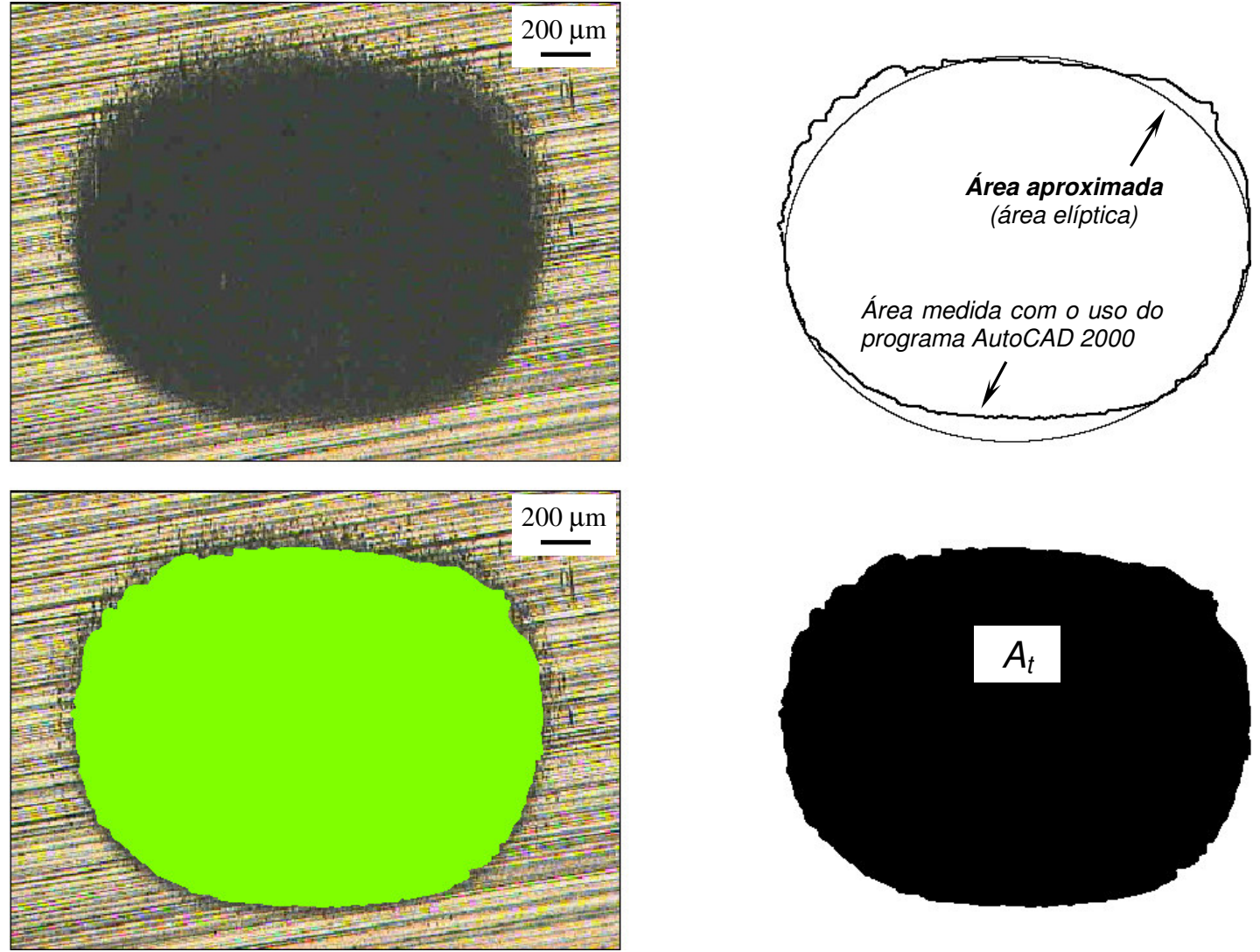

Figura 7.50: Corpo-de-prova de WC-Co P20. Distância de deslizamento de 35 metros. A área $A_{t}$ foi medida pelo Método 2. Atuação de desgaste abrasivo por rolamento $\left(A_{t}=A_{R O L}\right)$. 

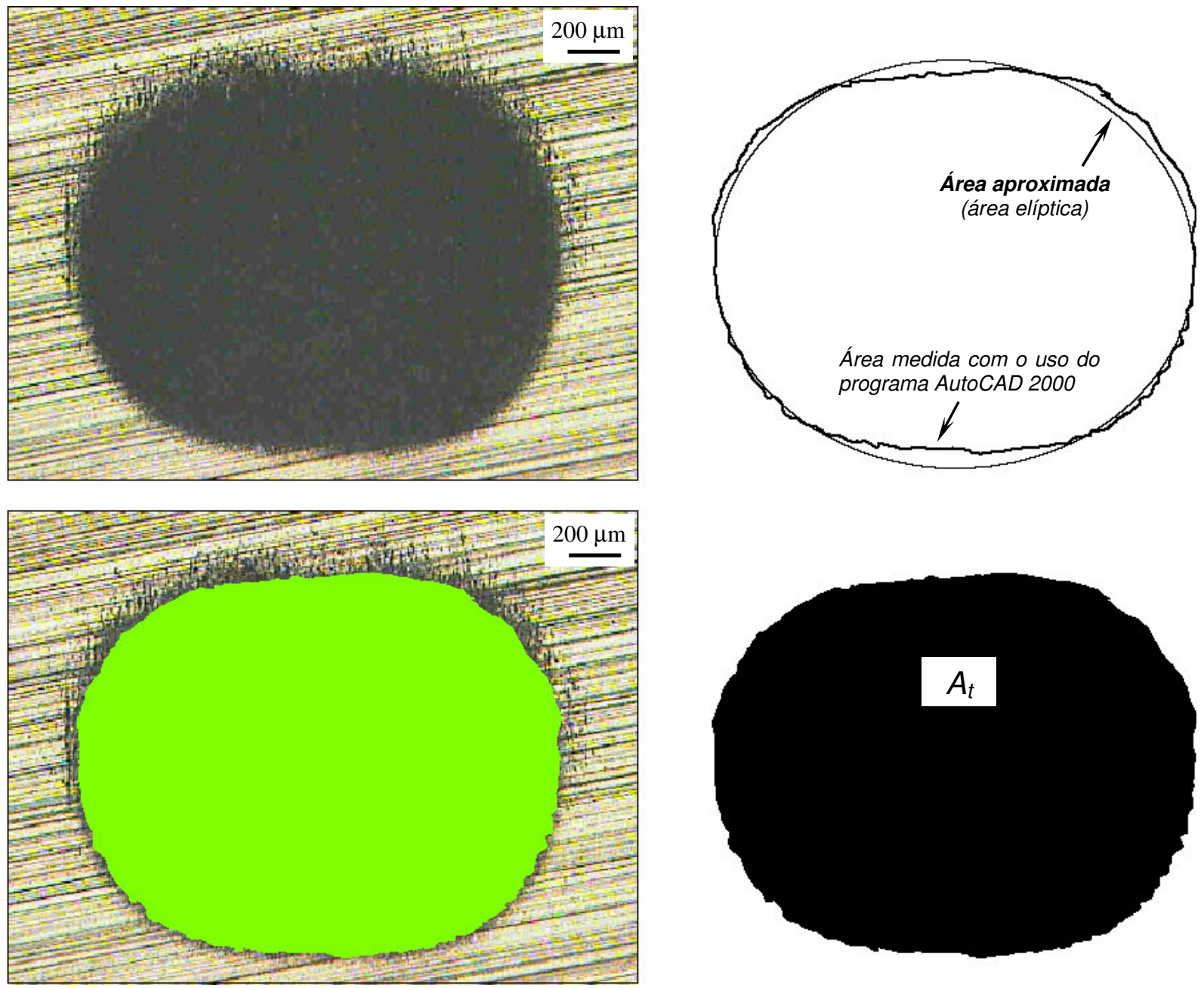

Figura 7.51: Corpo-de-prova de WC-Co P20. Distância de deslizamento de 40 metros. $A$ área $A_{t}$ foi medida pelo Método 2. Atuação de desgaste abrasivo por rolamento $\left(A_{t}=A_{R O L}\right)$. 


\subsubsection{Contornos das crateras de desgaste}

Nos ensaios realizados com os corpos-de-prova de aço ferramenta $M 2$, todas as calotas esféricas geradas com as distâncias de 15, 20, 25, 35 e 40 metros exibiram contornos tendendo a uma circunferência, como pode ser observado nas Figuras 7.4 à 7.11. Porém, os contornos das crateras obtidas com 8 metros, tenderam a uma elipse (Figuras 7.2 e 7.3). Em relação aos corpos-de-prova de WC-Co P20, todas as crateras de desgaste apresentaram contornos com tendência a uma elipse, como mostram as Figuras 7.23 à 7.36.

A Tabela 7.5 mostra os valores de $\boldsymbol{A}_{\boldsymbol{t}}$ para os corpos-de-prova de aço ferramenta M2, calculados pelos Métodos 1 e 2. Na Tabela 7.6 estão os resultados obtidos com os corpos-de-prova de WC-Co P20. Os valores das áreas $\boldsymbol{A}_{t}$ referentes ao HSS M2 já haviam sido relatadas nas Tabelas 7.1 e 7.2 e, as áreas $\boldsymbol{A}_{\boldsymbol{t}}$ concernentes ao WC-Co P20, nas Tabelas 7.3 e 7.4. Mas, para facilitar a leitura, esses resultados foram sintetizados nas Tabelas 7.5 e 7.6 .

A Figura 7.52 exibe o gráfico de $\boldsymbol{A}_{\boldsymbol{t}}=f(S)$ para os corpos-de-prova de aço ferramenta $M 2$ e, a Figura 7.53, para os corpos-de-prova de WC-Co P20. Nesses gráficos, estão superpostos os valores de $\boldsymbol{A}_{t}$ determinados pelos Métodos 1 e 2 .

Tabela 7.5: Corpos-de-prova de aço ferramenta M2. Valores de $A_{t}$ obtidos pelos Métodos 1 e 2.

\begin{tabular}{|c|c|c|c|c|c|c|c|c|c|}
\hline DIST. DESL. (S) & GRANDEZA & MÉTODO & ENSAIO 1 & ENSAIO 2 & ENSAIO 3 & ENSAIO 4 & MÉDIA & DESV. PAD. & ERRO \\
\hline \multirow{2}{*}{8 metros } & \multirow{2}{*}{$\boldsymbol{A}_{\boldsymbol{t}}\left[\mathrm{mm}^{2}\right]$} & 1 & 0,822 & 0,933 & 0,874 & 0,959 & 0,897 & - & - \\
\hline & & 2 & 0,709 & 0,811 & 0,669 & 0,601 & 0,698 & 0,088 & 0,044 \\
\hline \multirow{2}{*}{15 metros } & \multirow{2}{*}{$\boldsymbol{A}_{\boldsymbol{t}}\left[\mathrm{mm}^{2}\right]$} & 1 & 1,440 & 1,412 & 1,470 & 1,489 & 1,453 & - & - \\
\hline & & 2 & 1,478 & 1,323 & 1,401 & - & 1,401 & 0,078 & 0,045 \\
\hline \multirow{2}{*}{20 metros } & \multirow{2}{*}{$\boldsymbol{A}_{\boldsymbol{t}}\left[\mathrm{mm}^{2}\right]$} & 1 & 1,631 & 1,537 & 1,557 & 1,590 & 1,579 & - & - \\
\hline & & 2 & 1,604 & 1,523 & 1,401 & 1,387 & 1,479 & 0,103 & 0,052 \\
\hline \multirow{2}{*}{25 metros } & \multirow{2}{*}{$\boldsymbol{A}_{\boldsymbol{t}}\left[\mathrm{mm}^{2}\right]$} & 1 & 1,663 & 1,737 & 1,670 & 1,713 & 1,696 & - & - \\
\hline & & 2 & 1,686 & 1,711 & 1,650 & - & 1,682 & 0,031 & 0,018 \\
\hline \multirow{2}{*}{35 metros } & \multirow{2}{*}{$\boldsymbol{A}_{\boldsymbol{t}}\left[\mathrm{mm}^{2}\right]$} & 1 & 1,597 & 1,784 & 1,520 & 1,654 & 1,639 & - & - \\
\hline & & 2 & 1,696 & 1,563 & 1,433 & 1,501 & 1,548 & 0,112 & 0,056 \\
\hline \multirow{2}{*}{40 metros } & \multirow{2}{*}{$\boldsymbol{A}_{\boldsymbol{t}}\left[\mathrm{mm}^{2}\right]$} & 1 & 2,868 & 3,002 & 3,110 & 3,123 & 3,026 & - & - \\
\hline & & 2 & 2,963 & 2,901 & 2,610 & 2,738 & 2,816 & 0,155 & 0,078 \\
\hline
\end{tabular}




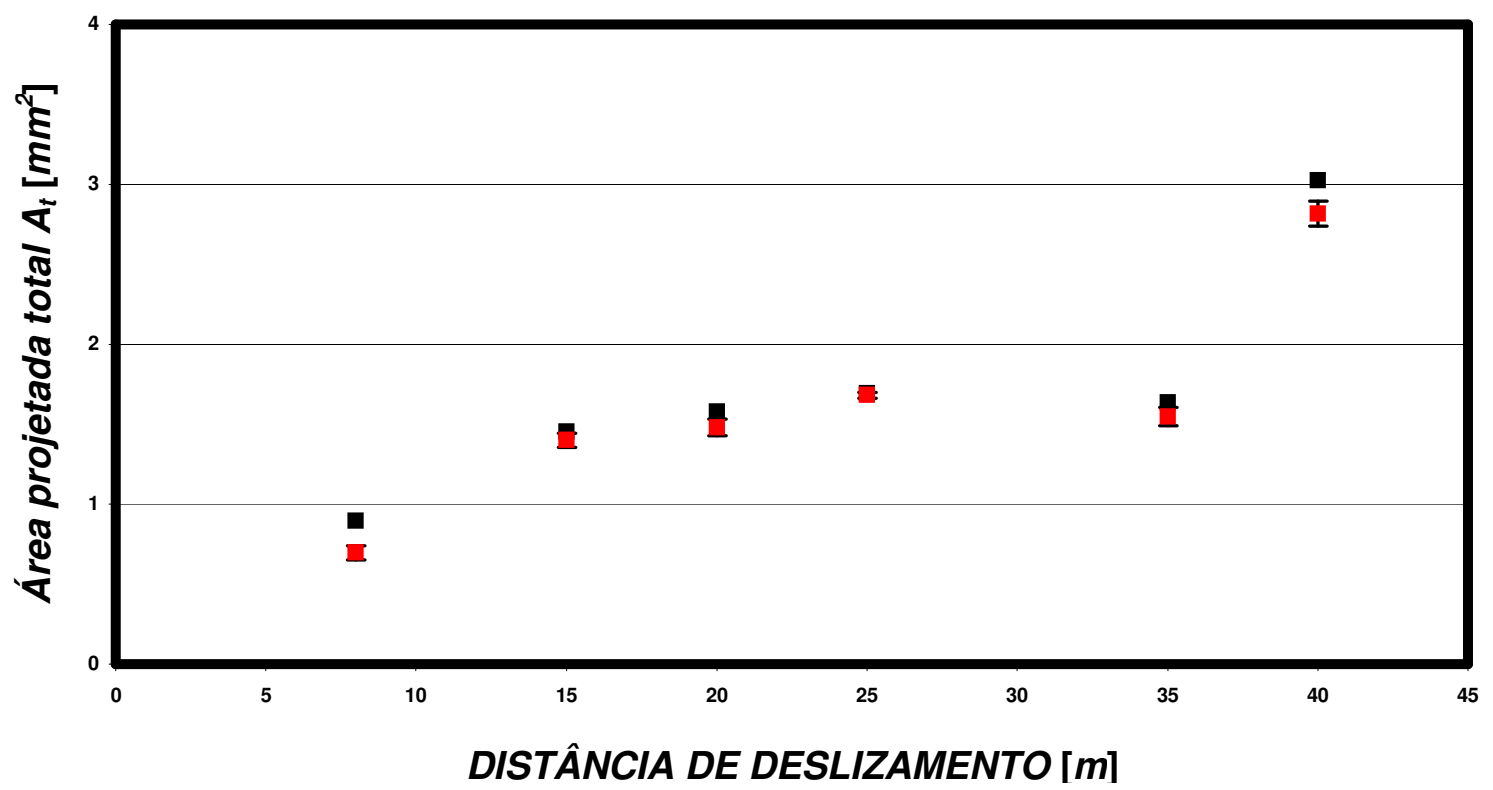

$A_{t}$ obtido pelo Método 1

$A_{t}$ obtido pelo Método 2

Figura 7.52: Corpos-de-prova de aço ferramenta M2. Gráfico de $A_{t}$ em função da distância de deslizamento.

Tabela 7.6: Corpos-de-prova de WC-Co P20. Valores de $A_{t}$ obtidos pelos Métodos 1 e 2.

\begin{tabular}{|c|c|c|c|c|c|c|c|c|c|}
\hline DIST. DESL. (S) & GRANDEZA & MÉTODO & ENSAIO 1 & ENSAIO 2 & ENSAIO 3 & ENSAIO 4 & MÉDIA & DESV. PAD. & ERRO \\
\hline \multirow{2}{*}{8 metros } & \multirow{2}{*}{$\boldsymbol{A}_{\boldsymbol{t}}\left[\mathrm{mm}^{2}\right]$} & 1 & 1,150 & 1,613 & 1,483 & 1,656 & 1,475 & - & - \\
\hline & & 2 & 1,120 & 1,298 & 0,930 & - & 1,116 & 0,184 & 0,106 \\
\hline \multirow{2}{*}{15 metros } & \multirow{2}{*}{$\boldsymbol{A}_{\boldsymbol{t}}\left[\mathrm{mm}^{2}\right]$} & 1 & 1,663 & 1,307 & 2,013 & 1,595 & 1,644 & - & - \\
\hline & & 2 & 1,406 & 1,002 & 1,656 & 1,148 & 1,303 & 0,289 & 0,144 \\
\hline \multirow{2}{*}{20 metros } & \multirow{2}{*}{$\boldsymbol{A}_{\boldsymbol{t}}\left[\mathrm{mm}^{2}\right]$} & 1 & 1,711 & 1,379 & 2,031 & 1,427 & 1,637 & - & - \\
\hline & & 2 & 1,368 & 1,104 & 1,619 & 1,044 & 1,274 & 0,277 & 0,138 \\
\hline \multirow{2}{*}{25 metros } & \multirow{2}{*}{$\boldsymbol{A}_{\boldsymbol{t}}\left[\mathrm{mm}^{2}\right]$} & 1 & 3,113 & 2,841 & 2,938 & 2,668 & 2,890 & - & - \\
\hline & & 2 & 2,680 & 2,442 & 2,808 & - & 2,643 & 0,186 & 0,107 \\
\hline \multirow{2}{*}{35 metros } & \multirow{2}{*}{$\boldsymbol{A}_{\boldsymbol{t}}\left[\mathrm{mm}^{2}\right]$} & 1 & 2,889 & 2,744 & 3,002 & 2,820 & 2,864 & - & - \\
\hline & & 2 & 2,356 & 2,811 & 2,665 & - & 2,611 & 0,232 & 0,134 \\
\hline \multirow{2}{*}{40 metros } & \multirow{2}{*}{$\boldsymbol{A}_{\boldsymbol{t}}\left[\mathrm{mm}^{2}\right]$} & 1 & 2,865 & 2,901 & 2,639 & 2,548 & 2,738 & - & - \\
\hline & & 2 & 2,409 & 2,781 & 2,352 & - & 2,514 & 0,233 & 0,135 \\
\hline
\end{tabular}




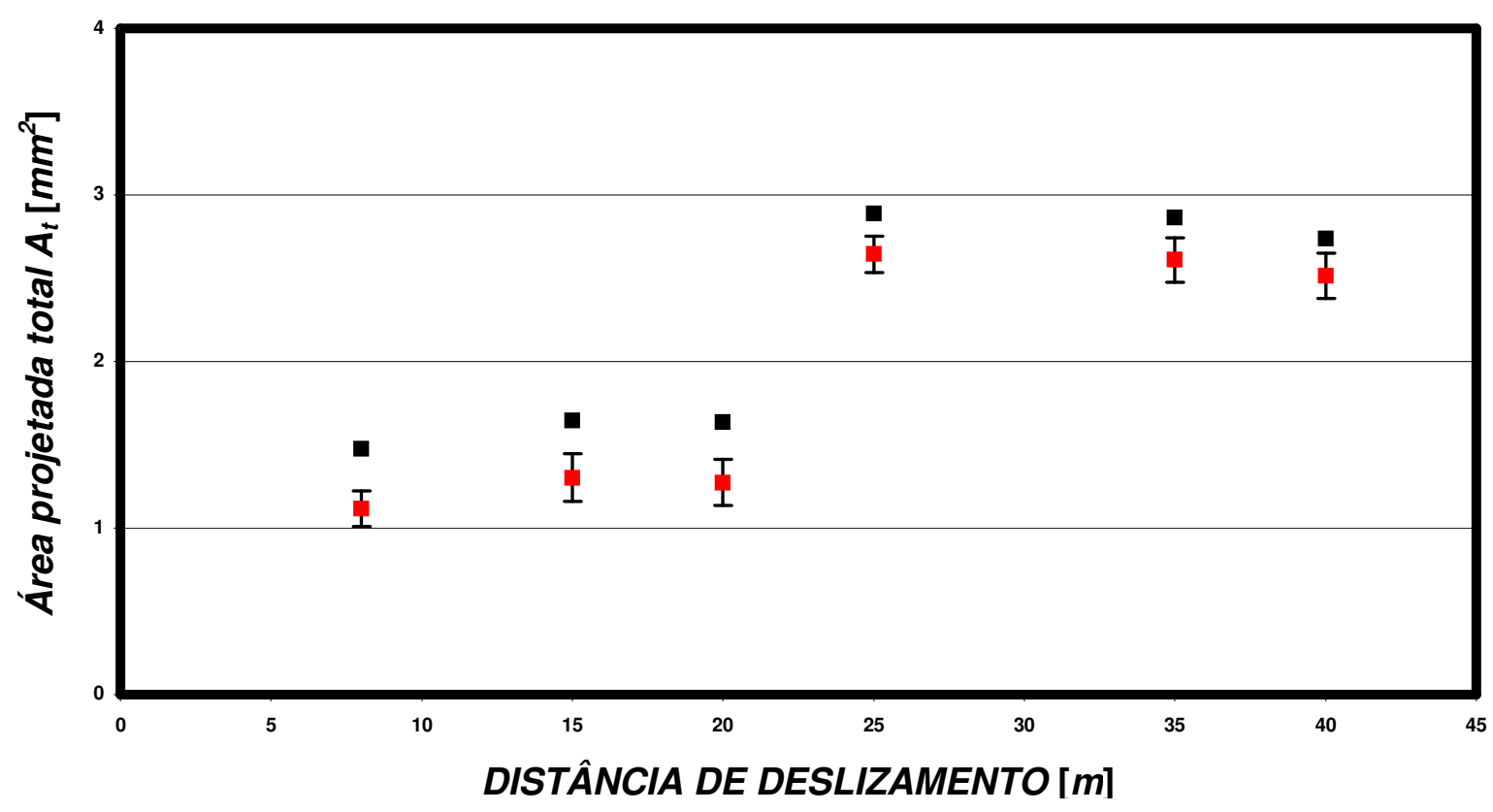

$A_{t}$ obtido pelo Método 1

$A_{t}$ obtido pelo Método 2

Figura 7.53: Corpos-de-prova de WC-Co P20. Gráfico de $A_{t}$ em função da distância de deslizamento.

Para a explicação dos gráficos das Figuras 7.52 e 7.53 , as áreas $\boldsymbol{A}_{t}$ calculadas pelo Método 1 receberão o expoente " 1 ", sendo denotadas por $\boldsymbol{A}_{t}^{1}$. As áreas $\boldsymbol{A}_{\boldsymbol{t}}$ determinadas pelo Método 2, receberão o expoente ' 2 ', sendo indicadas por $\boldsymbol{A}_{t}^{2}$.

Pelas Figuras 7.52 e 7.53 (ou, pelas Tabelas 7.5 e 7.6), nota-se que, para todos os valores médios, ocorreu $\boldsymbol{A}_{t}^{1}>\boldsymbol{A}_{t}^{2}$. A explicação desse comportamento está relacionada ao critério estabelecido para o Método 1 , onde $\boldsymbol{A}_{t}^{1}$ considera a cratera de desgaste como uma circunferência perfeita, sem qualquer imperfeição em seu contorno. $\boldsymbol{A}_{t}^{2}$ é um valor mais preciso, que atenta, além das imperfeições, para o fato do contorno da cratera tender, ou não, a uma elipse. É devido a essas formas distintas de análise do contorno da cratera que ocorre a diferença entre $\boldsymbol{A}_{t}^{1}$ e $\boldsymbol{A}_{t}^{2}$.

Para ambos corpos-de-prova, em algumas análises ocorreu $\boldsymbol{A}_{\boldsymbol{t}}^{\mathbf{1}}<\boldsymbol{A}_{\boldsymbol{t}}^{2}$. Nas Tabelas 7.5 e 7.6, esses valores estão sombreados de cinza. Porém, pode-se dizer que esses resultados foram exceções e não necessitam de uma discussão mais detalhada. 
Nos parágrafos seguintes, será explicado geometricamente o motivo pelo qual as crateras de desgaste apresentam contornos com tendência a uma circunferência ou a uma elipse.

A partir de um determinado grau de desgaste, as crateras apresentarão contornos com tendência a uma elipse. Esse fato tem influência direta no cálculo das dimensões da cratera de desgaste. Uma precisa circularidade conduz a valores confiáveis de $\boldsymbol{h}, \boldsymbol{V}$ e $\boldsymbol{A}_{\boldsymbol{t}}$, caso essas grandezas sejam calculadas em função de $\boldsymbol{d}$. Por outro lado, além da própria medição do diâmetro, a má formação da cratera de desgaste (caracterizada pelo contorno tendendo a uma elipse) acarreta cálculos errôneos de suas dimensões.

Quando a esfera está com um "baixo" nível de desgaste na linha de trabalho, o que irá formar a calota esférica no corpo-de-prova é o arco $\widehat{A B}$, cujo raio $\left(\boldsymbol{R}_{\boldsymbol{A B}}\right)$ é igual (ou, aproximadamente) ao raio da esfera $(\boldsymbol{R})$. Com isso, para $\boldsymbol{R}_{A B}=\boldsymbol{R}$, ou $\boldsymbol{R}_{A B} \cong \boldsymbol{R}$, o contorno da cratera de desgaste tenderá a uma circunferência, como é ilustrado na Figura 7.54.

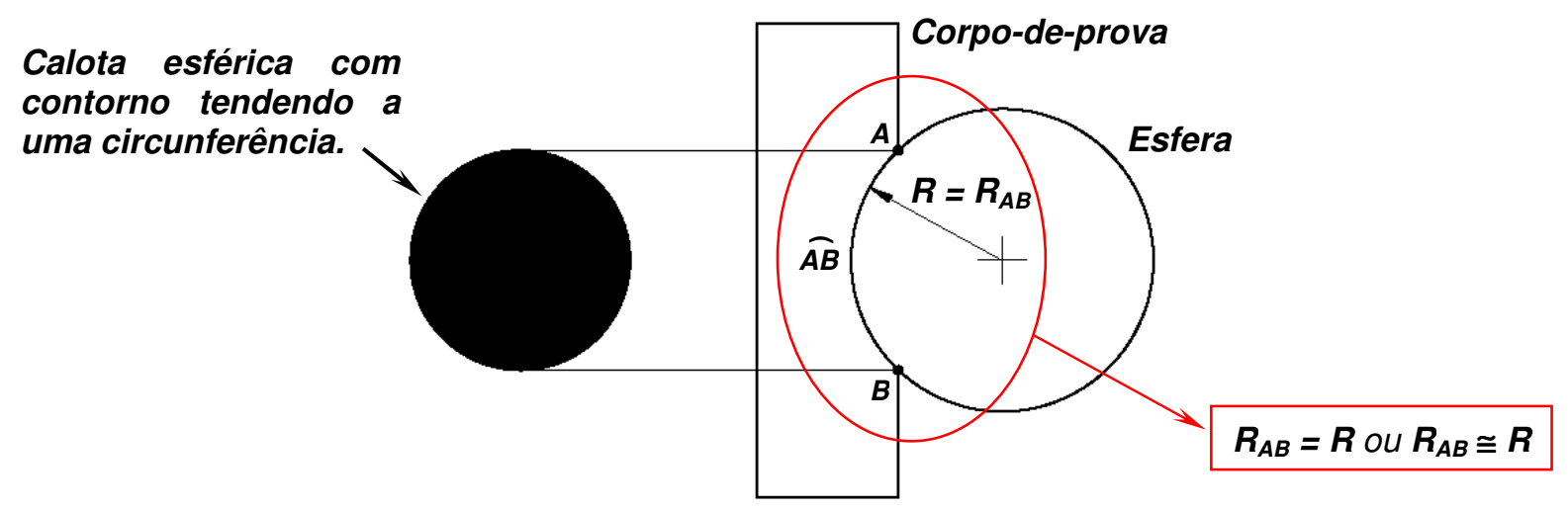

Figura 7.54: Quando $R_{A B}=R$ ou $R_{A B} \cong R$, o contorno da cratera de desgaste tenderá a uma circunferência.

Conforme os ensaios vão sendo realizados, a esfera, inevitavelmente, vai sofrendo desgaste. Isso faz com que o arco $\widehat{A B}$ não tenha mais o mesmo raio da esfera. O novo raio de $\widehat{A B}$ será $\boldsymbol{R}_{\boldsymbol{A B}}$ ', com $\boldsymbol{R}_{\boldsymbol{A B}}$ ' $>\boldsymbol{R}$, e o contorno da cratera de desgaste tenderá a uma elipse, como mostra a Figura 7.55. 


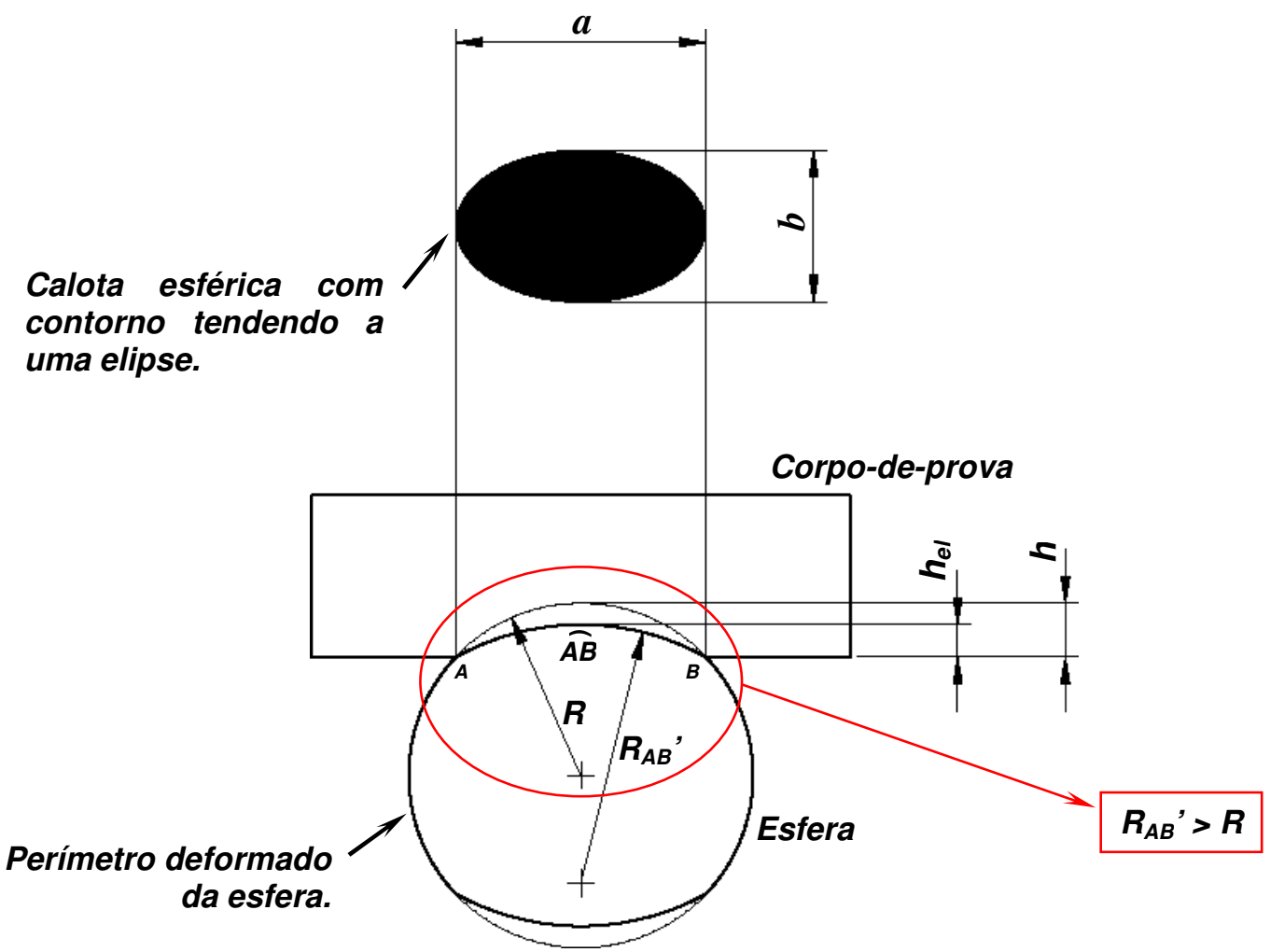

Figura 7.55: Quando $R_{A B}$ ' $>R$, o contorno da cratera de desgaste tende a uma elipse.

Analisando-se a área elíptica de diagonais " $a$ " e "b" da Figura 7.55, observa-se que é possível obter diversos valores de $\boldsymbol{d}, \operatorname{com} \boldsymbol{b} \leq \boldsymbol{d} \leq \boldsymbol{a}$. Como a área $\boldsymbol{A}_{\boldsymbol{t}}$ pode ser calculada em função de $\boldsymbol{d}$, se $\boldsymbol{d}=\boldsymbol{a}$, será obtido um valor de $\boldsymbol{A}_{\boldsymbol{t}}$ maior que o real e, se $\boldsymbol{d}=\boldsymbol{b}$, um valor menor. Como $\boldsymbol{h}$ é determinado em função de $\boldsymbol{d}$, o valor dessa dimensão também será impreciso. Além disso, pela Figura 7.55, nota-se ainda que $\boldsymbol{h}_{\boldsymbol{e} l}<\boldsymbol{h}$, onde $\boldsymbol{h}_{\boldsymbol{e l}}$ é a altura da cratera de desgaste quando seu contorno tende a uma elipse e, $\boldsymbol{h}$, quando tende a uma circunferência. Em relação a $\boldsymbol{V}$, como essa dimensão pode ser calculada tanto em função de $\boldsymbol{d}$ (Rutherford e Hutchings, 1997), quanto em função $\boldsymbol{h}$ (Equação 2.3), conseqüentemente será obtido um resultado inexato.

A Figura 7.56 compara as crateras de desgaste exibidas nas Figuras 7.4 e 7.27, referentes aos corpos-de-prova de aço ferramenta M2 e WC-Co P20, respectivamente. Nota-se que, o contorno da cratera de desgaste da Figura 7.4, tendeu a uma circunferência, e o contorno da cratera da Figura 7.27, a uma elipse. 


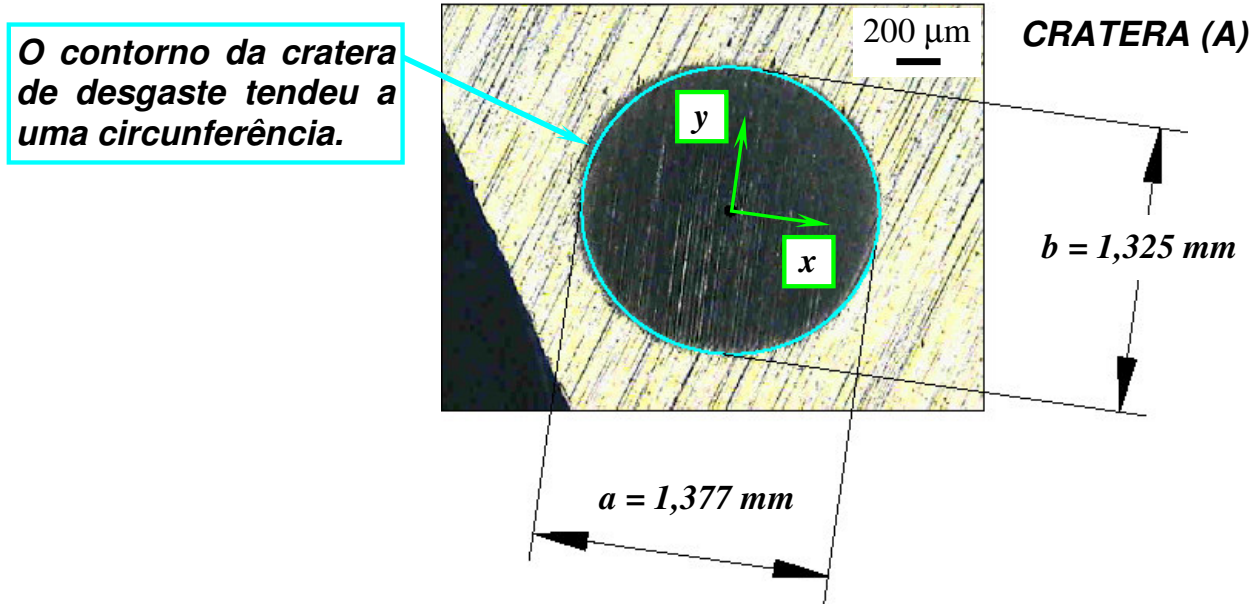

O contorno da cratera de desgaste tendeu a uma elipse.

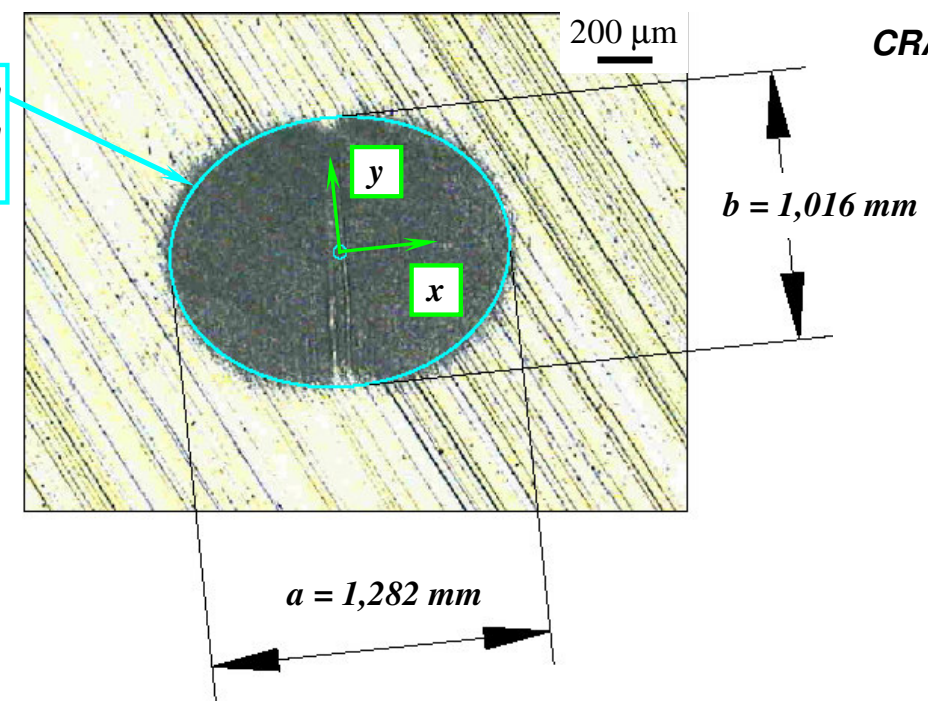

CRATERA (B)

Figura 7.56: CRATERA (A): ensaio realizado em um corpo-de-prova de aço ferramenta M2. Contorno da cratera de desgaste tendendo a uma circunferência. CRATERA (B): ensaio realizado em um corpo-de-prova de WC-Co P20. Contorno da cratera de desgaste tendendo a uma elipse.

A rigor, a equação que satisfaz os contornos das crateras de desgaste $(\boldsymbol{A})$ e $(\boldsymbol{B})$, é a de uma elipse. Com isso, considerando os planos cartesianos fixados nas crateras, tem-se $\frac{x^{2}}{\left(\frac{a}{2}\right)^{2}}+\frac{y^{2}}{\left(\frac{b}{2}\right)^{2}}=1$.

Os resultados da Figura 7.56 mostraram exemplos onde $\boldsymbol{R}_{\boldsymbol{A B}}=\boldsymbol{R}$ (ou, $\left.\boldsymbol{R}_{A B} \cong \boldsymbol{R}\right)$ e $\boldsymbol{R}_{A B}$ ' $>\boldsymbol{R}$. Entretanto, pode ocorrer a situação em que $\boldsymbol{R}_{A B}{ }^{\prime}>>>\boldsymbol{R}$. Nesse caso, a esfera de ensaio vai estar com um nível de desgaste mais elevado do que na situação em que $\boldsymbol{R}_{\boldsymbol{A} \boldsymbol{B}}{ }^{\prime}>\boldsymbol{R}$. Com isso, há um outro tipo de contorno, exibido na Figura 7.57 e aqui denominado de "contorno oblongo". 


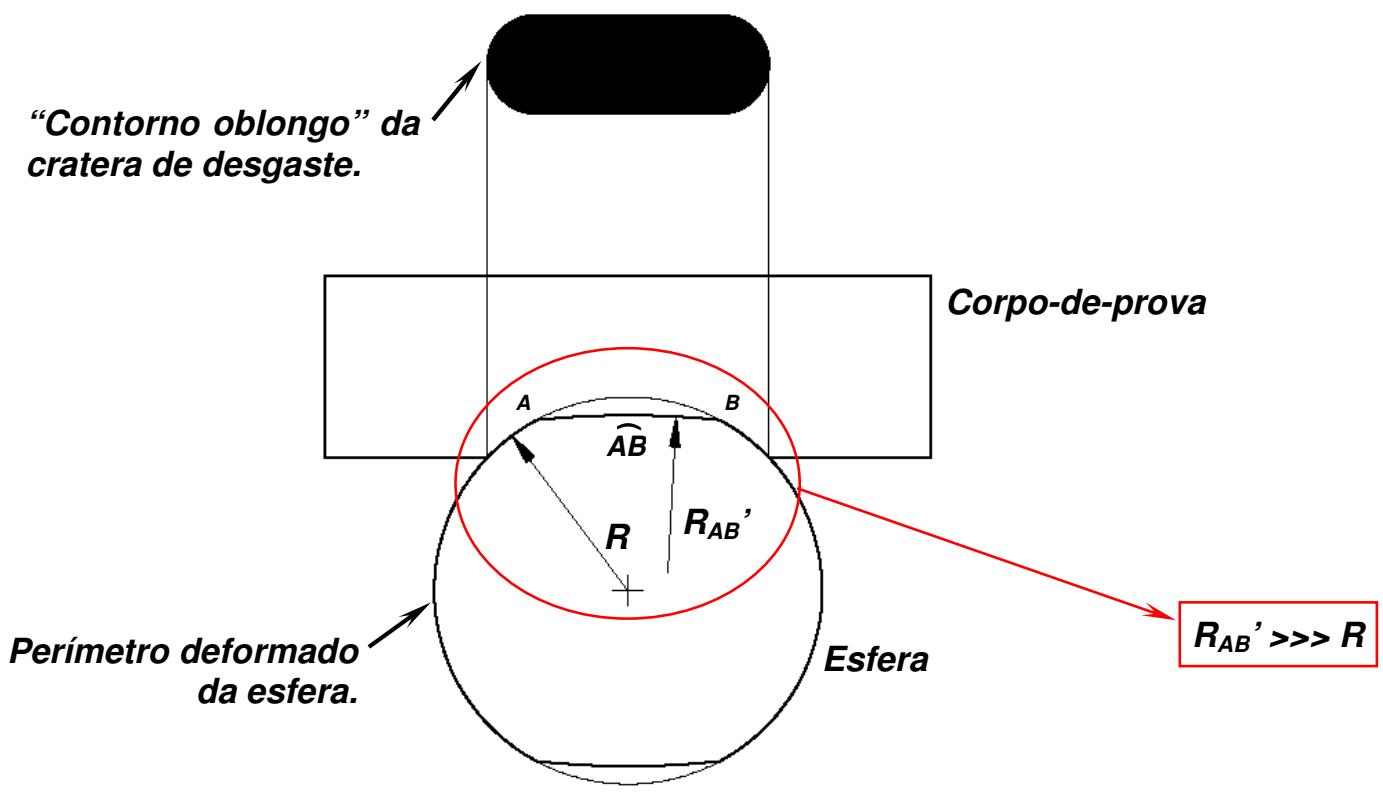

Figura 7.57: Caso em que $\boldsymbol{R}_{A B}$ ' $>$ R. "Contorno oblongo" da cratera de desgaste.

O contorno da Figura 7.57 foi observado em algumas crateras de desgaste geradas nos corpos-de-prova de WC-Co P20 (Figuras 7.29, 7.31, 7.32, 7.33 e 7.36). A Figura 7.58 mostra um exemplo de "contorno oblongo", referente ao contorno da cratera de desgaste da Figura 7.29.

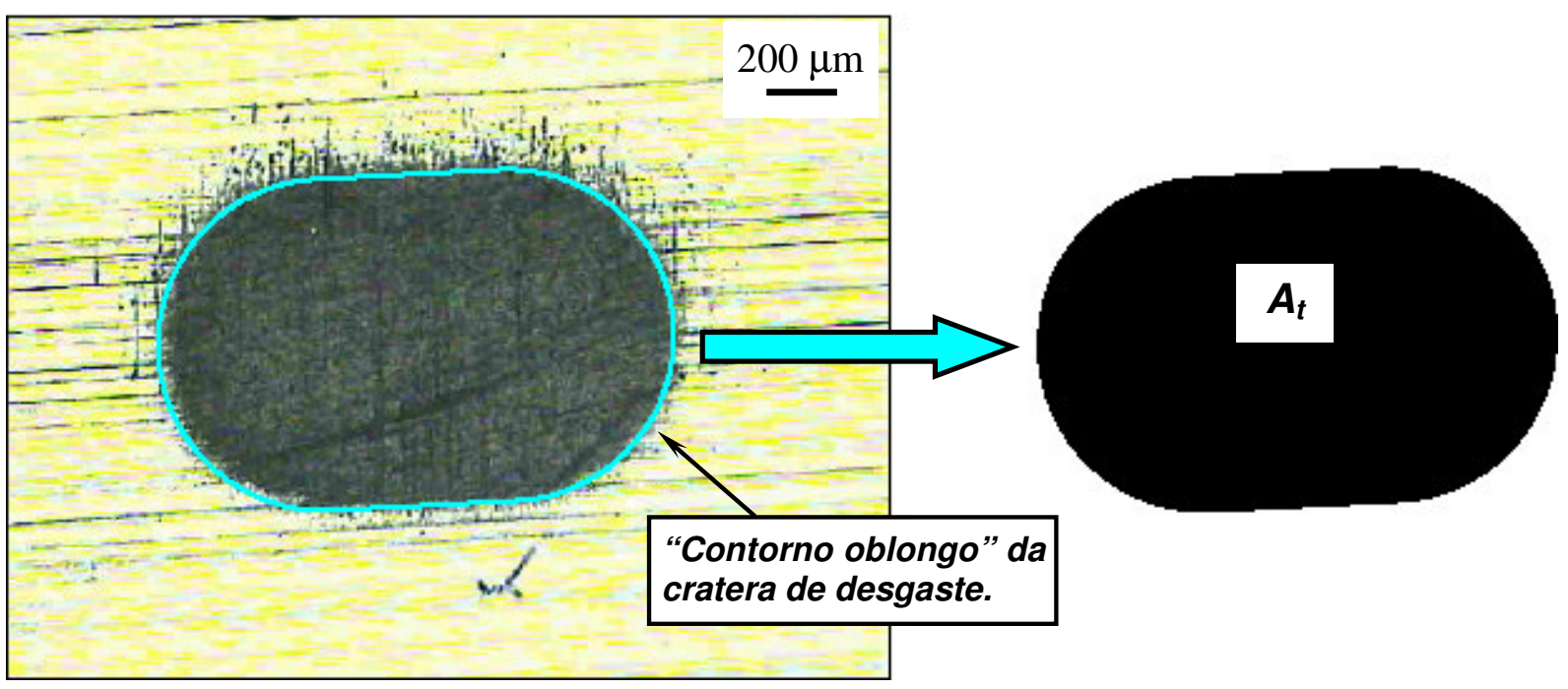

Figura 7.58: "Contorno oblongo" apresentado pela cratera de desgaste gerada em um corpo-de-prova de WC-Co P20.

Nos ensaios realizados com os corpos-de-prova de aço ferramenta $M 2$, as crateras de desgaste não apresentaram nenhum contorno semelhante ao "oblongo". Este resultado é justificável, pois, quando os ensaios foram conduzidos nos corpos- 
de-prova de HSS M2, a esfera não estava com o grau de desgaste necessário para gerar crateras com contornos semelhantes ao da Figura 7.58.

\subsubsection{Relação entre o desgaste da esfera e o desvio-padrão de $d_{\text {médio }}$}

Inicialmente, serão discutidos os resultados obtidos com o HSS M2 e, em seguida, os resultados referentes aos corpos-de-prova de WC-Co P20.

Neste item, $\sigma_{P}$ refere-se ao desvio-padrão de $\boldsymbol{d}_{\text {médio }}$ (média aritmética das quatro medidas de $\boldsymbol{d}$, para cada distância de deslizamento). No caso de crateras com contornos elíptico ou oblongo, a medida $\boldsymbol{d}$ corresponde ao maior diâmetro. $\mathrm{Na}$ Tabela 7.7 estão os valores de $\boldsymbol{d}_{\text {médio }}$ e $\sigma_{\boldsymbol{P}}$, obtidos com o aço ferramenta $M 2$ e com o WC-Co P2O.

Tabela 7.7: Corpos-de-prova de HSS M2 e WC-Co P20. Valores de $d_{\text {médio }}$ e $\sigma_{P .}$

\begin{tabular}{|c|}
\hline $\boldsymbol{S}[\boldsymbol{m}]$ \\
\hline 8 \\
\hline 15 \\
\hline 20 \\
\hline 25 \\
\hline 35 \\
\hline 40 \\
\hline
\end{tabular}

\begin{tabular}{|c|c|c|}
\hline & $\boldsymbol{d}_{\text {médio }}[\mathbf{m m}]$ & $\sigma_{P}[\mathbf{m m}]$ \\
\cline { 2 - 3 } & 1,068 & 0,037 \\
\cline { 2 - 3 } & 1,360 & 0,016 \\
\cline { 2 - 3 } $\mathcal{N}$ & 1,418 & 0,018 \\
\cline { 2 - 3 } & 1,469 & 0,015 \\
\hline & 1,444 & 0,049 \\
\cline { 2 - 3 } & 1,963 & 0,039 \\
\hline
\end{tabular}

\begin{tabular}{|c|c|c|}
\hline \multirow{7}{*}{ 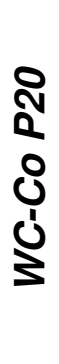 } & $d_{\text {médio }}[\mathrm{mm}]$ & $\sigma_{P}[\mathrm{~mm}]$ \\
\hline & 1,367 & 0,110 \\
\hline & 1,443 & 0,128 \\
\hline & 1,439 & 0,131 \\
\hline & 1,918 & 0,062 \\
\hline & 1,909 & 0,036 \\
\hline & 1,867 & 0,059 \\
\hline
\end{tabular}

A Figura 7.59 mostra a relação de $\sigma_{P}$ com $\Xi$, para os ensaios realizados com o HSS M2 e com o WC-Co P20. Para melhorar a escrita do texto, o termo "nível de desgaste da esfera", algumas vezes será denotado pelo símbolo grego " $\Xi$ " (lê-se, "xi"). 


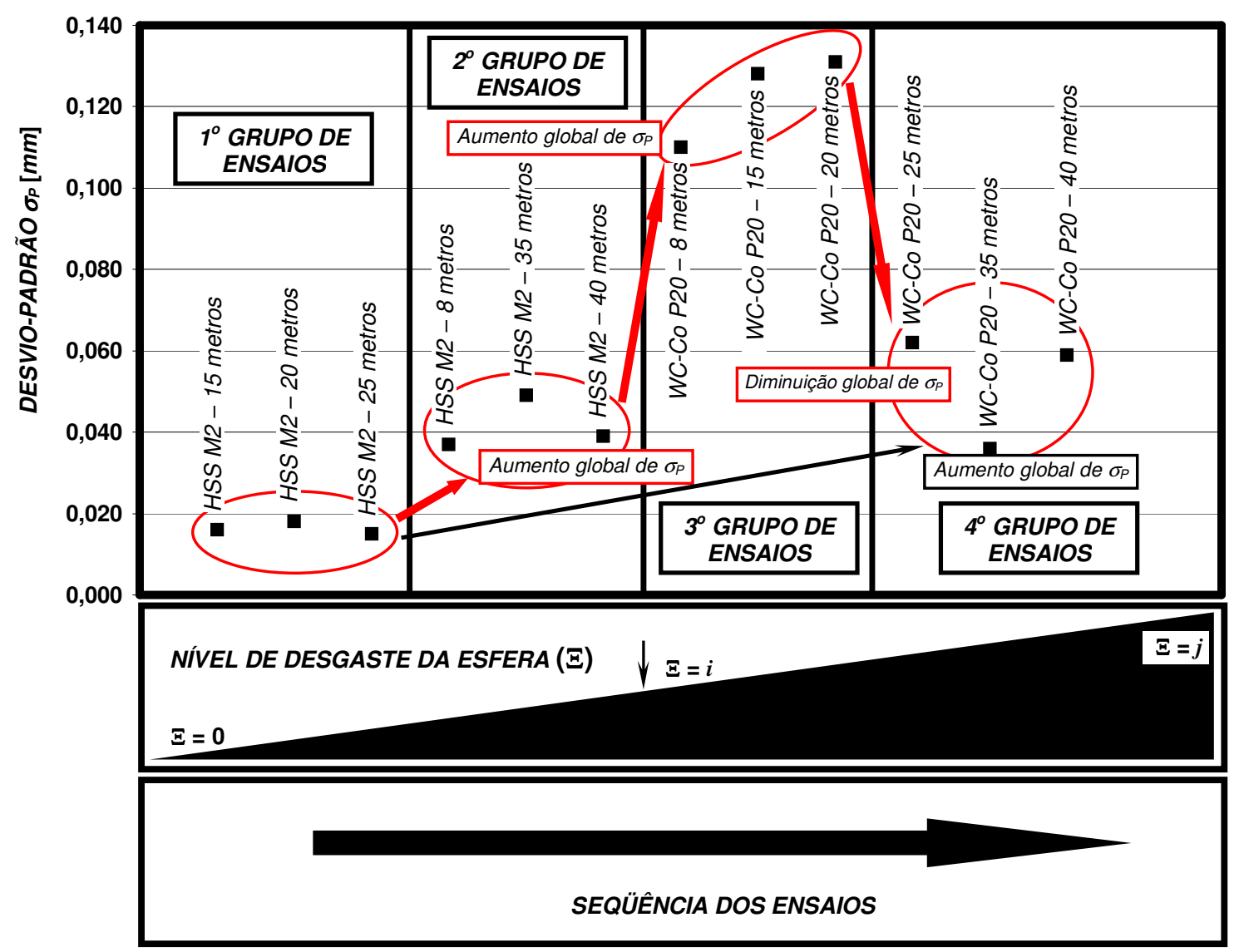

Figura 7.59: Corpos-de-prova de HSS M2 e WC-Co P20. Gráfico de $\sigma_{P}$ em função de $\Xi$.

Nesta Dissertação, convencionou-se que, no início dos ensaios com o HSS M2, $\boldsymbol{\Xi}=0$ e, no final, $\boldsymbol{\Xi}=\boldsymbol{i}$. Logo, é correto afirmar que, com o $W C$-Co $P 20$, a esfera iniciou os ensaios com $\boldsymbol{\Xi}=\boldsymbol{i}$, e terminou com um nível maior de desgaste, $\boldsymbol{\Xi}=\boldsymbol{j}$. " $\boldsymbol{i}$ " e "j" são referências qualitativas, adotadas para indicar que, "no final dos ensaios, a esfera está com um nível de desgaste maior que no início". Matematicamente, é correto escrever que $\boldsymbol{j}>\boldsymbol{i}$. No Item 7.1.8, além de "i" e “ $\boldsymbol{j}$ ", vão ser utilizados mais dois níveis qualitativos de desgaste. Porém, serão atribuídos valores numéricos a $\Xi$, mas não deixará de ser apenas um parâmetro qualitativo.

Analisando-se os dois primeiros grupos de ensaio (HSS M2), nota-se que, todos os valores de $\sigma_{P}$ do $1^{\circ}$ grupo, foram menores que os do $2^{\circ}$. Com os corpos-deprova de $W C$-Co $P 20$ ( $3^{\circ}$ e $4^{\circ}$ grupos), foram obtidos desvios-padrão relativamente elevados, quando comparados aos valores relatados para o HSS M2.

Globalmente, para os $1^{\circ}, 2^{\circ}$ e $3^{\circ}$ grupos, conforme os ensaios foram sendo realizados e, fatalmente o desgaste da esfera foi aumentando, os valores de $\sigma_{P}$ aumentaram. Somente o $4^{\circ}$ grupo não acompanhou essa tendência. 
Pelos resultados obtidos nesta Dissertação, são defendidos os conceitos de que $\boldsymbol{\Xi}$ exerce influência sobre $\sigma_{P}$, e que $\sigma_{P}$ tende a aumentar com o aumento de $\boldsymbol{\Xi}$ (embora a transição do $3^{\circ}$ para o $4^{\circ}$ grupo mostre um contra-exemplo).

\subsubsection{Atuação dos modos de desgaste abrasivo}

Os Itens 7.1.1 e 7.1.2 mostraram, para o HSS M2, os gráficos de $A_{R O a} / A_{R I S}=f(S)$ obtidos pelos Métodos 1 e 2, respectivamente. Os gráficos do WC-Co P20 foram exibidos nos Itens 7.1.3 e 7.1.4, respectivamente para os Métodos 1 e 2. Para cada material, seus respectivos gráficos foram superpostos. A Figura 7.60 refere-se ao aço ferramenta M2 e, a Figura 7.61, ao WC-Co P20.

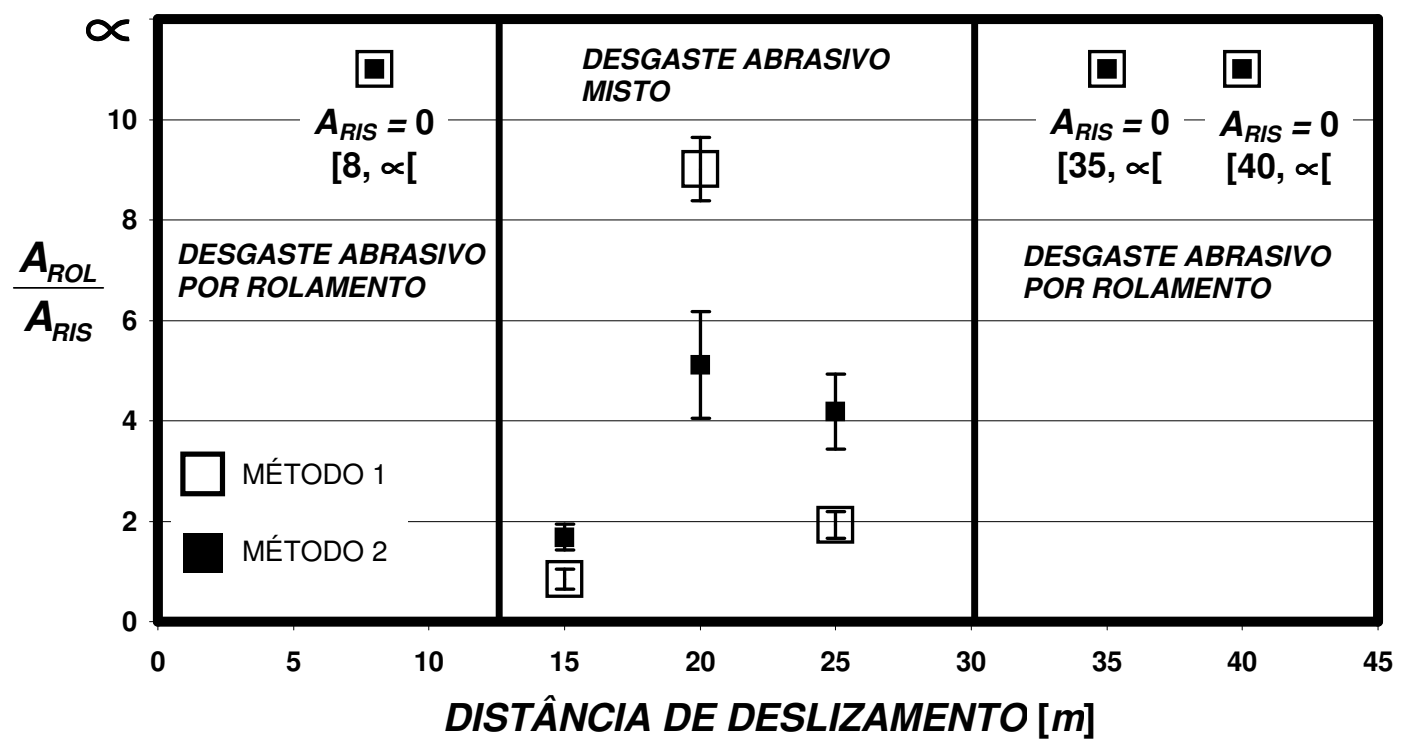

Figura 7.60: Corpos-de-prova de aço ferramenta M2. Sobreposição dos valores de $A_{R O L} / A_{R I S}$ obtidos pelos Métodos 1 e 2. 


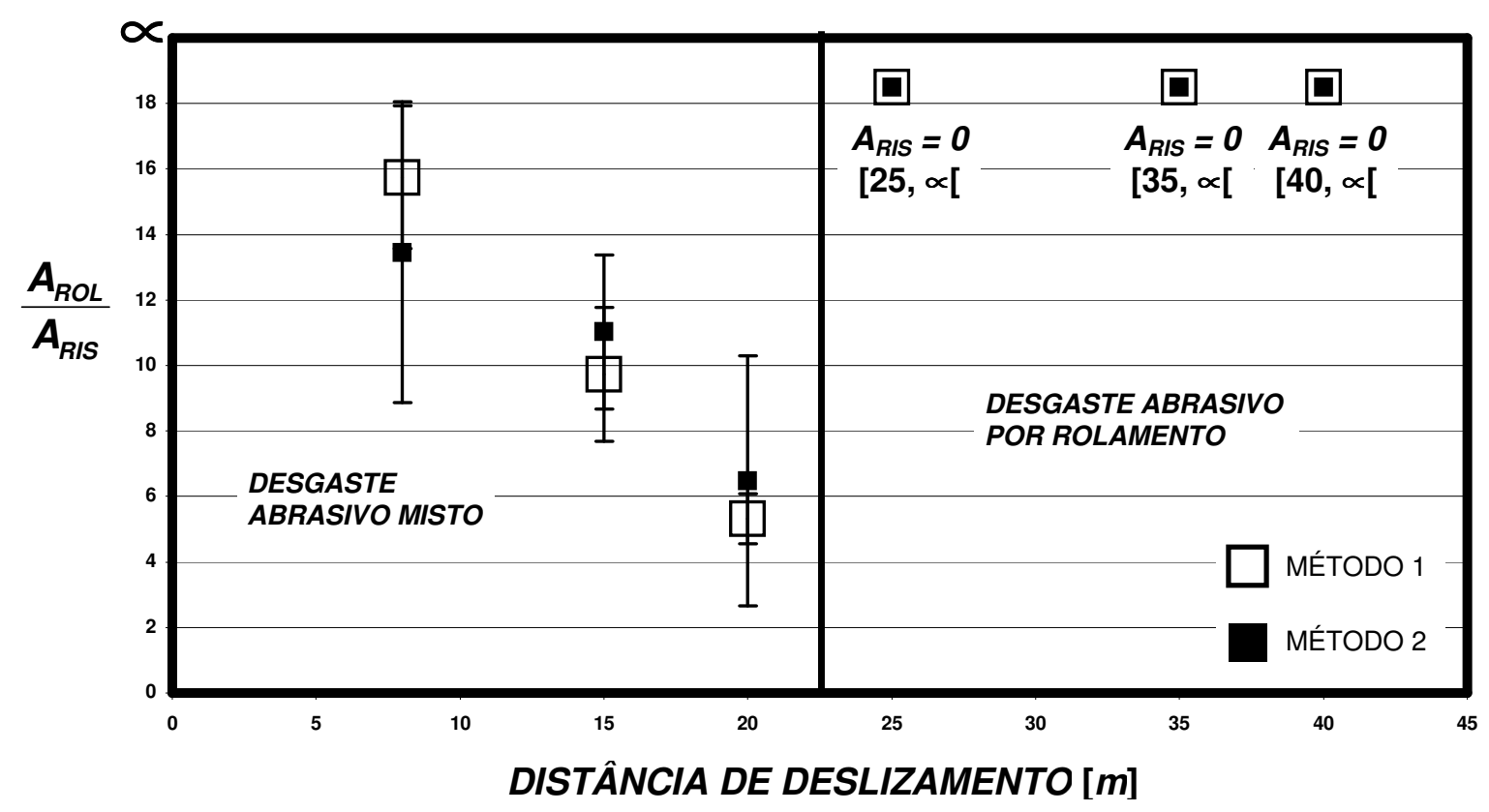

Figura 7.61: Corpos-de-prova de WC-Co P20. Sobreposição dos valores de $A_{R O L} / A_{R I S}$ obtidos pelos Métodos 1 e 2.

Em ambos os gráficos observa-se que, embora os valores de $A_{R O R O} / A_{R S}$ variaram quando determinados pelos Métodos 1 ou 2, a tendência de $A_{\mathrm{ARO}} A_{A \mathrm{AS}} \operatorname{com} \boldsymbol{S}$, permaneceu semelhante. Os valores das áreas $\boldsymbol{A}_{\boldsymbol{R} I S}$ e $\boldsymbol{A}_{\boldsymbol{R} O L}$ alteraram o quociente $A_{A_{00}} A_{A_{\text {As }}}$, mas não os modos de desgaste abrasivo.

Pela literatura (Trezona et al., 1999), elevadas forças normais e baixas concentrações de pasta abrasiva, favorecem o desgaste abrasivo por riscamento e, baixas forças normais e elevadas concentrações de pasta abrasiva, o desgaste abrasivo por rolamento. Nos gráficos das Figuras 7.64 e 7.65, em nenhum ponto foi observada a total atuação do desgaste abrasivo por riscamento. É um resultado justificável, pois foi adotado um valor médio de força normal $(1,25 \mathrm{~N})$, e uma concentração relativamente alta de pasta abrasiva, 1,045

$\frac{g_{\text {SiC }}}{\mathrm{cm}^{3} \mathrm{H}_{2} \mathrm{O}-\text { Dest. }}$ (Trezona et al., 1999).

Para a construção dos gráficos de $A_{A_{R O O}} /_{A_{R S}}=f(S)$, inicialmente foi levantada a hipótese de que o quociente $A_{A_{n O}} A_{A_{R S}}$ iria variar de forma ascendente ou descendente até uma determinada distância de deslizamento e, depois disso, tenderia a permanecer constante (HIPÓTESE 1 - Capítulo 3). As Figuras 7.62 e 7.63 mostram esquematicamente, o que foi sugerido para a HIPÓTESE 1. 


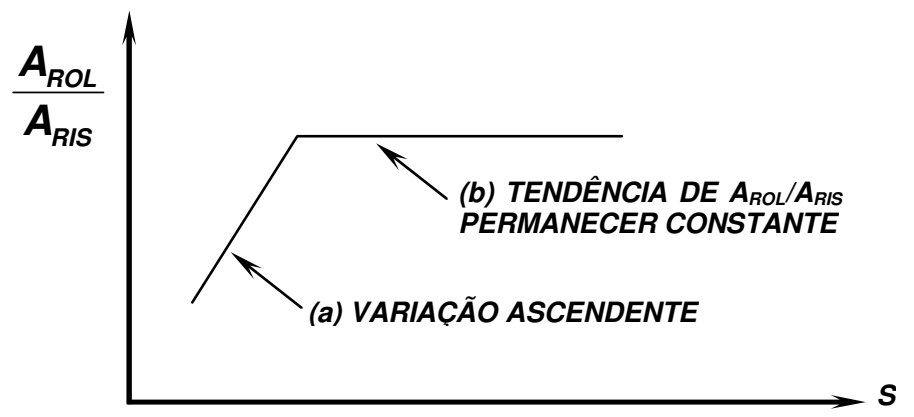

Figura 7.62: HIPÓTESE 1. (a) Variação ascendente e (b), tendência de $A_{R O L} / A_{R I S}$ permanecer constante com a distância de deslizamento.

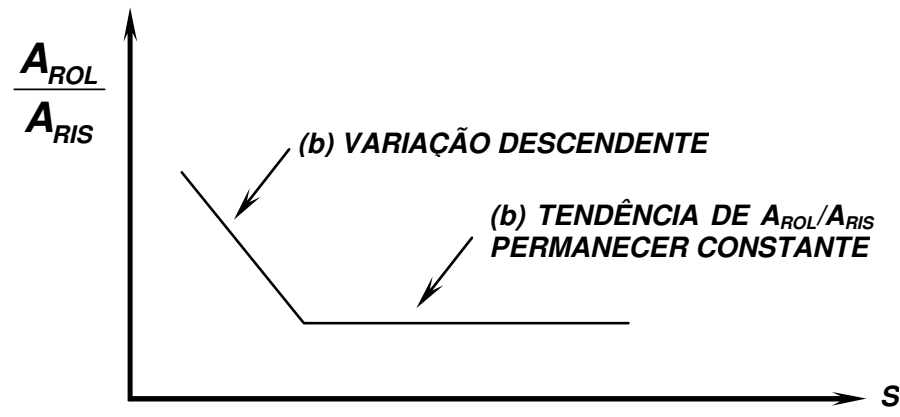

Figura 7.63: HIPÓTESE 1. (a) Variação descendente e (b), tendência de $A_{R O L} / A_{R I S}$ permanecer constante com a distância de deslizamento.

A HIPÓTESE 1 foi contestada. Os gráficos de $A_{R O L} / A_{R I S}=f(S)$ não apresentaram o comportamento idealizado na Figura 7.62 ou 7.63. Há dois argumentos para esse fato: 1) $A_{R o L} / A_{A S S}$ não apresenta um comportamento padrão com a variação de $\left.S ; 2\right)$ o desgaste da esfera exerceu influência sobre o quociente $A_{R O L} / A_{R I S}$.

Para qualquer uma das duas fundamentações levantadas, não foi encontrado qualquer trabalho que discutisse o assunto. Não é de conhecimento, se a justificativa 1) está correta, mas, pelos conceitos obtidos e pelas discussões, é a menos provável. Com isso, a discussão se concentrará em torno da influência do desgaste da esfera sobre o quociente $A_{R O O} / A_{A S S}$.

As Figuras 7.64 a 7.71 mostram as crateras de desgaste referentes aos ensaios extras, realizados com os corpos-de-prova de WC-Co $P 20$, para as distâncias de 15 e 35 metros (somente). As condições de ensaio estão mencionadas na Tabela 5.7. A seqüência das figuras é a mesma da realização dos ensaios. 


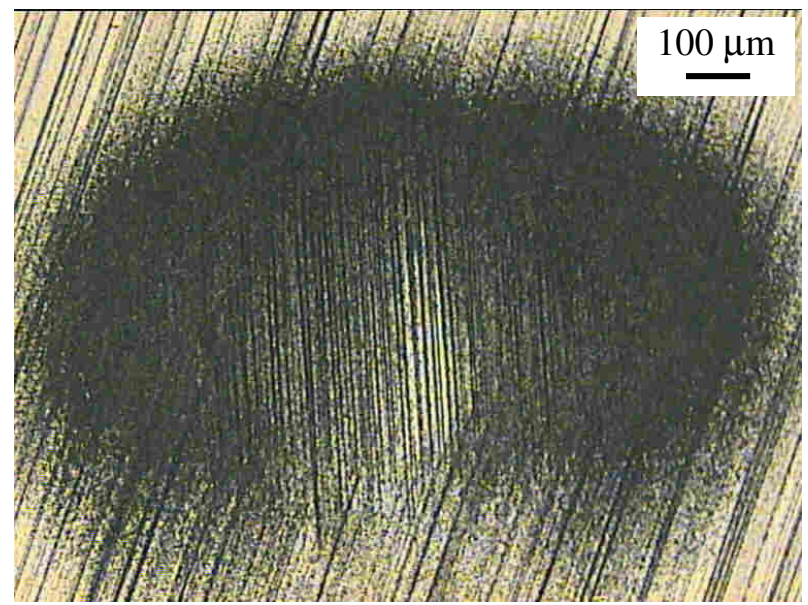

Figura 7.64: Corpo-de-prova de WC-Co P20. Distância de deslizamento de 15 metros. Atuação de desgaste abrasivo misto.

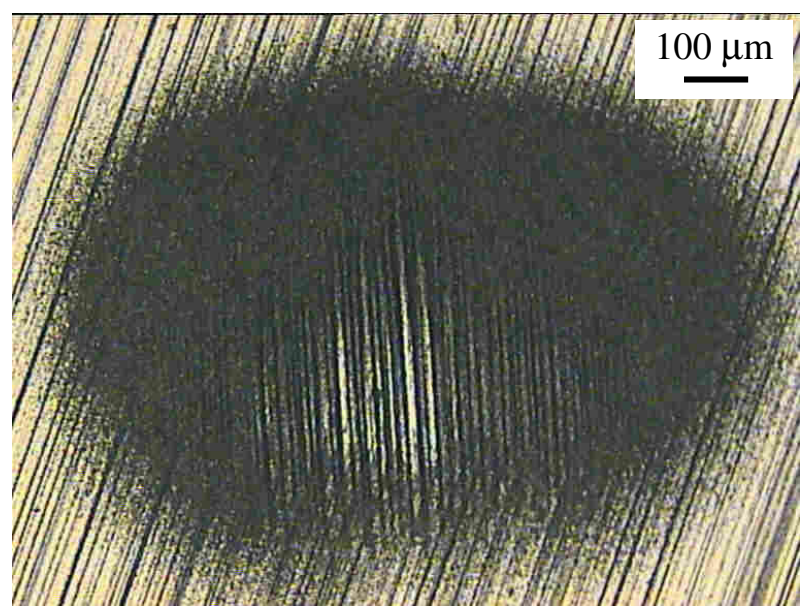

Figura 7.65: Corpo-de-prova de WC-Co P20. Distância de deslizamento de 15 metros. Atuação de desgaste abrasivo misto.

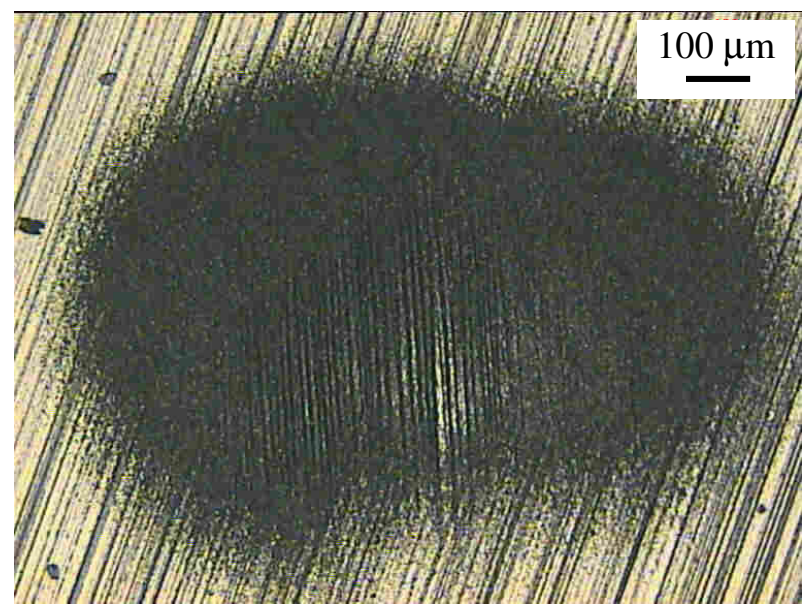

Figura 7.66: Corpo-de-prova de WC-Co P20. Distância de deslizamento de 35 metros. Atuação de desgaste abrasivo misto. 


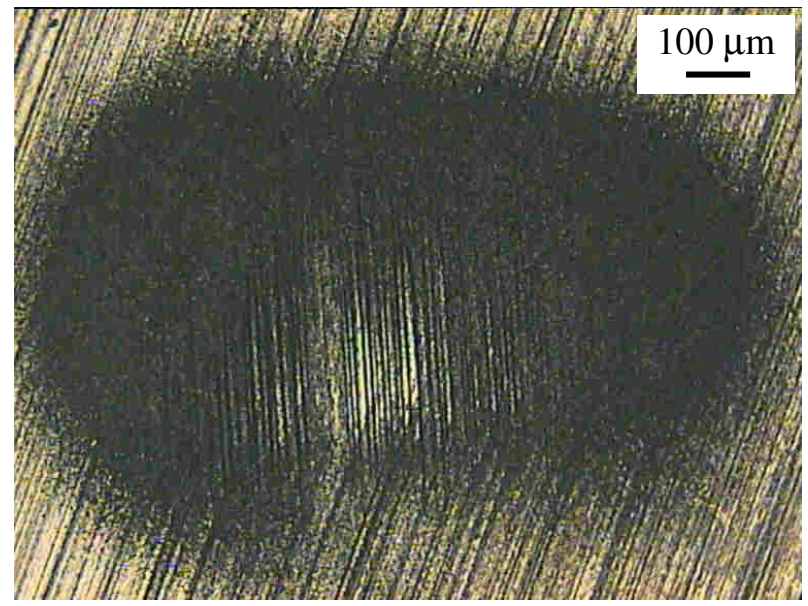

Figura 7.67: Corpo-de-prova de WC-Co P20. Distância de deslizamento de 15 metros. Atuação de desgaste abrasivo misto.

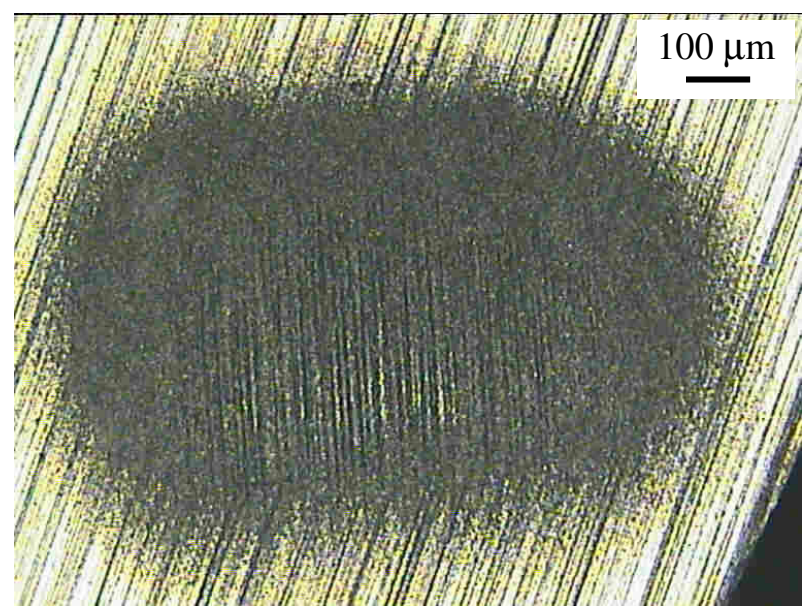

Figura 7.68: Corpo-de-prova de WC-Co P20. Distância de deslizamento de 35 metros. Atuação de desgaste abrasivo misto.

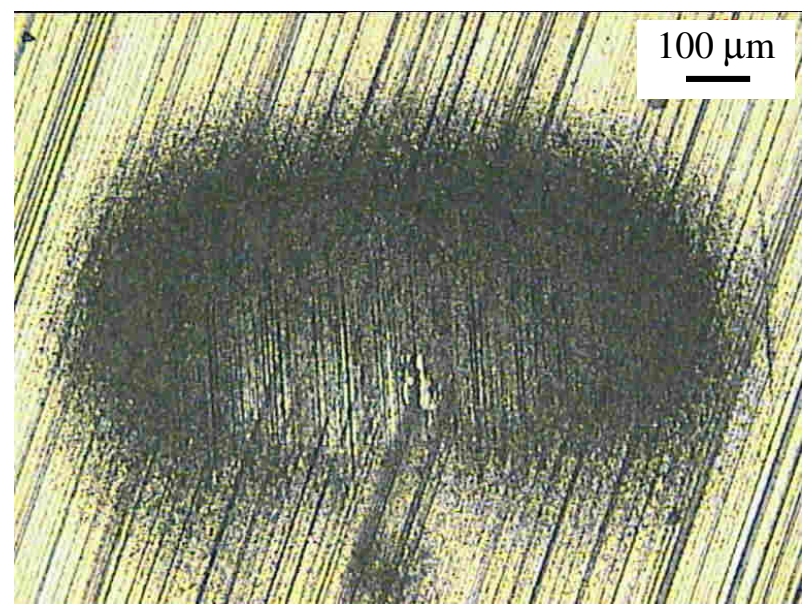

Figura 7.69: Corpo-de-prova de WC-Co P20. Distância de deslizamento de 15 metros. Atuação de desgaste abrasivo misto. 


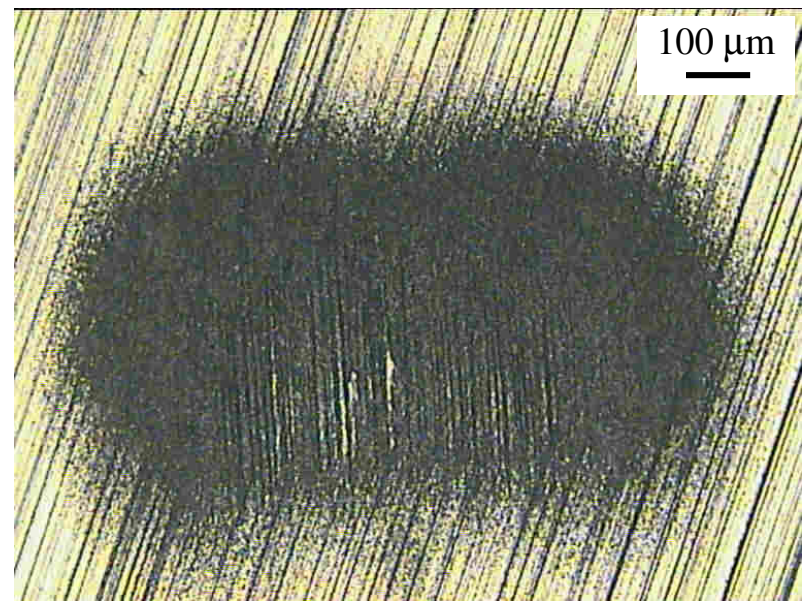

Figura 7.70: Corpo-de-prova de WC-Co P20. Distância de deslizamento de 35 metros. Atuação de desgaste abrasivo misto.

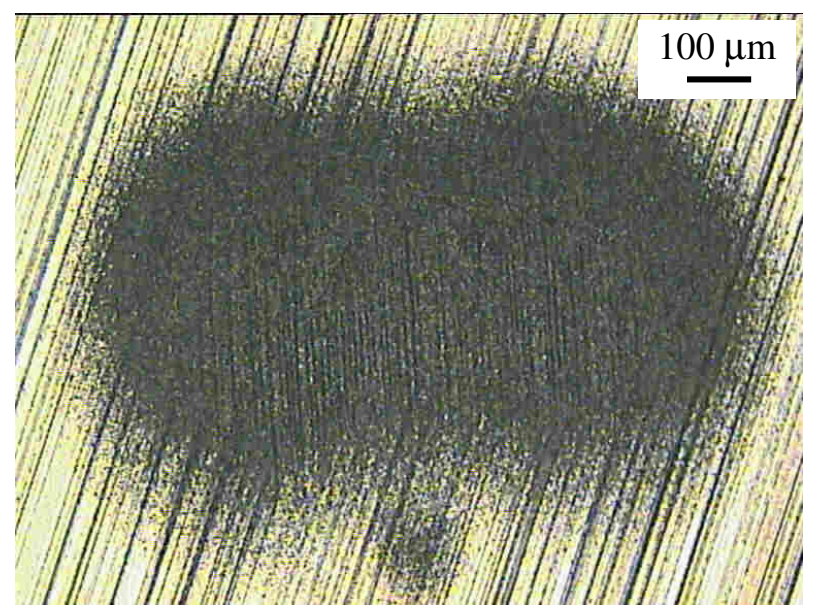

Figura 7.71: Corpo-de-prova de WC-Co P20. Distância de deslizamento de 35 metros. Atuação de desgaste abrasivo misto.

É possível elaborar um gráfico que relacione $\Xi$ com o modo de desgaste abrasivo, conforme a Figura 7.72.

\begin{tabular}{|c|c|c|c|c|}
\hline \multicolumn{2}{|c|}{ HSS M2 } & \multicolumn{3}{c|}{ WC-Co P20 } \\
\hline $1^{\circ}$ GRUPO DE & $2^{\circ}$ GRUPO DE & $3^{\circ}$ GRUPO DE & $4^{\circ}$ GRUPO DE & ENSAIOS EXTRAS \\
ENSAIOS & ENSAIOS & ENSAIOS & ENSAIOS & $(15,35$ metros $)$ \\
$(15,20,25$ metros $)$ & $(8,35,40$ metros $)$ & $(8,15,20$ metros $)$ & $(25,35,40$ metros $)$ & DESGASTE \\
\hline DESGASTE & DESGASTE & DESGASTE & DESGASTE \\
ABRASIVO MISTO & ABRASIVO POR & ABRASIVO MISTO & ABRASIVO POR & ABRASIVO MISTO \\
\hline
\end{tabular}

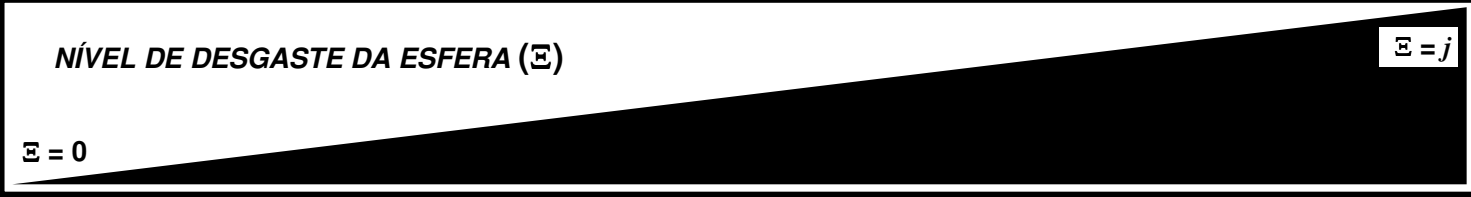

SEQÜÊNCIA DOS ENSAIOS

Figura 7.72: Atuação dos modos de desgaste abrasivo em função de $\Xi$. 
No $1^{\circ}$ grupo de ensaios, ocorreu desgaste abrasivo misto, no $2^{\circ}$, desgaste abrasivo por rolamento, no $3^{\circ}$, desgaste abrasivo misto, no $4^{\circ}$, desgaste abrasivo por rolamento e, nos ensaios extras, desgaste abrasivo misto. Com o andamento dos ensaios, o nível de desgaste da esfera foi aumentando. Isso ocasionou a alternância entre os modos de desgaste abrasivo.

Pelos resultados obtidos, conclui-se que, para ambos os materiais, $A_{R O O} / A_{R I S}=f(\mathrm{~S})$ não apresentou o comportamento sugerido, devido ao fato de $\Xi$ variar ao longo dos ensaios. Por outro lado, não é possível afirmar que, se $\Xi$ permanecesse constante com os ensaios, $A_{R O L O} /_{A_{R I S}}=f(S)$ exibiria a evolução sugerida. Em vista disso, a HIPÓTESE 1 fica em aberto.

\subsubsection{Alterações dos contornos das crateras de desgaste}

Durante os ensaios realizados com os corpos-de-prova de HSS M2 e WC-Co P20, foram observados diferentes contornos das crateras de desgaste, como mostra a Figura 7.73 .

\begin{tabular}{|c|c|c|c|c|}
\hline \multicolumn{2}{|c|}{ HSS M2 } & \multicolumn{3}{|c|}{ WC-Co P20 } \\
\hline $\begin{array}{c}1^{\circ} \text { GRUPO DE } \\
\text { ENSAIOS } \\
(15,20,25 \text { metros })\end{array}$ & $\begin{array}{c}2^{\circ} \text { GRUPO DE } \\
\text { ENSAIOS } \\
(8,35,40 \text { metros })\end{array}$ & $\begin{array}{c}3^{\circ} \text { GRUPO DE } \\
\text { ENSAIOS } \\
(8,15,20 \text { metros })\end{array}$ & $\begin{array}{c}4^{\circ} \text { GRUPO DE } \\
\text { ENSAIOS } \\
(25,35,40 \text { metros })\end{array}$ & $\begin{array}{c}\text { ENSAIOS EXTRAS } \\
(15,35 \text { metros })\end{array}$ \\
\hline & 0 & & & \\
\hline
\end{tabular}

NÍVEL DE DESGASTE DA ESFERA $(\Xi) \quad \Xi=j$

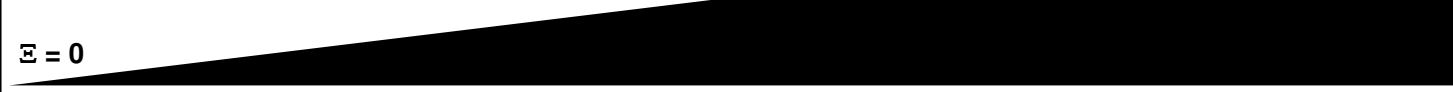

SEQÜÊNCIA DOS ENSAIOS

\begin{tabular}{|l|l|}
\hline & CONTORNO CIRCUNFERENCIAL \\
\hline & CONTORNO ELÍPTICO \\
\hline & CONTORNO OBLONGO \\
\hline & CONTORNO "8" \\
\hline
\end{tabular}

Figura 7.73: Ordem de alterações dos contornos das crateras de desgaste. 
Conforme $\Xi$ foi aumentando, os contornos das crateras de desgaste foram se alterando. Quando $\Xi$ estava relativamente baixo, os contornos tenderam a uma circunferência ("contorno circunferencial'). Com o aumento do nível de desgaste, os contornos começaram a tender para uma elipse ("contorno elíptico"). A partir de um determinado nível de desgaste da esfera, as crateras apresentaram contornos aqui denominados de "contorno oblongo". No nível mais elevado de desgaste atingido, a esfera gerou crateras com contornos semelhantes ao número 8 (oito). Esse contorno foi designado de "contorno 8".

Com base nos quatro contornos relatados, o desgaste da esfera foi classificado em quatro níveis $\Xi$ distintos, conforme a Figura 7.74.

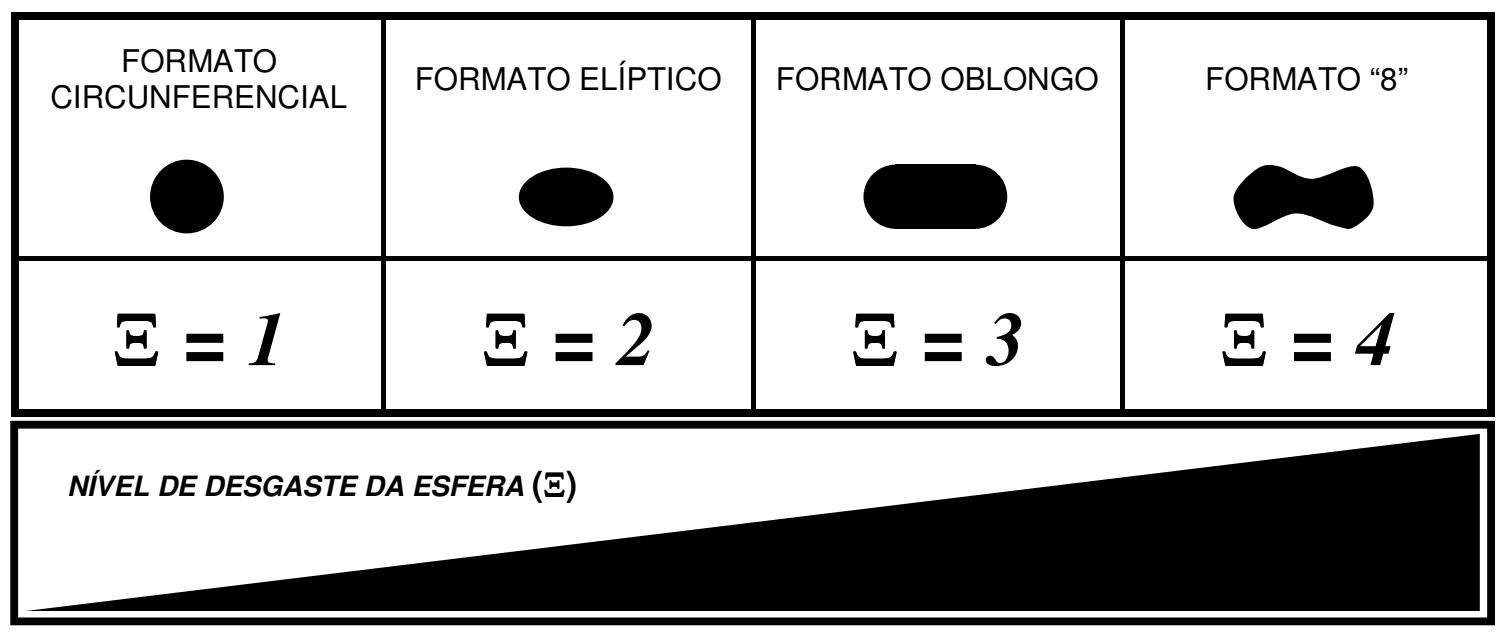

Figura 7.74: Classificação dos níveis de desgaste $\Xi$ da esfera, em função do contorno da cratera de desgaste.

Embora tenham sido atribuídos valores numéricos a $\Xi$, o mesmo continua sendo apenas um parâmetro qualitativo, não possuindo qualquer unidade. 


\subsection{ESTUDO DA OBTENÇÃO DO REGIME PERMANENTE DE DESGASTE}

\subsubsection{Resultados dos ensaios realizados com os corpos-de-prova de HSS M2}

Os resultados deste item referem-se aos ensaios realizados com os corposde-prova de aço ferramenta $M 2$, com as condições experimentais mencionadas na Tabela 5.6. A Tabela 7.8 mostra os valores de $\boldsymbol{A}_{\boldsymbol{t}}$ e $\boldsymbol{k}$. A área $\boldsymbol{A}_{\boldsymbol{t}}$ foi medida pelo Método 2, e $\boldsymbol{k}$, calculado pela Equação 2.6. Os valores de $\boldsymbol{A}_{\boldsymbol{t}}$ já haviam sido mencionados na Tabela 7.2, mas foram sintetizados para facilitar a leitura.

Tabela 7.8: Valores de $A_{t}$ e k. Resultados obtidos com os corpos-de-prova de HSS M2.

\begin{tabular}{|c|l|c|c|c|c|c|c|c|}
\hline S $[\mathrm{m}]$ & GRANDEZA & ENSAIO 1 & ENSAIO 2 & ENSAIO 3 & ENSAIO 4 & MÉDIA & $\sigma_{P}$ & ERRO \\
\hline \multirow{2}{*}{8} & $\boldsymbol{A}_{t}\left[\mathrm{~mm}^{2}\right]$ & 0,709 & 0,811 & 0,669 & 0,601 & 0,698 & 0,088 & 0,044 \\
\cline { 2 - 9 } & $\boldsymbol{k}\left[\mathrm{mm}^{3} / \mathrm{N} \cdot \mathrm{m}\right]$ & 3,1 & 4,1 & 2,8 & 2,3 & 3,1 & 0,8 & 0,4 \\
\hline \multirow{2}{*}{15} & $\boldsymbol{A}_{t}\left[\mathrm{~mm}^{2}\right]$ & 1,478 & 1,323 & 1,401 & - & 1,401 & 0,078 & 0,045 \\
\cline { 2 - 9 } & $\boldsymbol{k}\left[\mathrm{mm}^{3} / \mathrm{N} \cdot \mathrm{m}\right]$ & 7,3 & 5,8 & 6,6 & - & 6,6 & 0,7 & 0,4 \\
\hline \multirow{2}{*}{20} & $\boldsymbol{A}_{\boldsymbol{t}}\left[\mathrm{mm}^{2}\right]$ & 1,604 & 1,523 & 1,401 & 1,387 & 1,479 & 0,103 & 0,052 \\
\cline { 2 - 9 } & $\boldsymbol{k}\left[\mathrm{mm}^{3} / \mathrm{N} \cdot \mathrm{m}\right]$ & 6,4 & 5,8 & 4,9 & 4,8 & 5,5 & 0,8 & 0,4 \\
\hline \multirow{2}{*}{25} & $\boldsymbol{A}_{t}\left[\mathrm{~mm}^{2}\right]$ & 1,686 & 1,711 & 1,650 & - & 1,682 & 0,031 & 0,018 \\
\cline { 2 - 9 } & $\boldsymbol{k}\left[\mathrm{mm}^{3} / \mathrm{N} \cdot \mathrm{m}\right]$ & 5,7 & 5,9 & 5,5 & - & 5,7 & 0,2 & 0,1 \\
\hline \multirow{2}{*}{35} & $\boldsymbol{A}_{t}\left[\mathrm{~mm}^{2}\right]$ & 1,696 & 1,563 & 1,433 & 1,501 & 1,548 & 0,112 & 0,056 \\
\cline { 2 - 9 } & $\boldsymbol{k}\left[\mathrm{mm}^{3} / \mathrm{N} \cdot \mathrm{m}\right]$ & 4,1 & 3,5 & 2,9 & 3,2 & 3,4 & 0,5 & 0,2 \\
\hline \multirow{2}{*}{40} & $\boldsymbol{A}_{t}\left[\mathrm{~mm}^{2}\right]$ & 2,963 & 2,901 & 2,610 & 2,788 & 2,816 & 0,155 & 0,077 \\
\cline { 2 - 9 } & $\boldsymbol{k}\left[\mathrm{mm}^{3} / \mathrm{N} \cdot \mathrm{m}\right]$ & 11,0 & 10,5 & 8,5 & 9,7 & 10,0 & 1,1 & 0,6 \\
\hline
\end{tabular}

Na Figura 7.75 está o gráfico do coeficiente de desgaste em função da distância de deslizamento $(k=f(S))$, para os corpos-de-prova de aço ferramenta $M 2$.

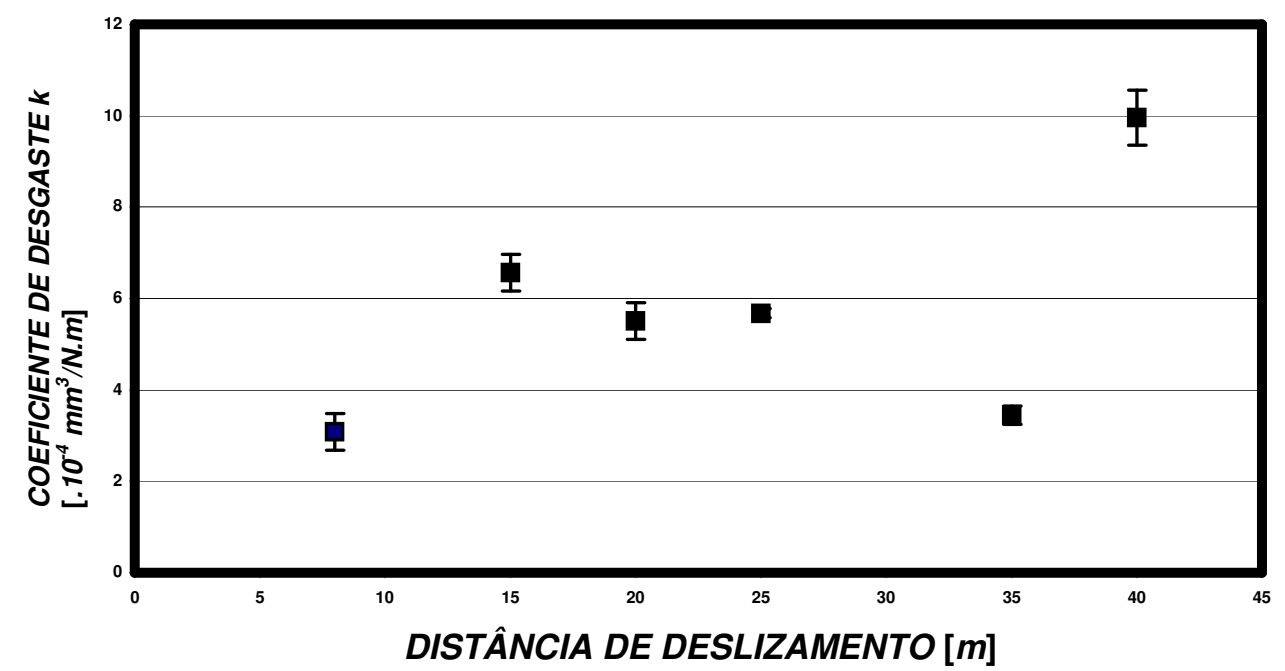

Figura 7.75: Gráfico de $k=f(S)$, para os corpos-de-prova de aço ferramenta M2. 


\subsubsection{Resultados dos ensaios realizados com os corpos-de-prova de WC-Co P20}

$\mathrm{Na}$ Tabela 7.9, estão os resultados dos ensaios realizados nos corpos-deprova de WC-Co P20, com a esfera E-52100-2. A área $\boldsymbol{A}_{t}$ foi medida pelo Método 2, e $\boldsymbol{k}$, calculado pela Equação 2.6. Esses ensaios foram conduzidos somente para as distâncias de 25, 35 e 40 metros. As condições de ensaio foram mencionadas na Tabela 5.8.

Tabela 7.9: Valores de $A_{t}$ e $k$. Ensaios realizados nos corpos-de-prova de WC-Co P20, com a esfera E-52100-2.

\begin{tabular}{|c|l|c|c|c|c|c|c|c|}
\hline \multirow{S}{S}[\mathrm{m}]{} & GRANDEZA & ENSAIO 1 & ENSAIO 2 & ENSAIO 3 & ENSAIO 4 & MÉDIA & $\sigma_{P}$ & ERRO \\
\hline \multirow{2}{*}{25} & $\boldsymbol{A}_{t}\left[\mathrm{~mm}^{2}\right]$ & 1,512 & 1,502 & 1,462 & 1,487 & 1,491 & 0,022 & 0,011 \\
\cline { 2 - 9 } & $\boldsymbol{k}\left[.10^{-4} \mathrm{~mm}^{3} / \mathrm{N} . \mathrm{m}\right]$ & 4,6 & 4,5 & 4,3 & 4,4 & 4,5 & 0,1 & 0,1 \\
\hline \multirow{2}{*}{35} & $\boldsymbol{A}_{t}\left[\mathrm{~mm}^{2}\right]$ & 1,820 & 1,991 & 1,702 & 1,698 & 1,803 & 0,138 & 0,069 \\
\cline { 2 - 9 } & $\boldsymbol{k}\left[.10^{-4} \mathrm{~mm}^{3} / \mathrm{N} \cdot \mathrm{m}\right]$ & 4,7 & 5,7 & 4,1 & 4,1 & 4,7 & 0,7 & 0,4 \\
\hline \multirow{2}{*}{40} & $\boldsymbol{A}_{t}\left[\mathrm{~mm}^{2}\right]$ & 1,691 & 1,867 & 2,101 & 1,995 & 1,914 & 0,177 & 0,088 \\
\cline { 2 - 9 } & $\boldsymbol{k}\left[.10^{-4} \mathrm{~mm}^{3} / \mathrm{N} . \mathrm{m}\right]$ & 3,6 & 4,4 & 5,5 & 5,0 & 4,6 & 0,8 & 0,4 \\
\hline
\end{tabular}

Na Figura 7.76 está o gráfico do coeficiente de desgaste em função da distância de deslizamento $(k=f(S))$, para os corpos-de-prova de WC-Co P2O.

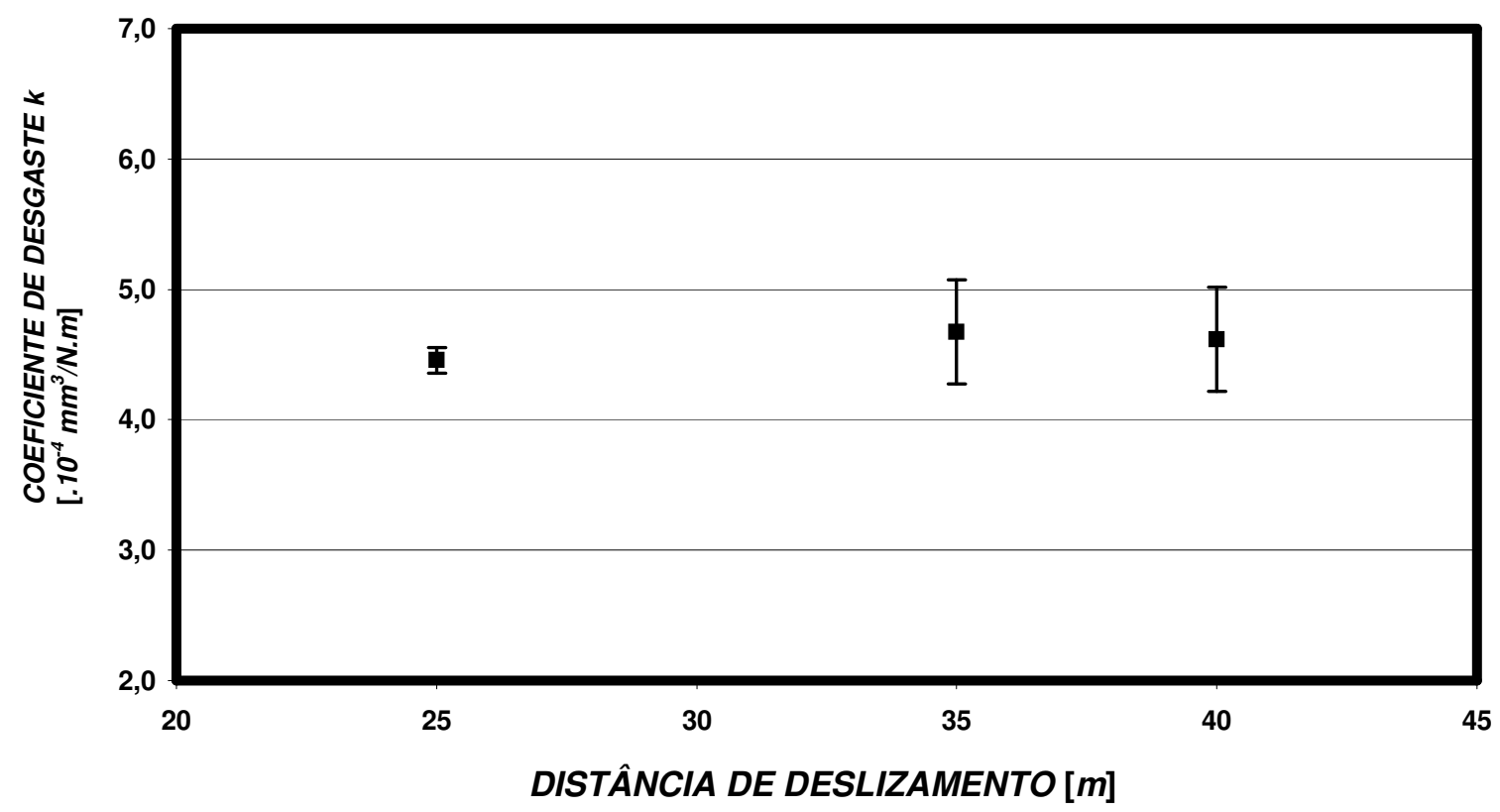

Figura 7.76: Gráfico de $k=f(S)$, para os corpos-de-prova de WC-Co P20.

Nas Figuras 7.77 à 7.82, estão algumas crateras de desgaste geradas nos corpos-de-prova de WC-Co P20, com a esfera E-52100-2. 


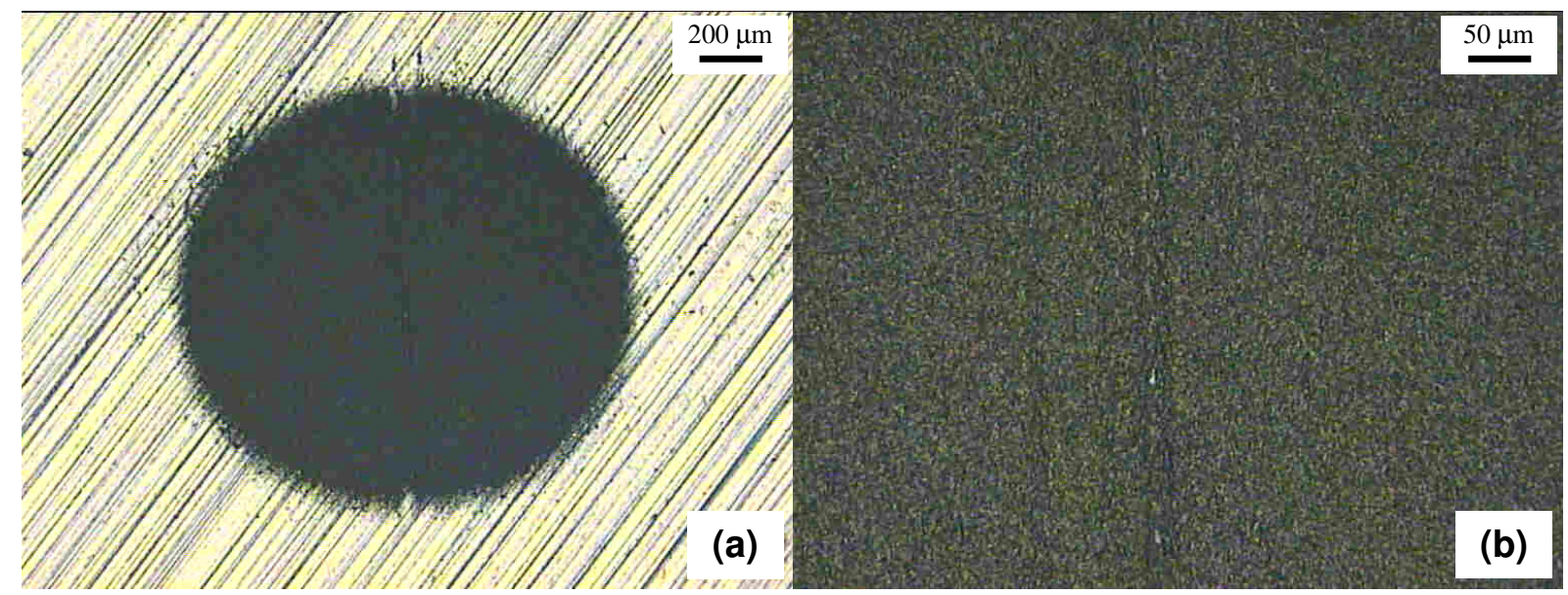

Figura 7.77: Corpo-de-prova de WC-Co P20. (a) Cratera de desgaste gerada com uma distância de deslizamento de 25 metros; (b) Total atuação do desgaste abrasivo por rolamento.

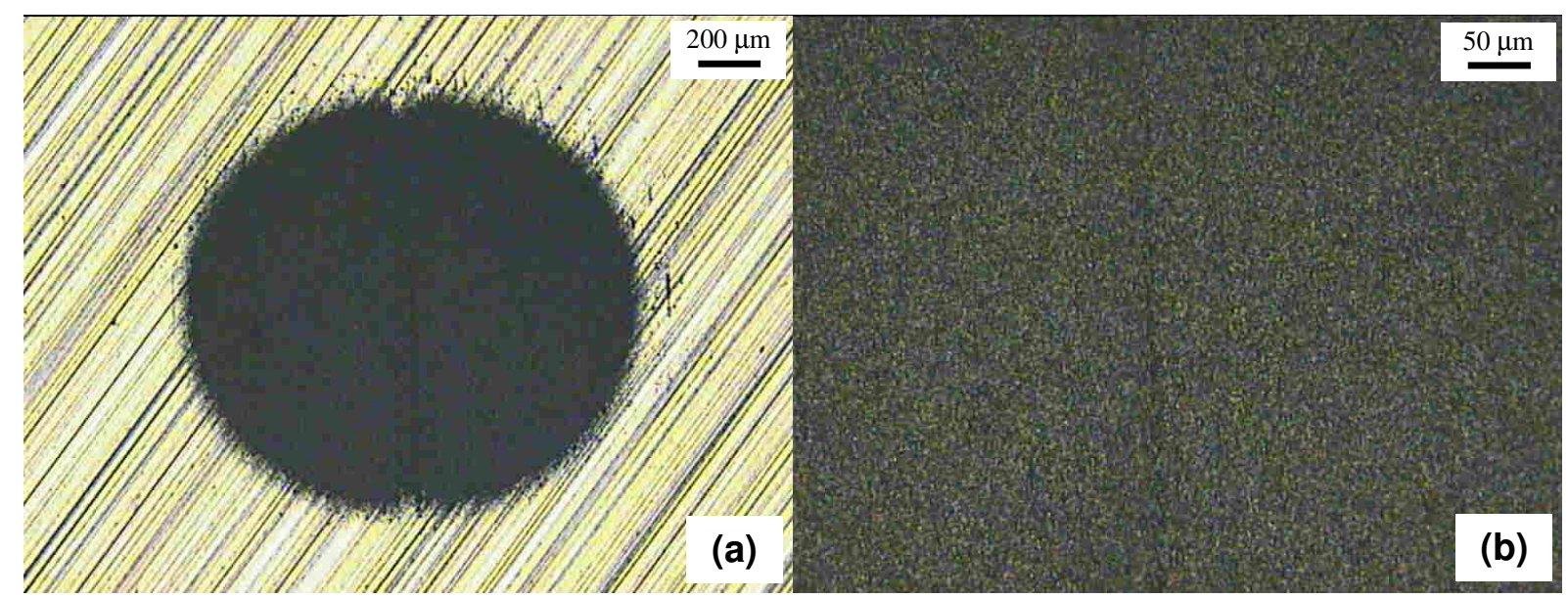

Figura 7.78: Corpo-de-prova de WC-Co P20. (a) Cratera de desgaste gerada com uma distância de deslizamento de 25 metros; (b) Total atuação do desgaste abrasivo por rolamento.

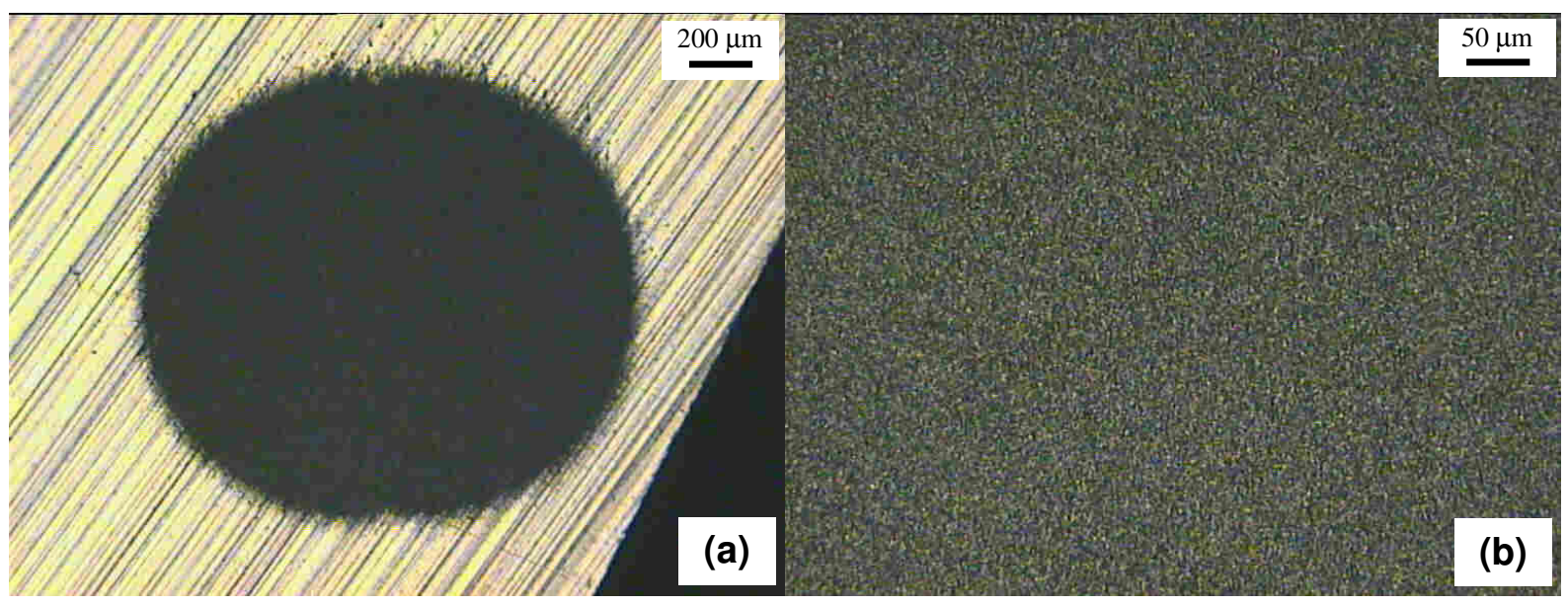

Figura 7.79: Corpo-de-prova de WC-Co P20. (a) Cratera de desgaste gerada com uma distância de deslizamento de 35 metros; (b) Total atuação do desgaste abrasivo por rolamento. 


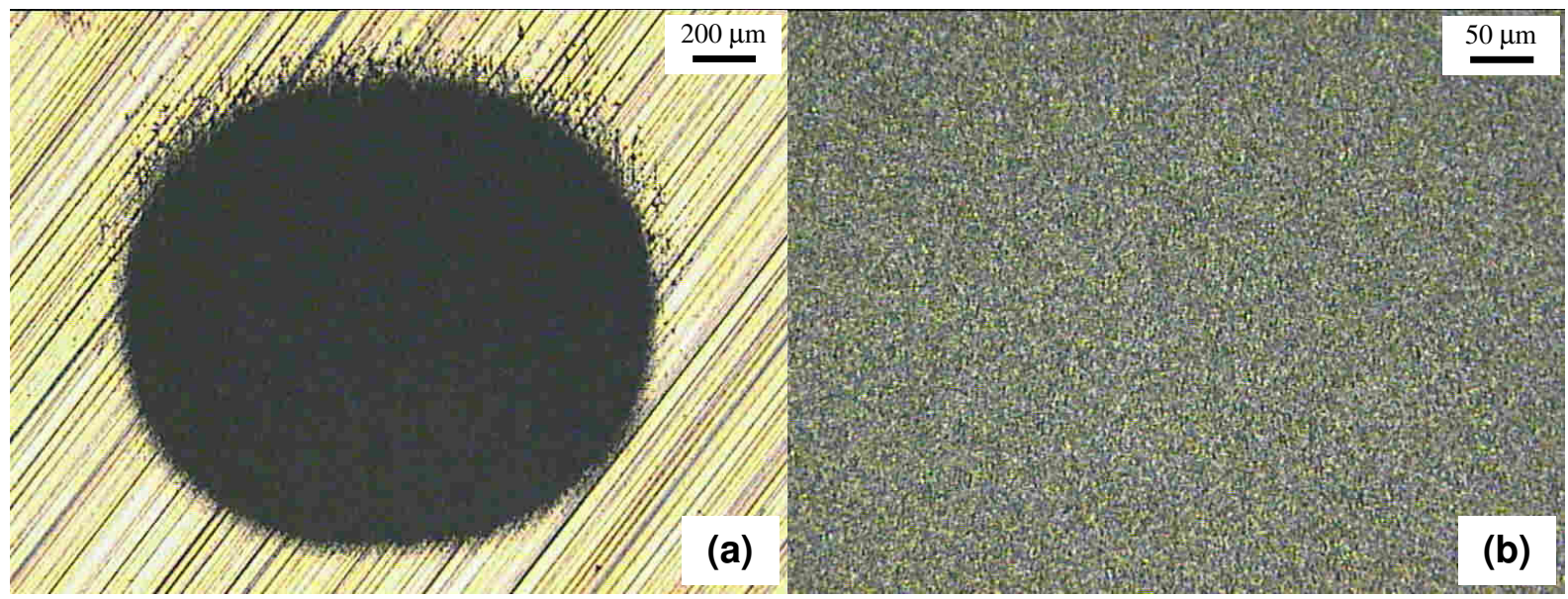

Figura 7.80: Corpo-de-prova de WC-Co P20. (a) Cratera de desgaste gerada com uma distância de deslizamento de 35 metros; (b) Total atuação do desgaste abrasivo por rolamento.

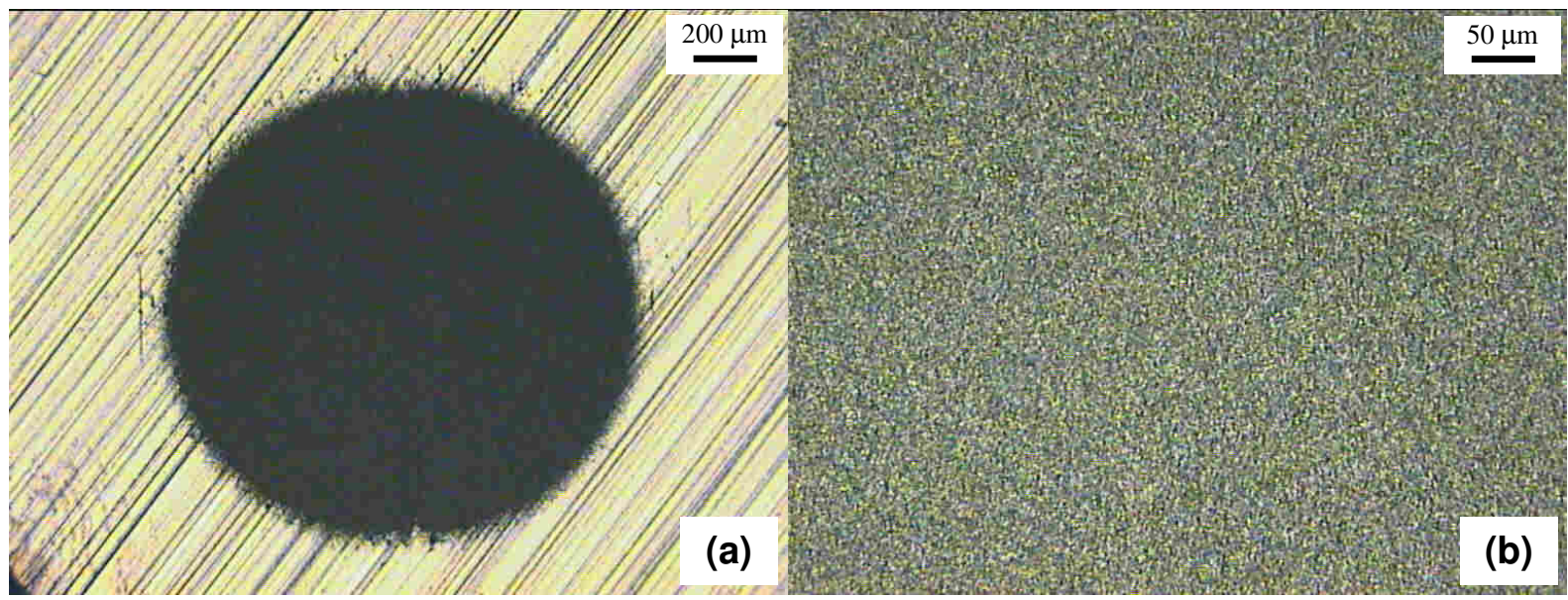

Figura 7.81: Corpo-de-prova de WC-Co P20. (a) Cratera de desgaste gerada com uma distância de deslizamento de 40 metros; (b) Total atuação do desgaste abrasivo por rolamento.

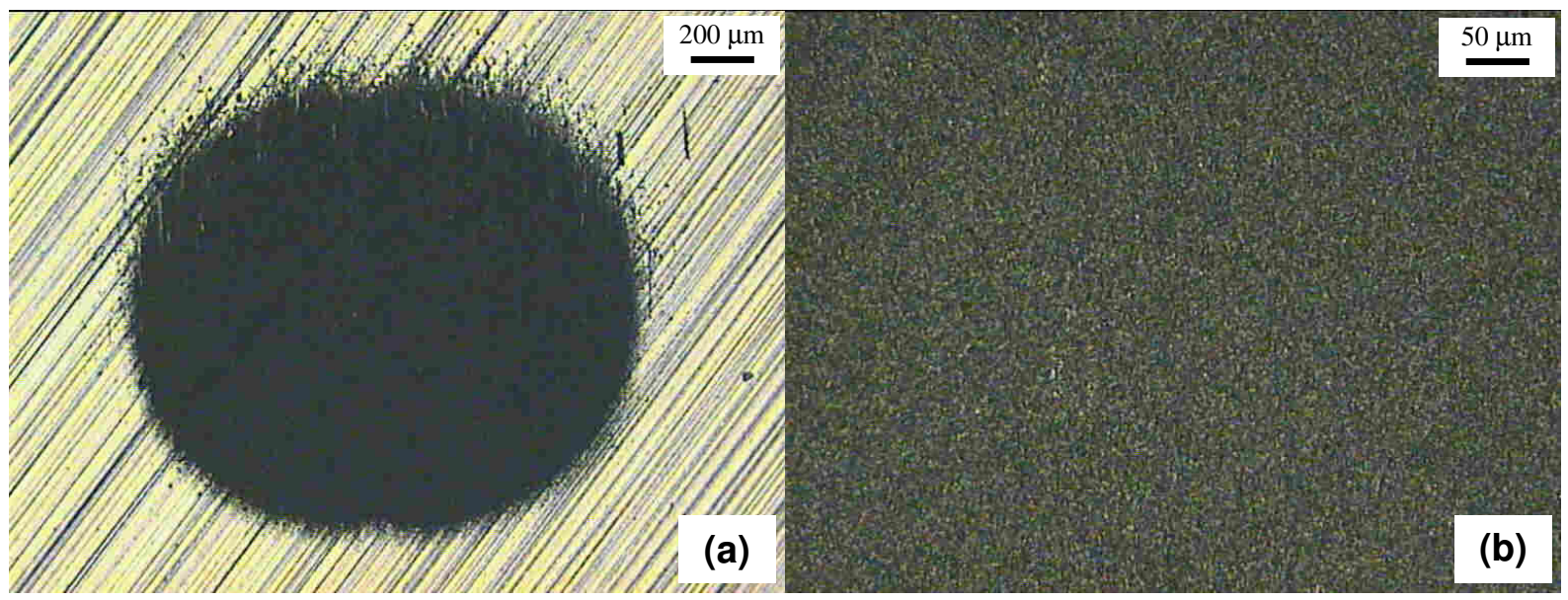

Figura 7.82: Corpo-de-prova de WC-Co P20. (a) Cratera de desgaste gerada com uma distância de deslizamento de $\mathbf{4 0}$ metros; (b) Total atuação do desgaste abrasivo por rolamento. 


\subsubsection{Regime permanente de desgaste}

Ratificando e relembrando o que foi escrito no Capítulo 2, o processo de desgaste atinge o regime permanente quando, a taxa de desgaste $(\boldsymbol{Q})$, ou o coeficiente de desgaste $(\boldsymbol{k})$, permanece constante ao longo do tempo. Nesta Dissertação, o regime permanente de desgaste será discutido com base no gráfico de $k=f(S)$.

Para facilitar a leitura e a discussão desse item, os gráficos de $k=f(S)$, para - HSS M2 (Figura 7.75) e para o WC-Co P20 (Figura 7.76), foram dispostos novamente abaixo.

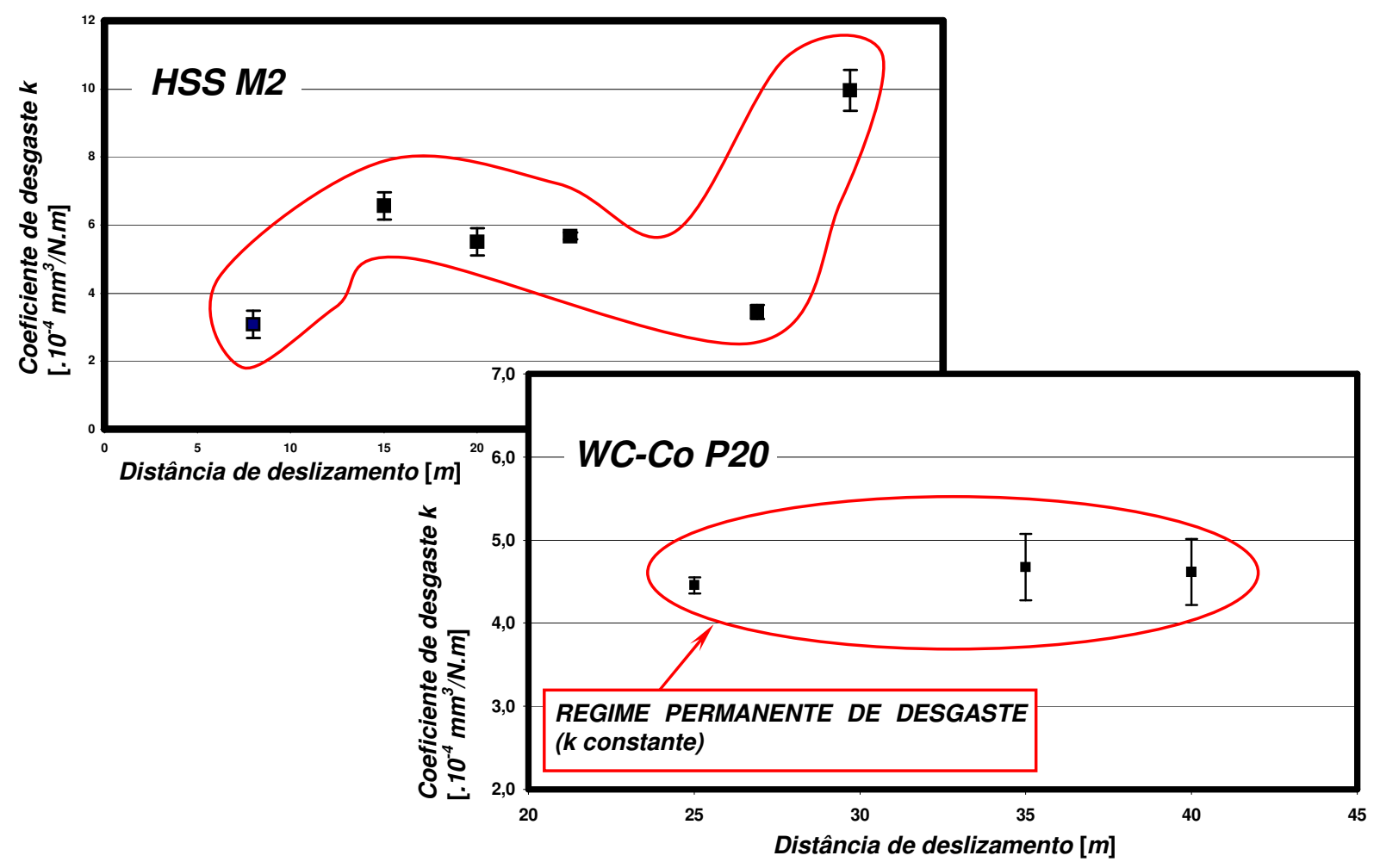

Figura 7.83: Corpos-de-prova de aço ferramenta M2 e WC-Co P20. Gráficos de $k=f(S)$.

Para o HSS M2, conclui-se que o regime permanente de desgaste não foi alcançado, pois, até a distância de deslizamento de 40 metros, $\boldsymbol{k}$ não tendeu a permanecer constante.

Até que o regime permanente de desgaste não tenha sido atingido, o gráfico de $k=f(S)$ pode apresentar qualquer comportamento, como pode ser observado nas Figuras 2.33 e 2.34 . 
Não existe uma distância de deslizamento característica ou, uma faixa de valores, a partir da qual, o processo de desgaste entre em regime permanente. Isso depende dos materiais envolvidos e das condições de ensaio. Nos ensaios realizados por Silva Jr. (2003), em sua Dissertação de Mestrado, o processo de desgaste entrou em regime permanente a partir de 42 metros (3 minutos de ensaio). A esfera possuía $30 \mathrm{~mm}$ de diâmetro e sua rotação foi fixada em $150 \mathrm{rpm}$. A força normal ficou entre 0,2 e 0,23 N. Pesquisas desenvolvidas no LTM (Laboratório de Tribologia e Materiais - Faculdade de Engenharia Mecânica da Universidade Federal de Uberlândia) mostraram que, para os materiais utilizados e as condições de ensaio adotadas, o regime permanente de desgaste foi atingido a partir de 283 metros (20 minutos de ensaio). Foi utilizada uma esfera de diâmetro $30 \mathrm{~mm}$ e rotação de 150 rpm e, a força normal, fixada em 0,45 N. No trabalho de Trezona et al. (1999), o desgaste entrou em regime a partir de 8 metros, com uma esfera de diâmetro 25,4 $m m$, rotação de 37,6 rpm e $\boldsymbol{F}_{\boldsymbol{N}}=0,25 \mathrm{~N}$. Nos ensaios conduzidos nesta Dissertação, a maior distância de deslizamento foi de 40 metros. Pelos resultados tomados como referência e, pelos resultados obtidos, a explicação mais plausível para o fato do desgaste não ter alcançado o regime permanente está relacionada à distância de deslizamento, que, para os materiais e condições de ensaios, pode ter sido baixa.

Em relação ao WC-Co $P 20$, os resultados obtidos com a esfera E-52100-2 indicam que o regime permanente de desgaste foi obtido, pois o coeficiente de desgaste tendeu a permanecer constante com a variação da distância de deslizamento.

\subsection{COMENTÁRIOS}

Como mencionado, a máquina de desgaste micro-abrasivo construída é do tipo "esfera fixa". Esse modelo apresenta vantagens e desvantagens em relação a configuração "esfera livre".

No equipamento tipo "esfera livre", a ação da força normal está baseada no próprio peso da esfera. Na configuração "esfera fixa", é possível a aplicação de cargas maiores, pelo princípio de "peso morto" ou através do sistema projetado para o equipamento construído.

Entretanto, no âmbito desta Dissertação, com o modelo "esfera fixa", o custo de cada ensaio foi relativamente alto, quando comparado à configuração "esfera 
móvel'. O valor de cada esfera de aço AISI 52100 foi de $R \$ 2,50$. Como esse material possui elevada dureza, não é possível realizar a usinagem do furo de fixação por processos convencionais (furação e posterior alargamento). É necessário erodir o furo, através de eletroerosão por "penetração" ou "a fio". O custo desse processo variou entre $\mathrm{R} \$ 80,00$ e $\mathrm{R} \$ 120,00$. Adicionalmente, é possível utilizar somente uma "linha de trabalho" da esfera. Na configuração "esfera livre", além de não ser necessário realizar a usinagem do furo, é possível utilizar varias "linhas de trabalho".

Para os ensaios realizados nesta Dissertação, foram utilizadas duas esferas de aço AISI 52100. O custo de cada esfera, somado à usinagem de ambas, totalizou $\mathrm{R} \$ 245,00$. Com esse valor, é possível adquirir 98 esferas. No total, foram realizados 76 ensaios líquidos. Se o equipamento fosse por "esfera livre" poderia ser utilizada, por exemplo, uma esfera para cada cratera de desgaste. Logo, seriam gastos $R \$ 190,00$, equivalente à compra de 76 esferas.

É difícil fazer outras comparações entre as duas configurações de equipamentos. Isso porque, para a realização desta Dissertação, não foi utilizada uma máquina de desgaste micro-abrasivo por esfera rotativa livre. Entretanto, sua construção pode vir a ser discutida futuramente. 
Mantenha aceso seu ideal de felicidade.

Trabalhe visando ao bem próprio e ao bem da humanidade.

Mas não tenha apenas a preocupação de acumular riquezas, que os vermes destroem e a ferrugem consome.

Acumule riquezas duradouras, constituídas dos benefícios que presta a seus irmãos, porque amanhã você receberá de todos a alegria da vitória, auxiliada por você.

A alegria do bem que se realiza é o maior tesouro que podemos obter. 


\section{CAPÍTULO 8 - CONCLUSÕES}

\section{- CONCLUSÕES DOS ENSAIOS PRELIMINARES}

Em relação aos Ensaios Preliminares, os resultados e as discussões expostos no Capítulo 6 conduzem às seguintes conclusões:

1) Embora ainda sejam necessárias algumas melhorias no equipamento, estão sendo obtidos resultados reprodutíveis, quando a grandeza analisada é o diâmetro da calota esférica;

2) Os quatro pontos superpostos na Figura 6.9 mostram que os resultados alcançados nesses ensaios estão em concordância qualitativa com os resultados obtidos por Adachi e Hutchings (2003).

\section{- CONCLUSÕES DOS ENSAIOS DEFINITIVOS}

A seguir, são apresentadas as conclusões dos Ensaios Definitivos, cujos resultados foram apresentados e discutidos no Capítulo 7.

CONCLUSÃO DA HIPÓTESE 1: EM ABERTO. Pelos gráficos das Figuras 7.1, e 7.12 (referentes ao aço ferramenta M2) e, 7.22 e 7.37 (referentes ao WC-Co P20), deduz-se que o quociente $\boldsymbol{A}_{R O L} / \boldsymbol{A}_{\boldsymbol{R} I S}$ não apresentou relação com a distância de deslizamento. Entretanto, dois fatores podem ter influenciado os comportamentos dos gráficos mencionados: $i$ ) o desgaste da esfera e ii) a não obtenção do regime permanente de desgaste. A Figura 7.72 mostra que, conforme os ensaios foram sendo realizados e, inevitavelmente, o nível de desgaste ( $\Xi)$ da esfera aumentando, os modos de desgaste abrasivo foram se alternando entre desgaste abrasivo misto e desgaste abrasivo por rolamento. Além disso, os resultados obtidos com o HSS M2, não estão em regime permanente de desgaste, o que também pode ter influenciado o comportamento de $\boldsymbol{A}_{\boldsymbol{R} O L} / \boldsymbol{A}_{\boldsymbol{R} I S}$ com a variação da distância de deslizamento. 
CONCLUSÃO DA HIPÓTESE 2: ACEITA. Quando a esfera de ensaio atinge um determinado nível de desgaste, serão geradas crateras de desgaste com contornos tendendo a uma elipse. Dependendo do nível de desgaste da esfera de ensaio, as crateras de desgaste podem apresentar diferentes contornos, como mostram as figuras dos Itens 7.1.1, 7.1.3 e 7.7. Nesta Dissertação, foram catalogados quatro contornos ("contorno circunferencial", "contorno elíptico", "contorno oblongo" e "contorno 8"), conforme a Figura 7.73. O nível de desgaste da esfera ( $\Xi$ ) pode ser avaliado qualitativamente pelo contorno da cratera de desgaste gerada. Com base nos quatro contornos registrados, neste trabalho convencionou-se que, quando 0 contorno da cratera de desgaste é circunferencial, $\Xi=1$, elíptico, $\Xi=2$, oblongo, $\Xi=3$ e contorno "8", $\Xi=4$.

CONCLUSÃo DA HIPÓteSE 3: ACEITA. Para as condições de ensaio estabelecidas nesta Dissertação (Capítulo 5), o processo de desgaste não atingiu o regime permanente com o aço ferramenta M2 (Figura 7.75) e atingiu com o WC-Co P2O (Figura 7.76). Esses resultados sugerem que, para a mesma condição de ensaio, diferentes pares de materiais podem atingir o regime permanente de desgaste em diferentes distâncias de deslizamento. 


\section{SUGESTÕES PARA TRABALHOS FUTUROS}

Para a continuidade desse trabalho, são sugeridas três pesquisas:

\section{PESQUISA 1:}

- Colocação do problema: um assunto pouco, ou talvez não discutido na literatura, diz respeito ao desgaste da esfera durante ensaios de desgaste micro-abrasivo por esfera rotativa. O desgaste da mesma pode fazer com que as crateras de desgaste geradas apresentem contornos tendendo a uma elipse. Conseqüentemente, essa imperfeição ocasionará erros quando forem calculados a altura e volume da cratera de desgaste, além de erros, durante a medição de seu próprio diâmetro. O cálculo impreciso do volume de desgaste pode, conseqüentemente, inserir erros significativos na determinação do coeficiente de desgaste, parâmetro utilizado para o estudo do regime permanente de desgaste.

- Objetivo: estudar a influência do desgaste da esfera de ensaio na formação das crateras de desgaste.

- Sugestão para início da pesquisa: para diferentes materiais de corpos-de-prova, utilizar esferas de aço AISI 52100 com diferentes níveis de desgaste na linha de trabalho. Após os ensaios, analisar as crateras de desgaste por meio de um microscópio óptico, com a finalidade de observar seus contornos. Após as aquisições das imagens, transferir os arquivos para um programa de $C A D$ (por exemplo, AutoCAD 2000 ou CATIA V4). Independente da forma do contorno da cratera de desgaste, aproximar a mesma para uma elipse (lembrando que, uma elipse com diagonais de medidas iguais, equivale a uma circunferência). Em função das diagonais da elipse, propor uma equação para o cálculo do volume da cratera de desgaste. Essa equação pode ser deduzida com base em conceitos de geometria diferencial, que podem ser adquiridos no livro de Manfredo Perdigão do Carmo Elementos de Geometria Diferencial - Editora Universidade de Brasília. 


\section{PESQUISA 2:}

- Colocação do problema: a partir de uma determinada distância de deslizamento percorrida pela esfera de ensaio, as crateras de desgaste apresentarão contornos tendendo a uma elipse, como pôde ser observado nos Capítulos 6 e 7.

- Objetivo: estimar a máxima distância de deslizamento que a esfera de ensaio pode percorrer sem que comece a gerar crateras de desgaste com contornos tendendo a uma elipse.

- Sugestão para início da pesquisa: nesta Dissertação, foram utilizados corpos-deprova de aço ferramenta M2 e WC-Co P20, esferas de aço AISI 52100 e, como material abrasivo, carbeto de silício preto. Utilizar esses materiais e definir os valores da força normal, rotação da esfera de ensaio, concentração da pasta abrasiva e vazão da mesma sobre o contato corpo-de-prova/esfera. Em função das condições de ensaio, deduzir uma equação que permita estimar a máxima distância de deslizamento que a esfera pode percorrer sem começar a gerar crateras de desgaste com contornos tendendo a uma elipse.

\section{PESQUISA 3:}

- Colocação do problema: durante um ensaio de desgaste micro-abrasivo por esfera rotativa, teoricamente, a esfera de ensaio não entra em contato com o corpo-de-prova. Entre a esfera de ensaio e o corpo-de-prova, estão as partículas abrasivas. Entretanto, para o cálculo da severidade de contato $\left(\boldsymbol{S}_{C}\right)$, Adachi e Hutchings (2003) ignoram esse fato, considerando apenas, propriedades do corpo-de-prova e da esfera de ensaio (dureza, módulo de elasticidade e coeficiente de Poisson). Em relação ao próprio material abrasivo, além de sua fração volumétrica na concentração de pasta abrasiva, somente seu tamanho médio é considerado.

- Objetivo: estudar a influência da dureza das partículas abrasivas no cálculo da severidade de contato. 
- Sugestão para início da pesquisa: desprezar o módulo de elasticidade e o coeficiente de Poisson do material abrasivo. Embora aparentemente não seja correto, essa simplificação talvez possa facilitar o estudo. Com os mesmos materiais utilizados nesta Dissertação (corpos-de-prova, esferas de ensaio e material abrasivo), deduzir uma equação que considere a dureza do material abrasivo no cálculo da severidade de contato. Não é necessário utilizar diversos materiais de corpos-prova e/ou esferas de ensaio e/ou materiais abrasivos. Ao invés disso, caso seja necessário, basta variar a força normal para se obter diversos valores de $\boldsymbol{S}_{\boldsymbol{c}}$. 


\section{ANEXO I - DEDUÇÃO DA EQUAÇÃO DE ARCHARD PARA O DESGASTE ABRASIVO}

A dedução da equação é iniciada considerando uma partícula cônica deslizando sobre uma superfície plana de um material dútil sob a ação de uma carga normal $\Delta \boldsymbol{F}_{\boldsymbol{N}}$ (Figura I-1):

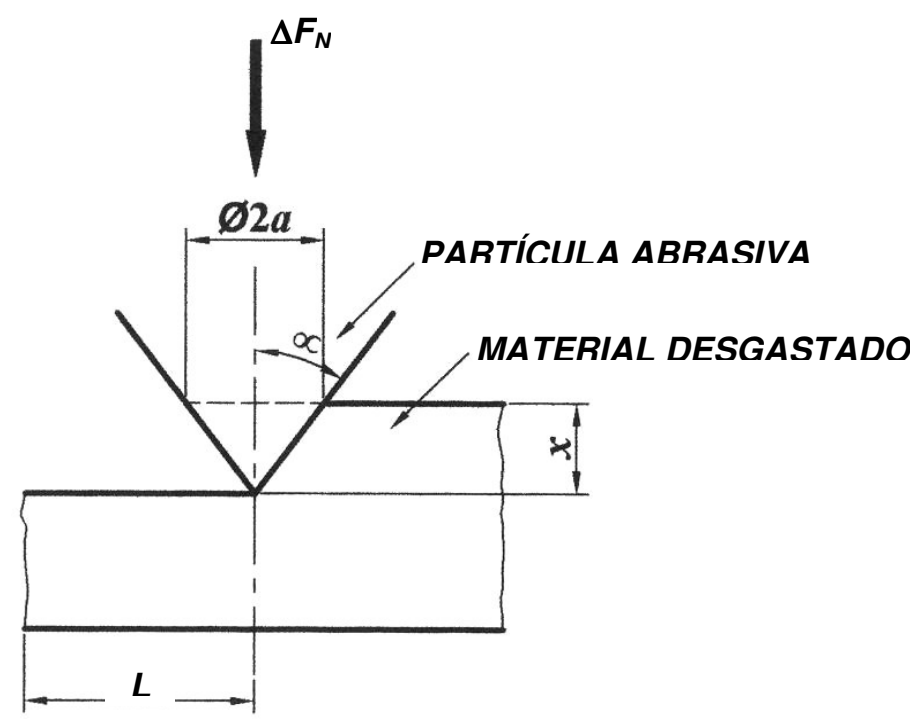

Figura l-1: Partícula abrasiva com formato cônico deslizando sobre uma superfície plana.

A carga $\Delta \boldsymbol{F}_{\boldsymbol{N}}$ causa uma pressão $\boldsymbol{P}$ que age sobre toda área de contato entre a partícula e a superfície. Como a partícula está em movimento de translação, o contato ocorre somente sobre sua superfície frontal. Portanto, $\Delta F_{N}$ fica:

$$
\Delta F_{N}=P \frac{\pi \cdot a^{2}}{2}
$$

Mas, pela Figura $1-1, \tan \alpha=\frac{a}{x}$. Então, $a^{2}=x^{2} \cdot \tan ^{2} \alpha$. Substituindo na Equação l-1:

$$
\Delta F_{N}=\frac{1}{2} P \cdot \pi \cdot x^{2} \cdot \tan ^{2} \alpha
$$


A deformação plástica na superfície do material será desprezível, caso a partícula abrasiva se deforme, ou se rompa antes que $\boldsymbol{P}$ atinja o valor de aproximadamente $\sigma_{E S C}$ (sendo $\sigma_{E S C}$, a tensão de escoamento do material da superfície). Entretanto, se $\boldsymbol{P}$ atingir $\cong 3 \sigma_{E S C}$, a superfície sofrerá uma acentuada deformação plástica. Esse valor de $\boldsymbol{P}$ é denominado dureza de indentação, ou seja, é a dureza do material $(\boldsymbol{P}=\boldsymbol{H})$, e possui dependência com a forma da partícula abrasiva. Nessa condição, o volume de material deslocado ao longo da ranhura a uma distância $\boldsymbol{L}$ fica definido por:

$$
V_{d}=\text { L.a.x }
$$

Mas, $a=x \cdot \tan \alpha$ (Figura l-1). Logo, substituindo na Equação I-3:

$$
V_{d}=L \cdot x^{2} \cdot \tan ^{2} \alpha
$$

Entretanto, de todo material deslocado lateralmente à partícula, somente uma fração $\beta$ é removida como fragmentos de desgaste, por unidade de distância de deslizamento. Logo, a taxa de desgaste de uma partícula (q) fica:

$$
\begin{gathered}
q=\beta \frac{V_{d}}{L} \\
q=\beta \frac{L \cdot x^{2} \cdot \tan ^{2} \alpha}{L}
\end{gathered}
$$$$
q=\beta \cdot x^{2} \cdot \tan ^{2} \alpha
$$

Na Equação l-2, isolando-se $\boldsymbol{x}^{2}$ :

$$
x^{2}=\frac{2 \Delta F_{N}}{P \cdot \pi \cdot \tan ^{2} \alpha}
$$


E substituindo na Equação l-5:

$$
q=\beta \frac{2 \Delta F_{N}}{P \cdot \pi \cdot \tan \alpha}
$$

Para " $\boldsymbol{n}_{\boldsymbol{P}}$ " partículas, o volume de material total removido por unidade de distância de deslizamento, $\boldsymbol{Q}$, fica definido por:

$$
Q=\sum_{i=1}^{n} q_{i}=\left(\frac{2 \beta}{H \cdot \pi \cdot \tan \alpha}\right) \sum_{i=1}^{n} \Delta F_{N_{i}}
$$

$$
Q=\left(\frac{2 \beta}{\pi \cdot \tan \alpha}\right) \frac{F_{N}}{H}
$$

Sendo $\boldsymbol{F}_{\boldsymbol{N}}$, a carga normal total aplicada sobre o sistema e $\boldsymbol{H}$ a dureza do material.

$$
\begin{aligned}
& \text { Fazendo } K=\frac{2 \beta}{\pi \cdot \tan \alpha} \text {, a Equação l-7 torna-se: } \\
& Q=K \frac{F_{N}}{H}
\end{aligned}
$$

Unidades: $Q \Rightarrow\left[\frac{m m^{3}}{m}\right], F_{N} \Rightarrow[N]$ e $H \Rightarrow\left[\frac{N}{m m^{2}}\right]$

Fazendo $k=\frac{K}{H}$ e substituindo na Equação l-8:

$$
Q=k \cdot F_{N}
$$

Unidades: $Q \Rightarrow\left[\frac{m m^{3}}{m}\right], k \Rightarrow\left[\frac{m m^{3}}{N . m}\right]$ e $F_{N} \Rightarrow[N]$ 


\section{ANEXO II - ENSAIO DE MICRO-ABRASÃO: EQUAÇÕES UTILIZADAS}

As equações foram deduzidas para o desgaste de filmes finos. As equações estão divididas em dois casos: Caso 1 - Revestimento e substrato são desgastados; Caso 2 - Somente o revestimento é desgastado. O Caso 2 pode ser aplicado para análises de crateras de desgaste geradas em corpos-de-prova sem revestimento.

\section{Caso 1: Revestimento e substrato são desgastados}

\section{- Profundidade total de penetração da esfera de ensaio $\left(h_{T}\right)$ :}

Aplicando o Teorema de Pitágoras, com base na Figura II-1:

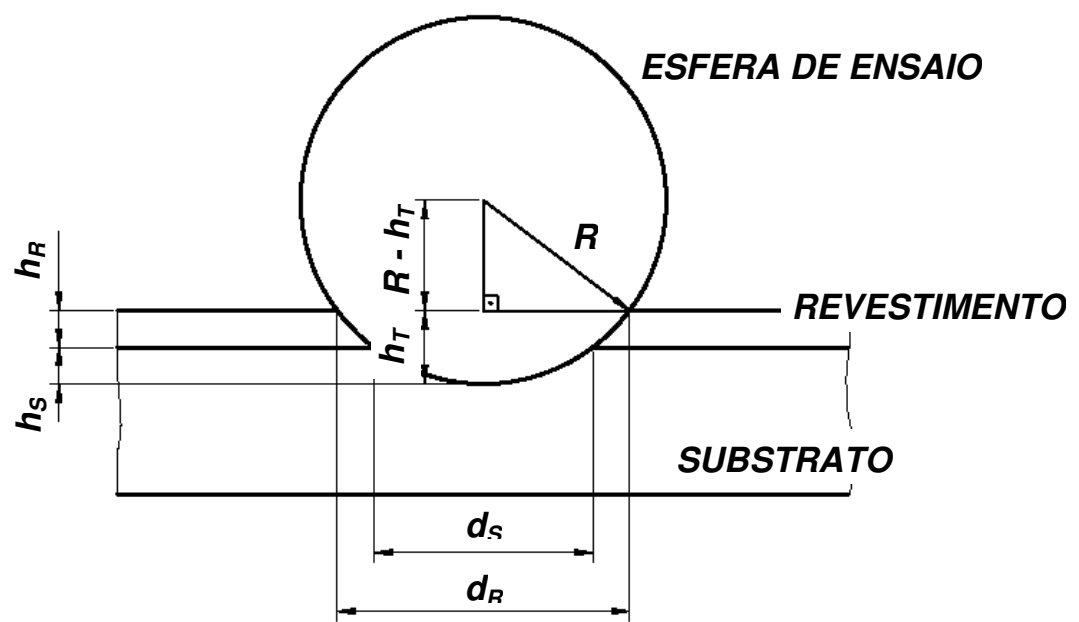

Figura II-1: Caso em que revestimento e substrato são desgastados pela esfera de ensaio.

$$
\begin{aligned}
& R^{2}=\left(\frac{d_{R}}{2}\right)^{2}+\left(R-h_{T}\right)^{2} \\
& R^{2}=\frac{d_{R}^{2}}{4}+R^{2}+h_{T}^{2}-2 \cdot R \cdot h_{T}
\end{aligned}
$$

Igualando a zero a Equação II-1:

$$
h_{T}^{2}-2 \cdot R \cdot h_{T}+\frac{d_{R}^{2}}{4}=0
$$


Os coeficientes da Equação $/ I-2$ são $A=1, B=-2 R$ e $C=\frac{d^{2}}{4}$. Então:

$$
\begin{gathered}
\Delta=B^{2}-4 A C \\
\Delta=[-2 R]^{2}-4 \cdot 1 \cdot \frac{d_{R}^{2}}{4} \\
\Delta=4 R^{2}-d_{R}^{2}
\end{gathered}
$$

Logo, a equação de $\boldsymbol{h}_{\boldsymbol{T}}$ fica:

$$
\begin{gathered}
h_{T}=\frac{-B \pm \sqrt{\Delta}}{2 a} \\
h_{T}=\frac{2 R \pm \sqrt{4 R^{2}-d_{R}^{2}}}{2}
\end{gathered}
$$

Analisando a Figura II-1, pode-se concluir que:

$$
\left\{\begin{aligned}
d_{R}=0 & \Rightarrow h_{T}=0 \\
d_{R}=25,40 m m & \Rightarrow h_{T}=12,70 m m
\end{aligned}\right.
$$

Essa condição é satisfeita somente para $h_{T}=\frac{2 R-\sqrt{4 R^{2}-d_{R}^{2}}}{2}$. Com isso, como nessa dissertação foi utilizada uma esfera de diâmetro 25,40 $\mathrm{mm}(\boldsymbol{R}=12,70 \mathrm{~mm})$ :

$$
\begin{gathered}
h=\frac{2.12,70 m m-\sqrt{4(12,70 m m)^{2}-d_{R}^{2}}}{2} \\
h_{T}=12,70-\sqrt{161,29-0,25 d_{R}^{2}}
\end{gathered}
$$

Unidades: $h_{T} \Rightarrow[\mathrm{mm}]$ e $d_{R} \Rightarrow[\mathrm{mm}]$ 


\section{- Espessura do revestimento $\left(h_{R}\right)$ :}

Pela Figura II-1, a espessura do revestimento pode ser calculada por:

$$
h_{R}=h_{T}-h_{S}
$$

Fazendo uma analogia à Equação $I I-3, h_{S}$ fica:

$$
h_{S}=12,70-\sqrt{161,29-0,25 d_{s}^{2}}
$$

Com isso:

$$
\begin{array}{r}
h_{R}=12,70-\sqrt{161,29-0,25 d_{R}^{2}}-\left\lfloor 12,70-\sqrt{161,29-0,25 d_{S}^{2}}\right\rfloor \\
h_{R}=\sqrt{161,29-0,25 d_{S}^{2}}-\sqrt{161,29-0,25 d_{R}^{2}}
\end{array}
$$

Unidades: $h_{R} \Rightarrow[\mathrm{mm}], d_{S} \Rightarrow[\mathrm{mm}]$ e $d_{R} \Rightarrow[\mathrm{mm}]$

- Volume total da cratera de desgaste $\left(V_{T}\right)$ :

Observando a Figura II-2 e aplicando a fórmula $V=\pi \int_{0}^{h}[f(x)]^{2} d x$, o volume total da cratera de desgaste pode ser calculado por:

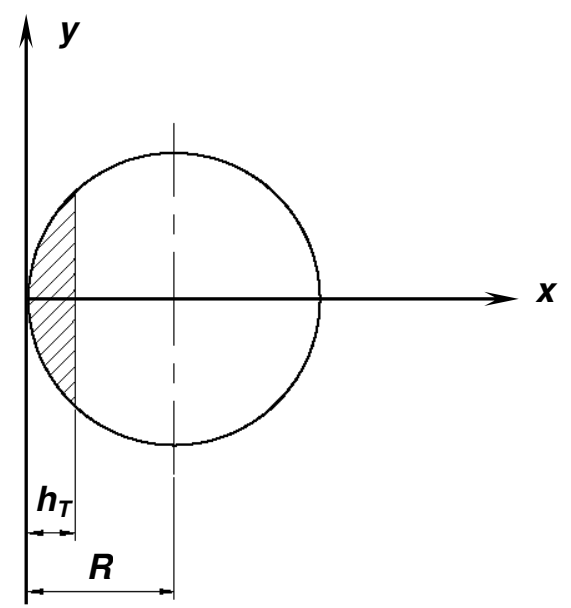

Figura II-2: Cálculo do volume total da cratera de desgaste. 


$$
\begin{gathered}
V_{T}=\pi \int_{0}^{h_{T}}\left[R^{2}-(x-R)^{2}\right] d x \\
V_{T}=\pi \int_{0}^{h_{T}}\left[R^{2}-\left(x^{2}+R^{2}-2 \cdot R \cdot x\right)^{2}\right] d x \\
V_{T}=\pi \int_{0}^{h_{T}}\left(2 \cdot R \cdot x-x^{2}\right) d x \\
V_{T}=\left.\pi\left[2 R \frac{x^{2}}{2}-\frac{x^{3}}{3}\right]\right|_{0} ^{h_{T}} \\
\left.V_{T}=\pi\left[12,70 h_{T}^{2}-\frac{h_{T}^{3}}{3}\right)\right) \\
V_{T}=\pi\left[\left.\left(R \cdot h_{T}^{2}-\frac{x^{3}}{3}\right]\right|_{0} ^{h_{T}^{3}}\right. \\
\left.\left.V_{T}=\pi \cdot h_{T}^{2}-\frac{h_{T}^{3}}{3}\right)-0\right]
\end{gathered}
$$

Unidades: $V_{T} \Rightarrow\left[\mathrm{mm}^{3}\right]$ e $h_{T} \Rightarrow[\mathrm{mm}]$

- Volume da cratera de desgaste do substrato $\left(V_{S}\right)$ :

Verificando a Figura II-2 e fazendo uma analogia à Equação /I-5:

$$
V_{S}=\pi\left(12,70 h_{S}^{2}-\frac{h_{S}^{3}}{3}\right)
$$

Unidades: $V_{S} \Rightarrow\left\lfloor\mathrm{mm}^{3}\right\rfloor$ e $h_{S} \Rightarrow[\mathrm{mm}]$ 
- Volume de desgaste do revestimento $\left(V_{R}\right)$ :

Baseando-se na Figura II-2, $\boldsymbol{V}_{\boldsymbol{R}}$ pode ser calculado por:

$$
V_{R}=V_{T}-V_{S}
$$

Então:

$$
\begin{gathered}
V_{R}=\pi\left(12,70 h_{T}^{2}-\frac{h_{T}^{3}}{3}\right)-\pi\left(12,70 h_{S}^{2}-\frac{h_{S}^{3}}{3}\right) \\
V_{R}=12,70 \pi \cdot h_{T}^{2}-\pi \frac{h_{T}^{3}}{3}-12,70 \pi \cdot h_{S}^{2}+\pi \frac{h_{S}^{3}}{3} \\
V_{R}=12,70 \pi\left[h_{T}^{2}-h_{S}^{2}\right]+\frac{\pi}{3}\left[h_{S}^{3}-h_{T}^{3}\right]
\end{gathered}
$$

Unidades: $V_{R} \Rightarrow\left\lfloor\mathrm{mm}^{3}\right\rfloor, h_{T} \Rightarrow[\mathrm{mm}]$ e $h_{S} \Rightarrow[\mathrm{mm}]$

Caso 2: Somente o revestimento é desgastado

- Profundidade de penetração da esfera de ensaio (h):

Analisando a Figura /I-3 e fazendo uma analogia à Equação /I-3:

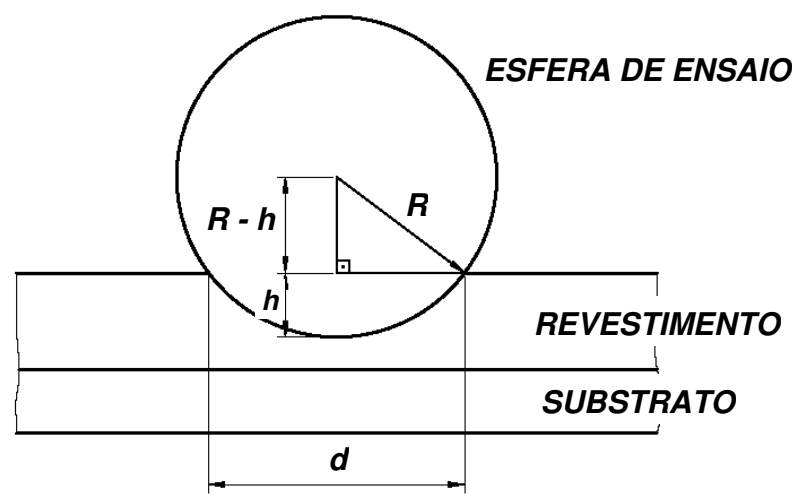

Figura II-3: Caso em que somente o revestimento é desgastado pela esfera de ensaio. 


$$
h=12,70-\sqrt{161,29-0,25 d^{2}}
$$

Unidades: $h \Rightarrow[\mathrm{mm}]$ e $d \Rightarrow[\mathrm{mm}]$

- Espessura do revestimento $\left(h_{R}\right)$ : Deve ser, necessariamente, calculado pelo Caso 1.

- Volume da cratera de desgaste ( ()$:$

Por analogia à Equação II-5:

$$
V=\pi\left(12,70 h^{2}-\frac{h^{3}}{3}\right)
$$

Unidades: $V \Rightarrow\left[\mathrm{mm}^{3}\right]$ e $h \Rightarrow[\mathrm{mm}]$

- Coeficientes de desgaste $\left(k_{S}\right.$ e $\left.k_{R}\right)$ :

Aqui, os coeficientes de desgaste do substrato e do revestimento $\left(\boldsymbol{k}_{\boldsymbol{S}}\right.$ e $\boldsymbol{k}_{\boldsymbol{R}}$, respectivamente), devem ser calculados de modo dependente. Ou seja, para se determinar $\boldsymbol{k}_{\boldsymbol{R}}$, deve-se conhecer $\boldsymbol{k}_{\boldsymbol{S}}$ (ou vice-versa).

$\boldsymbol{k}_{\boldsymbol{R}}$ pode ser determinado em um ensaio, onde somente o revestimento é desgastado, com o uso da seguinte equação:

$$
k_{R}=\frac{V}{S . F_{N}}
$$

Onde $\boldsymbol{S}$ é a distância de deslizamento, entre a esfera e o corpo-de-prova e $\boldsymbol{F}_{\boldsymbol{N}}$, é a força normal aplicada.

Unidades: $k_{R} \Rightarrow\left[\frac{m m^{3}}{N . m}\right], V \Rightarrow\left[m^{3}\right], S \Rightarrow[m]$ e $F_{N} \Rightarrow[N]$ 
A distância de deslizamento $\mathbf{S}$ pode ser definida por:

$$
\begin{gathered}
S=v_{T} . t \\
S=\left(\omega_{E S F} . R\right) t \\
S=\left[2 \pi \frac{n_{E S F}}{60} R\right] t \\
S=\frac{12,70 \pi}{30.000} n_{E S F} . t
\end{gathered}
$$

Unidades: $S \Rightarrow[m], n_{E S F} \Rightarrow[r p m]$ e $t \Rightarrow[s]$

A Equação II-10 pode ser desenvolvida, para considerar o desgaste do revestimento e do substrato. Logo, depois de calculado $\boldsymbol{k}_{\boldsymbol{R}}$, calcula-se $\boldsymbol{k}_{\boldsymbol{S}}$, através da equação:

$$
\begin{array}{r}
\frac{V_{R}}{k_{R}}+\frac{V_{S}}{k_{S}}=S . F_{N} \\
\frac{V_{S}}{k_{S}}=S . F_{N}-\frac{V_{R}}{k_{R}} \\
k_{S}=\frac{V_{S}}{S . F_{N}-\frac{V_{R}}{k_{R}}}
\end{array}
$$

Unidades: $k_{S} ; k_{R} \Rightarrow\left[\frac{m m^{3}}{N . m}\right], V_{S} ; V_{R} \Rightarrow\left\lfloor m m^{3}\right\rfloor$ e $S \Rightarrow[m]$ 


\section{ANEXO III - EQUAÇÃO ALTERNATIVA PARA O CÁLCULO DO COEFICIENTE DE} DESGASTE

O coeficiente de desgaste é calculado pela Equação III-1:

$$
k=\frac{V}{F_{N} \cdot S}
$$

Na Equação III-1, o volume de desgaste pode ser escrito pela Equação III-2:

$$
V=\frac{\pi \cdot d^{4}}{64 R}
$$

Substituindo a Equação III-2 na Equação III-1, chega-se à:

$$
k=\frac{\pi \cdot d^{4}}{64 \cdot F_{N} \cdot S \cdot R}
$$

A Equação III-3 pode ser escrita da seguinte forma:

$$
k=\frac{\pi(d)^{2} \cdot(d)^{2}}{64 \cdot F_{N} \cdot S \cdot R}
$$

Porém, $\boldsymbol{d}=2 \boldsymbol{r}$, onde $\boldsymbol{r}$ é o raio da calota esférica. Logo, reescrevendo a Equação III-4:

$$
\begin{gathered}
k=\frac{\pi(2 r)^{2}(2 r)^{2}}{64 \cdot F_{N} \cdot S \cdot R} \\
k=\frac{\pi\left(4 r^{2}\right) \cdot\left(4 r^{2}\right)}{64 \cdot F_{N} \cdot S \cdot R}
\end{gathered}
$$


Reorganizando os termos do numerador na Equação III-6, obtêm-se:

$$
k=\frac{16\left(\pi \cdot r^{2}\right) \cdot\left(r^{2}\right)}{64 \cdot F_{N} \cdot S \cdot R}
$$

$\mathrm{Na}$ Equação III-7, multiplicando o numerador e o denominador por $\pi$.

$$
k=\frac{16\left(\pi \cdot r^{2}\right) \cdot\left(r^{2}\right)}{64 \cdot F_{N} \cdot S \cdot R} \frac{\pi}{\pi}
$$

Organizando os termos do numerador e do denominador da Equação III-8:

$$
k=\frac{16\left(\pi \cdot r^{2}\right) \cdot\left(\pi \cdot r^{2}\right)}{64 \pi \cdot F_{N} \cdot S \cdot R}
$$

Na Equação III-9, o termo $\pi \cdot r^{2}$ equivale à área $\boldsymbol{A}_{t}$ da calota esférica, quando a sua projeção é considerada uma circunferência perfeita. Logo, o termo $\pi \cdot r^{2}$ pode ser substituído por $\boldsymbol{A}_{t}$. Com isso, chega-se na Equação III-10:

$$
k=\frac{16\left(A_{t}\right) \cdot\left(A_{t}\right)}{64 \pi \cdot F_{N} \cdot S \cdot R}
$$

Simplificando a Equação III-10:

$$
k=\frac{A_{t}^{2}}{4 \pi \cdot F_{N} \cdot S \cdot R}
$$

Porém, $\boldsymbol{A}_{\boldsymbol{t}}$ não precisa ser necessariamente determinada pela equação $\boldsymbol{A}_{t}=\pi \frac{\boldsymbol{d}^{2}}{4}$ ou $\boldsymbol{A}_{t}=\pi \cdot \boldsymbol{r}^{2}$. Ao invés disso, o valor de $\boldsymbol{A}_{t}$ pode ser obtido como no Item 5.4.1, pelo Método 2. 


\section{ANEXO IV - CONTATOS \& DESENHOS TÉCNICOS}

1. GlobalMag

- Marcelo Lancarotte, MSc.

info@globalmag.com.br - (11) 3039-8330 / São Paulo

2. Rolamentos Paulista RPL Ltda.

www.rpl.com.br

- Nelson Thimóteo da Silva Jr.

nelson@rpl.com.br - (11) 3024-4014 / São Paulo

3. Rexroth - Bosch Group

- Vagner Alvares - Controles e Comandos Elétricos

vagner.álvares@boschrexroth.com.br - (11) 4414-5691 / Atibaia

- Eng. Ronaldo Costa - Sistemas Lineares

ronaldo.costa@boschrexroth.com.br - (11) 4414-5725 / Atibaia

4. Roning Indústria e Comércio Ltda.

- Augusto Mestres Bahia - Diretor

- Luiz Carlos Corso - Técnico (Cel.: 9574-3764)

roning@roning.com.br - (11) 4368-4900 / São Bernardo do Campo

5. Mectrol - Automação Industrial

- Fernando Bolsoni de Castro

vendasp@mectrol.com.br - (11) 5671-4001 / São Paulo

6. Kalatec Automação

www.kalatec.com.br

- Edilson Cravo Oliveira - Eng. Aplicação

kalatec@kalatec.com.br - (11) 5685-6040 / São Paulo

7. RS do Brasil

www.rsdobrasil.com.br

vendas@rsdobrasil.com.br - (11) 3031-4491 / 3031-0610 / São Paulo

8. Eletro Técnica Tsukamoto Ltda.

www.eletrotsukamoto.hpg.com.br

eletrotsukamoto@uol.com.br - (11) 4362-3516 / 4367-2206 / São Bernardo do Campo

9. Varimar - Variadores Eletromagnéticos

www.varimar.com.br

varimar@uol.com.br - (11) 4178-3053 / São Bernardo do Campo

10. Alfa Instrumentos Eletrônicos Ltda.

www.alfainstrumentos.com.br

vendas@alfainstrumentos.com.br - (11) 3952-2299 / São Paulo

11. Valsan - Equipamentos Industriais

Eng. Paulo H. Warneke - Diretor

(11) 3826-0344 / São Paulo 
12. Provitec - Sistemas de Controle e Dosagem

www.provitec.com.br - (11) 5660-8082 / 5666-7662 / Guarulhos

\section{Tetralon - Bombas \& Válvulas}

www.tetralon.com.br

(11) 3340-5500 / São Paulo

\section{IGUS}

www.igus.com.br

- Áurea Lira

aurea@igus.com.br

(11) 5641-5662 / São Paulo

15. Comercial Redubrás Ltda.

(11) 3207-1022 / 3277-1845 / São Paulo

16. Zagretti - Indústria Mecânica Zagretti Ltda.

zagretti@zagretti.com.br - (11) 4974-6406 / Santo André

17. Correias Schneider Ltda.

www.correias.com.br

vendas@correias.com.br - (11) 3315-0777 / 3326-3955 / São Paulo

18. Jaguaré Protótipos Ltda.

- Álvaro Fontes

alvarofontes@hotmail.com - (11) 3714-5419 / São Paulo

19. SAE Ferramentaria S.A.

(11) 4392-0391 / São Bernardo do Campo

20. Ferramentas Afisolda Ltda.

www.afisolda.cjb.net

- Ademar Vergara

afisolda@bol.com.br - (11) 3625-0546 / São Paulo

21. SENAI Mario Amato

Núcleo de Tecnologia Cerâmica

(11) 4109-9499 / São Bernardo do Campo

22. TOSHIBA - Industrial Inverter

VF-S7 SERIES - Instruction Manual

\section{Só Esferas}

(11) 3846-5255 / São Paulo

\section{Norton Abrasivos}

www.norton-abrasivos.com.br

25.MINASOLO - Comércio e Representações Ltda.

- Juarez A. de Oliveira

(11) 6604-3033 / São Paulo 

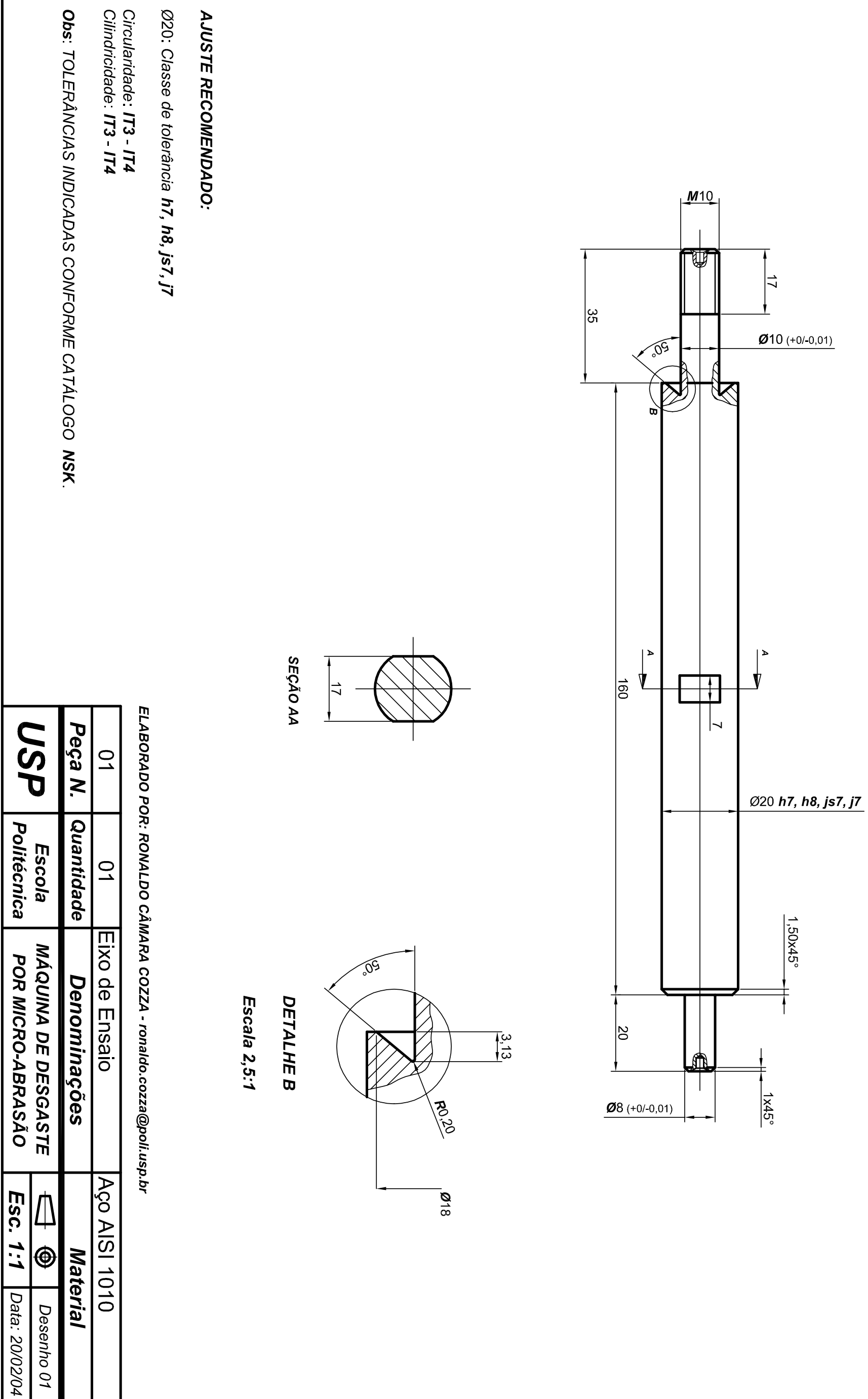


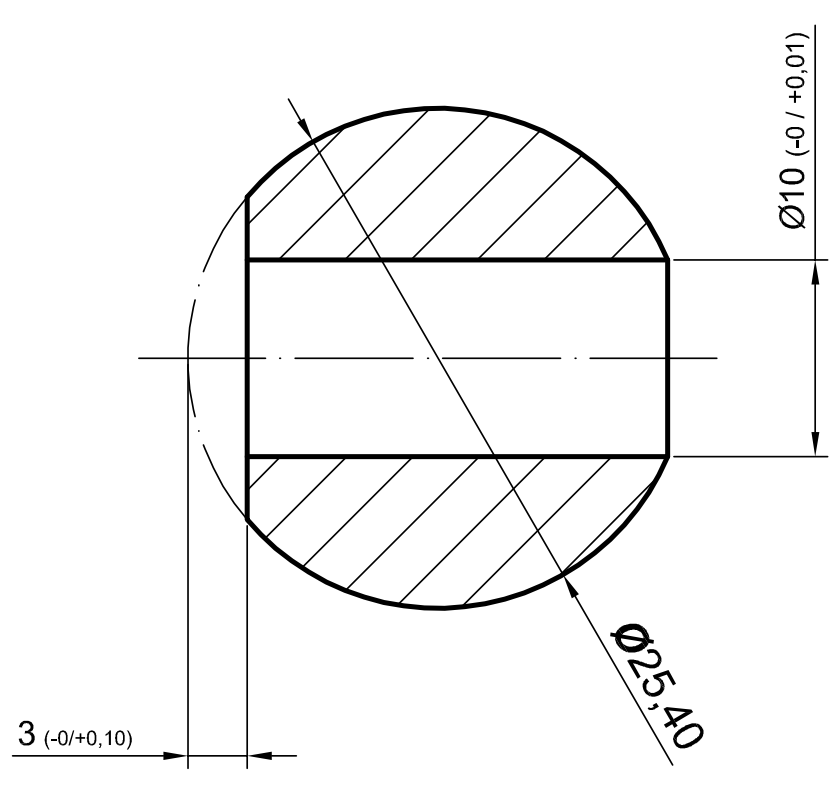

ELABORADO POR: RONALDO CÂMARA COZZA - ronaldo.cozza@poli.usp.br

\begin{tabular}{|c|c|c|c|c|}
\hline 02 & & Esfera de Ensaio & \multicolumn{2}{|c|}{} \\
\hline Peça N. & Quantidade & Denominações & \multicolumn{2}{|c|}{ Material } \\
\hline USP & $\begin{array}{c}\text { Escola } \\
\text { Politécnica }\end{array}$ & $\begin{array}{c}\text { MÁQUINA DE DESGASTE } \\
\text { POR MICRO-ABRASÃO }\end{array}$ & ESC. 2:1 & Data: 20/02/04 \\
\hline
\end{tabular}




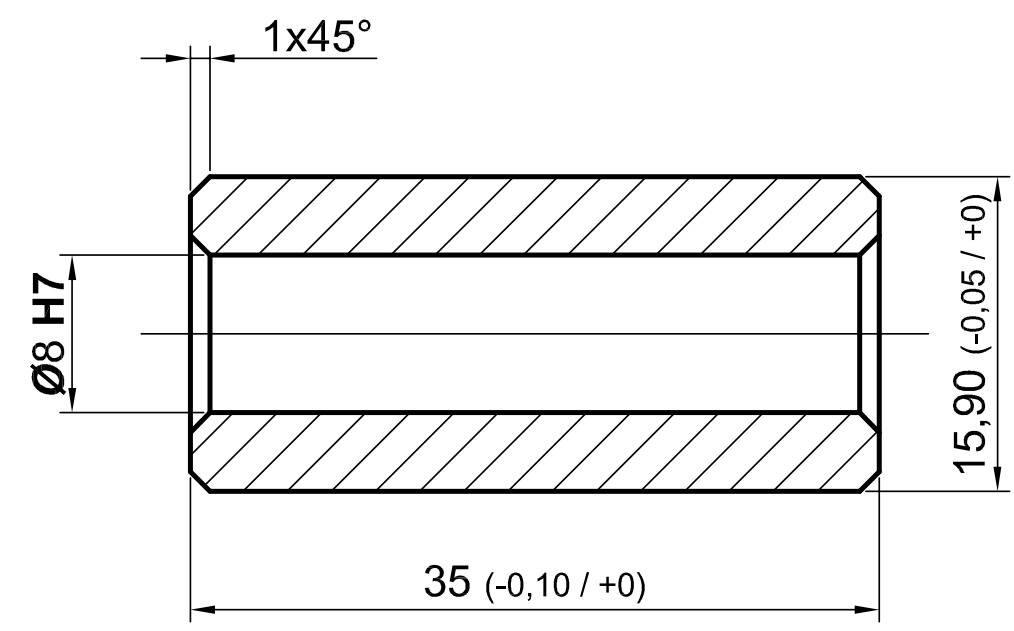

ELABORADO POR: RONALDO CÂMARA COZZA - ronaldo.cozza@poli.usp.br

\begin{tabular}{|c|c|c|c|c|}
\hline 03 & 01 & Bucha & \multicolumn{2}{|c|}{ Aço AISI 1010 } \\
\hline Peça N. & Quantidade & Denominações & \multicolumn{3}{|c|}{ Material } \\
\hline USP & Escola & MÁQUINA DE DESGASTE & @ & Desenho 03 \\
\cline { 4 - 6 } & Politécnica & POR MICRO-ABRASÃO & EsC. 2:1 & Data: 20/02/04 \\
\hline
\end{tabular}




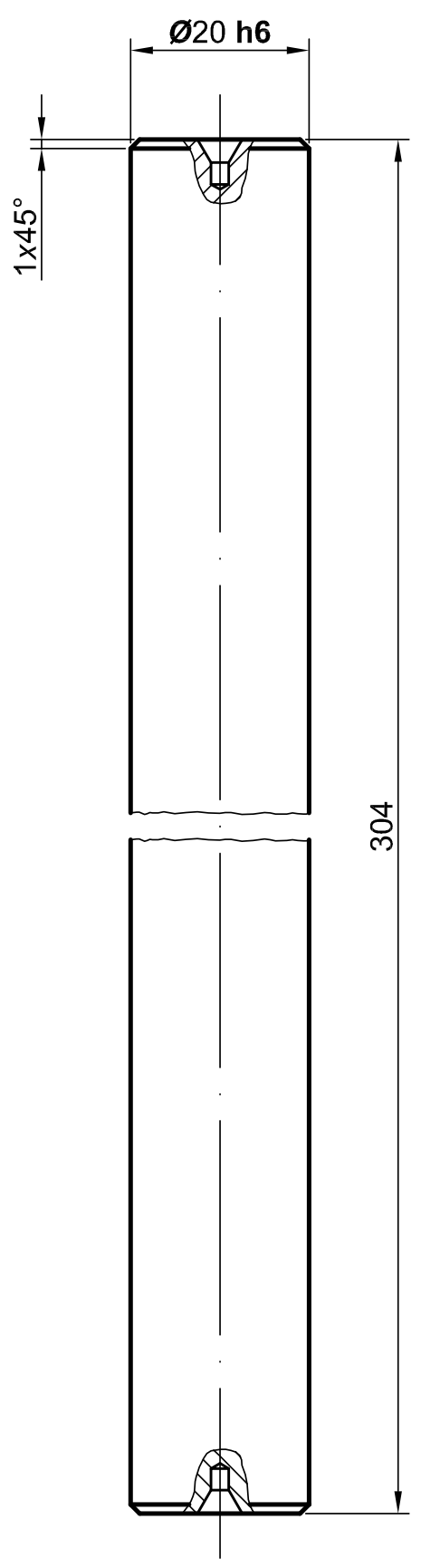

ELABORADO POR: RONALDO CÂMARA COZZA - ronaldo.cozza@poli.usp.br

\begin{tabular}{|c|c|l|l|c|}
\hline 04 & 02 & Guia & Aço AISI 1010 \\
\hline Peça N. & Quantidade & Denominações & \multicolumn{2}{|c|}{ Material } \\
\hline USP & $\begin{array}{c}\text { Escola } \\
\text { Politécnica }\end{array}$ & $\begin{array}{c}\text { MÁQUINA DE DESGASTE } \\
\text { POR MICRO-ABRASÃO }\end{array}$ & ESC. 1:1 & Data: 20/03/04 \\
\cline { 4 - 6 } & & &
\end{tabular}



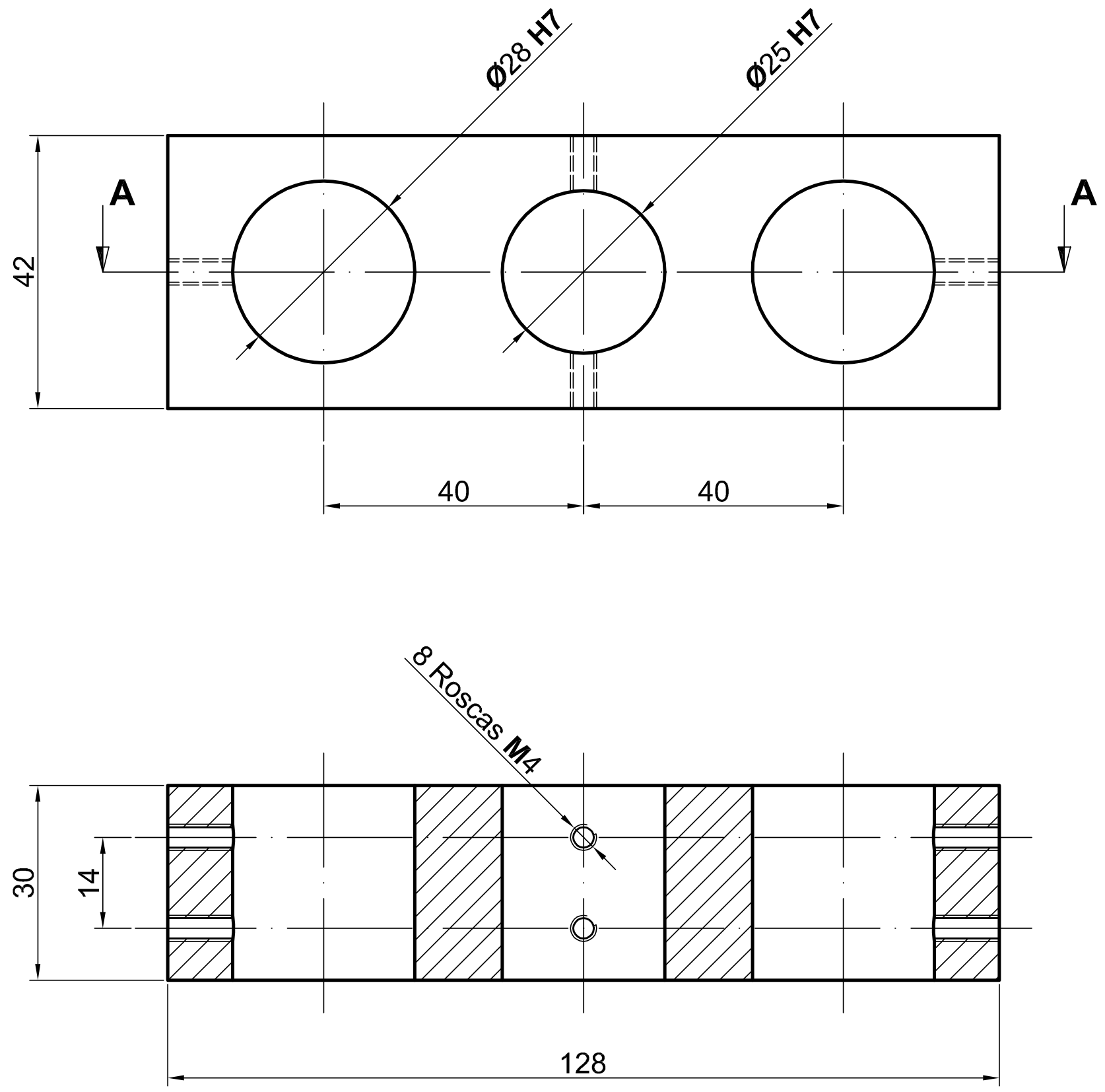

CORTE AA

ELABORADO POR: RONALDO CÂMARA COZZA - ronaldo.cozza@poli.usp.br

\begin{tabular}{|c|c|c|c|c|}
\hline 05 & 01 & Berço de Movimentação & \multicolumn{2}{|l|}{ Alumínio } \\
\hline Peça N. & Quantidade & Denominações & \multicolumn{2}{|c|}{ Material } \\
\hline USP & $\begin{array}{c}\text { Escola } \\
\text { Politécnica }\end{array}$ & $\begin{array}{c}\text { MÁQUINA DE DESGASTE } \\
\text { POR MICRO-ABRASÃo }\end{array}$ & Esc. 1:1 & Data: 20/03/04 \\
\cline { 4 - 6 } & & &
\end{tabular}




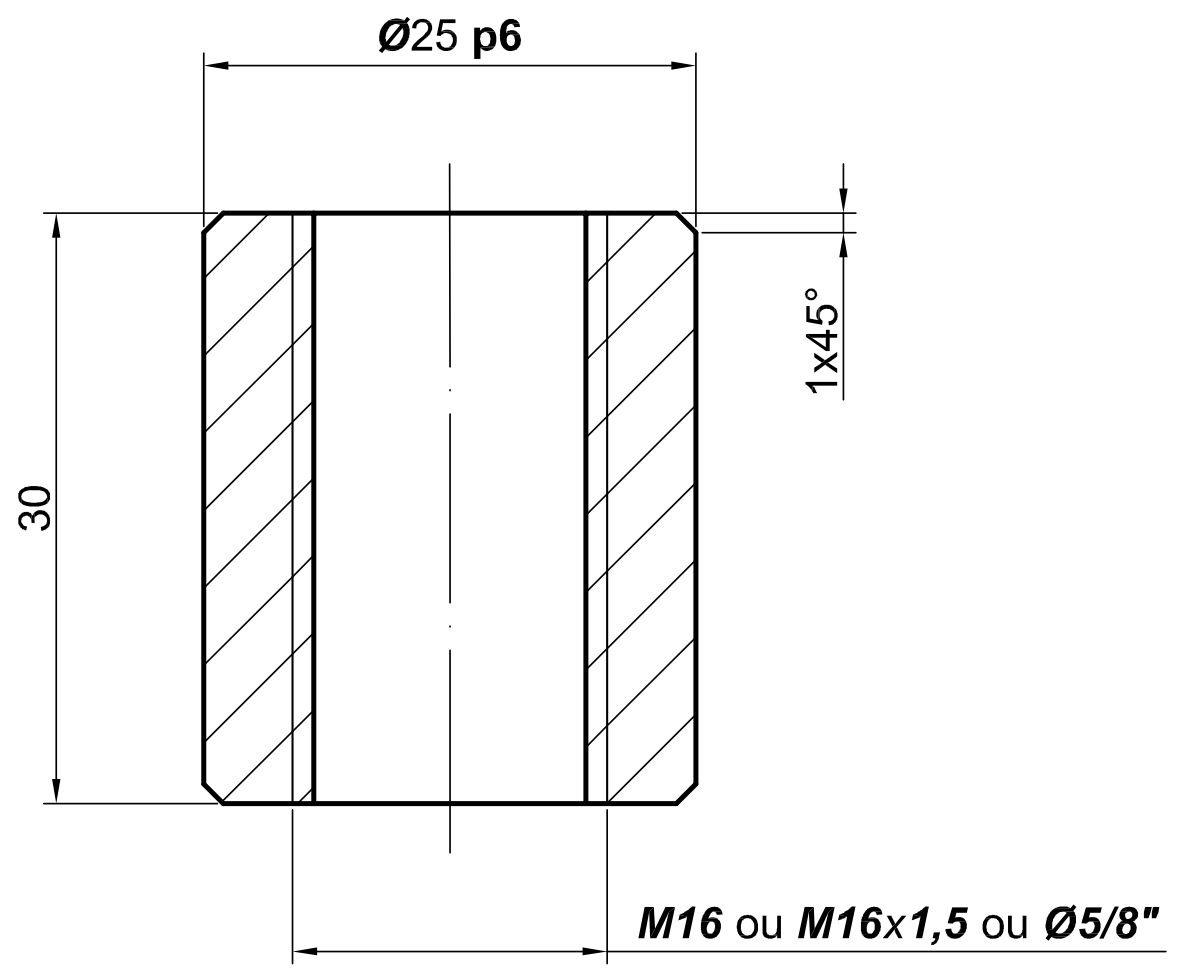

ELABORADO POR: RONALDO CÂMARA COZZA - ronaldo.cozza@poli.usp.br

\begin{tabular}{|c|c|c|c|c|}
\hline 06 & 01 & Porca - Berço de Movimentação & \multicolumn{1}{|l|}{ Bronze } \\
\hline Peça N. & Quantidade & Denominações & \multicolumn{3}{|c|}{ Material } \\
\hline USP & Escola & MÁQUINA DE DESGASTE & @ & Desenho 06 \\
\cline { 4 - 6 } & Politécnica & POR MICRO-ABRASÃO & ESC. 2:1 & Data: 20/03/04 \\
\hline
\end{tabular}




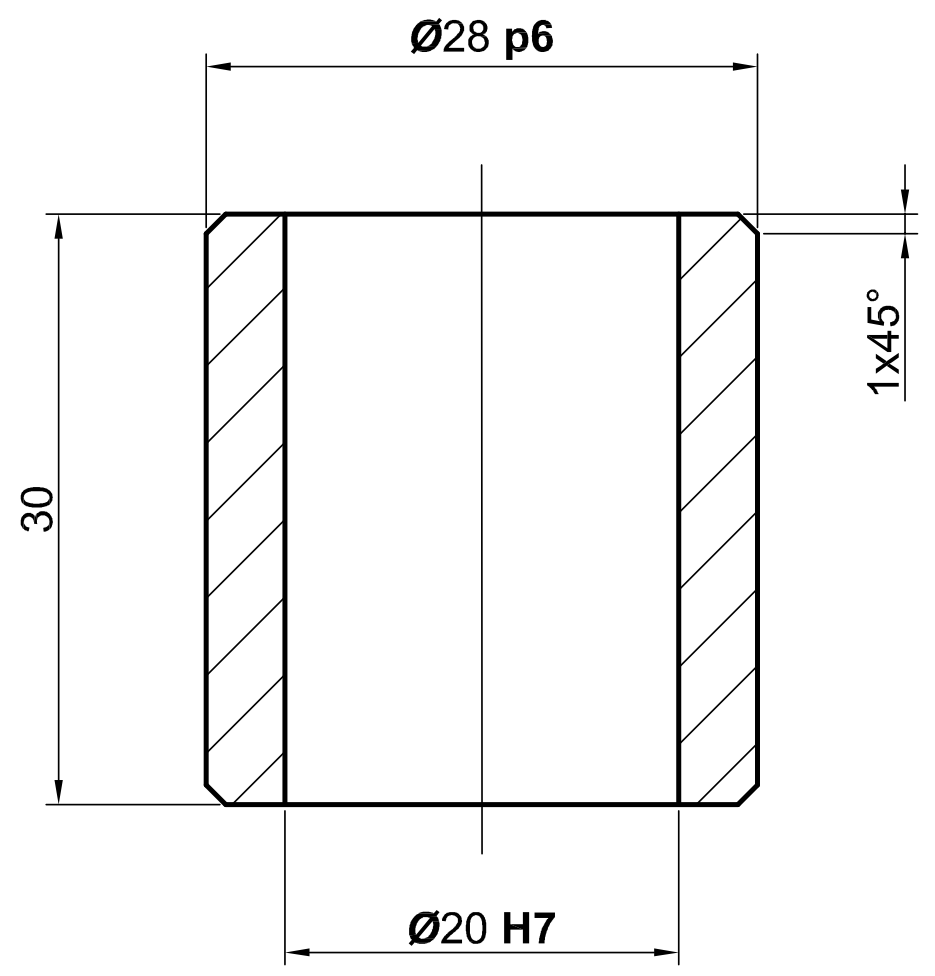

\begin{tabular}{|c|c|c|c|c|c|}
\multicolumn{6}{|c|}{ ELABORADO POR: RONALDO CÂMARA COZZA - ronaldo.cozza@poli.usp.br } \\
\hline 07 & 02 & Bucha - Berço de Movimentação & \multicolumn{1}{l|}{ Bronze } \\
\hline Peça N. & Quantidade & Denominações & \multicolumn{3}{|c|}{ Material } \\
\hline USP & $\begin{array}{c}\text { Escola } \\
\text { Politécnica }\end{array}$ & $\begin{array}{c}\text { MÁQUINA DE DESGASTE } \\
\text { POR MICRO-ABRASÃO }\end{array}$ & EsC. 2:1 & Data: 20/03/04 \\
\hline
\end{tabular}



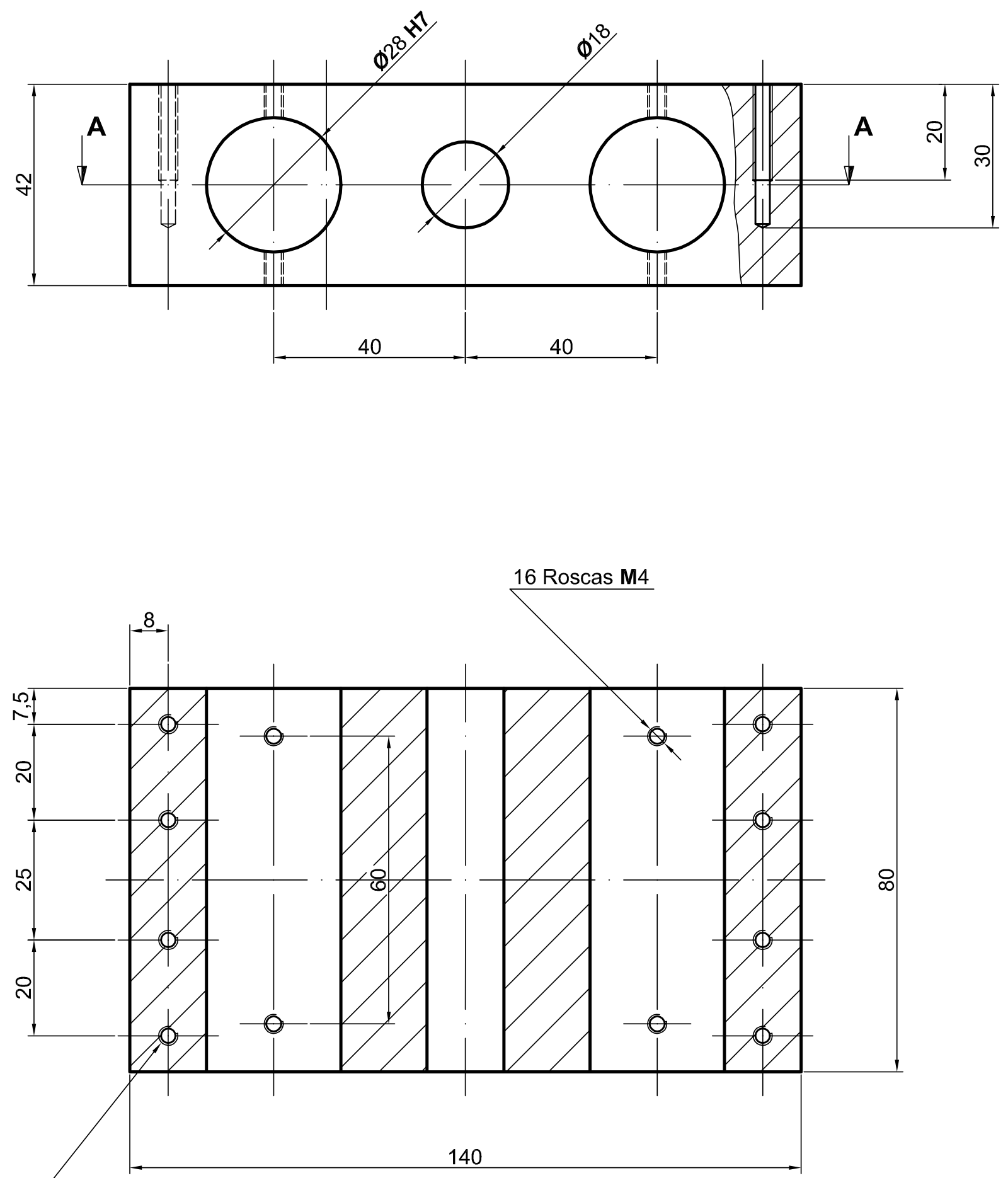

CORTE AA

OBSERVAÇÃO: Fazer as roscas laterais M4 em conjunto com as PEÇAS 17 e 18

ELABORADO POR: RONALDO CÂMARA COZZA - ronaldo.cozza@poli.usp.br

\begin{tabular}{|c|c|c|c|c|}
\hline 08 & 01 & Berço Movimentado & Alumínio & \\
\hline Peça N. & Quantidade & Denominações & \multicolumn{2}{|c|}{ Material } \\
\hline \multirow{2}{*}{ USP } & \multirow{2}{*}{$\begin{array}{c}\text { Escola } \\
\text { Politécnica }\end{array}$} & \multirow{2}{*}{$\begin{array}{c}\text { MÁQUINA DE DESGASTE } \\
\text { POR MICRO-ABRASÃO }\end{array}$} & $\exists @$ & Desenho 08 \\
\hline & & & Esc. 1:1 & Data: 20/03/04 \\
\hline
\end{tabular}




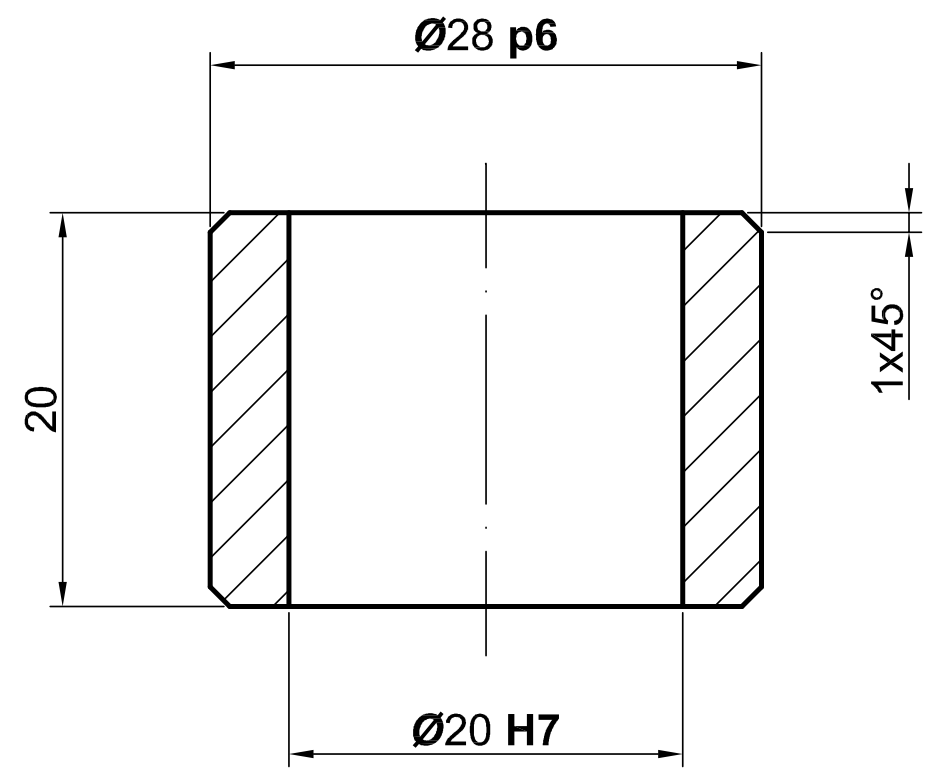

ELABORADO POR: RONALDO CÂMARA COZZA - ronaldo.cozza@poli.usp.br

\begin{tabular}{|c|c|c|c|c|}
\hline 09 & 04 & Bucha - Berço Movimentado & \multicolumn{2}{|l|}{ Bronze } \\
\hline Peça N. & Quantidade & Denominações & \multicolumn{3}{|c|}{ Material } \\
\hline USP & Escola & MÁQUINA DE DESGASTE & @ & Desenho 09 \\
\cline { 4 - 6 } & Politécnica & POR MICRO-ABRASÃO & EsC. 2:1 & Data: 20/03/04 \\
\hline
\end{tabular}



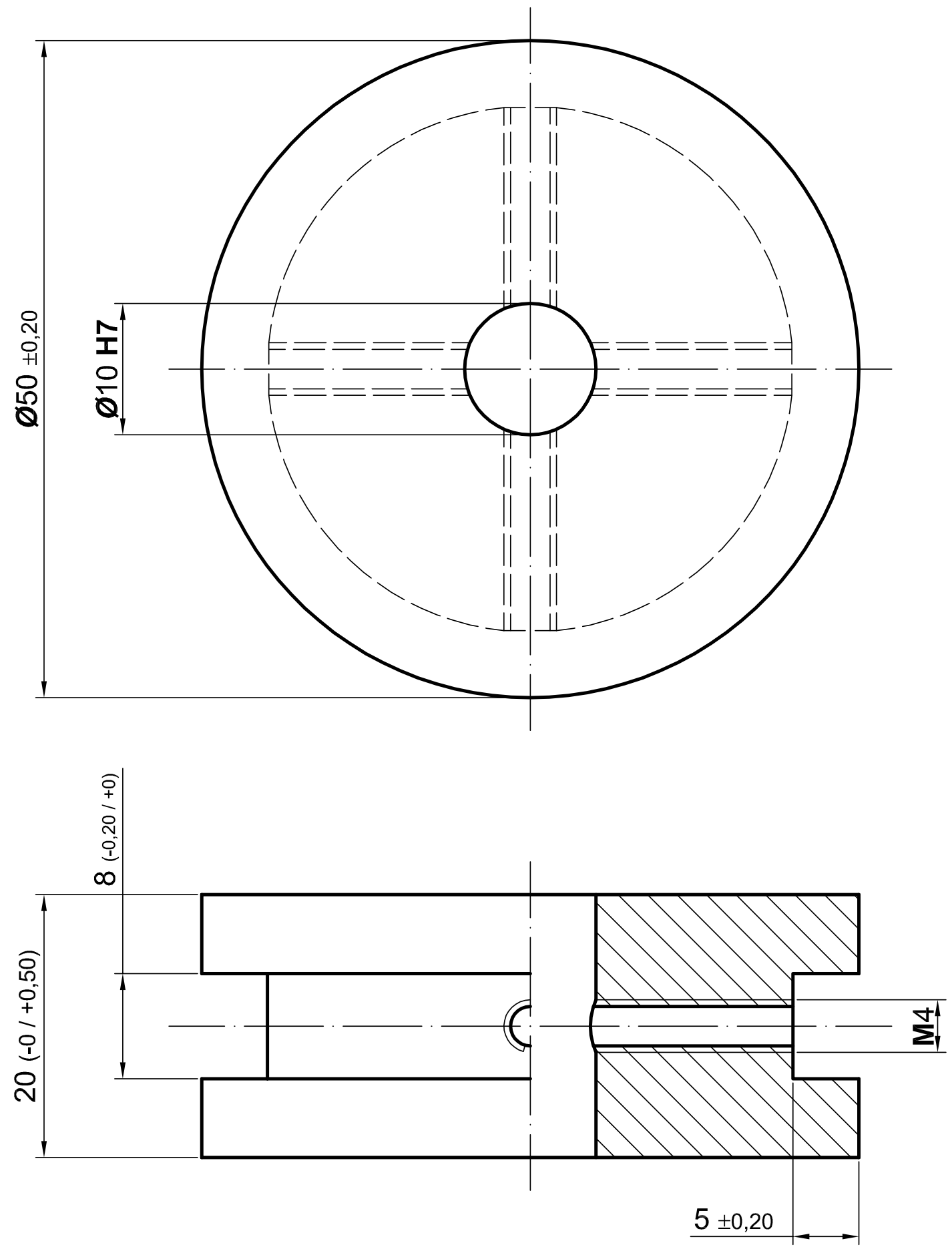

ELABORADO POR: RONALDO CÂMARA COZZA - ronaldo.cozza@poli.usp.br

\begin{tabular}{|c|c|c|c|c|}
\hline 12 & 01 & Disco (Força Normal) & Aço AISI 1010 \\
\hline Peça N. & Quantidade & Denominações & \multicolumn{2}{|c|}{ Material } \\
\hline USP & $\begin{array}{c}\text { Escola } \\
\text { Politécnica }\end{array}$ & $\begin{array}{c}\text { MÁQUINA DE DESGASTE } \\
\text { POR MICRO-ABRASÃO }\end{array}$ & ESC. 2:1 & Data: 07/12/04 \\
\cline { 4 - 6 } & & &
\end{tabular}




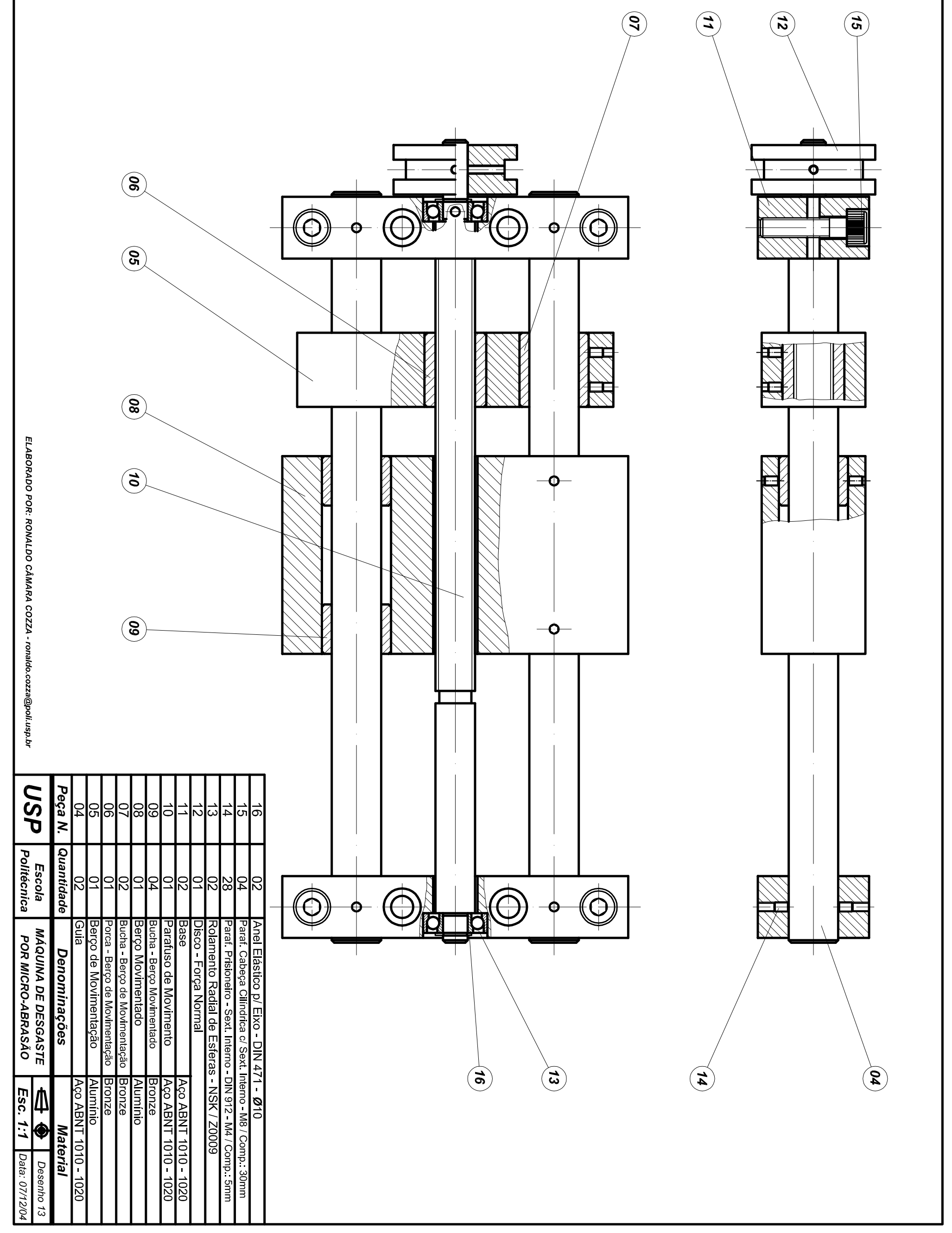




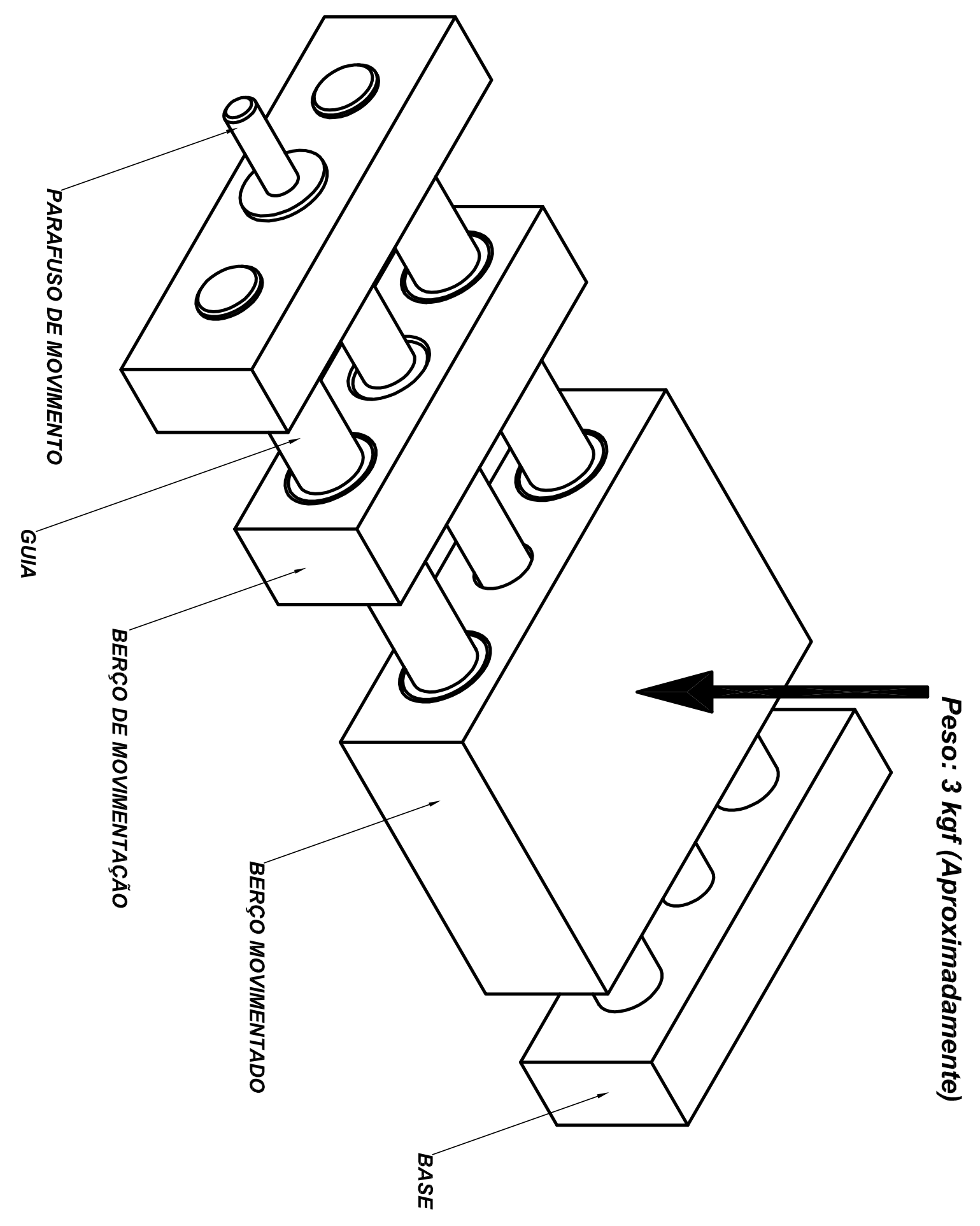



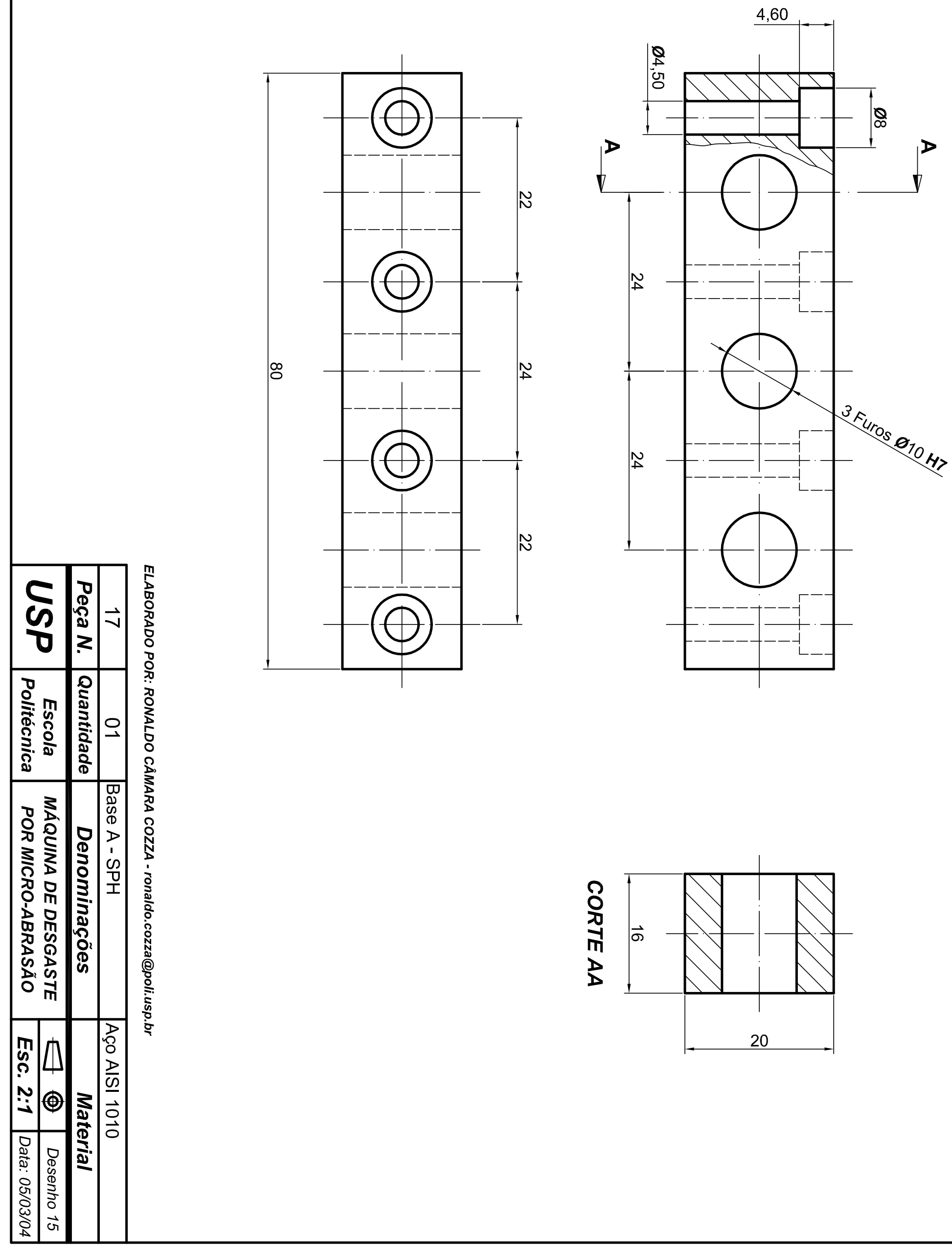

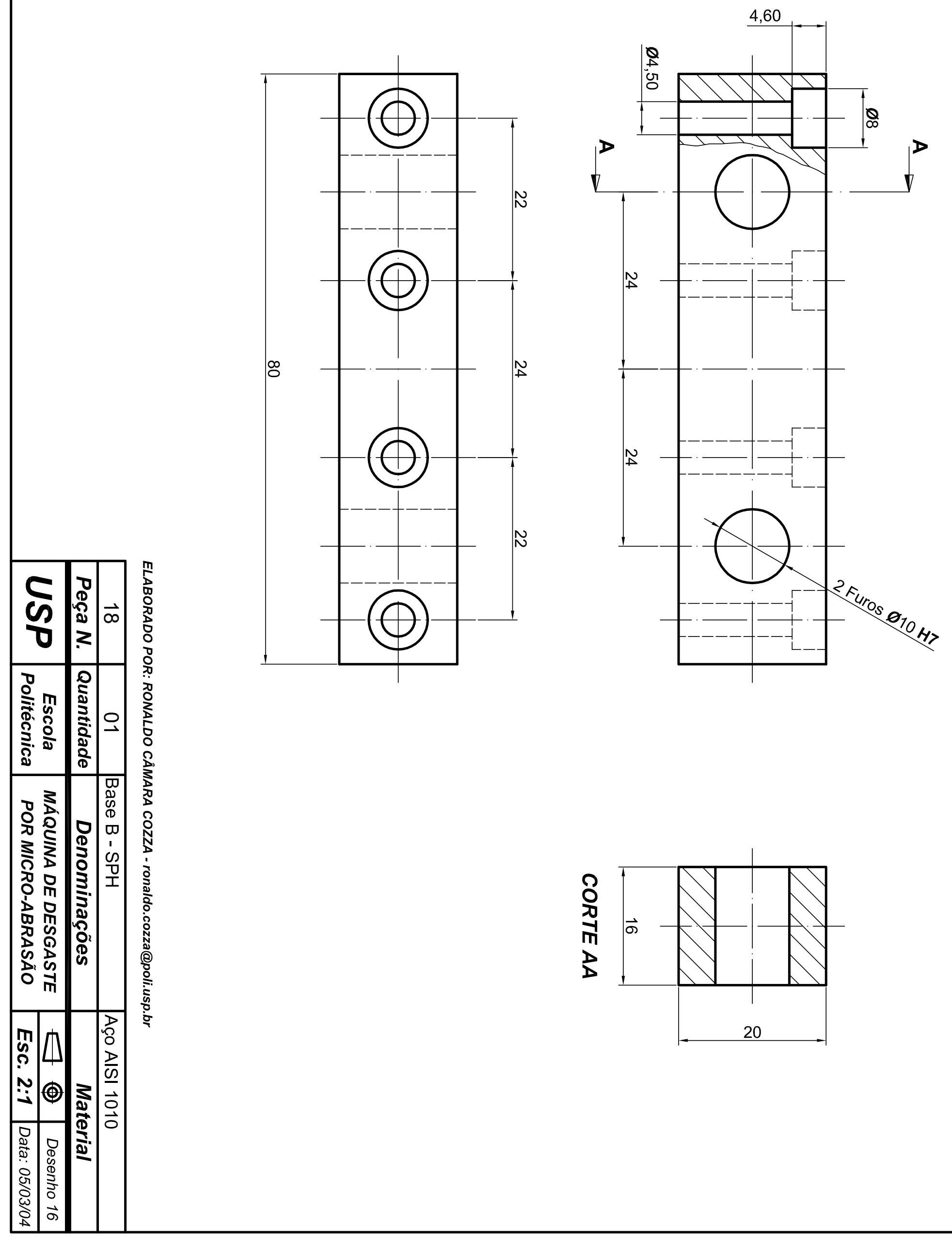

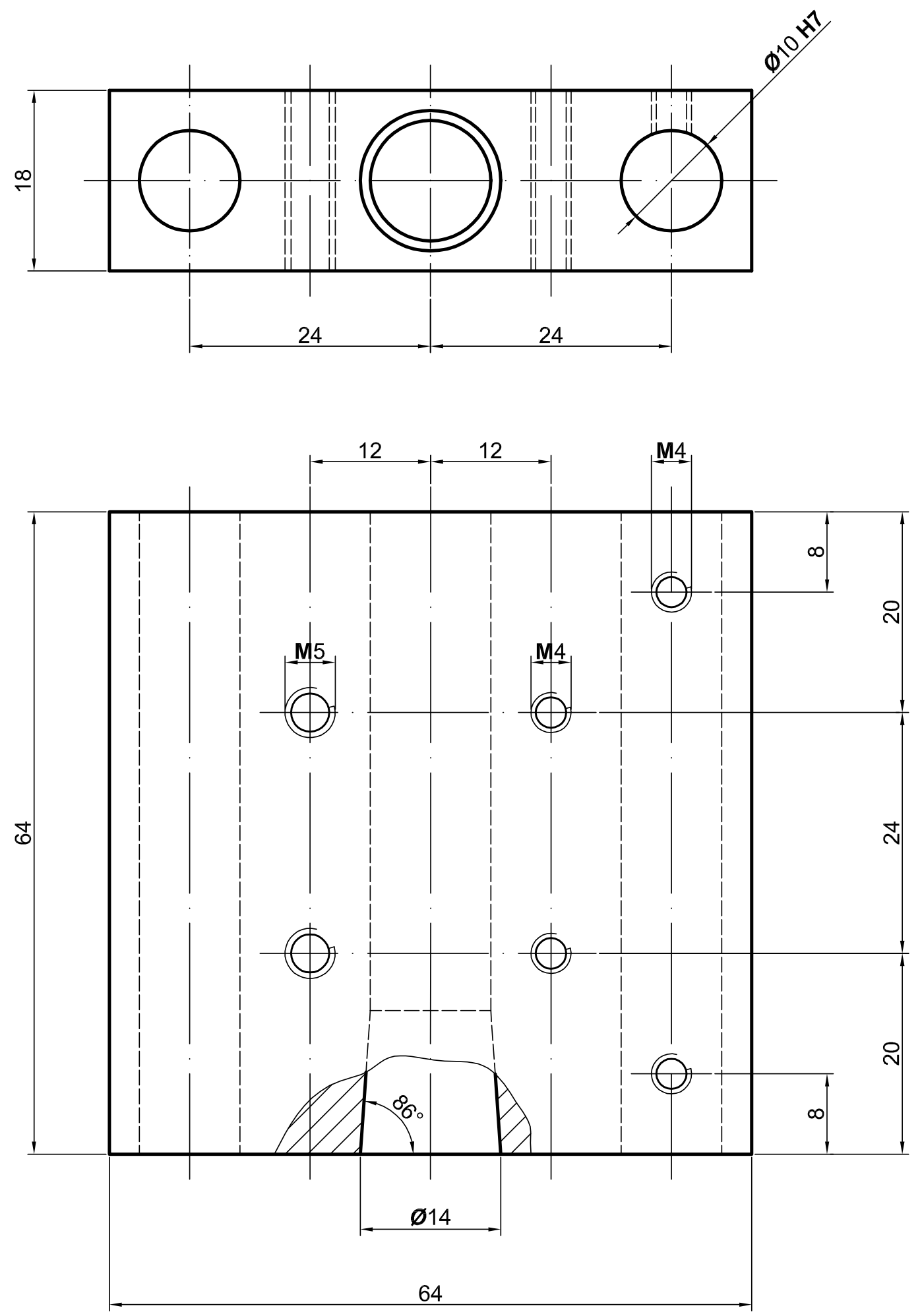

OBSERVAÇÃO: Fazer as roscas M5 em conjunto com a PEÇA 23 (ESTRUTURA - SPV) e as roscas M4 (centrais) em conjunto com a PEÇA 24 (APOIO DA ESTRUTURA - SPV).

ELABORADO POR: RONALDO CÂMARA COZZA - ronaldo.cozza@poli.usp.br

\begin{tabular}{|c|c|c|c|c|}
\hline 20 & 01 & Base de Movimentação - SPH & \multicolumn{2}{|c|}{ Aço ABNT 1010 - 1020 } \\
\hline Peça N. & Quantidade & Denominações & \multicolumn{2}{|c|}{ Material } \\
\hline \multirow{2}{*}{$\boldsymbol{U S P}$} & $\begin{array}{c}\text { Escola } \\
\text { Politécnica }\end{array}$ & $\begin{array}{c}\text { MÁQUINA DE DESGASTE } \\
\text { POR MICRO-ABRASÃO }\end{array}$ & EsC. 2:1 & Data: 05/04/04 \\
\cline { 5 - 6 } & & &
\end{tabular}



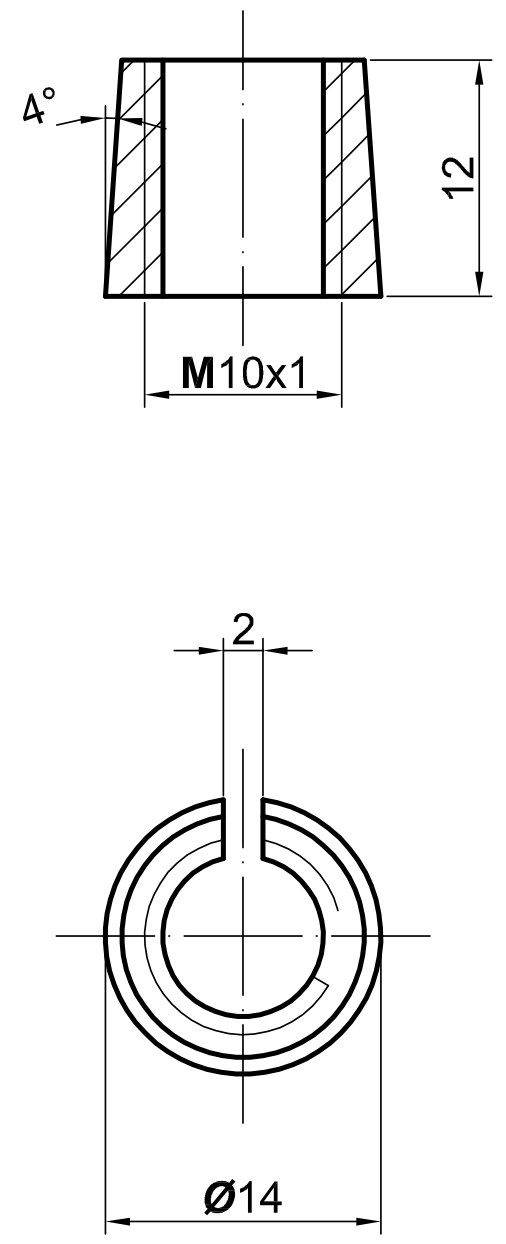

ELABORADO POR: RONALDO CÂMARA COZZA - ronaldo.cozza@poli.usp.br

\begin{tabular}{|c|c|l|l|l|}
\hline 21 & 01 & Bucha & \multicolumn{1}{|l|}{ Teflon } \\
\hline Peça N. & Quantidade & Denominações & \multicolumn{3}{|c|}{ Material } \\
\hline USP & $\begin{array}{c}\text { Escola } \\
\text { Uolitécnica }\end{array}$ & $\begin{array}{c}\text { MÁQUINA DE DESGASTE } \\
\text { POR MICRO-ABRASÃO }\end{array}$ & ESC. 2:1 & Data: 05/04/04 \\
\cline { 4 - 6 } & & &
\end{tabular}




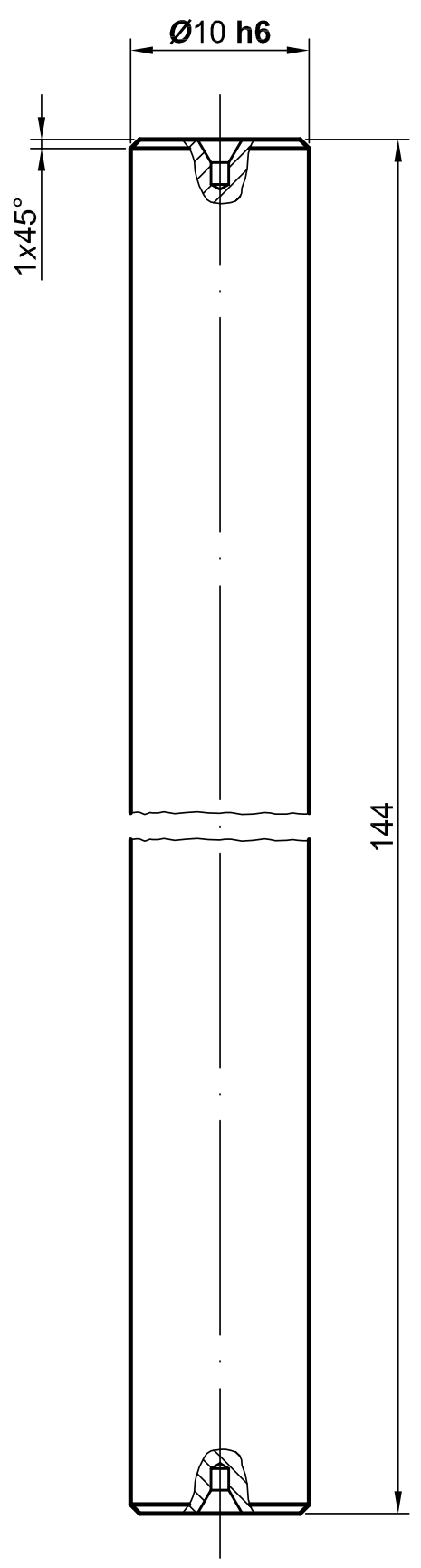

ELABORADO POR: RONALDO CÂMARA COZZA - ronaldo.cozza@poli.usp.br

\begin{tabular}{|c|c|c|c|c|}
\hline 22 & 02 & Guia - Sist. Pos. Horizontal & \multicolumn{2}{|c|}{ Aço ABNT 1010 - 1020} \\
\hline Peça N. & Quantidade & Denominações & \multicolumn{2}{|c|}{ Material } \\
\hline USP & Escola & MÁQUINA DE DESGASTE & @ & Desenho 20 \\
\cline { 4 - 6 } & Politécnica & POR MICRO-ABRASÃO & EsC. 2:1 & Data: 25/03/04 \\
\hline
\end{tabular}




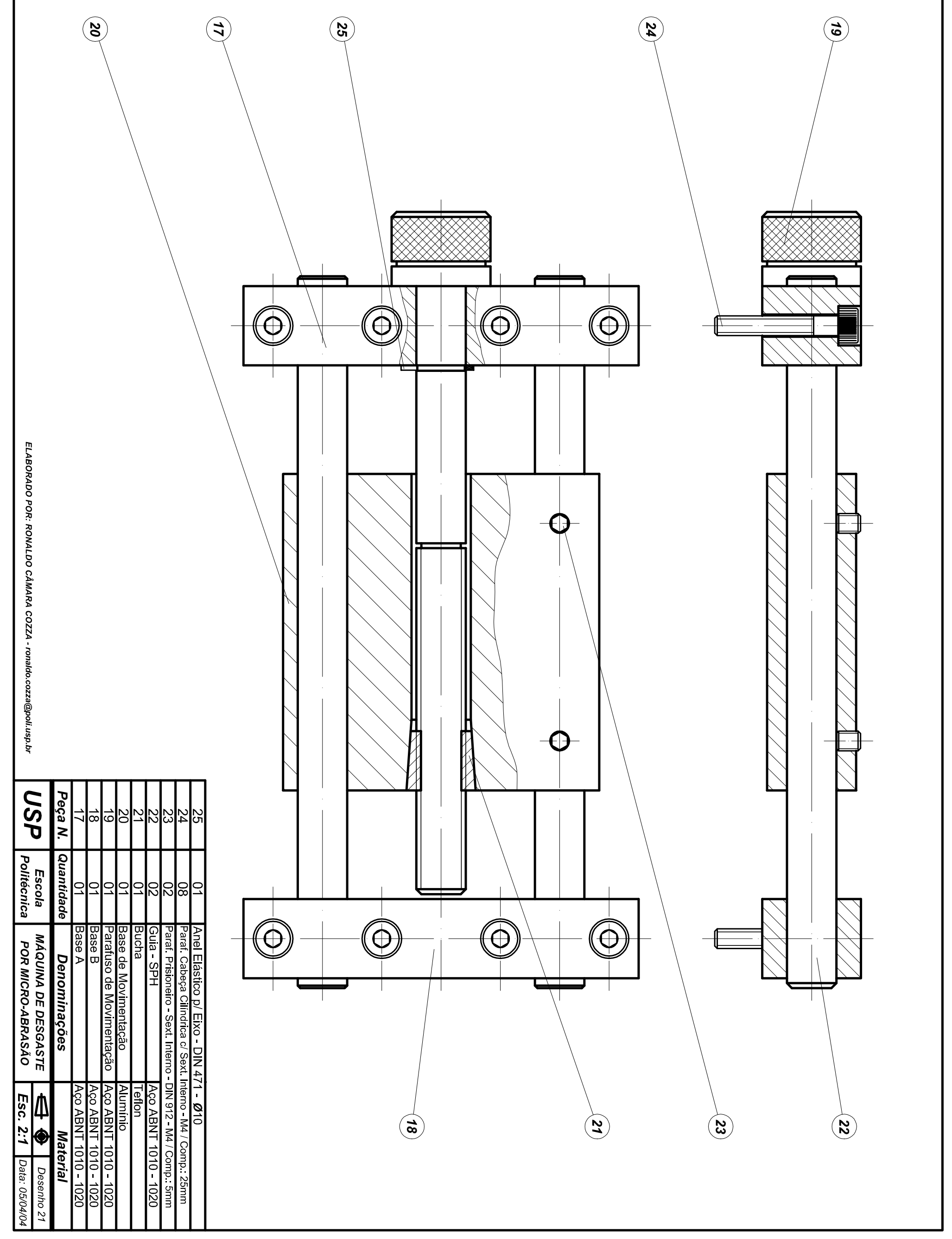



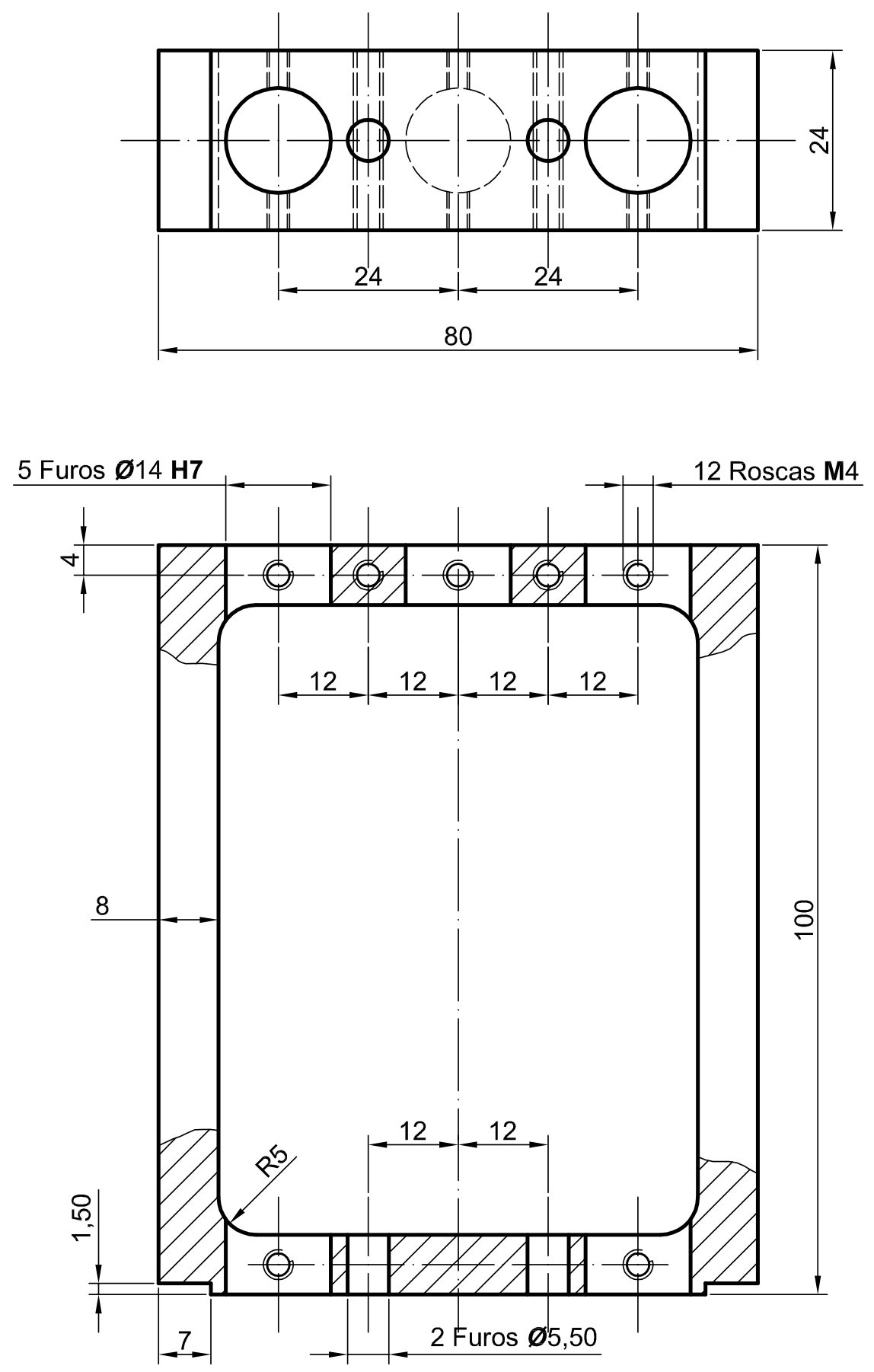

OBSERVAÇÃO:

- Fazer os furos de Ø5,50 em conjunto com a PEÇA 20 (BASE DE MOVIMENTAÇÃO - SPH);

- Fazer as roscas M4 (superiores) em conjunto com a PEÇA 24 (APOIO DA ESTRUTURA - SPV).

ELABORADO POR: RONALDO CÂMARA COZZA - ronaldo.cozza@poli.usp.br

\begin{tabular}{|c|c|l|l|c|}
\hline 23 & 01 & Estrutura - SPV & \multicolumn{2}{|l|}{ Alumínio } \\
\hline Peça N. & Quantidade & Denominações & \multicolumn{2}{|c|}{ Material } \\
\hline USP & $\begin{array}{c}\text { Escola } \\
\text { Politécnica }\end{array}$ & $\begin{array}{c}\text { MÁQUINA DE DESGASTE } \\
\text { POR MICRO-ABRASÃO }\end{array}$ & ESC. 1:1 & Data: 05/04/04 \\
\cline { 4 - 6 } & & &
\end{tabular}



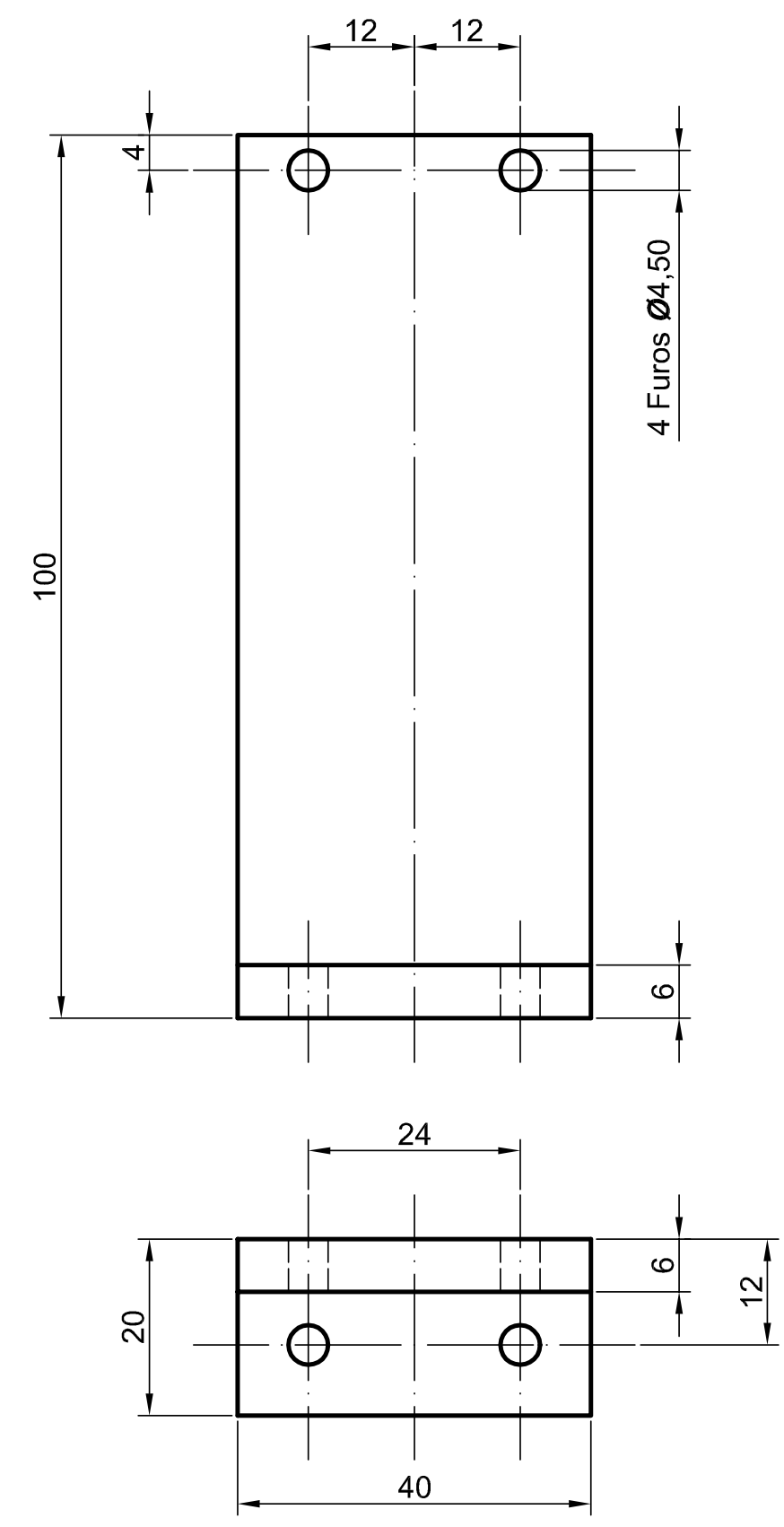

OBSERVAÇÃO:

- Fazer os furos de $\emptyset 4,50$ em conjunto com a PEÇA 20 (BASE DE MOVIMENTAÇÃO - SPH) e com a PEÇA 23 (ESTRUTURA - SPV).

ELABORADO POR: RONALDO CÂMARA COZZA - ronaldo.cozza@poli.usp.br

\begin{tabular}{|c|c|c|c|c|}
\hline 24 & 01 & Apoio da Estrutura - SPV & \multicolumn{1}{|c|}{ Aço ABNT 1010 - 1020 } \\
\hline Peça N. & Quantidade & Denominações & \multicolumn{2}{|c|}{ Material } \\
\hline USP & $\begin{array}{c}\text { Escola } \\
\text { Politécnica }\end{array}$ & $\begin{array}{c}\text { MÁQUINA DE DESGASTE } \\
\text { POR MICRO-ABRASÃO }\end{array}$ & ESC. 1:1 & Data: 05/04/04 \\
\cline { 4 - 6 } & & &
\end{tabular}




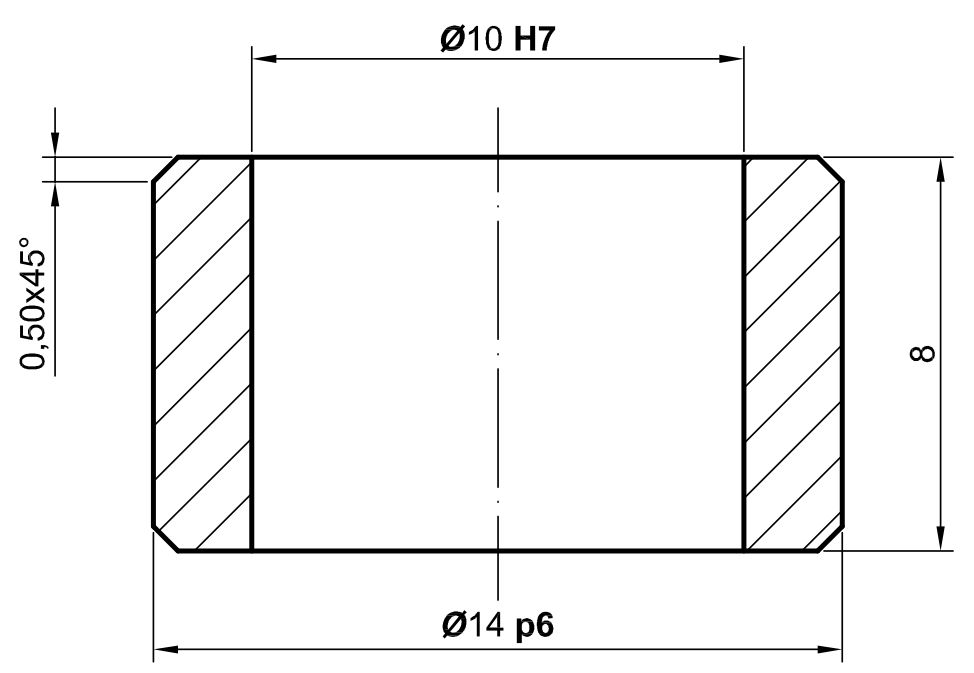

ELABORADO POR: RONALDO CÂMARA COZZA - ronaldo.cozza@poli.usp.br

\begin{tabular}{|c|c|c|c|c|}
\hline 25 & 05 & Bucha - SPV & \multicolumn{2}{|l|}{ Bronze } \\
\hline Peça N. & Quantidade & Denominações & \multicolumn{3}{|c|}{ Material } \\
\hline USP & Escola & MÁQUINA DE DESGASTE & @ & Desenho 25 \\
\cline { 4 - 6 } & Politécnica & POR MICRO-ABRASÃO & EsC. 5:1 & Data: 05/04/04 \\
\hline
\end{tabular}




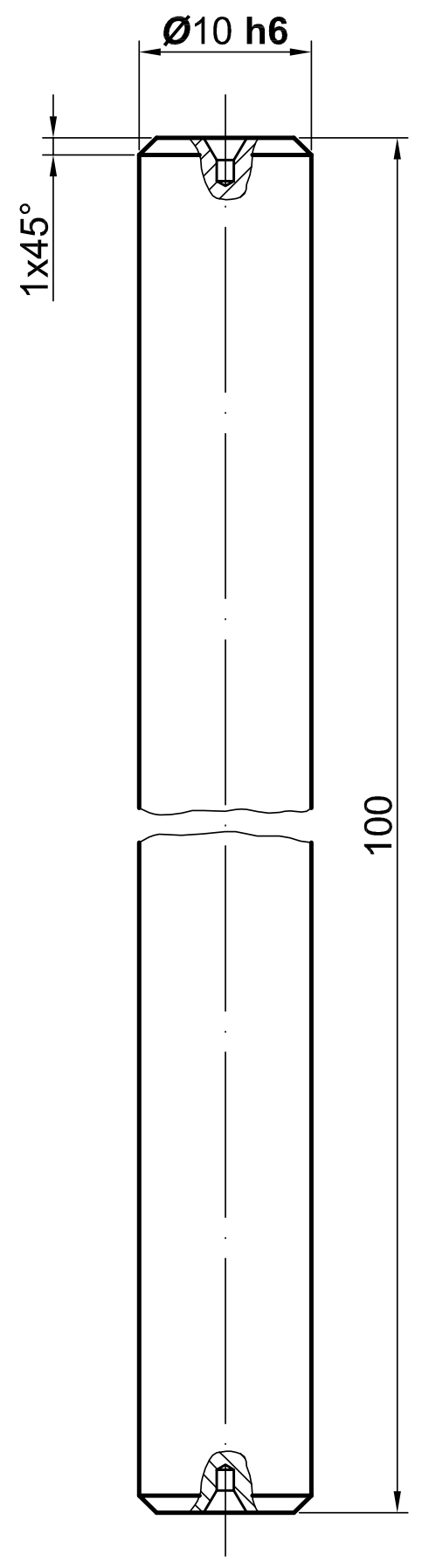

ELABORADO POR: RONALDO CÂMARA COZZA - ronaldo.cozza@poli.usp.br

\begin{tabular}{|c|c|c|c|c|}
\hline 26 & 02 & Guia - SPV & \multicolumn{2}{|c|}{ Aço ABNT 1010 - 1020 } \\
\hline Peça N. & Quantidade & Denominações & \multicolumn{2}{|c|}{ Material } \\
\hline USP & $\begin{array}{c}\text { Escola } \\
\text { Politécnica }\end{array}$ & $\begin{array}{c}\text { MÁQUINA DE DESGASTE } \\
\text { POR MICRO-ABRASÃO }\end{array}$ & ESC. 2:1 & Data: 05/04/04 \\
\cline { 4 - 6 } & & & &
\end{tabular}



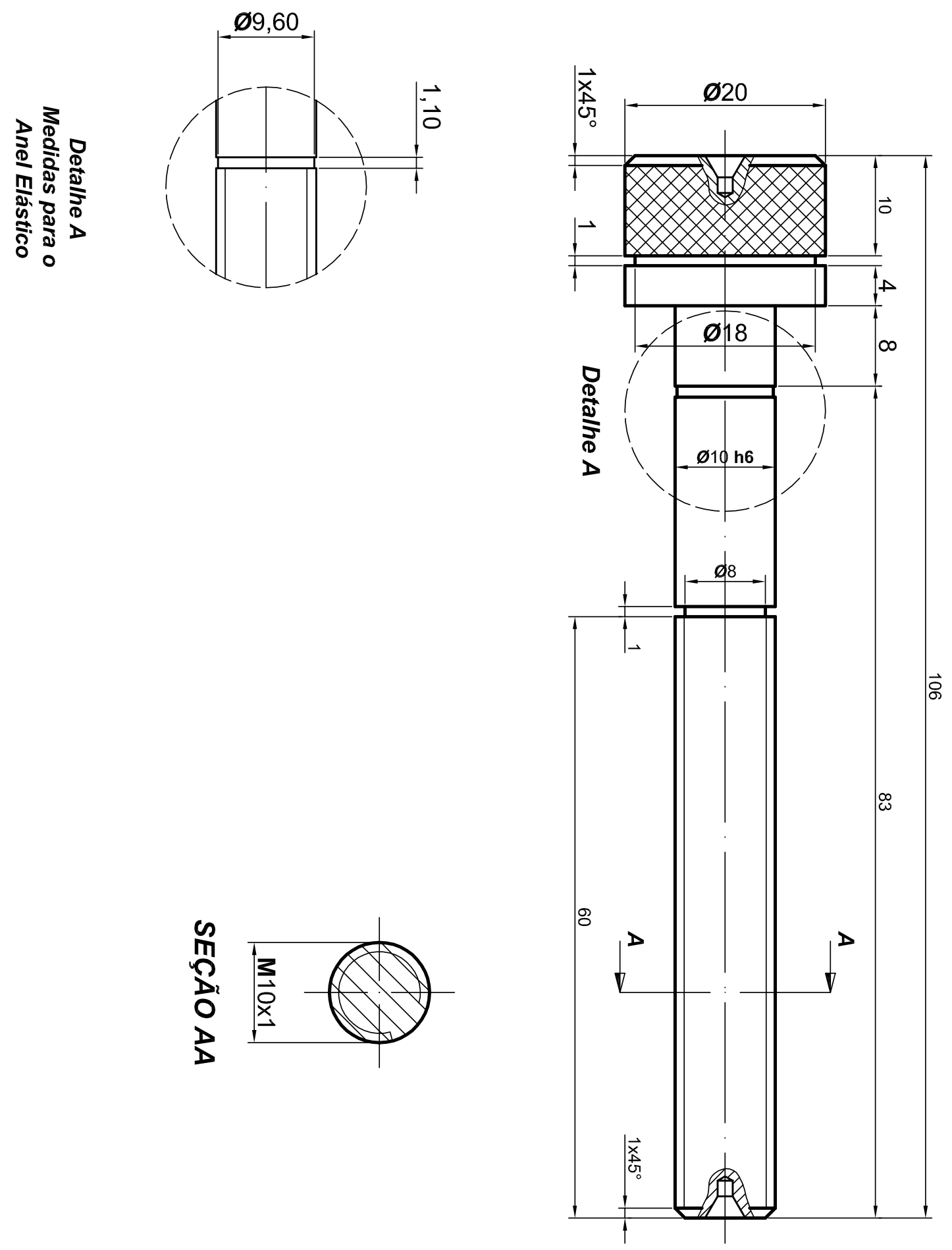

\begin{tabular}{|c|c|c|}
\hline$\frac{1}{0}$ & 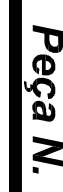 & $\stackrel{N}{V}$ \\
\hline 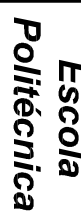 & 20 & $\stackrel{0}{=}$ \\
\hline 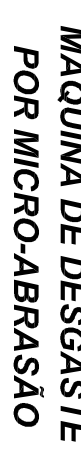 & 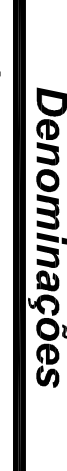 & 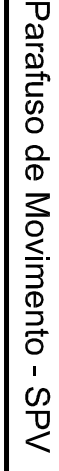 \\
\hline 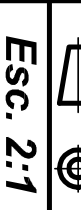 & 곤 & $\begin{array}{l}\text { D } \\
\text { D } \\
\text { D } \\
\text { 茫 } \\
\end{array}$ \\
\hline 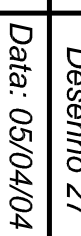 & $\frac{10}{2}$ & $\begin{array}{l}0 \\
\text { O } \\
1 \\
\text { D } \\
\text { O }\end{array}$ \\
\hline
\end{tabular}

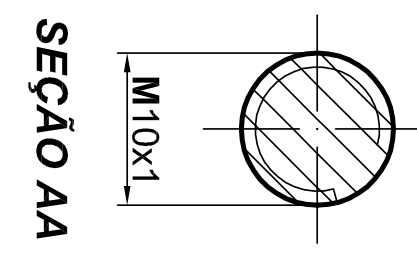



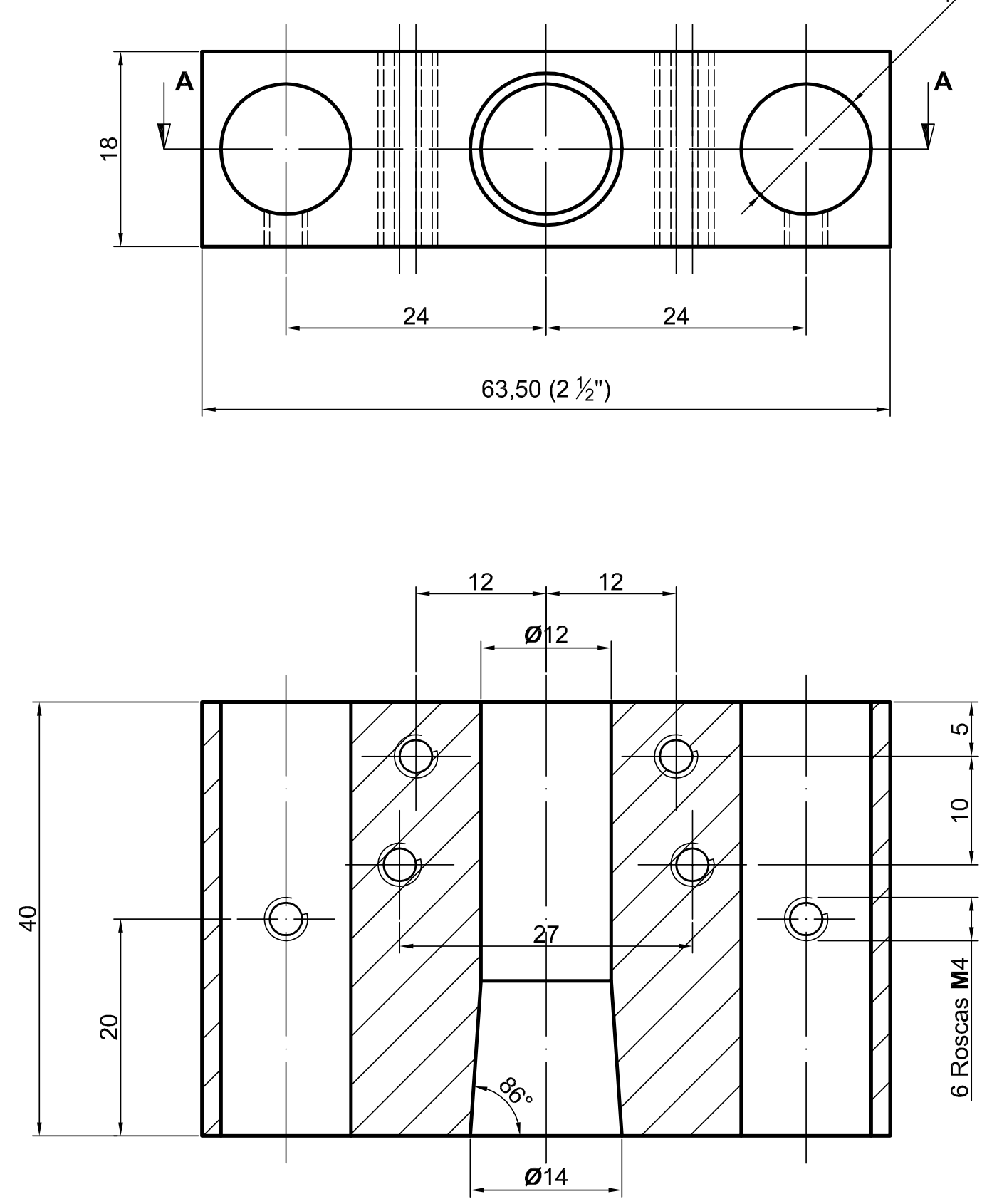

CORTE AA

OBSERVAÇÃO:

Fazer as roscas M4 (centrais) em conjunto com a PEÇA 29 (BASE DE FIXAÇÃO - SPV).

ELABORADO POR: RONALDO CÂMARA COZZA - ronaldo.cozza@poli.usp.br

\begin{tabular}{|c|c|c|c|c|}
\hline 28 & 01 & Base de Movimentação - SPV & Alumínio & \\
\hline Peça N. & Quantidade & Denominações & \multicolumn{2}{|c|}{ Material } \\
\hline \multirow{2}{*}{ USP } & \multirow{2}{*}{$\begin{array}{c}\text { Escola } \\
\text { Politécnica }\end{array}$} & \multirow{2}{*}{$\begin{array}{c}\text { MÁQUINA DE DESGASTE } \\
\text { POR MICRO-ABRASÃO }\end{array}$} & $\exists \oplus$ & Desenho 28 \\
\hline & & & Esc. 2:1 & Data: $16 / 04 / 04$ \\
\hline
\end{tabular}



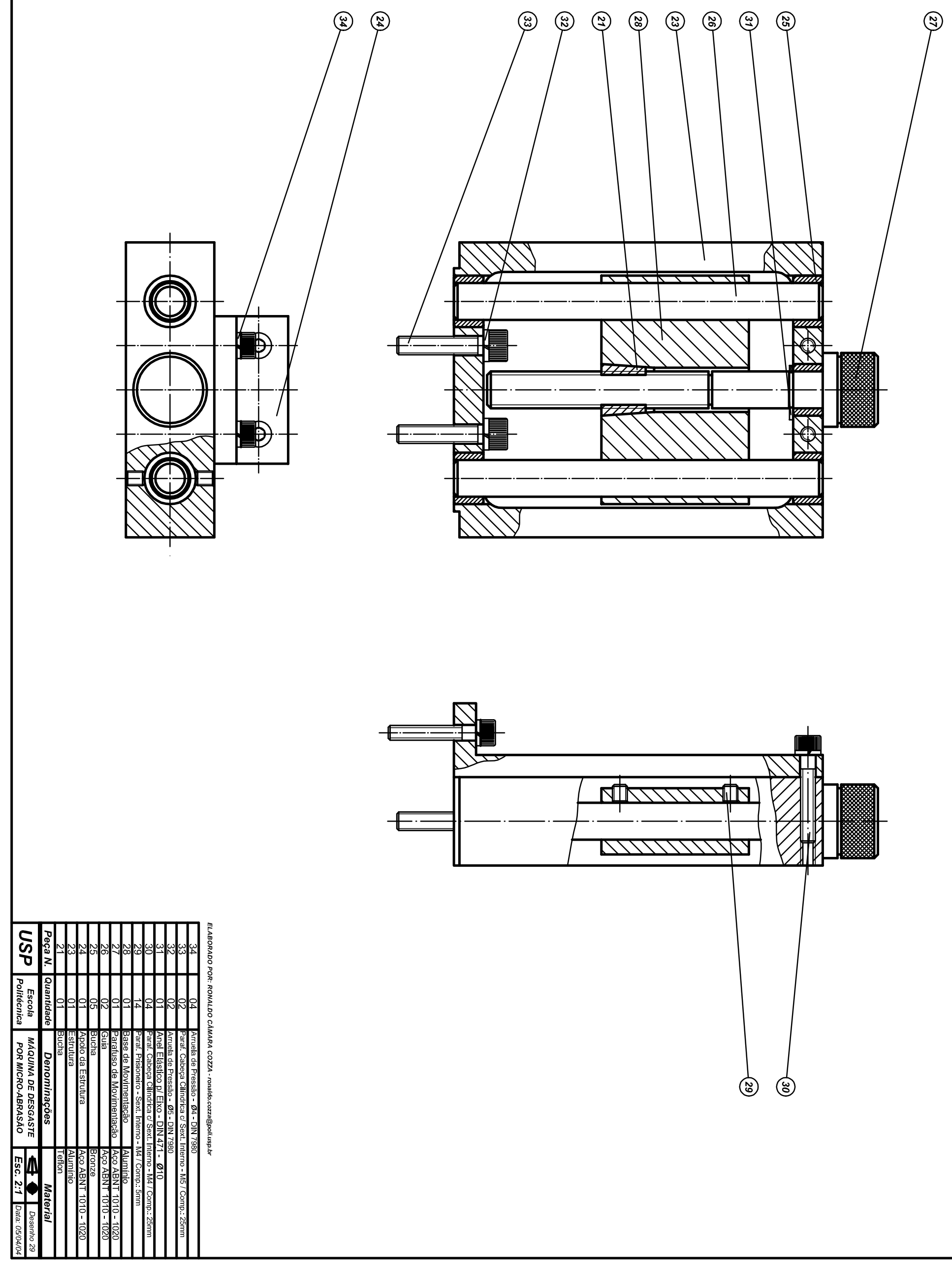
- MESA DE TRANSLAÇÃo

- SISTEMA DE POSIÇÃO HORIZONTAL

- SISTEMA DE POSIÇÃO VERTICAL
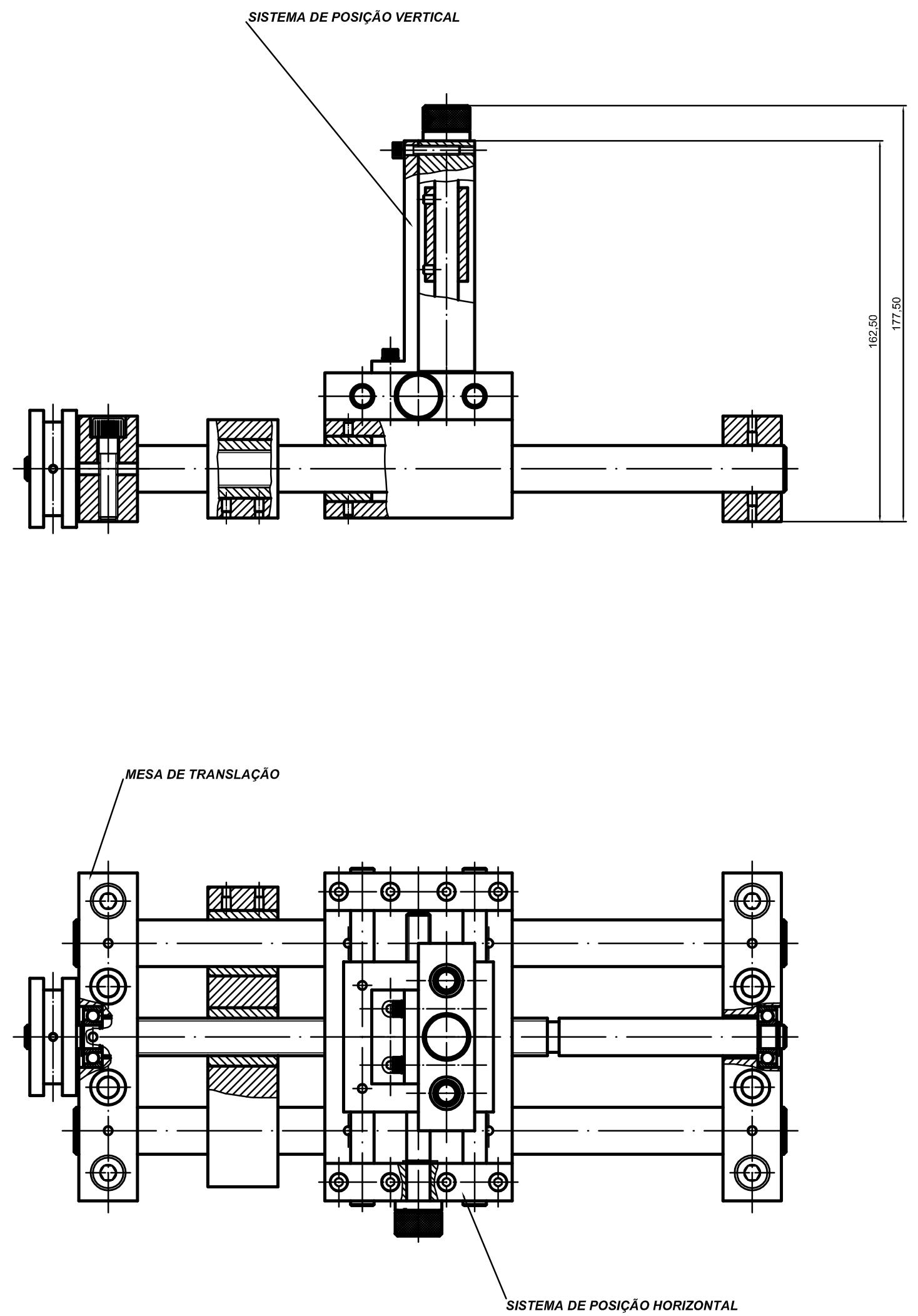


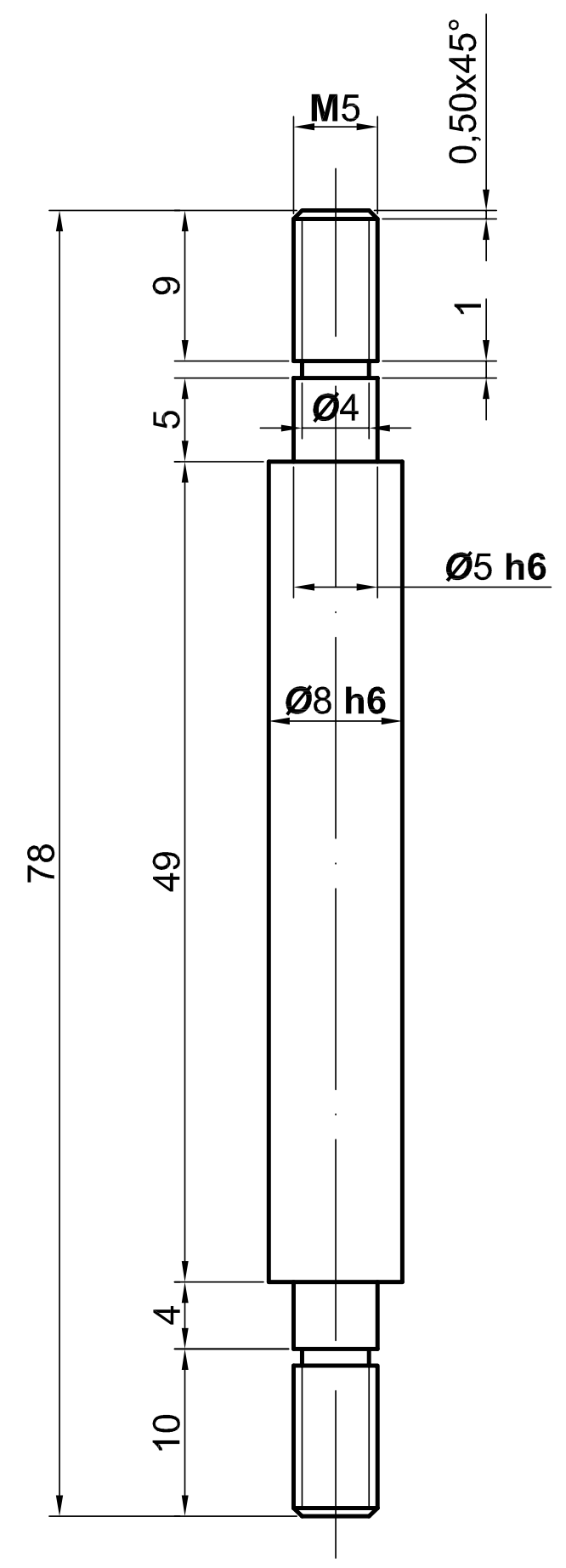

ELABORADO POR: RONALDO CÂMARA COZZA - ronaldo.cozza@poli.usp.br

\begin{tabular}{|c|c|c|c|c|}
\hline 30 & 01 & Eixo - Base de Fixação & \multicolumn{2}{|c|}{ Aço ABNT 1010 - 1020 } \\
\hline Peça N. & Quantidade & Denominações & \multicolumn{2}{|c|}{ Material } \\
\hline USP & Escola & MÁQUINA DE DESGASTE & @ & Desenho 32 \\
\cline { 4 - 6 } & Politécnica & POR MICRO-ABRASÃO & EsC. 2:1 & Data: 15/04/04 \\
\hline
\end{tabular}



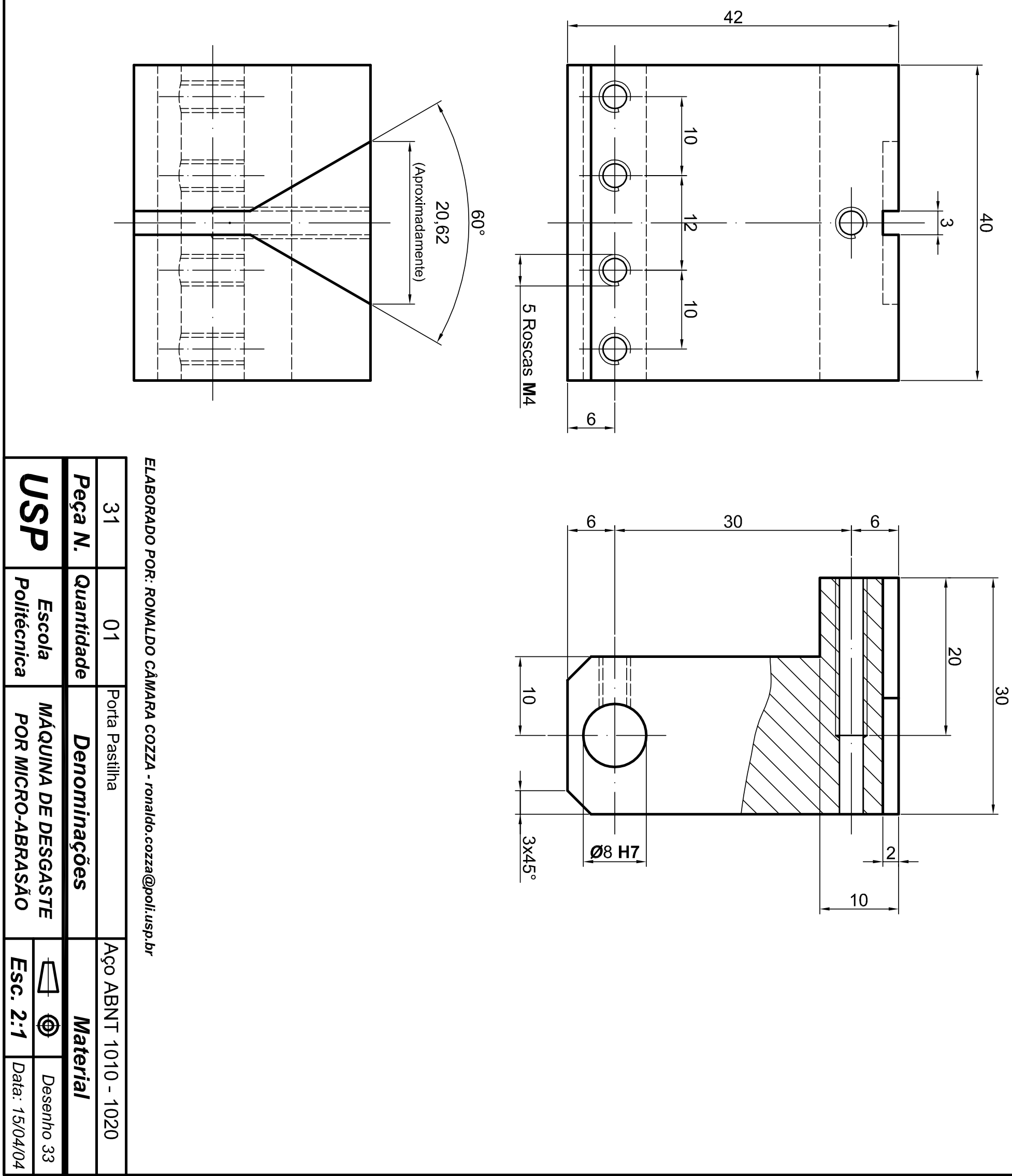

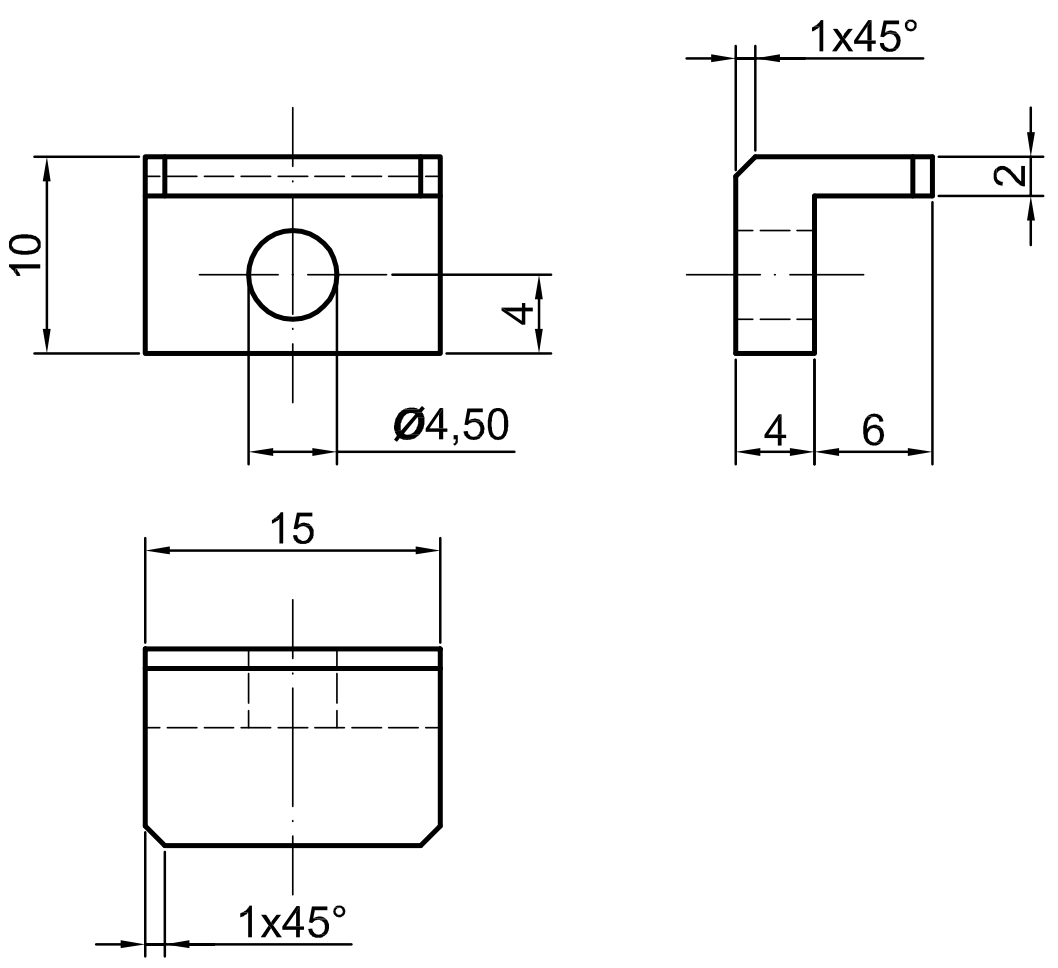

ELABORADO POR: RONALDO CÂMARA COZZA - ronaldo.cozza@poli.usp.br

\begin{tabular}{|c|c|c|c|c|}
\hline 32 & 01 & Fixador da Pastilha - SPV & \multicolumn{2}{|c|}{ Aço ABNT 1010 - 1020 } \\
\hline Peça N. & Quantidade & Denominações & \multicolumn{2}{|c|}{ Material } \\
\hline USP & $\begin{array}{c}\text { Escola } \\
\text { Politécnica }\end{array}$ & $\begin{array}{c}\text { MÁQUINA DE DESGASTE } \\
\text { POR MICRO-ABRASÃO }\end{array}$ & ESC. 2:1 & Data: 15/04/04 \\
\cline { 4 - 6 } & & & &
\end{tabular}




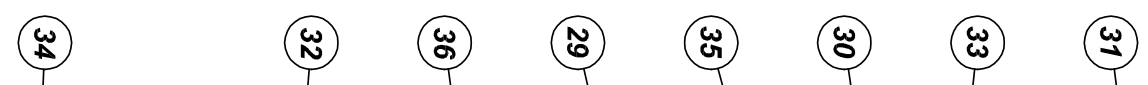
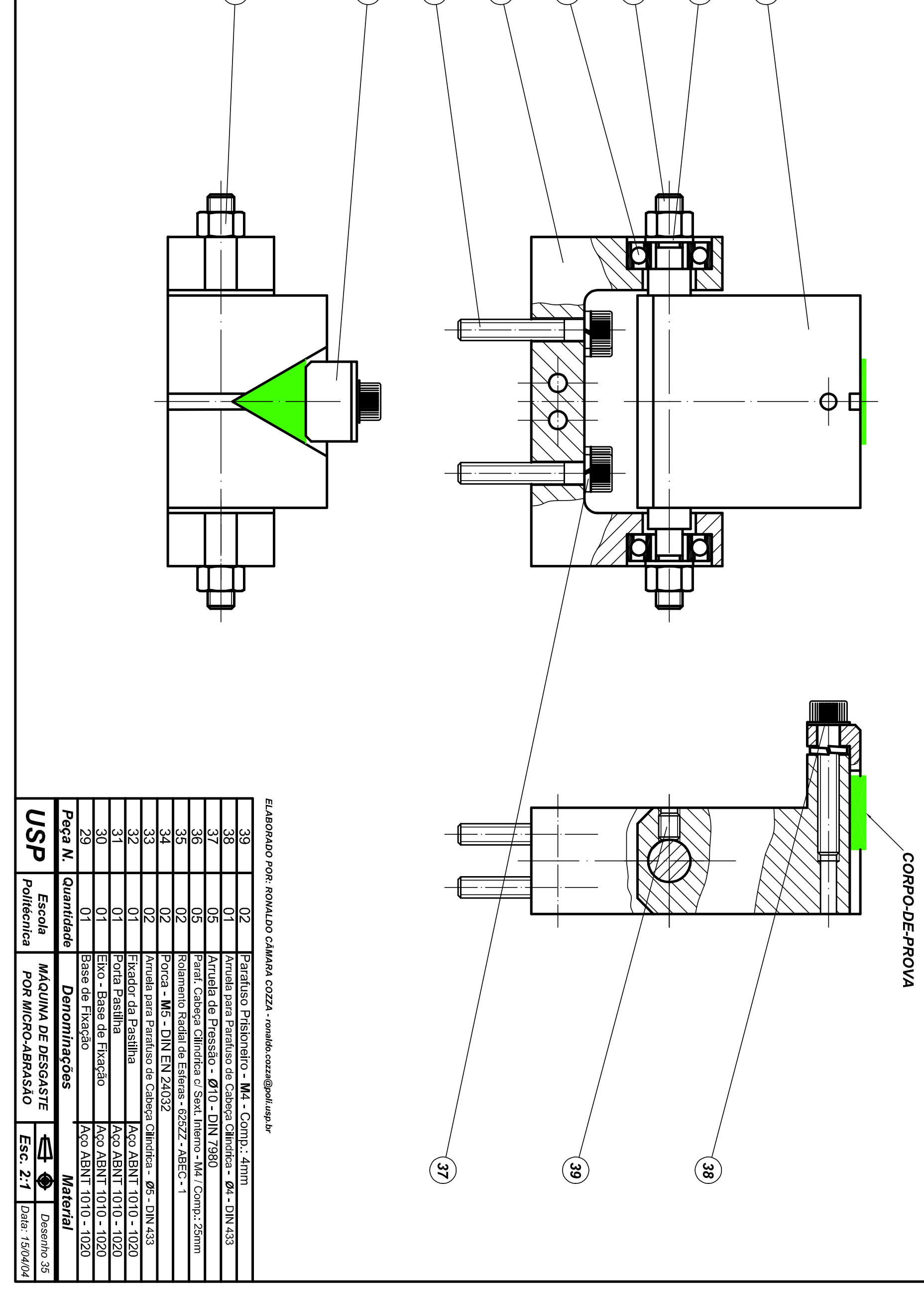
- MESA DE TRANSLAÇÃO

- SISTEMA DE POSIÇÃO HORIZONTAL

- SISTEMA DE POSIÇÃO VERTICAL

- DISPOSITIVO PARA FIXAÇÃO DO CORPO-DE-PROVA

OBSERVAÇÃO:

AS CÉLULAS DE CARGA PARA MEDIÇÃO DAS FORÇAS NORMAL E TANGENCIAL NÃO ESTÃO ESQUEMATIZADAS.
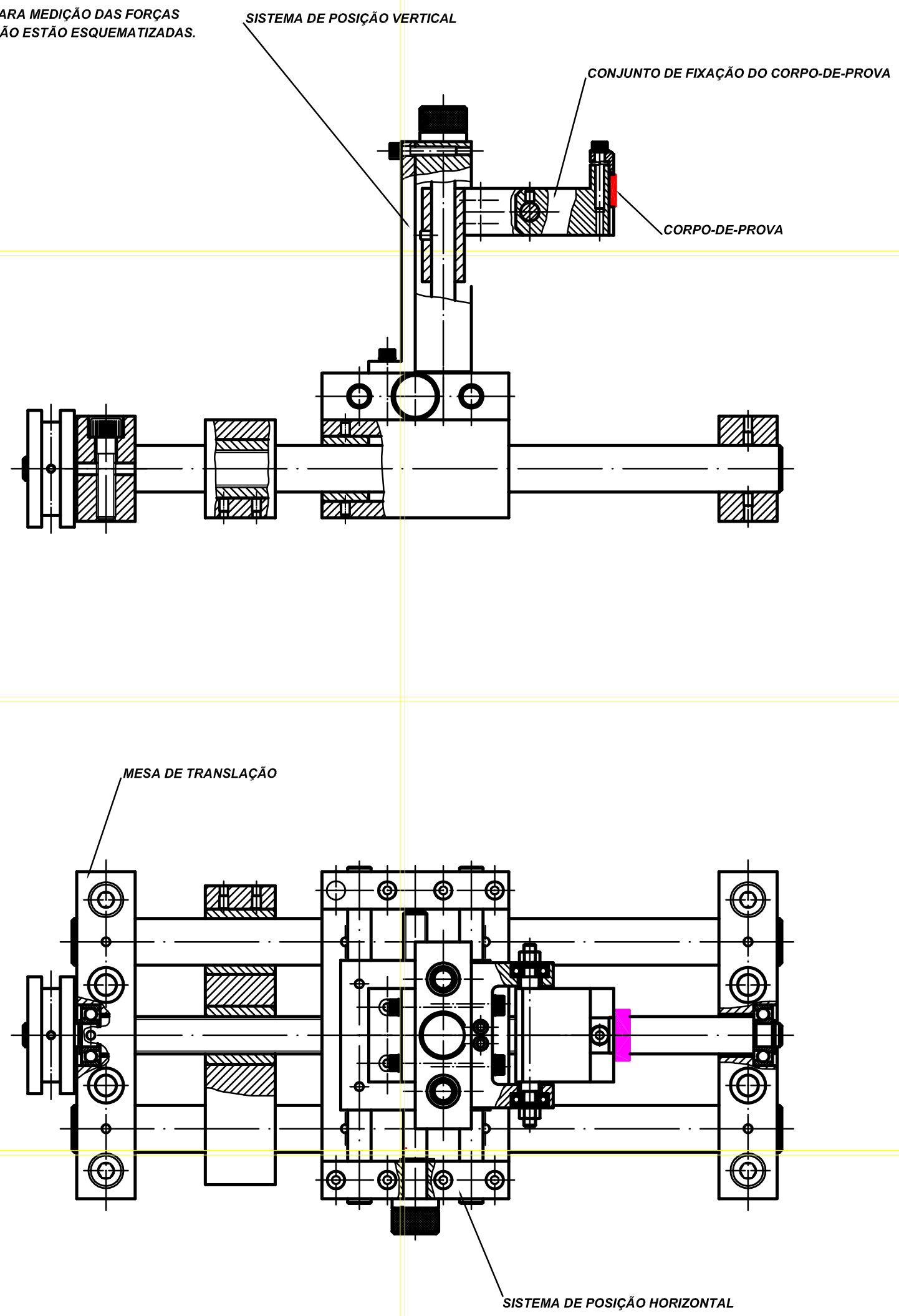

ELABORADO POR: RONALDO CÂMARA COZZA - ronaldo.cozza@poli.usp.br 


\section{REFERÊNCIAS BIBLIOGRÁFICAS}

Adachi, K., Hutchings, I. M. Wear-mode mapping for the micro-scale abrasion test. Wear, 23 - 29, 255, 2003.

Adachi, K., Hutchings, I. M. Sensitivity of wear rates in the micro-scale abrasion test to test conditions and material hardness. Wear, 258, 318 - 321, 2005.

Allsopp, D. N., Hutchings, I. M. Micro-scale abrasion and scratch response of PVD coatings at elevated temperatures. Wear, 251, 1308 - 1314, 2001.

ASM HANDBOOK - Friction, Lubrication and Wear Technology. Volume 18. ASM International - The Materials Information Society, 1998.

ASTM G40-96: Standard Terminology Relating to Wear and Erosion.

ASTM G77-91: Standard Test Method for Ranking Resistance of Materials to Sliding Wear Using Block-on-Ring Wear Test.

Baptista, A. M., Ferreira, J., Pinto, N. Ensaios de micro-abrasão por esfera rotativa. $7^{\mathrm{a}}$. Jornada Portuguesa de Tribologia, Porto, Portugal, 29 e 30 de Junho, 2000.

Bello, J. O., Wood, R. J. K. Micro-abrasion of filled and unfilled polyamide 11 coatings. Wear, 258, 294 - 302, 2005.

Bergantin, R. Máquina de desgaste por micro-abrasão. São Paulo, 2002. Trabalho de formatura - EPUSP - Escola Politécnica da Universidade de São Paulo

Bose, K., Wood, R. J. K. Optimun tests conditions for attaining uniform rolling abrasion in ball cratering tests on hard coatings. Wear, 258, 322 - 332, 2005.

Coutinho, C. B. Materiais metálicos para engenharia. $1^{a}$.edição. Belo Horizonte: Fundação Christiano Ottoni, 1992. 
Cozza, R. C., Souza, R. M., Tanaka, D. K. Wear mode transition during the microscale abrasion of WC-Co P20 and M2 tool steel. COBEM 2005 $18^{\text {th }}$ International Congress of Mechanical Engineering. Ouro Preto - MG, 6 a 11 de novembro de 2005. Anais em CD ROM.

Dogan, C. P., Hawk, J. A. Microestructure and abrasive wear in silicon nitride ceramics. Wear, 250, 256 - 263, 2001.

Erickson, L. C., Hawthorne, H. M., Troczynski, T. Correlations between microstructural parameters, micromechanical properties and wear resistance of plasma sprayed ceramic coatings. Wear, 250, 569 - 575, 2001.

Gahlin, R., Jacobson, S. The particle size effect in abrasion studied by controlled abrasive surfaces. Wear, 224, 118 - 125, 1999.

Gates, J. D. Two-body and three-body abrasion: A critical discussion. Wear, 214, 139 - 146, 1998.

Gee, M. G., Gant, A. J., Hutchings, I. M., Kusano, Y., Schiffman, K., Van Acker, K., Poulat, S., Gachon, Y., von Stebut, J., Hatto, P., Plint, G. Results from an interlaboratory exercise to validate the micro-scale abrasion test. Wear, 259, 27 - 35, 2005.

Hogmark, S., Jacobson, S., Larsson, M. Design and evaluation of tribological coatings. Wear, 246, 20 - 33, 2000.

Hutchings, I. M. Tribology - Friction and Wear of Engineering Materials. $7^{\text {th. }}$ edition. London: Edward Arnold, 1992.

Hutchings, I. M. Abrasive and erosive wear tests for thin coatings: a unified approach. Tribology International, 31, 1 - 3, 5 - 15, 1998.

Izhevskyi, V. A., Genova, L. A., Bressiani, J. C., Bressiani, A. H. A. Liquid phase sintered SiC ceramics from starting materials of different grade. Cerâmica, $50,261-267$.

Kato, K. Wear in relation to friction - a review. Wear, 241, 151 - 157, 2000. 
Kattamis, T. Z., Chen, M., Skolianos, S., Chambers, B. V. Effect of residual stresses on the strength, adhesion and wear resistance of SiC coatings obtained by plasma-enhanced chemical vapor deposition on low alloy steel. Surface and Coatings Technology, 70, 43 - 48, 1994.

Kelly, D. A., Hutchings, I. M. A new method for measurement of particle abrasivity. Wear, 250, 76 - 80, 2001.

Kennedy, D. M., Hashmi, M. S. J. Methods of wear testing for advanced surface coatings and bulk materials. Journal of Materials Processing Technology, 77, 246 - 253, 1998.

Kruschov, M. M. Resistance of metals to wear by abrasion as related to hardness. In: Conference on lubrication and wear, London, 1957, Proceedings, Institution of Mechanical Engineering, p. 655 - 659.

Kusano, Y., Hutchings, I. M. Sources of variability in the free-ball micro-scale abrasion test. Wear, 258, 313 - 317, 2005.

Marcondes, F. C. A história do metal duro. $1^{\text {a }}$ edição. São Paulo: Unida Artes Gráficas e Editora Ltda., 1990.

Mergler, Y. J., Huis in 't Veld, H. Micro-abrasive wear of semi-crystalline polymers. Tribological Research and Design for Engineering Systems, 165 - 173, 2003.

Misra, A., Finnie, I. A classification of three-body abrasive wear and design of a new tester. Wear, 60, $111-121,1980$.

Ohring, M. Engineering materials science. San Diego: Academic Press, 1995.

Pintaúde, G. Análise dos regimes moderado e severo de desgaste abrasivo utilizando ensaios instrumentados de dureza. São Paulo, 2002. Tese de Doutorado - EPUSP - Escola Politécnica da Universidade de São Paulo.

Rutherford, K. L., Hutchings, I. M. A micro-abrasive wear test, with particular application to coated systems. Surface and Coatings Technology, 79, 231 - 239, 1996. 
Rutherford, K. L., Hutchings, I. M. Theory and application of a micro-scale abrasive wear test. Journal of Testing and Evaluation, JTEVA, 25, 2, 250 260, 1997.

Sasada, T., Oike, M., Emori, N. The effect of abrasive grain size on the transition between abrasive and adhesive wear. Wear, 97, 291 - 302, 1984.

Shipway, P. H., Howell, L. Microscale abrasion-corrosion behaviour of WC-Co hardmetals and HVOF sprayed coatings. Wear, 258, 303 - 312, 2005.

Silva Jr., W. M. Efeito da pressão de compactação e tamanho do pó de ferro na micro-abrasão do ferro sinterizado oxidado a vapor. Uberlândia, 2003. Dissertação de Mestrado - Universidade Federal de Uberlândia.

Spero, C., Hargreaves, D. J., Kirekaldie, R. K., Fliu, H. J. Review of test methods for abrasive wear in ore grinding. Wear, 146, $389-411,1991$.

Trezona, R. I., Allsopp, D. N., Hutchings, I. M. Transitions between two-body and three-body abrasive wear: influence of test conditions in the microscale abrasive wear test. Wear, 225 - 229, 205 - 214, 1999.

Trezona, R. I., Hutchings, I. M. Three-body abrasive wear testing of soft materials. Wear, 233 - 235, 209 - 221, 1999. 